\title{
JURISDICTIONAL INTEGRATION: \\ How Economic Globalisation is \\ Changing State Sovereignty
}

\author{
By \\ Murray Campbell Petrie
}

A thesis

submitted to the Victoria University of Wellington in fulfilment of the requirements for the degree of

Doctor of Philosophy

in Public Policy

Victoria University of Wellington

2009 


\section{Abstract}

Despite intense debate over the impact of globalisation on state sovereignty, there is a gap in the literature on conceptualisation, measurement, and research on the depth of international policy cooperation. This thesis introduces a new concept, jurisdictional integration, defined as international agreements that constrain, to varying degrees, a state's jurisdiction to make or enforce policies free from external involvement. State jurisdiction - the recognized authority to govern by domestic law - is a more coherent and tractable concept than the traditional concept of Westphalian sovereignty. A generic spectrum of points of increasing integration of state jurisdiction is presented, together with a taxonomy of points of increasing depth of international economic policy cooperation. The practicality and value of the framework is illustrated in two ways. First, an empirical analysis is presented of the depth of jurisdictional integration in Regional Trade Agreements (RTAs), using WTO data, to test hypotheses of the relationship between economic integration and the depth of policy cooperation in RTAs. The results indicate that the average frequency of occurrence of the deep policy cooperation provisions increased by $118 \%$ in RTAs signed 1990-1998 compared to those signed prior to 1990 . Secondly, international cooperation in competition policy is analysed through compilation of a new database of stand-alone Competition Enforcement Agreements (CEAs), and the provisions in the Competition Policy Chapters of RTAs. Ordinal indices of increasing depth of jurisdictional integration with respect to competition policy are developed. New families of agreements are identified through vector analysis. Ninety-two international agreements are ranked on an enforcement cooperation index, and are used to test descriptive propositions about international competition policy cooperation. There are an increasing number of North-South agreements; and there has been both a widening and deepening of enforcement cooperation over time. Contingency table analysis is conducted of the relationship, given the existence of an agreement, between depth of enforcement cooperation and predictor variables. Whether all signatories are OECD members is a very good predictor of deep enforcement cooperation. A lack of similarity between substantive competition laws is a very good predictor of low enforcement cooperation. The level of trade integration is a moderately good predictor of the depth of enforcement cooperation; while geographic proximity is a good predictor for RTAs but not for CEAs. The depth of cooperation is almost independent of the level of economic asymmetry between signatories. These results are consistent with theories of regulatory competition and elite norm diffusion as causal mechanisms of increased international economic policy cooperation. The depth of enforcement cooperation is also found to be a very good predictor of whether agreements are "intergovernmental" or transgovernmental. The thesis suggests that the concept of jurisdictional integration can make a significant contribution to measuring the depth of all types of international economic cooperation agreements, and potentially also to cooperation in noneconomic domains; to research on the causes and consequences of international policy cooperation; and to policy development and public debate on the management of globalisation. 


\section{ACKNOWLEDGEMENTS}

My sincerest thanks to Professor Gary Hawke, my supervisor, who provided expert guidance throughout the course of this thesis, drawing on the wisdom of experience, and on his enthusiasm for and deep knowledge of international economic cooperation.

I am also extremely grateful to Professor John Deely, who provided extensive guidance on the statistical analysis, always with patience and good humour beyond 3 sigma.

My thanks also to the many people who helped me at various times along the way, in the spirit of academic collegiality, some of whom were generous with their time throughout. They are too numerous to name them all individually, but in particular I would like to thank my good friend Rory McLeod, an expert practitioner of international economic cooperation; Dr. Roderic Alley, who provided early encouragement; Professor Campbell McLachlan, who provided guidance to the literature on international law; Dr. Philip Marsden, who completed an independent ranking of a sample of agreements against the enforcement cooperation index developed in this thesis; Dr. James Smith; Dr.Vincent Della Sala; Dr. James Mathis; Professor Armand de Mestral; Dr. Andrew Ladley; Dr. Meredith Lewis; and Nataliya Yacheistova. Dr. Frank Havlicek provided enthusiastic early encouragement, and I am sorry he will not be able to see where the project ended up.

Of course, any remaining errors in this thesis are entirely my own responsibility.

Participants at seminars and small group discussions provided helpful comments and suggestions, including three seminars at the School of Government at Victoria University over the period 2005-2007; at the Asia Pacific School of Economics and Government at the Australian National University in May 2006; at a PhD Summer School on Regional Integration at the University of Trento in August 2006; and at a Roundtable on Regional Trade Agreements at the University of Montreal in December 2007.

I would also like to acknowledge the support provided by the School of Government, including assistance with my travel to Canberra and Trento. Victoria University kindly granted me a Doctoral Scholarship.

No PhD is completed without the support (and surprise) of friends and family, and I received help from many quarters, for which I am very grateful.

Words cannot properly express the contribution of some. Mum and Dad taught me the value of education. I will never be able to thank Juanita sufficiently. My three wonderful girls, Juanita, Marie, and Danielle, are a constant source of inspiration in every thing I do. 


\section{CONTENTS}

ABBREVIATIONS

PART 1 Research Problem

CHAPTER 1

Introduction

CHAPTER 2

The Research Problem

CHAPTER 3

Purpose Statement and Methodology

3.1 Purpose Statement

3.2 Scholarly Framework

3.3 Methodology and Approach

PART 2 Jurisdictional Integration: A New Concept

OVERVIEW

CHAPTER 4

The Literatures on International Cooperation: An Interdisciplinary Review

4.1 Introduction to the Literatures

4.2 International Law

4.3 International Relations Theory

4.4 The Stages of Economic Integration

4.5 Regional Integration Theory

4.6 International Policy Cooperation

4.7 Fiscal Federalism

4.8 Conclusions

CHAPTER 5

Sovereignty, Jurisdiction, and Jurisdictional Integration

5.1 State Sovereignty and State Jurisdiction

5.2 The Dimensions of State Jurisdiction

5.3 Jurisdictional Integration

CHAPTER 6

A Stylized Spectrum of Jurisdictional Integration

6.1 Criteria for Locating Points on the Spectrum

6.2 A Generic Spectrum of Jurisdictional Integration

6.3 Populating the Jurisdictional Integration Spectrum

6.3.1 Simple Cooperation

6.3.2 Coordination

6.3.3 Horizontal and Vertical Integration

6.4 Policy Trade-offs in Moving along the Spectrum 
PART 3 Empirical Analysis of Jurisdictional Integration: Measuring the Depth of International Policy Cooperation

OVERVIEW

CHAPTER 7

The Determinants of International Economic Policy Cooperation

7.1 Competing Theories

7.2 Hypotheses

CHAPTER 8

Measuring the Changing Depth of Policy Cooperation in Regional

Trade Agreements

8.1 Measuring by Proxy: Simple Ratio Analysis by RTA-type 108

8.2 A Direct Measure of the Depth of Policy Cooperation in RTAs 112

CHAPTER 9

An Overview of International Cooperation in Competition Policy

9.1 Introduction

9.2 Economic Globalisation and Unilateral Extra-territorial Enforcement 118

9.3 The Evolution of International Cooperation in Competition Policy 122

9.3.1 Plurilateral and Multilateral Instruments

9.3.2 Regional Trade Agreements

9.3.3 Stand-alone Competition Enforcement Agreements

9.3.4 Other Instruments of International Cooperation

9.4 Previous Studies of International Competition Cooperation $\quad 130$

9.5 Conclusions

CHAPTER 10

Measuring the Depth of International Cooperation: Indices of

Jurisdictional Integration in Competition Policy

10.1 An Index of Non-Judicial Enforcement Cooperation

10.2 An Index of Prescriptive Jurisdictional Integration 148

10.3 An Index of Judicial Enforcement Cooperation 153

10.4 An Index of Cooperation in Inter-State Adjudication

CHAPTER 11

Research Questions Specific to International Competition

Policy Cooperation

11.1. Descriptive Propositions 158

11.2. Hypotheses

CHAPTER 12

The Dataset of International Competition Policy Agreements

12.1 Datasets in Previous Studies

12.2 Competition Policy Chapters in Regional Trade Agreements

12.3 Enforcement Cooperation Agreements Between

Competition Authorities

12.4 A Blended Dataset of International Competition

Enforcement Agreements

12.5 Multilateral Instruments 
CHAPTER 13

Measuring the Depth of International Cooperation in Competition Policy 181

13.1 Ranking Agreements by Depth of Enforcement Cooperation 182

13.2 Summary Descriptive Statistics $\quad 184$

13.3 Identifying "Families" of Agreements: A Vector Approach 191

13.4 Testing Descriptive Propositions 193

CHAPTER 14

Predicting the Depth of International Competition Policy Cooperation 198

14.1 Enforcement Cooperation, OECD Membership, and

Level of Development 199

14.2 Enforcement Cooperation and Economic Integration 204

14.3 Enforcement Cooperation and Economic Asymmetry 206

14.4 Enforcement Cooperation and the Stages of

Economic Integration 208

14.5 Enforcement Cooperation and Similarity of Competition Laws 212

14.6 Enforcement Cooperation and Geography 218

14.7 Enforcement Cooperation and Transgovernmentalism 221

14.8 Multivariate Analysis 226

14.9 Validity of Results $\quad 230$

14.10 Conclusions 231

\section{PART 4 Conclusion}

CHAPTER 15

Thesis Conclusions

15.1 Contribution to Knowledge 243

15.2 Limitations and Further Research
15.2.1 Potential Limitations

15.2.2 Possible Extensions $\quad 257$

15.2.3 Possible Applications to Other Policy Domains 259

APPENDICES

1. Table of Selected Empirical Studies of International Policy Cooperation $\quad 262$

2. Table of RTAs Containing Provisions on Competition Policy
Cooperation Other Than Enforcement Cooperation

$\begin{array}{ll}\text { GLOSSARY } & 270\end{array}$

$\begin{array}{ll}\text { REFERENCES } & 272\end{array}$

FIGURES

1. Map of the Literatures on International Economic 38

Policy Cooperation

2. The Overlapping Categories of State Jurisdiction 62

3. A Stylized Spectrum of Jurisdictional Integration 75

4. The Spectrum of RTA Competition Provisions 135

5. Taylor's Continuum of International Agreements 139 
7. Enforcement Cooperation in RTAs 185

8. Enforcement Cooperation: All Agreements 190

TEXT BOXES

1. A Taxonomy of the Depth of International Economic 76 Policy Cooperation

2. The Potential Economic Gains from International

Economic Policy Cooperation

3. The Index of Non-judicial Enforcement Cooperation in Competition Policy

4. The Index of Prescriptive Jurisdictional Integration in Competition Policy

5. The Index of Judicial Enforcement Cooperation in Competition Policy

6. An Index of International Cooperation in Adjudicating Inter-state Competition Policy Disputes

7. The WTO's Dataset on Regional Trade Agreements

8. The Index of International Enforcement Cooperation 182 in Competition Policy

9. Notes on Coding Agreements by Depth of Enforcement Cooperation

10. Transgovernmentalism as a Dependent Variable

\section{TABLES}

1. Alternative Measures of the Depth of Regional Trade 110 Agreements

2. Increasing Depth of Jurisdictional Integration in RTAs 115

3. The Dataset of RTAs Containing Enforcement 170 Cooperation by Period

4. The Dataset of Competition Enforcement Agreements by Period 173

5. Comparison of Datasets of International Agreements 178 Containing General Competition Law Provisions

6. Competition Agreements by Type, Depth of Cooperation, 188 and Year

7. Competition Enforcement Cooperation and OECD membership 199

8. Competition Enforcement Cooperation and Level of 202 Development

9. Competition Enforcement Cooperation and Trade Integration 205

10. Competition Enforcement Cooperation and 207 Economic Symmetry

11. Competition Enforcement Cooperation in Customs Unions 208 and FTAs

12. Competition Enforcement Cooperation in CEAs by Form of Associated RTA

13. Competition Enforcement Cooperation in CEAs by Form of Associated RTA and by Period

14. Measures of Similarity of Competition Laws Between APEC Country Pairs

15. Competition Enforcement Cooperation and Similarity of Competition Laws $(\mathrm{n}=19)$ 
16. Competition Enforcement Cooperation and Similarity of 216 Competition Laws $(\mathrm{n}=55)$

17. Competition Enforcement Cooperation and Similarity of Competition Laws (legal similarity redefined)

18. Competition Enforcement Cooperation and Common Land Border

19. Competition Enforcement Cooperation and Common Region

20. Competition Enforcement Cooperation and Transgovernmentalism

21. Transgovernmentalism and Depth of Cooperation in CEAs

22. Enforcement Cooperation, OECD Membership, Economic Symmetry, and Form of Agreement

23. Enforcement Cooperation, Economic Symmetry, and OECD Membership

24. Enforcement Cooperation, Form of Agreement, and OECD Membership.

25. Summary Table: International Cooperation in Enforcing Competition Laws 


\section{ABBREVIATIONS}

\begin{tabular}{|c|c|}
\hline ANDEAN Group & An RTA between Bolivia, Colombia, Ecuador, Peru and Venezuela \\
\hline APEC & Asia Pacific Economic Community \\
\hline CARICOM & Caribbean Community \\
\hline CEA & Competition Enforcement Agreement \\
\hline CEMAC & Central African Economic and Monetary Community \\
\hline CER & Closer Economic Relations Agreement between Australia and New Zealand \\
\hline CIS & Commonwealth of Independent States \\
\hline COMESA & Common Market of Eastern and Southern Africa \\
\hline $\mathrm{EC}$ & European Community \\
\hline ECA & European Competition Association \\
\hline $\mathrm{ECN}$ & European Competition Network \\
\hline EEA & European Economic Area \\
\hline EFTA & European Free Trade Area \\
\hline EJI & Enforcement Jurisdictional Integration \\
\hline $\mathrm{EU}$ & European Union \\
\hline FDI & Foreign Direct Investment \\
\hline FTA & Free Trade Agreement \\
\hline FTAA & Free Trade Agreement of the Americas \\
\hline GDP & Gross Domestic Product \\
\hline $\mathrm{ICN}$ & International Competition Network \\
\hline IFIs & International Financial Institutions \\
\hline IMF & International Monetary Fund \\
\hline MFN & Most Favoured Nation \\
\hline NAFTA & North American Free Trade Agreement \\
\hline $\mathrm{NGO}$ & Non-Government Organisation \\
\hline OECD & Organisation for Economic Cooperation and Development \\
\hline PTA & Preferential Trade Agreement \\
\hline RTA & Regional Trade Agreement \\
\hline SACU & Southern African Customs Union \\
\hline UNCTAD & United Nations Conference on Trade and Development \\
\hline WAEMU & West African Economic and Monetary Union \\
\hline WTO & World Trade Organisation \\
\hline
\end{tabular}


PART 1

Research Problem 


\section{Chapter 1}

\section{INTRODUCTION}

“...the state is not disappearing, it is disaggregating. Its component institutions...are all reaching out beyond national borders in various ways...the official observers of the international scene - scholars, pundits, policymakers - cannot fully see and appreciate this phenomenon because they are handicapped by the conceptual lenses of the unitary state. Although they are accustomed to thinking of "governments" domestically - as complex conglomerates of different institutions responsible for different governance functions - they think of "states" internationally."

Slaughter, A New World Order. ${ }^{1}$

International economic cooperation is a central feature of modern international relations. Virtually every country in the world is now a party to international agreements that impinge in some way on their formal authority to make and implement economic policies free from external interference or involvement. Such agreements cover a wide range of areas. They include agreements on trade, monetary cooperation, investment, regulation, and taxation. They are embodied in bilateral, regional, and multilateral agreements, and may be described as treaties, conventions, executive agreements, agency-to-agency agreements, memoranda of understanding, declarations, or codes and guidelines issued by international organisations.

Yet while globalisation is the subject of much public and academic interest, attention has focused on international economic integration. International policy cooperation has received much less attention. ${ }^{2}$ Concerns are often expressed about the impact of economic globalisation on the sovereignty of states; and of course policy makers design

\footnotetext{
${ }^{1}$ Slaughter 2004, pp. 31-31.

2 The main categories of globalisation usually identified are economic, policy or political, and cultural. See Babones, in Ritzer, Ed, 2007, Chapter 7.
} 
international economic cooperation agreements on the basis that some constraints on sovereignty are likely to result in increased economic integration e.g. increased trade and/or foreign investment. However, while there is a wide range of measures of international economic integration, there are no satisfactory measures of the varying impacts of international policy cooperation on state sovereignty. ${ }^{3}$

The objectives of this thesis are to develop a new conceptual framework to measure the depth of international economic policy cooperation; to operationalize the framework by measuring international cooperation in specific policy domains; and to undertake exploratory statistical analysis of some of the factors influencing decisions by states to commit to shallow or deep forms of cooperation.

\section{The key point to grasp at the outset is the distinction between international policy} integration (or cooperation), and international economic integration. The two phenomena are quite different. And yet the terms are often used interchangeably, unintentionally conflated, or merely confused one for the other.

International policy integration - hereafter referred to generically as international policy cooperation - refers to the wide variety of agreements or arrangements between states to cooperate in the development or implementation of government policies. International policy cooperation is embodied in international agreements, official international organisations, or less formal cross-border interactions between official institutions.

International economic integration, on the other hand, can be defined broadly as increasing levels of trade and foreign investment, the transnational integration of production chains within firms, and the progressive creation of single markets for factors of production. The concept of international economic integration is commonly operationalized by measuring variables such as the ratio of a country's international trade to its gross domestic product (GDP), or the ratio of its foreign investment to GDP.

In contrast, current approaches to measuring international policy cooperation are seriously inadequate, for a number of reasons.

\footnotetext{
${ }^{3}$ For measures of international economic integration, see OECD (2005), and Babones (2007).
} 
First, and foremost, there is no conceptually coherent basis for measuring the depth of international policy cooperation. The depth of policy cooperation is defined here as the extent to which a state has agreed to constrain its recognized authority to make and/or to enforce policies free from external interference or involvement. Both the disciplines of international relations and international law, for instance, have paid relatively little attention to voluntarily agreed limitations on state authority to make and/or to enforce policies.

Measurement and research on the depth of international economic policy cooperation remains unduly focused on the stages of economic integration. However, whether an international agreement is classified as a Free Trade Agreement (FTA) or a Customs Union, for instance, is less and less useful as a proxy measure of the depth of international policy cooperation. ${ }^{4}$

From a different perspective, many researchers have recorded whether selected provisions are present or not in a sample of international economic agreements, but not the varying depth of the provisions..$^{5}$ Alternatively, a widely known measure of a country's level of international policy cooperation - the A.T.Kearney/Foreign Policy measure of international political engagement - merely measures the number of selected Treaties signed, and membership of selected international organisations, irrespective of the varying depth of cooperation these engagements entail. ${ }^{6}$

The second reason that current approaches to measuring cooperation are inadequate is that international economic policy cooperation, even that confined to official government-to-government cooperation, is effected by a large number of entities, using a wide range of instruments. There is typically no centralized repository of information on the extent of international economic policy cooperation, either within a single state across all agencies and policy functions, or across states by a single policy function.

\footnotetext{
${ }^{4}$ The stages of economic integration refer to specific types of international economic agreements, starting with Free Trade Agreements, and ending with economic unions such as the European Union. See section 4.4 of the thesis for a discussion. Examples of research that has used the stage of economic integration as a proxy measure of the depth of international economic and/or policy cooperation is that by Schiff 2000 , and $\mathrm{Wu} 2004$.

${ }^{5}$ See for example OECD 2006, Cernat 2005.

${ }^{6}$ See the A.T.Kearney Globalization Index, discussed further in Chapter 12.1, at http://www.atkearney.com/main.taf?p=5,4,1,127
} 
Thirdly, the increasing depth of policy cooperation in FTAs is a relatively recent (post1990 or so) phenomenon, and data classification and research have not yet caught up with this. For instance, the World Trade Organisation (WTO) retains its primary, historical, legally based classification of Regional Trade Agreements as either FTAs or Customs Unions.

For these reasons, cross-country quantitative research on international economic policy cooperation has focused on the burgeoning number of Regional Trade Agreements (RTAs) as the source of information. ${ }^{7}$ RTAs, along with the WTO agreement itself, are probably the single most important vehicle for international economic policy cooperation. They function as a coordinating and umbrella mechanism in a wide range of policy areas. More recent RTAs typically go well beyond trade issues to incorporate a range of provisions on behind the border issues such as investment, competition, domestic regulation, and so on. They therefore have some validity as a source of information on signatory countries' depth of international economic policy cooperation.

However, RTAs by no means capture the full extent of any particular country's level of international economic policy cooperation - not even the full extent of cooperation in any particular policy domain covered in the agreement. Government agencies are increasingly cooperating directly with their counterpart agencies in other states, rather than through the mechanism of an RTA. In the field of competition policy (anti-trust) cooperation, for instance, a key instrument, in addition to Competition Policy Chapters in RTAs, is the stand-alone competition enforcement agreement between two or more national Competition Authorities. To properly measure the depth of policy cooperation by country in a specific policy domain, therefore, it is necessary to assemble a dataset across all the international instruments in which such cooperation is embodied.

This thesis attempts to address each of the weaknesses that prevent satisfactory measurement of the depth of international economic policy cooperation. It does so by:

\footnotetext{
${ }^{7}$ The term RTA is used in this thesis to refer to all types of regional or bilateral trade agreements, including FTAs, Customs Unions, Common Markets, and Economic Unions, and including agreements between countries in different regions.
} 
1. Developing a new conceptualisation of the impact of international economic cooperation on state sovereignty, by using the lens of state jurisdiction, rather than the contested concept of state sovereignty.

2. Identifying different dimensions of state jurisdiction, and developing a stylized spectrum of increasing generic points of imposition on state policy autonomy arising from the different provisions in international economic agreements.

3. Using an existing WTO dataset on non-tariff provisions in RTAs to measure the changing depth of international policy cooperation over time, and to test hypotheses about the relationship between the depth of policy cooperation in RTAs and multilateral trade liberalization.

4. Developing ordinal indices of the depth of international economic policy cooperation in a specific policy domain - competition policy.

5. Assembling a new comprehensive dataset of international agreements that embody competition policy cooperation. The dataset incorporates both the provisions in RTAs, and stand-alone agreements outside RTAs.

6. Testing descriptive propositions about the nature of international competition policy cooperation, and hypotheses about its causes.

There appear to have been few previous attempts to directly measure the depth of international policy cooperation. One notable exception is the work of Smith (2000), who devised a measure of legalism in dispute settlement mechanisms in RTAs. A much earlier exception was the work of Lindberg (1970) and Nye (1968), who developed measures of regional policy integration.

There have also been few attempts to assess policy cooperation in a specific policy domain across the different international instruments in which such cooperation is embodied; a number of studies, for instance, analyze international policy cooperation in a particular policy domain by looking only at the provisions in RTAs e.g. OECD 2006, UNCTAD 2005.

The thesis is organized in four parts. The remainder of Part One presents a statement of the research problem (Chapter 2), and a discussion of the Purpose Statement and Methodology (Chapter 3). 
Part Two of the thesis commences with a focused, integrative review of the main strands in the literature on international cooperation, focusing on international economic cooperation (Chapter 4). The objective is to substantiate the claim that existing frameworks for conceptualizing and measuring the impact of international cooperation on formal legal (de jure) state authority are inadequate.

Chapter 5 then discusses the contested concept of state sovereignty, and argues that the alternative concept of state jurisdiction provides a more coherent, and more tractable foundation for measuring the depth of international economic policy cooperation.

In Chapter 6, stylized spectrums of increasing jurisdictional integration are presented, together with a taxonomy of the depth of international economic policy cooperation.

Part Three of the thesis applies the concept of jurisdictional integration to specific policy domains and international agreements. It demonstrates the practicality of the concept, and its potential contribution to more accurate measurement of, and research on the depth of international economic policy cooperation.

Chapter 7 discusses competing hypotheses of the general causes of international economic policy cooperation, and the key variables influencing decisions by states over the extent to which they will agree to constrain their jurisdiction.

Chapter 8 then analyses the changing depth of policy cooperation in RTAs, by applying the concept of jurisdictional integration to existing WTO data on non-tariff provisions in RTAs. This allows some testing of competing hypotheses about the relationship between policy cooperation in RTAs and multilateral trade liberalization.

Existing datasets have severe limitations, however, in terms of measuring the depth of international economic policy cooperation. To that end, the remaining chapters in Part Three apply the concept of jurisdictional integration to international cooperation in competition policy. 
Chapter 9 provides an overview of the evolution of international cooperation in competition policy, while in Chapter 10, ordinal indices of jurisdictional integration of competition policy are derived. Chapter 11 sets out research questions on international competition policy cooperation, to be tested along with the general hypotheses in Chapter 7, using a new dataset of international competition policy agreements compiled in Chapter 12. Agreements are then ranked (Chapter 13) on the jurisdictional integration indices, and statistical analysis is conducted in Chapter 14, primarily using the depth of cooperation in enforcing competition policies as the dependent variable.

Part Four presents the conclusions of the thesis. First, an assessment is made of the thesis' contribution to knowledge. This is followed by a discussion of its limitations, and suggested avenues for further research. 


\section{Chapter 2}

\section{THE RESEARCH PROBLEM}

International economic cooperation is a central feature of modern international relations. In 1996, for instance, Trachtman declared that “...economic integration is the leading motivation for new public international law today", describing it as the "international economic law revolution." 8 The increasing internationalization of economic exchange has been accompanied by a significant increase both in the number of international economic agreements, and in the extent to which they impact on "behind the border" issues hitherto largely the sole preserve of domestic policy. ${ }^{9}$ That is, while traditional trade agreements regulated tariffs, quotas, and other policies "at the border," modern agreements increasingly also regulate domestic regulatory policies, such as regulatory standards, intellectual property, or competition policy.

This has resulted in a blurring of the boundary between international and domestic policy. Bolewski has described this as the "internationalisation of domestic policy", or the "administrative diversification of foreign policy.", 10

Yet despite intense public and scholarly debate over the impact of international economic integration on state sovereignty, existing frameworks for analysing international cooperation are inadequate for the task. This is because they pay insufficient attention to the differential impacts of alternative forms of cooperation on

\footnotetext{
${ }^{8}$ Trachtman 1996, p. 3.

${ }^{9}$ Evidence for the increased number of international economic agreements is usually cited from the number of RTAs notified to the WTO - see Crawford and Fiorentino 2005. There has also been a less well-documented increase in the number of other types of international economic agreements, such as international regulatory agreements, and investment treaties. Evidence in support of the increasing depth of international economic agreements is cited later in this thesis (Chapters 8.2, 13.2, and 14.4).

${ }^{10}$ Bolewski 2007, p. 19.
} 
the de jure autonomous authority of the state. ${ }^{11}$ While such impacts attracted considerable interest during an earlier wave of scholarship on regional integration, and have been the subject of increased attention in recent years, there remains a significant gap in the literature in this area. This gap continues to hinder theorisation, measurement, research, and policy development on globalisation and state sovereignty.

For instance, much scholarly debate over the impact of international economic agreements on the de jure policy autonomy and authority of the state has focused on broad concepts such as "derogations of sovereignty", "sovereignty costs", or "impingements on legal sovereignty." Scholte asserts the "end of sovereignty" and the arrival of a new world of "post-sovereign governance.", 12

It is well recognized that sovereignty is a multi-faceted, ambiguous, and at times emotive term (see for example Krasner 1999, and Jackson 2003). Analysing and debating the impact of international cooperation in terms of the umbrella concept of sovereignty is therefore highly problematic and fruitless. As Lowe has noted, the concept of sovereignty is often used "... as a rhetorical flourish in discussions of constraints upon the freedom of States to act. But it does little else." (Lowe, 2008, p. 79).

Less well recognised is that conceptualizing the issue in binary terms is also inadequate. Formulations such as soft or hard international law, intergovernmentalism or supranationality, ${ }^{13}$ shallow or deep integration, ${ }^{14}$ negative or positive integration, ${ }^{15}$ sovereignty-bound or intrusive regionalism, ${ }^{16}$ government or governance, ${ }^{17}$ intergovernmental or transgovernmental agreements ${ }^{18}-$ do not on their own allow for the

\footnotetext{
${ }^{11}$ The term autonomous authority is used here to refer to the authority to make and implement decisions free from interaction with or interference from external authority structures.

${ }^{12}$ Scholte 2000, pp. 135-138.

${ }^{13}$ Sandholtz and Sweet 1998.

${ }^{14}$ Lawrence 1996.

${ }^{15}$ Trachtman 2007, p. 64.

${ }^{16}$ Acharya 2002.

${ }^{17}$ Krahmann 2003.

${ }^{18}$ Slaughter 2004.
} 
fact that there is a large and growing menu of policy integration options available to states that vary in a number of dimensions in terms of their impact on a state's policy autonomy. ${ }^{19}$

Some other analysts are inclined to retain an overly sharp disjuncture between an increasingly borderless international economy, on the one hand, and a political world that remains divided into nation states with fixed borders and a monopoly of legitimate coercion over their citizens. For instance, Alesina and Spolaore state that "...the EU does not have the monopoly of legitimate coercion over its citizens, and it is extremely unlikely that the member states... will ever relinquish it." ${ }^{20}$ Yet the coercive powers of a state - while jealously guarded - are in principle divisible and can be allocated between a state and international institutions. It is not a binary choice of a monopoly at the level of EU member states, or a monopoly at the EU level. For instance, EC regulatory agencies in some cases have authority to promulgate new regulations, to use coercive enforcement powers, and to have their decisions enforced, albeit through national court systems. In similar vein, Schiff (2000, p. 8) notes: "Rather than assume that public goods are provided either at the union [EU] level [or] at the country level....it seems more realistic to assume that these public goods can coexist at the various levels. Also, it seems more fruitful to think...in terms of a continuum with, say...countries within a RIA [Regional Integration Agreement] becoming more or less politically integrated.”

While EC-style supranational institutions are uncommon, virtually all states have entered into international arrangements that involve constraints of varying degrees on their de jure policy autonomy. Political borders as well as economic borders are increasingly porous.

This thesis surveys the various literatures on international cooperation, focusing on international economic cooperation. In very general terms, a key finding is that the

\footnotetext{
${ }^{19}$ Policy integration is defined here, not as approximation or harmonization of substantive policy settings per se-although it includes this - but as increasing levels of international cooperation and coordination of the formal processes by which policies are formulated and implemented. Policies can be coordinated in a wide variety of ways, including by information exchange, explicit agreement, or by setting up joint institutions that play an on-going role in establishing or implementing joint policies. The latter may be termed institutional integration, but for the rest of this article the umbrella term international policy cooperation will be used to refer to all forms of international policy cooperation and institutional integration.

${ }^{20}$ Alesina and Spolaore 2003, p. 205.
} 
literature has neglected the phenomena of voluntarily agreed limitations on a state's recognised authority to make and to enforce rules.

More specifically, the existing literatures either:

- Have relatively little to say on classification of the full range of types of international policy cooperation in terms of their differential impacts on de jure state policy autonomy e.g. international law, recent regional integration theory.

- $\quad$ Conflate economic and policy integration e.g. stages of economic integration.

- Do not cover the full range of policy integration mechanisms e.g. more recent regional integration theory, the international policy cooperation literature, international law, and international relations theory.

This thesis attempts to demonstrate that the concept of state jurisdiction is both more conceptually coherent, and provides more tractability than the concept of sovereignty for the purpose of analysing the impacts of international economic cooperation on the formal authority of the state.

State jurisdiction is the authority of a state under international law to govern persons or property by its municipal law i.e. its domestic or national law. Jurisdictional integration is defined here as a process by which a state chooses, through entering formal agreements with other states, to restrict its de jure authority to autonomously make, and/or to enforce decisions in a specific domain or domains.

More specifically, jurisdictional integration is conceived of as a spectrum running from complete policy autonomy through to, but stopping short of, full political integration. It covers all forms of cooperative (as opposed to unilateral) policy cooperation, and all types of institutional integration short of full political integration.

The concept of jurisdictional integration builds on those parts of the literature in international relations that view states as the primary actors in the international arena. That is, while recognizing that other actors - such as sub-national governments, and non-state actors such as standards bodies and Non-Government Organisations (NGOs) are becoming increasingly important, states are considered to remain a key locus of 
decision-making and legitimisation in all policy domains, and, overall, remain the key locus.

Whether a state can, in practice, exercise effective control over specific economic activities is outside the scope of this enquiry. That is, the focus is solely on formal legal authority, not the state's capacity to exercise that authority. As Howse has noted, these two questions are often not clearly separated: "Part of the project of demystifying the notion of "sovereignty lost" is to address these questions separately." ${ }^{21}$ The framework developed in this thesis is intended to provide an improved basis for researching the relationships between de jure state authority and de facto state capacity.

The concept of jurisdictional integration responds to the calls of international relations theorists for research on the transformation of fundamental structures in international relations, such as state sovereignty (Czempiel and Rosenau 1989, Ruggie 1993). Jurisdictional integration encapsulates what Ruggie describes as the "unbundling" of exclusive territoriality, what Cohen depicts as the unbundling and repackaging of the state's authority, and what Slaughter describes as the disaggregation of sovereignty. ${ }^{22}$ It uses as its point of departure Krasner's careful differentiation between different aspects of state sovereignty (Krasner 1999). The concept builds on the suggested continuum running from intergovernmentalism to supra-nationality proposed by Sandholtz and Sweet (1998). ${ }^{23}$

Similarly, the concept of jurisdictional integration addresses the "... almost urgent need for new ideas and much better analytical and disaggregated explorations of existing international law and international economic law concepts" (Jackson, 2006). In this regard, it develops Jackson's suggested focus on the allocation of government decisionmaking power in deriving a refined concept of sovereignty.

\footnotetext{
${ }^{21}$ Howse, 2008, p. 65. Abbott et. al. (2000, p. 402) make the same point with respect to the relationship between the formal legalization of international relations, and the effects legal rules have on behaviour and outcomes.

${ }^{22}$ Ruggie 1993, p. 165, 171; Cohen 2001, p. 80; Slaughter 2004, p. 5.

${ }^{23}$ Sandholtz and Sweet, 1998, pp. 8-9.
} 
Jackson states that there is a need to:

"...disaggregate and to analyze: break down the complex array of "sovereignty" concepts and examine particular aspects in detail and with precision to understand what is actually at play. A major part of this approach is to understand the pragmatic functionalism of the allocation of power as between different levels of governance entities in the world." 24

The concept builds on the early work of Lindberg and Nye in disaggregating regional integration into conceptually distinct components, and on recent scholarship on the legalization of international relations. ${ }^{25}$ The concept also helps to meet an identified need for research on international economic integration that transcends individual regions, and that is capable of comparing and throwing light on integration arrangements of varying types (Moravcsik 1998, Laursen 2003). This includes the need to incorporate the European Union $(\mathrm{EU})^{26}$ in comparative studies, instead of viewing it as sui generis, or as the standard against which other regions are implicitly or explicitly judged. $^{27}$

In doing so, the thesis builds on Stein's framework for analysing the level of integration of international organisations (Stein 2001), Smith's analysis of the level of legalism in dispute resolution mechanisms in RTAs (Smith 2000), and on other research on the depth of RTAs e.g. Dorrucci et al 2002, 2004, Wu, 2004.

Finally, the concept responds to the pressing need for governments to determine how best to manage increasing international economic integration. As Keohane and Nye have observed, "sovereignty is up for grabs in a way that has not been seen since the

\footnotetext{
24 Jackson, 2008, pp. 24-25.

${ }^{25}$ Lindberg 1970, Nye 1968; Abbott et. al. 2000.

${ }^{26}$ The EU comprises three pillars: the European Communities; the Common Security and Foreign Policy; and the Justice and Home Affairs pillar. The first pillar, in turn, comprises the European Steel and Coal Community 1952, the European Community (EC), and the European Atomic Energy Community. The EC, originally the European Economic Community created by the Treaty of Rome 1957, is the main vehicle for economic cooperation, and contains deeper cooperation than the second and third pillars. Hence most references to economic cooperation between EU member countries in this thesis will be to the EC.

${ }^{27}$ Breslin et. al. 2002, pp. 11-13.
} 
seventeenth century." ${ }^{28}$ Keohane (2002, p. 748) has also suggested that sovereignty can be viewed as a bargaining chip, something to be given up in limited ways in the pursuit of other goals. This research aims to provide improved clarity over how "sovereignty" is being used as a "bargaining chip." In doing so, the thesis builds on the literature on international policy cooperation (Cooper 1987, OECD 1994, Goddard 2002), and responds to calls for improved conceptual tools to facilitate higher quality debate on globalisation (Jackson, 2006).

\footnotetext{
${ }^{28}$ Keohane and Nye, 1989, p. 25.
} 


\section{Chapter 3}

\section{PURPOSE STATEMENT AND METHODOLOGY}

\subsection{Purpose STATEMENT}

The objectives of this thesis are to:

1 Provide an improved conceptualisation of state sovereignty, the fundamental unit of analysis in international relations, international law, and foreign economic policy.

2 Provide an improved basis for describing and measuring the functioning of the inter-state system.

3 Define a new variable - jurisdictional integration - to measure the depth of international economic policy cooperation.

4 Define conceptually coherent and distinct dimensions of this variable, to facilitate accurate measurement.

5 Introduce a taxonomy to describe broad levels of the depth of international economic policy cooperation.

6 Develop instruments to measure the depth of international economic policy cooperation in comparative research in a specific policy domain.

7 Present a theoretical perspective on the variables likely to be associated with decisions by states to enter international agreements entailing different depths of cooperation.

8 Measure the level of jurisdictional integration in selected international economic cooperation agreements, and test descriptive propositions about the nature of international cooperation in a specific policy domain.

9 Conduct exploratory statistical and other analysis of selected international economic agreements, to test hypotheses on the causes of international economic cooperation, and to demonstrate the potential contribution of the framework to research and policy analysis. 
10 Assist policy makers to identify the full range of options available to states for the governance of international economic integration, and some of the key trade-offs involved.

The thesis is intended to contribute to knowledge by addressing specific research questions of both a descriptive and inferential nature.

\section{Descriptive questions:}

1 What is the depth of policy cooperation in selected international economic agreements?

2 How has the depth of policy cooperation in international economic agreements changed over time?

3 What cross-country patterns (or "families" of agreements) can be identified?

Inferential questions:

4 Has the depth of policy cooperation in RTAs increased over time with increasing international economic integration?

5 Is there any significant relationship between the depth of policy cooperation in selected agreements, and whether the agreement is an FTA or a Customs Union?

6 Do country pairs that have a higher level of international economic integration sign deeper policy cooperation agreements?

7 Do country pairs that sign deeper policy cooperation agreements have similar sized economies?

8 Do countries that sign deeper policy cooperation agreements have higher quality governance?

9 Do country pairs that sign deeper regulatory enforcement cooperation agreements have more similar domestic laws?

10 Do neighbouring countries sign deeper policy cooperation agreements? 


\subsection{THE SCHOLARLY FRAMEWORK}

\subsubsection{Philosophical assumptions}

The proposed research approach is based mainly on the "scientific method" - also referred to as positivist/post-positivist research, or quantitative research in which data, objectivity, and rational analysis generate knowledge. It is presumed that outcomes in the real world have possible or likely causes that are capable of being discovered through the application of empirical research methods - although it is also recognized that reality is complex and the ability to reach strong conclusions about causality in the social sciences is severely limited.

The objective, however, is to test for statistical relationships between a small set of variables that are hypothesized to be important on the basis of a theory of causality - a so-called reductionist approach. The researcher collects data that is presumed to measure objective reality. The data either supports or refutes the theory, which is then modified as necessary. It is recognized that research findings are always imperfect, and knowledge often advances through rejection of hypotheses rather than proof of hypotheses.

The proposed research also adopts the perspective of pragmatism, a school of thought on knowledge claims that focuses on problems and the applications that work in solving them, rather than on the research methods themselves. This is an appropriate approach for a $\mathrm{PhD}$ in public policy, in which the policy problem is central and the analyst uses whatever approaches are necessary to throw light on the problem. It reflects the fact that the author's interest in this research topic was stimulated in the course of a consulting assignment he undertook for the New Zealand government on how best to analyse and manage global integration. ${ }^{29}$

\subsubsection{Personal perspective}

The approach to this research is non-normative. Increasing international economic and policy integration are not necessarily desirable ends. While they will often contribute to higher living standards, they can instead impose economic costs. They will impact on different groups within and across countries in different ways, and entail trade-offs between competing public policy goals, such as legitimacy, efficiency, and flexibility.

\footnotetext{
${ }^{29}$ See Economics and Strategy Group 2002.
} 
That said, however, the underlying perspective is one that views international economic integration as a major potential source of improvements in the human condition globally, and choices over how to manage international integration as one of the key strategic issues facing any government and society.

The research perspective is therefore in line with those writers who, rather than seeing globalization as placing countries in a straight jacket, view it as presenting governments at the same time with new constraints on policy choices as well as new opportunities for achieving public policy goals (see for instance OECD 1994, Kahler and Lake Eds., 2003).

The thesis also adopts a neutral perspective in the debate over regional versus multilateral approaches to international economic integration. The framework developed here is intended to contribute to better measurement, description, research, and analysis of all forms of international policy cooperation, whichever of the "laterals" in which they are embodied. The thesis is therefore intended to assist comparison of bilateral, regional, and multilateral approaches, while promoting neither regionalism nor multilateralism. The observation is made, however, that "behind the border" provisions increasingly found in RTAs often require the existence at the national level of developed systems of law and regulatory capacity. These pre-requisites present serious obstacles to a multilateral approach, and mean that bilateral or regional approaches may in some circumstances be the only realistic alternative, in the short term, to no reduction in non-tariff barriers. While a multilateral approach may be theoretically optimal in a zero transactions costs world, a bilateral or regional approach my in some situations be optimal in the real world.

Furthermore, in at least one policy domain, bilateral or regional cooperation may inherently be on a Most Favoured Nation basis. For example, in the field of anti-trust, international cooperation to prosecute a domestic or international cartel benefits all exporters active in the relevant markets. Exporters from non-cooperating countries provided they have access to the market - cannot be excluded from benefiting from the more competitive markets that result. 
Finally, the research approach is also non-teleological. The historical record indicates that increasingly deep international economic policy cooperation is by no means inevitable, or unidirectional. Amongst numerous examples of fluctuations in the depth of international policy cooperation is the abandonment of the Gold Standard in the 1930s; a period of no international cooperation on exchange rates; the introduction of the Bretton Woods system of fixed exchange rates in 1946; the collapse of that system in the early 1970s; and its replacement from 1978 by the current system of floating exchange rates. In the post-World War II period, member states agreed to maintain the value of their currencies within one percent of their par value, and to adjust the par value only with the concurrence of the IMF. These restrictions on economic policy autonomy are no longer in place.

\subsubsection{Theoretical framework}

The theoretical framework in which this research is embedded is one that recognizes that international economic cooperation is the outcome of both the demand for, and the supply of cooperation by governments, and is also the result of inter-state negotiation. A number of broad theories of the determinants of international economic policy cooperation are discussed more fully in Chapter 7. Of these, a key theoretical determinant is economic integration, but the relationship between international economic integration and international economic cooperation is a two-way relationship. Policy-makers focus on the expected impact of international cooperation on economic integration. The few empirical studies in this area find some support for an impact of policy cooperation on economic integration - see Appendix 1 for a summary table of selected studies.

However, it is also likely that, in some circumstances at least, economic integration creates a demand for increased policy cooperation (Lawrence 1998). Consistent with the overall focus of the thesis on re-conceptualizing the impact of economic integration on state sovereignty, the perspective that will be adopted will be to treat policy cooperation primarily as the dependent variable, and to begin to explore the conditions influencing states to sign up to international economic cooperation arrangements entailing varying depths of cooperation.

This will contribute to the small empirical literature on the causes of international policy cooperation, which at present is largely confined to studies looking at a binary choice of 
cooperation versus no cooperation e.g. Mansfield, Milner and Rosendorff 2002, Baier and Bergstrand 2002, or studies that use a combined measure of economic and policy integration as the dependent variable e.g. Wu 2004.

Competition policy is a good candidate for this research, for a number of reasons. First, increasingly mobile economic actors create the need for increased "regulatory reach" and potential jurisdictional conflict. This can be seen from the increase in international mergers, and increasing concern about the activities of international cartels. Secondly, there has been a rapid expansion in the last two decades in the number of countries that have national competition laws, resulting in a large increase in the potential for jurisdictional conflicts. Thirdly, there are a growing number of international competition policy agreements, incorporating all dimensions of state jurisdiction, and at bilateral, regional, and multilateral levels. Furthermore, these agreements are generally available on web sites of competition agencies and international organizations. Fourthly, there is no comprehensive WTO agreement on competition, so that a country's economy-wide international commitments can be assessed on the basis of specific bilateral and regional agreements, without the need to compare those geographically bound commitments against broader multilateral commitments. Finally, for some time there has been a high level of international policy and research interest, reflected, for instance, in the long-standing competition policy work programs of UNCTAD and the OECD, and reflected more recently in the creation of the International Competition Network in 2001.

\subsection{METHODOLOGY AND APPROACH.}

It is proposed to adopt a deductive approach that tests a theory and hypotheses derived from the theory. The literature reviews have been used to identify and clarify testable hypotheses and to prompt the development of new hypotheses. The overall scientific approach to the research points to the use of statistical analysis as the main methodology.

Following Lazarsfeld, the development of the concept of jurisdictional integration is followed by the identification of distinct underlying dimensions, reflecting different aspects of the concept. ${ }^{30}$ These dimensions, based on different types of state

\footnotetext{
${ }^{30}$ Lazarsfeld, 1958, cited in Bryman and Cramer, 1994, pp. 67-69.
} 
jurisdiction, are drawn initially from international law (as discussed in Chapter 5). The identification of dimensions reduces the abstractness of a concept, making it easier to operationalize for measurement and research. Ordinal scales are then developed for each of the dimensions, against which individual international agreements can be ranked.

The theoretical framework requires data on the depth of international cooperation at the country level. To the author's knowledge, there is no existing dataset of the provisions of a substantial number of international economic agreements that would allow the ranking of countries by the depth of policy cooperation. This is first and foremost a reflection of the lack of a conceptually coherent basis for measuring the depth of international policy cooperation. Existing datasets were primarily compiled to measure phenomena such as the legal form of an agreement, the simple presence or absence of specific agreement features, or the extent to which provisions are compatible with the multilateral trading system, not to measure the depth of cooperation.

A WTO inventory of non-tariff provisions in RTAs is utilised in Chapter 8 to derive a measure of the depth of policy cooperation in a sample of agreements, but the data is not sufficiently disaggregated to allow a measure of the depth of cooperation by country.

Furthermore, RTAs do not necessarily capture the full extent of signatories' level of international economic policy cooperation in a specific policy domain covered in the agreement. A country may also be party to bilateral agreements, other regional agreements, or multilateral agreements that must also be taken into account when measuring its level of international cooperation in a particular area. To fully measure the depth of policy cooperation by country, therefore, it is necessary to assemble a dataset that incorporates provisions in at least the main relevant international instruments to which that country is party.

To that end, a new dataset of international agreements is constructed in Chapter 12, comprising bilateral, regional, and multilateral agreements containing provisions on international competition policy cooperation. The agreements are then ranked against ordinal indices of the depth of international competition policy cooperation derived in Chapter 10. Because the data for the dependent variable, and for a number of the 
predictor variables, is ordinal data, the appropriate technique to use to test for statistical relationships is contingency table analysis, drawing on a variety of approaches. ${ }^{31}$ Hypothesized relationships between the depth of enforcement cooperation and predictor variables are explored.

Given the methodological approach, the validity of the results is influenced by how robust the ordinal indices are, and by the reliability of the ranking of agreements against the indices. The indices are based on an extensive review of the competition policy literature, and have been tested against expert opinion. The reliability of the ranking has been subjected to a test of inter-rater reliability, to provide some assurance that other researchers and competition policy experts would rate the agreements in broadly the same way. To that end, a stratified random sample of 10 of the 92 agreements in the dataset was selected for independent ranking, as described in Chapter 14.9.

The pragmatic perspective adopted for this thesis suggests the desirability of using more than one approach in an attempt to throw additional light on complex reality. Mixed methods approaches are generally seen as involving both quantitative and qualitative methodologies (Creswell 2003).

This thesis attempts to achieve a form of convergence primarily through the use of different types of quantitative approaches - for instance, simple quantitative analysis of the overall depth of policy cooperation in RTAs, supplemented by statistical analysis of the relationship between the depth of competition policy enforcement cooperation and predictor variables by country and/or by agreement. The statistical analysis, in turn, utilises techniques suited both to large populations and small populations, in order to increase the robustness of the results. This reflects the fact that the relatively small size of the dataset constructed in Chapter 12 limits the extent to which standard large population statistical techniques can be relied upon. In addition, both classical

\footnotetext{
${ }^{31}$ Ordinal data is categorical data i.e. data measured in terms of categories, in which the observations have a natural or built-in order. For example, health status measured in terms of the categories "poor health, fair health, good health, excellent health" is an ordinal variable, and a dataset consisting of such categories is ordinal data. The sequence "poor health, fair health, good health, excellent health" is an ordinal index, and may be arbitrarily numbered from 1 (poor health) to 4 (excellent health). In contrast, categorical data merely records whether a particular observation is or is not a member of a specific category. However, ordinal data is not count or interval data. That is, the distance between poor health (1) and fair health (2) is not necessarily the same as the distance between fair health (2) and good health (3).
} 
confidence tests and Bayesian techniques are used to shed light on how much confidence can be placed on the strength of the statistical results.

The specific type of mixed methods approach is a concurrent procedure, in which all data is collected at the same time and the results are integrated in the overall conclusions (Creswell, 2003).

The approach to the research has primarily been to conduct exploratory statistical analysis with the objective of operationalising a new dependent variable - jurisdictional integration. The aim is not to attempt to rigorously identify all the predictor variables, or to control for all likely confounding variables, much less to attempt to establish the direction of causality running between, for instance, international policy cooperation and international economic integration. Rather, the objective is to begin to explore relationships between the more salient predictor variables, to test some descriptive statements and hypotheses, and to point the way to avenues for future research. 
PART 2

Jurisdictional Integration: A New Concept 


\section{OVERVIEW}

In Part 2, the literature on international cooperation is reviewed as a prelude to the development of a new concept that better captures the impact of economic globalisation on state sovereignty.

Chapter 4 presents a focused, interdisciplinary literature review.

This is followed in Chapter 5 by a discussion of the contested concept of state sovereignty. The argument is developed that the alternative concept of state jurisdiction, well established in international law, provides a more coherent and tractable foundation for conceptualising, and ultimately for measuring, the depth of international cooperation. Jurisdictional integration is then defined as the process by which states increasingly constrain their formal policy authority through signing international agreements.

Chapter 6 presents a stylized spectrum of jurisdictional integration, and an associated taxonomy of the depth of cooperation. The spectrum is illustrated with examples of international economic cooperation of increasing depth. Generic trade-offs between competing public policy objectives are discussed as a state moves from low to higher levels of jurisdictional integration.

Part 2 of the thesis provides the conceptual tools for the measurement and statistical analysis of the depth of international economic cooperation that is undertaken in Part 3. 


\section{Chapter 4}

\section{THE LITERATURES ON INTERNATIONAL COOPERATION: AN INTERDISCIPLINARY REVIEW}

\subsection{INTRODUCTION TO THE LITERATURES}

Meeting the objectives set out in Part One requires, inter alia, substantiation of the claim that the literature has paid insufficient attention to the varying impacts of different types of international cooperation on the de jure authority of the state.

The type of literature review conducted is an integrative review that summarizes a broad theme running across the different disciplines. ${ }^{32}$

A number of disciplines deal extensively with international cooperation, including political science, economics, law, and public policy. Some strands of the literature are themselves inter-disciplinary - for example, there is recent collaboration between international relations theorists and international lawyers on the "legalization of international relations."

This chapter contains a review of a wide range of the relevant literatures in:

- International law.

- International relations theory.

- The legalization of international relations.

- Regional integration theory.

- The literature on stages of economic integration.

- The literature on international policy coordination.

- The literature on fiscal federalism.

\footnotetext{
${ }^{32}$ Cooper, 1984, cited in Creswell, 2003, p. 32.
} 
Figure 1 presents a Literature Map to provide an accessible overview of the relevant literatures.

These literatures are voluminous, and any attempt to extract key contributions with respect to any one topic will inevitably fail to do justice in some regard. Given space limitations, the focus is limited to those aspects bearing on the impact of international cooperation on the de jure authority of the state.

\subsection{INTERNATIONAL LAW}

"International law deals with the propriety of the exercises of jurisdiction by a state, and the resolution of conflicts of jurisdiction between states." ${ }^{\text {33 }}$

As this quote suggests, in general, international Law has been primarily concerned with the problems of avoiding excessive unilateral extra-territorial assertions of jurisdiction, and ameliorating the problem of a party facing conflicting requirements from two or more states asserting jurisdiction over the same party or activity, rather than with international cooperation between states.

This focus is reflected in the emergence of principles that limit jurisdiction to prescribe, to adjudicate, or to enforce to circumstances where the exercise of such jurisdiction is reasonable. ${ }^{34}$ It has lead to a rule that a state may not conduct official activities in the territory of another state without that state's consent e.g. law enforcement officials of one state may take judicial enforcement actions in the territory of another state only with the consent of the other state. It has also resulted in the defence of foreign government compulsion - a state may not require a person to do something in another state (or refrain from doing something) that is prohibited (or required) by the law of that

\footnotetext{
${ }^{33}$ American Law Institute, 1987, p. 233.

${ }^{34}$ American Law Institute, 1987, pp. 244-254 (with respect to jurisdiction to prescribe), pp. 304-313 (with respect to jurisdiction to adjudicate), and pp. 320-339 (with respect to jurisdiction to enforce). Note that the standards of reasonableness are not the same across the different categories of jurisdiction.
} 


\section{Figure 1 Map of the Literatures on International Economic Policy Cooperation}

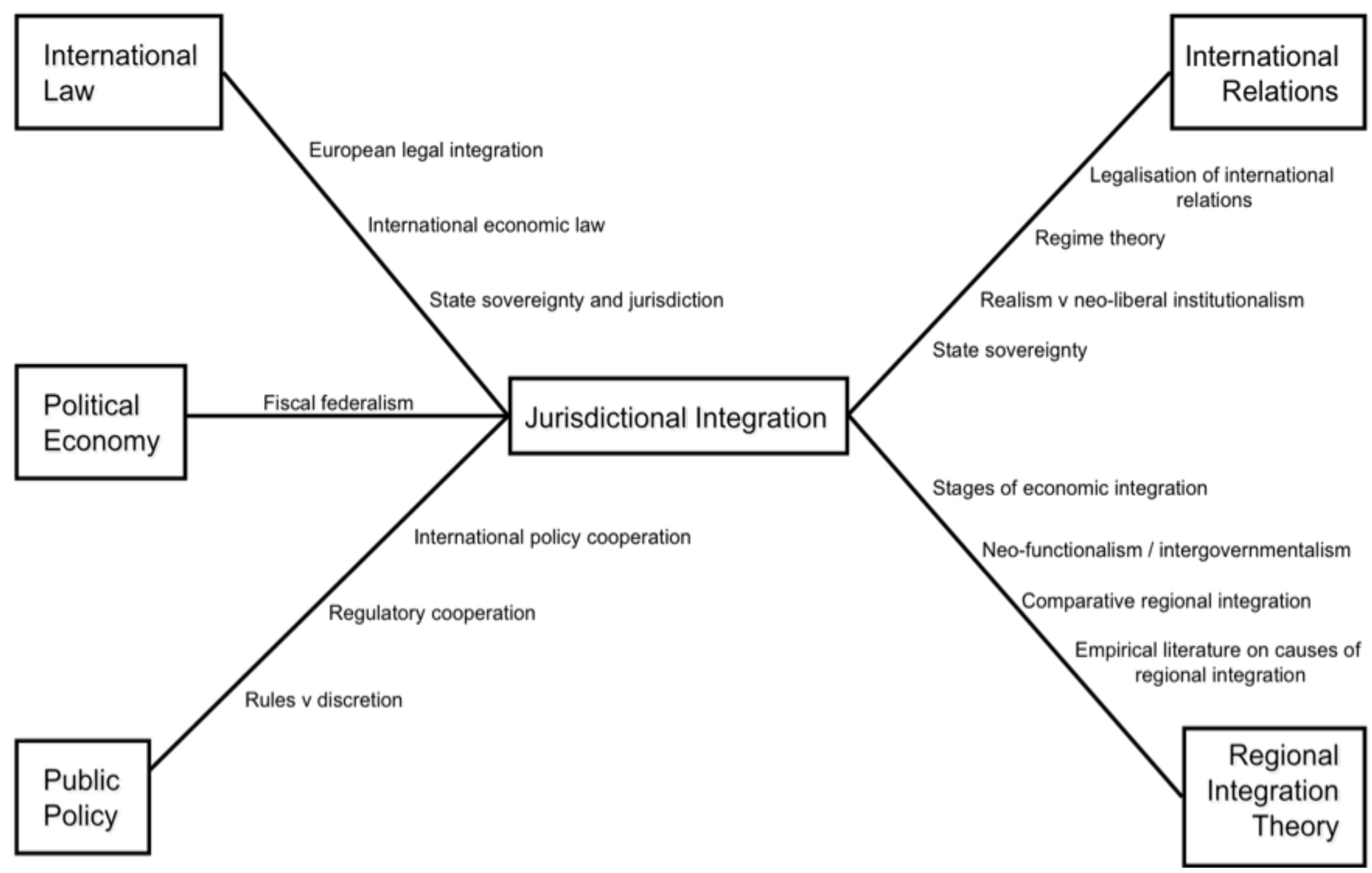


state or by the law of the state of which he is a national; while a state may require a person of foreign nationality to do something in that state (or refrain from doing something) even if it is prohibited (or required) by law of the state of which he is a national. ${ }^{35}$

Finally, limitations on state jurisdiction are reflected in the Act of State Doctrine in United States law. Under the Act of State Doctrine developed by the US Supreme Court, "...courts in the United States will generally refrain from examining the validity of a taking by a foreign state of property within its own territory, or from sitting in judgment on other acts of a governmental character done by a foreign state within its own territory..." and "A state or state instrumentality is immune from the jurisdiction of the courts of another state, except with respect to claims arising out of activities of the kind that may be carried on by private persons." ${ }^{36}$ There is no such general immunity from jurisdiction to prescribe, provided it is reasonable, except that relating to diplomatic and consular activities, and even governmental acts can be enforced through non-judicial means.

In international law, the long-recognized ability of states to enter into commitments amongst themselves is regarded as constituting an attribute of sovereignty, rather than being a diminution of sovereignty. ${ }^{37}$ In general, however, international law does not distinguish between different types of international treaties or agreements. For instance, neither the International Law Commission, nor the Vienna Convention on the Law of Treaties, makes a distinction between different types of treaties. ${ }^{38}$ Distinctions have at times been made between primary international (treaty) law, and secondary international law (law created by international organizations), ${ }^{39}$ and between the few

\footnotetext{
${ }^{35}$ See American Law Institute 1987, p. 341.

${ }^{36}$ American Law Institute 1987, pp. 366-376 (Act of State Doctrine); p. 396 (state immunity from foreign courts); and p. 440 (immunity from jurisdiction to prescribe).

${ }^{37}$ In the Wimbledon case the Permanent Court of International Justice ruled that the right to enter into international commitments is an attribute of State sovereignty, not an act of abandoning sovereignty. (1923), PCIJ, Ser. A, no I, p. 25.

${ }^{38}$ See Brownlie 1998, pp. 638-639, on which this paragraph draws.

${ }^{39}$ See Alvarez, 2005, p. 13 for a discussion of law making by international organizations. Alvarez identifies four ways in which international organisations make law: by serving as a venue for inter-state negotiations; through enacting internal rules dealing with intra-organizational issues; through political organs taking action which is hortatory or binding to various degrees; and through the activities of institutionalised dispute settlers.
} 
treaties, such as the United Nations Charter (Article 103) that assert a superior relationship to other treaties.

Beyond these broad distinctions, international law also recognizes more intensive interstate cooperation - such as found in the EU and other regional agreements - in the form of the concept of "associations of states" or confederations. At some point, the concessions or delegations of powers granted by one state to others in an association, or to an international organization, may result in the extinction in international law of the separate legal personality of a state, and the creation of a dependent state or of a federation. Brownlie identifies the following criteria of extinction of personality: "the obligatory nature of membership; majority decision-making; the determination of jurisdiction by the organization itself; and the binding quality of decisions of the organization apart from consent of member states."40

Crawford argues that a broad discretionary authority to intervene in the internal affairs of a state, even if arising from consent of that state, would appear to be inconsistent with formal independence, and therefore with statehood. ${ }^{41} \mathrm{He}$ also suggests that a distinguishing feature of a federation i.e. a single state, as opposed to a confederation of states, is that the central government's powers include substantially all the foreign affairs powers. $^{42}$

Note, however, that there is a strong presumption against the extinction of a state once it is firmly established in international law, despite at times extensive loss of actual authority. Crawford states that extinction is not effected by substantial loss of independence, and that even deep forms of cooperation - such as the creation by Austria-Hungary between 1861-1918 of joint organs for foreign affairs, defence, finance and trade - do not necessarily derogate from formal independence. Crawford states that Austria and Hungary "probably remained separate legal entities" during this period. $^{43}$

\footnotetext{
${ }^{40}$ Brownlie 1998, p. 292 and p. 73. See also Sarooshi, cited in Howse 2008, p. 65.

${ }^{41}$ Crawford, 2006, pp. 71-72.

${ }^{42}$ Crawford, 2006, p. 485.

${ }^{43}$ Crawford, 2006, p. 701, and p. 70.
} 
The criteria for extinction of state personality overlap somewhat with features of a very small number of international economic agreements - typically confined to the EC Treaty and WTO 1994 - that are considered by some legal scholars to be more in the nature of constitutions than international treaties. ${ }^{44}$ Trachtman considers treaties to be "constitution-like" that "establish bases for further legislation and adjudication i.e. treaties that do more than simply create substantive rules for application, but create a method, beyond mere intergovernmentalism, for creating further substantive rules either through legislation or adjudication. ${ }^{, 45}$

With respect to the EC, the supremacy of EC law over domestic law, and its direct effect in the legal systems of member states are viewed as the key mechanisms for constitutionalization. ${ }^{46}$ In relation both to the EC and WTO 1994, Petersmann considers the protections of the ability to exercise individual economic rights across international borders free from abuses of governmental powers, to fulfil constitutional functions. ${ }^{47}$

While the criteria for extinction of international legal sovereignty, and the indicators of constitutionalism are all highly pertinent to identifying the highest levels of international cooperation, they are not found in the vast majority of international agreements. International law has much less to say on classification of the plethora of less deep forms of cooperation in terms of their differential impact on de jure state authority.

Trachtman has suggested that there is a growing range of options for the use of international legal rules, from less binding force to greater binding force. He briefly sets out the following options to promote international cooperation: rules of jurisdiction; rules of treatment e.g. national treatment; rules of proportionality of national law; rules of recognition of foreign regulation, including mutual recognition; harmonization of law; and institutions that will legislatively or adjudicatively conduct these tasks in the future. ${ }^{48}$ In a recent contribution, Trachtman distinguishes between negative integration

\footnotetext{
${ }^{44}$ Trachtman 1996, note 7.

${ }^{45}$ Trachtman, 1996, note 7.

${ }^{46}$ Weiler and Trachtman, 1996-97, 17:254.

${ }^{47}$ Petersmann, 1996-97, p. 405.

${ }^{48}$ Trachtman, 1996, pp. 6-8.
} 
rules - such as national treatment and least trade restrictive measure - that proscribe certain domestic measures taken by states, and positive integration rules - such as mutual recognition or harmonization of regulations - that establish new rules. ${ }^{49}$

Trachtman's approach covers a number of important elements in international economic cooperation, and his listing of options appears in a number of cases to be in some ascending order of degree of intrusion on state autonomy. However, rules of jurisdiction range from less intrusive rules over the horizontal interface between national legal systems e.g. double tax treaties, through to hierarchical relationships in which a supranational entity has jurisdiction of varying types over activities taking place within member states e.g. the competition policy enforcement authorities established by RTAs such as the EC and the West African Economic and Monetary Union (WAEMU), which are discussed in more detail in Chapter 10. As will also become evident in Chapters 5 and 6 and in Part Three, it is possible to significantly expand on Trachtman's policy cooperation options, in part by distinguishing between prescriptive and enforcement activities, and by incorporating options other than legal approaches.

Chayes and Chayes (1995) and Stein (2001) have each gone some way towards this end. Chayes and Chayes put forward a 'managerial model' of treaty compliance, suggesting that a range of 'soft' approaches are more effective than coercive instruments in inducing state cooperation. They identify regime participation; transparency provisions (reporting, monitoring, verifying) by a treaty body; ${ }^{50}$ non-binding conciliation and binding adjudication; and capacity building (helping countries to comply with their obligations). These are important elements of approaches to enforcement, and will be drawn on in Chapter 6 and Part Three. They leave out 'hard law' instruments, however, and also omit integration of rule making authority, and international cooperation between enforcement agencies.

Stein classifies international organizations according to whether they are cooperative and non-rule directed; rule oriented (authorized to propose rules and treaties, impose international obligations, and adopt rules without or with direct effect in member

\footnotetext{
${ }^{49}$ Trachtman 2007, p. 641.

${ }^{50}$ This echoes the arguments of international relations theorists that information, evidence, and proof have become essential instruments for getting states to "cooperate, comply, desist or otherwise alter their behaviour." Rosenau, 1989, pp. 35-37.
} 
states); or rule enforcing (providing reports on compliance, publicity, dispute settlements of various kinds). ${ }^{51}$ These three categories cover both legal and non-legal mechanisms, and differentiate between rule-making and rule enforcement. The approach outlined in subsequent chapters similarly distinguishes between rule making and rule enforcement, but introduces a number of further distinctions within these categories.

\subsection{INTERNATIONAL RELATIONS THEORY}

International relations theorists have tended to focus on the conditions under which international cooperation is likely to occur, and the functions it performs, rather than with the differential impacts of alternative forms of cooperation on state autonomy. In regime theory, for instance, international regimes are defined as sets of implicit or explicit principles, norms, rules and decision-making procedures around which actors' expectations converge in a given area of international relations. ${ }^{52}$ Regime theory thus combines instruments that have very different implications for state autonomy.

In recent years, however, there has been increasing interest amongst mainstream international relations and international legal scholars in the proliferation of "quasilegal" instruments in international treaties in all domains, especially but not limited to international economic cooperation agreements.

Smith, for instance, in a study of dispute resolution mechanisms in RTAs, devised a spectrum of legalism, beginning with agreements in which there is no right to independent third party review. ${ }^{53}$ He identified increasing levels of legalism represented by agreements with non-binding dispute settlement mechanisms; agreements giving states an automatic right to binding rulings by ad hoc arbitrators; agreements that establish a standing tribunal; and agreements giving rulings direct effect in national law, and allowing entities other than states to bring disputes for resolution. Smith's levels of

\footnotetext{
${ }^{51}$ Stein, 2001, p. 494.

${ }^{52}$ Krasner 1983, p. 2.

${ }^{53}$ Smith 2000, pp. 139-143.
} 
legalism are drawn on in Chapter 10 in identifying increasing depth of cooperation with respect to adjudication of inter-state disputes. ${ }^{54}$

A more ambitious attempt to devise a framework covering all types of 'legalism' in all policy domains culminated in a special issue of the journal International Organization in Summer 2000 entitled 'Legalization and World Politics.' Legalization, as defined by these (mainly international relations) scholars, is characterized by three components: the degree to which rules are obligatory; their precision; and the extent of delegation to third parties.

For each of the three components of legalization, the authors identify increasing levels of legalization. For instance:

- The indicators of obligation range from non-binding norms and guidelines, through national reservations on specific obligations, to unconditionally binding instruments.

- The indicators of precision range from standards which are meaningful only in specific situations, through broad areas of discretion, to determinate rules with only narrow issues of interpretation.

- The indicators of delegation of dispute resolution (which has some similarity to Smith's spectrum of legalism) range from pure political bargaining, through binding arbitration, to courts with general jurisdiction and direct private access.

- The indicators of delegation of rule making and implementation range from a forum for negotiations; to recommendations and decentralized monitoring; to coordination standards; to legitimization of decentralized enforcement; through to binding regulations with centralized enforcement.

These indicators, which are arrayed in order of increasing impact on de jure state autonomy, are drawn on in developing discrete levels of jurisdictional integration in Chapter 6 and Part Three.

However, from the broader perspective of international policy cooperation, there are some limitations in the concept of legalization as adumbrated by these authors. First, the focus, not surprisingly, is on the use of legal and quasi-legal forms and processes

\footnotetext{
${ }^{54}$ Note that Smith's index of legalism covers both public and private law. For some purposes it may be desirable to treat them separately, as discussed in Chapters 5 and 10.
} 
(courts, treaties, and dispute resolution), rather than on all the mechanisms through which international policy cooperation is effected. Legalization does not deal to any great extent with increasingly important "non-legalistic" mechanisms, such as agreements on common definitions of policy terms, technical cooperation, or informal trans-national networks of officials.

Secondly, as noted by Finnemore and Tooope, the authors focus on delegation of authority to adjudicate. ${ }^{55}$ They pay little attention to delegation of authority to make rules, or delegation of authority to enforce rules through non-judicial means. One consequence of this, perhaps, is that the authors combine delegation of rule making with delegation of rule implementation, although these are conceptually distinct. ${ }^{56}$ They are treated separately in this thesis, along the lines of the distinction between the prescriptive jurisdiction and the enforcement jurisdiction (see Chapter 5.2). This assists in the identification and measurement of additional types of policy cooperation, such as international enforcement cooperation between regulatory agencies, and cooperation in the delivery of public services that span state borders.

Thirdly, the indicators of delegation of rule making do not explicitly incorporate some important generic "legalistic" mechanisms - for instance, mutual recognition, majority voting, and direct effect. The omission of the last two mechanisms means that the legalization framework cannot differentiate between the EC and the WTO Agreement on Trade Related Investment Provisions (TRIPS agreement). Both are ranked by Abbott et. al. as the highest level of legalization, perhaps because the authors place greater weight on obligation compared to delegation (p. 405). Yet, in addition to binding third party adjudication, the EC also features majority voting and direct effect, very deep forms of delegation of rule making not found in the WTO-TRIPS agreement. ${ }^{57}$

Finally, the legalization framework pays little attention to the relationship between "legalization" and state sovereignty. For instance, Abbott and Snidal note that sovereignty is a highly contested term. "We skirt these conceptual debates, focusing instead on the fact that states often perceive international legalization as infringing on

\footnotetext{
55 "The processes of law [in the special issue] are viewed overwhelmingly as processes of dispute resolution." Finnemore and Toope 2001, p. 745.

${ }^{56}$ Abbott et. al. 2000, pp. 416-417.

57 Abbott et. al. 2000, p. 406.
} 
their sovereignty, broadly conceived." ${ }^{, 58}$ The authors in the same special issue prefer to treat legalized restrictions on state autonomy as a general and vague imposition on "sovereignty." They do not attempt to identify the different dimensions of state sovereignty, and consider how different forms of legalization impact on states' authority for independent action along these dimensions. This latter perspective points to an alternative approach to classifying international policy cooperation, based on the disaggregation of state jurisdiction.

A recent contribution to the literature by Krahmann focuses more broadly on the increasing fragmentation of state authority. Krahmann outlines a continuum between two ideal typical modes: "government" - the centralization of political authority within the state - and "governance," structures and processes of coordination in the absence of a unifying political authority. ${ }^{59}$ She identifies dimensions in which authority is increasingly fragmented at the international level, including devolution to actors that regulate across national borders; differentiation in policy making processes by policy function; the devaluation of the norm of state sovereignty; a shift to non-consensual decision making; and policy implementation via self-enforcement mechanisms and voluntary agreements. Krahmann's schema is useful as a broad framework. It does not, however, provide a basis for identifying discrete points on a continuum between government and governance. To do so requires both an exploration of how international cooperation impacts on state sovereignty, and the disaggregation of decision-making and implementation processes at the international level.

\subsection{THE STAGES OF ECONOMIC INTEGRATION}

Following Balassa, economists have long distinguished between different stages of economic integration. ${ }^{60}$ The classic stages are Free Trade Area (FTA), Customs Union, Common Market, Economic Union, and total economic integration. By assumption, at each stage an additional layer of policy discrimination between economic actors in participating states is removed, creating an increasingly integrated economic space.

\footnotetext{
${ }^{58}$ Abbott and Snidal 2000, FN 47.

${ }^{59}$ Krahmann 2003, p. 331.

${ }^{60}$ Balassa 1961.
} 
These stages are often conceived as being cumulative, so that each subsequent stage subsumes the features of the previous steps.

Molle has suggested a refinement of this classic schema along the following lines: FTA, incomplete Customs Union, Customs Union, incomplete Common Market, Common Market, economic union, monetary union, economic and monetary union, political union, and full union. Political union is reached when integration is extended beyond the realm of economics to encompass such fields as policing, foreign policy, and security policy. Full union involves complete unification of the economies involved, and comprises some form of federalism. ${ }^{61} \mathrm{Wu}$ adds sectoral trading agreements as a first, very limited stage, reflecting trade cooperation rather than actual integration (although, as Schelling has noted, sectoral cooperation may also entail deep policy integration, as in the European Coal and Steel Community). ${ }^{62}$ Cernat adds association agreements between the EU and neighbouring countries, as an intermediate step between Customs Unions and Common Markets, recognizing that, although these agreements do not adopt a common trade policy, they involve a high level of integration in trade-related areas. ${ }^{63}$

There is an important association between the stages of economic integration, and the level of policy cooperation required to support it. For instance, compared to an FTA, a Customs Union signals the intention to negotiate a common external tariff and the setting up of administrative machinery to collect and share tariff revenues. Moving beyond a Customs Union has traditionally been viewed as entailing progressively more extensive policy coordination, as domestic policies that can distort trade and investment become subject to collective discussion and international cooperation.

This literature has, however, largely treated international economic integration as being at the same time both an economic, and a political phenomenon. It has not attempted to clearly distinguish economic integration from policy integration, and to analyze them as distinct - albeit related - phenomena.

\footnotetext{
${ }^{61}$ Molle, 1997.

${ }^{62} \mathrm{Wu}, 2003$, p. 5; Schelling, 1958.

${ }^{63}$ Cernat 2005, p. 9.
} 
Yet, as earlier noted by Nye, economic and policy integration do not co-vary in any systematic manner. ${ }^{64}$ There is an increasingly large variation in the depth of policy integration within and across the different stages of economic integration. For instance, FTAs now generally cover more than just trade in goods e.g. services, investment, and therefore often contain (sometimes extensive) provisions on a range of "behind the border" policies, such as domestic regulatory settings.

RTAs also exhibit a wide range of practice with respect to the creation and functions of new international organizations. This institutional variation does not necessarily co-vary with the stages of economic integration. For instance, the Closer Economic Relations Agreement between Australia and New Zealand has a number of features of both a common market and an economic union, but has no trans-national secretariat of any kind.

Furthermore, some international economic agreements include elements of deep integration, but do not include all the 'prior' steps of shallow integration. For example, NAFTA has dispute resolution processes that allow non-state entities to bring actions against signatory governments, but is not a customs union. ${ }^{65}$

Stage theory also limits international policy cooperation to bilateral or regional trade agreements. It is not capable of application to multilateral economic agreements such as the WTO, or to the large number of agreements that are not embodied in trade agreements.

Stage theory, then, represents an important contribution to conceptualizing important dimensions of international economic integration. The stages are often also associated with increasing levels of policy cooperation. However, by conflating economic and policy integration, stage theory over-simplifies the nature of the relationship between the two, and submerges policy cooperation as a subject of study in its own right.

\footnotetext{
${ }^{64}$ Nye, 1968, pp. 860-861. Molle also acknowledges that in practice FTAs, Customs Unions and Common Markets are unlikely to succeed without some form of policy integration: "So for the intermediate states between an FTA and full integration, the solutions for concrete integration problems are likely to imply different combinations of elements of market and policy integration." Molle, 1997, p. 12.

${ }^{65}$ NAFTA has at least five different dispute resolution mechanisms, two of which (unfair trade laws, Chapter 19, and investment, Chapter 11) include binding rulings and standing for individuals. Smith 2000, p. 158.
} 


\subsection{REGIONAL INTEGRATION THEORY}

Regional integration theory has focused on describing the nature of integration in Europe since the formation of the European Economic Community in 1957. The main debate has been between those who view European integration as an intergovernmental phenomenon - with member states "pooling sovereignty" but retaining control ${ }^{66}$ - and those who view it as a new form of supranational governance in which EC institutions enjoy autonomous capacity to influence outcomes.

In a restatement of the latter, neo-functionalist view, Sandholtz and Sweet put forward a continuum between two ideal-typical modes of governance: the intergovernmental and the supranational. ${ }^{67}$ However, the authors talk only generally of movements along the spectrum, and do not identify points between the two modes.

In sharp contrast to this highly aggregated approach, an earlier wave of regional integration theorists, led by Lindberg (1970) and Nye (1968), stressed the need to disaggregate the concept of regional integration. They distinguished between economic, social, and political integration, and developed detailed frameworks for the measurement of each type and sub-type, noting that "political integration is by far the most ambiguous and difficult for which to develop satisfactory indices."68

For instance, to measure one property of political integration, Lindberg identified a sixpoint scale of range of decision stages. ${ }^{69}$ In ascending order, the scale incorporated collective problem recognition; agreement on a range of compatible policies; collective decision on policy guidelines; detailed collective goal setting; policy decisions directly binding on individuals; and collective implementation and enforcement.

Lindberg's hierarchy appears to be based around the time sequence of the policy process, rather than the degree of intrusion on policy autonomy. For instance, collective

\footnotetext{
${ }^{66}$ For example, Moravscik 1998.

${ }^{67}$ Sandholtz and Sweet 1998, p. 8.

${ }^{68}$ Nye, 1968, p. 864.

${ }^{69}$ Lindberg 1970, pp. 670-671.
} 
enforcement is at the top of Lindberg's hierarchy. Collective enforcement in the form of non-binding independent arbitration is relatively common, much more so than decision making in regional organizations with direct effect in member states, and is less, rather than more constraining of state autonomy. ${ }^{70}$

Lindberg also identified the resources available to collective decision makers as an important property, defining them to include whether international organizations have initiating, participatory, advocacy, policy making, or monitoring powers; whether future actions are self-executing; and whether there is majority voting. ${ }^{71}$ Lindberg listed these as attributes, noting that they could be redefined as continuous variables, although he does not appear to have done so. ${ }^{72}$

Nye also disaggregated political integration into sub-types. Relevant here is his concept of jurisdictional integration, which he defined as the extent to which regional institutions have autonomy from direct control by member states. Nye suggested that jurisdictional integration could be measured, inter alia, by the degree of supranationality in decision-making. He identified five levels, ranging from unanimity amongst member states, through decisions with and without a national veto, up to decisions made by the administrative organs of regional organizations. ${ }^{73}$ This captures an important element of policy cooperation as defined here, but omits international cooperation at earlier stages of the policy process, prior to the decision-making stage, and does not cover integration of enforcement authority. ${ }^{74}$

From the perspective of this paper - the need for more disaggregated conceptions of international policy cooperation - the more recent regional integration literature is a backward step. The early wave of regional integration theorists developed an impressive set of tools for conceptualizing, defining, and measuring levels of regional policy

\footnotetext{
${ }^{70}$ Lindberg noted: “...we may be interested in ...precisely describing the extent to which the autonomy (range of choices and resources) of national decision makers is affected." He does not appear, however, to have developed this aspect. Lindberg 1970, p. 709.

${ }^{71}$ Lindberg 1970, pp. 682-697.

${ }^{72}$ Lindberg 1970 , p. 684.

${ }^{73}$ Nye 1968, pp. 867-868.

${ }^{74}$ Nye also defined policy integration as a separate category, but defined it to include horizontal scope and political salience. He does not appear to have devised a concept of the depth of policy integration, aside from his concept of jurisdictional integration. Nye 1968, p. 868.
} 
integration. While they appear to have confined their analysis to regional integration, the framework they developed would seem to be capable of application to other forms of international policy cooperation.

It is curious that their work has not had more impact. It is perhaps due to the loss of favour of regional integration theory shortly thereafter. ${ }^{75}$ There remains today a clear tendency to use the stages of economic integration as a measure of regional policy integration. For instance, it is commonplace to assert that a Customs Union is a deeper form of policy integration than an FTA because of the existence of - or in some cases just the intention to create - a common external tariff. Comprehensive attempts to develop measures of international policy cooperation use only crude indicators of international policy cooperation.

For instance, the measure of international political integration compiled by A.T. Kearney/Foreign Policy, defined as political engagement, incorporates membership in selected international organizations, contributions to UN peacekeeping missions, international treaties ratified per year, and governmental transfers. None of these provides a satisfactory or direct measure of the depth or scope of international policy integration. $^{76}$

The framework developed in this thesis has some similarities to the frameworks developed by Lindberg and Nye. Key differences are that the starting point in this paper is the disaggregation of the concept of state sovereignty; the focus is solely on the impact of policy cooperation on states' recognized authority to make or enforce rules; and the analysis incorporates all forms of international economic cooperation. These differences result in the development of a new variable to measure the depth of international policy cooperation.

\footnotetext{
${ }^{75}$ As suggested to the author by Joseph Nye in an email (2 October 2006). For instance, in 1976, a leading regional integration theorist, Ernst Haas, responding to the perceived stalling of European integration at that time, wrote a book entitled "The Obsolescence of Regional Integration Theory."

${ }^{76}$ See A.T. Kearney/Foreign Policy 2005.
} 
In contrast to much of the literature reviewed above, the policy cooperation literature, not surprisingly, focuses closely on the detailed mechanisms through which international cooperation takes place. In an important early contribution, Cooper identified a hierarchy of levels of international policy cooperation, ranging from information exchange and consultation, to progressively adopting common rules (convergence, approximation, unification), to, at the highest level, setting up a common institution to administer the same or similar rules. Cooper also subdivided information exchange and consultation into levels of increasing intrusion: exchange of information on the current situation; agreement on common definitions of concepts and measurements; agreement on norms and objectives; exchange of information on prospective policy actions; coordination of national actions; and joint action in the name of all participating parties. ${ }^{77}$

Leebron has developed this approach with respect to 'arms-length' international regulatory coordination between states that share no common political or economic authority (by which he meant to exclude agreements such as customs unions, common markets and economic unions). ${ }^{78}$ Leebron distinguishes between unilateral and cooperative coordination. With respect to the latter, he distinguishes between harmonization of general policy objectives; harmonization of policy principles; harmonization of specific rules; and harmonization of institutional structures and procedures. ${ }^{79}$ In similar vein, Goddard identifies the following mechanisms for international regulatory coordination: mutual recognition; common rules with separate national regulatory agencies; a single trans-national regulatory agency implementing separate national rules; and a single agency implementing common rules. ${ }^{80}$

The international policy cooperation literature generally arrays policy integration mechanisms in broad relation to their impacts on de jure state autonomy in decision-

\footnotetext{
${ }^{77}$ Cooper 1987, p. 183. See also Kahler 1995, p. xvii, who identifies points on a continuum for the management of international convergence (mutual recognition, monitored decentralization, coordination, and explicit harmonization); and White 1997, pp. 13-17.

${ }^{78}$ Leebron 1996, pp. 43-50.

${ }^{79}$ Leebron defines harmonization as making the regulatory requirements or governmental policies of different jurisdictions identical, or at least more similar.

${ }^{80}$ Goddard 2002.
} 
making. However, Cooper's hierarchy only includes policy settings, leaving out international cooperation over policy implementation and dispute resolution. In addition, his intermediate steps (convergence, approximation, unification) are cast in terms of regulatory outcomes, rather than in terms of mechanisms that distinguish on the basis of differential impacts on de jure state authority. For instance, convergence, approximation, and unification can all be achieved unilaterally or cooperatively.

Leebron's characterization of international policy harmonization does not suffer from this last shortcoming. It does not, however, fully incorporate all the elements in international policy cooperation that impact on state jurisdiction, such as integration of dispute settlement or other enforcement activities, or the deeper forms of integration found in a number of RTAs and exemplified by the EC.

\subsection{FISCAL FEDERALISM}

Fiscal federalism is concerned with which economic functions should be performed by different levels of government. While the initial focus of the literature was on the allocation of fiscal functions between central and sub-national governments, the framework has been extended to cover the allocation of a wider set of functions, and to incorporate relationships between states and international or supranational institutions.

A key insight in this literature is that, in principle, public goods such as economic regulation should be supplied by that level of government "whose jurisdictional boundaries are co-terminous with the geographic scope of the regions affected." ${ }^{\prime 81}$ For example, regulation of economic activities that have no effects outside a country should be left to national or sub-national governments, but activities that impact significantly on other countries (such as international trade or investment) are potential candidates for international policy cooperation of varying types.

Aligning jurisdictional boundaries with policy effects, by allocating functions to an international entity, can reduce transactions costs and externalities across jurisdictions. This comes at the cost, however, of having to tailor public goods to a more diverse and geographically dispersed population; the costs arising from having multiple overlapping jurisdictions; and the loss of economies of scope in concentrating authority for many

\footnotetext{
${ }^{81}$ Wildasin, 2008.
} 
functions at the same level, which in most cases is at the level of the nation state (Alesina and Spolaore 2003).

This literature treats the scope of state jurisdiction as a variable, rather than taking it as given, which is very much the perspective adopted in this thesis. However, the literature takes a broad and general view of the options for allocating functions between states and international organisations. For instance, there is a focus on the full attribution of prerogatives, or on the number of policy areas where an international institution is active, rather than on the different degrees of attribution of prerogatives to the international level, and the different types of activities undertaken. Ruta points to recent "a la carte" agreements in Europe, such as Economic and Monetary Union and the Schengen Treaty, which provide the potential for different "clubs" of varying membership. ${ }^{82}$

However, from one perspective, these are only very deep examples of a more general phenomena. As Slaughter has argued in "The New World Order", what is emerging in international relations is a world latticed by countless horizontal and vertical government networks. In practice nearly every country in the world is already a member of a variety of different "economic regulation clubs.",

This thesis will attempt to develop and operationalize a framework for measuring the depth of the rich variety of "economic governance clubs" that states are participating in, and to demonstrate that the policy and research menus are much more diverse than full allocation or non-allocation of authority to the national or international levels.

\subsection{CONCLUSIONS}

To summarize at this point, in very general terms - and with the notable exception of scholarship on comparative regional integration in the 1960s, and to some extent the recent focus on the legalization of international relations - the existing literatures:

- Have relatively little to say on classification of the full range of types of inter-state cooperation in terms of their differential impacts on de jure state

\footnotetext{
${ }^{82}$ Ruta, 2005, p. 16.

${ }^{83}$ Slaughter 2004, p. 35.
} 
authority e.g. international law, international relations theory, and regional integration theory; and/or

- $\quad$ Conflate economic and policy integration e.g. stages of economic integration theory; and/or

- Cover only a sub-set of the full range of international economic cooperation arrangements e.g. regional integration theory, stages of economic integration, and the literatures on international regulatory cooperation and the legalization of international relations.

A key finding is that the literature has paid insufficient attention to the phenomena of voluntarily agreed limitations on a state's recognised authority to make and to enforce rules. For instance, international law has focused much more on the problem of excessive extra-territorial assertions of state jurisdiction, and of overlapping and conflicting jurisdiction, than on the degree of intrusion on jurisdiction voluntarily agreed to between states. International relations, on the other hand, has focused on the conditions under which cooperation occurs, and the functions cooperation performs, rather than how cooperation varies in its impact on state authority. These conceptual shortcomings are in turn reflected in an inability to satisfactorily measure the depth of international policy cooperation.

The literature on legalization goes some way to redressing this. Smith's approach to measuring the depth of cooperation in dispute resolution mechanisms in RTAs shows the potential contribution of this avenue to measurement and research. ${ }^{84}$ More generally, the indicators of obligation, precision and delegation are important parameters that influence the depth of international policy cooperation, and will be drawn on subsequently. However, they are not sufficient for the objective of this thesis - to act as a framework for the reconceptualization, measurement, and analysis of all forms of international economic cooperation in terms of their impact on state authority.

In the next chapter an attempt is made to develop a conceptual framework that addresses these shortcomings. This involves at the outset revisiting the foundational but contested concept of state sovereignty.

\footnotetext{
${ }^{84}$ Smith 2000.
} 


\section{Chapter 5}

SOVEREIGNTY, JURISDICTION, AND JURISDICTIONAL INTEGRATION

"Much of the confusion about the implications of globalization for the nation-state is due to the reification of the state, reinforced by the concept of "sovereignty."

Picciotto ${ }^{85}$

\subsection{StATE SOVEREIGNTY AND STATE JURISDICTION}

The term sovereignty is used in a wide variety of ways, creating ambiguity and confusion. State sovereignty may refer to the possession of international legal personality, or to the possession of particular legal competences or powers. It may refer to de jure state authority or to de facto state capacity. It may be used to refer to the full set of a state's legal powers or capacities, to the minimum autonomy a state must possess to be a state, or to just one or other of those powers and capacities. It is often not clear which aspect or meaning is being applied in a particular case.

Crawford notes that, in its most common usage, "As a legal term 'sovereignty' refers not to omnipotent authority... but to the totality of powers that states may have under international law. By contrast, as a political term, its connotations are those of untrammelled authority and power and it is in such discourse that the term can be problematic. ${ }^{, 86}$

\footnotetext{
${ }^{85}$ Picciotto, 1996, p. 98.

${ }^{86}$ Crawford, 2006, p.33.
} 
In an influential attempt at clarification, Krasner has identified four categories of sovereignty: ${ }^{87}$

1. Domestic sovereignty: the formal organization of political authority within the state and the ability to exercise effective control within the state's borders.

2. Interdependence sovereignty: the ability to control cross-border flows.

3. Westphalian sovereignty: political organisation within a specific territory based on the exclusion of external actors from domestic authority structures. ${ }^{88}$

4. International legal sovereignty: the possession of recognized legal personality on the international plane.

Domestic sovereignty involves both state authority and state capacity; interdependence sovereignty is solely concerned with state capacity; and the last two categories involve state authority only.

Krasner points out that these four meanings of sovereignty are not logically coupled, nor have they co-varied in practice. Indeed, he points out that the exercise of one type of sovereignty can undermine another. When a state enters into international agreements that recognize the authority of external actors within its territory - such as various types of international economic agreements - it is undermining its Westphalian sovereignty. "International legal sovereignty is the necessary condition for rulers to compromise voluntarily aspects of their Westphalian sovereignty. ${ }^{, 89}$ But in retaining their international legal sovereignty, they also retain the right to withdraw from international agreements they have previously entered, thus reclaiming whatever Westphalian sovereignty they had previously compromised.

A further illustration that the four meanings of sovereignty do not co-vary in practice is that compromises of Westphalian sovereignty in an increasingly interdependent world are often intended to strengthen interdependence sovereignty - as argued by the "new

\footnotetext{
${ }^{87}$ Krasner 1999, p. 9.

${ }^{88}$ Westphalian sovereignty is also referred to as external sovereignty.

${ }^{89}$ Krasner 1999, p. 19.
} 
sovereignty" theorists. ${ }^{90}$ That is, by giving up some of their de jure authority in international economic agreements, states can increase their de facto ability to influence trans-national activities or spill-overs.

Krasner comments that, while Westphalian sovereignty can be compromised through invitation as well as intervention, invitation has received much less attention in the literature. He considers this is the case "...because observers have confounded international legal and Westphalian sovereignty. Intervention violates both. Invitation violates only Westphalian sovereignty. ${ }^{, 91}$

In international law, actions by a state to accept the jurisdiction of another state in it's territory are described as derogations from that state's sovereignty. However, the other state is not considered to thereby gain sovereignty i.e. legal personality. ${ }^{92}$ In similar vein, Keohane has stated that sovereignty as a legal concept should not be confused with the claim that a particular state actually does make its decisions autonomously i.e. has not given up its legal competence in some manner to another state or international organization. ${ }^{93}$ And Raustiala has argued that, if pooling sovereignty in the EU is functionally effective, '...then pooling (and "sacrificing") national sovereignty may be the best way for Europeans to maximize their sovereignty... ${ }^{94}$

The examples in the previous paragraph illustrate the somewhat tortuous and ambiguous usages of the term sovereignty. When the same action can be described as both sacrificing sovereignty and maximizing sovereignty it is time to revisit the language. As noted by Dingwerth and Pattberg, if concepts are to fulfil their basic function in social science of ordering and structuring our perception of the world, a single concept should not group together dissimilar phenomena. If this rule is broken, “... we cannot achieve a basic level of agreement on the terms by which we analyse the social world, [and]

\footnotetext{
${ }^{90}$ For example, Chayes and Chayes 1995, Raustiala 2003.

${ }^{91}$ Krasner 1999, pp. 20-22.

${ }^{92}$ For instance, the administration of Germany after the Second World War by the four allied powers represented a derogation of German sovereignty, but the legal sovereignty of the German state continued (the legal basis was "akin to legal representation or agency of necessity"). Brownlie, 1998, p.107.

${ }^{93}$ Keohane, 2002, p.385.

${ }^{94}$ Raustiala, 2003, p.15.
} 
agreement on conclusions is impossible." 95 With respect to the concept of sovereignty, multiple meanings reduce the analytical contribution of the concept, require added efforts by analysts to discern the meaning in specific instances, and may limit the cumulativeness of research.

Motivated similarly to improve conceptual clarity, Jackson suggests that most debates over 'sovereignty' are actually about the allocation of power, usually government decision-making power. ${ }^{96} \mathrm{He}$ suggests a pragmatic approach to analyzing such 'core sovereignty' issues in terms of careful analysis of the criteria that support the allocation of public powers to sub-national, national, and international levels. He labels this approach 'sovereignty-modern.'

This thesis attempts to build on Krasner's concept of 'compromises of Westphalian sovereignty by invitation,' and on Jackson's suggested focus on the allocation of government decision-making powers. It does so by developing a new framework jurisdictional integration - to conceptualise, describe, and provide a basis to measure the increasingly diverse ways in which states are choosing to restrict their authority by entering international economic agreements.

The new framework is based on substituting the term 'state jurisdiction' for the

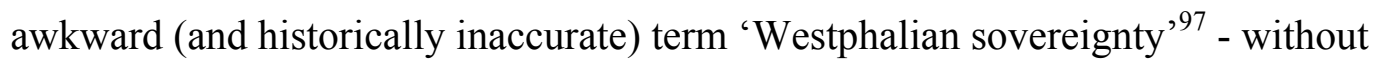
disturbing the other meanings of sovereignty identified by Krasner or recognized in international law. ${ }^{98}$

State jurisdiction is the recognized authority of a state under international law to govern persons and property by its municipal law i.e. domestic or national law. In European terminology, jurisdiction as recognized authority is also referred to as competence, as in "The European Commission has competence in agriculture policy."

\footnotetext{
${ }^{95}$ Gerring and Baresi, cited in Dingwerth and Pattberg, 2006, p. 187.

${ }^{96}$ Jackson 2003, p. 8. As a US court observed: "[Appellant would have us believe that sovereignty is an "all or nothing" concept...we disagree...[T]his argument ignores the distinction between sovereignty, or the legal personality of the nation, and jurisdiction, or the rights and powers of the nation over its inhabitants. Heller v US, 776F2d92, 96-7 ( $3^{\text {rd }}$ Cir 1985). Cited in Crawford 2006, pp.32-33.

${ }^{97}$ For discussion of the 'myth of Westphalia', see Osiander 2001.

${ }^{98}$ As Crawford notes, the term sovereignty “... seems to be ineradicable, and anyway its eradication might only make matters worse." (2006, p.32).
} 
State jurisdiction is at the same time a statement of the limits on a state's authority, in order to limit the problem of excessive assertions of jurisdiction.

In contrast to sovereignty, Arend has stated: "There seems to be little controversy over what "jurisdiction" as a legal concept means... while different states may have conflicting views over when a particular state has jurisdiction, the concept of jurisdiction is shared." 99 This meaning of jurisdiction also conforms broadly to how the word is used in more popular discourse, such as reference to the jurisdiction of a court.

Jurisdiction involves both the right of a state to exercise authority, given the existence of a (generally territorially-defined) close connection with the state, and the duty to recognize the same right of other states. States have considerable discretion in deciding whether to claim jurisdiction. As noted in Chapter 4, the focus of attention in international law has been on the problem of limiting excessive (unilateral) claims of jurisdiction, ${ }^{100}$ and on managing overlapping and conflicting jurisdiction, rather than on cooperative approaches to inter-jurisdictional issues.

\subsection{THE DimENSIONS OF STATE JURISDICTION}

State jurisdiction can be disaggregated into key substantive components. In Brownlie's words:

"Jurisdiction is an aspect of sovereignty and refers to judicial, legislative and administrative competence. Distinct from the power to make decisions or rules (the prescriptive or legislative jurisdiction) is the power to take executive action in pursuance of or consequent on the making of decisions or rules (the enforcement or prerogative jurisdiction).",101

A more detailed analysis of the different dimensions of state jurisdiction appears in the Third Restatement of the Foreign Relations Law of the United States, produced by the

\footnotetext{
${ }^{99}$ Arend 1999, pp. 135-136.

${ }^{100}$ Mann 1970, pp. 10-11.

${ }^{101}$ Brownlie 1998, p. 301.
} 
American Law Institute. ${ }^{102}$ The Institute considers that the traditional distinction between jurisdiction to prescribe and jurisdiction to enforce, which was the basis of the Second Restatement, is too simple. For example, enforcement may be carried on by agencies of the executive branch, such as regulatory agencies, rather than through the courts. On the other hand, "adjudication is often used for purposes that are not strictly "enforcement," but rather for declaration of rights and vindication of private interests. The process of adjudication, whatever the purposes for which it is used, is a significant category in the foreign relations law of the United States."

The Institute therefore puts forward three categories of state jurisdiction: ${ }^{104}$

1. Jurisdiction to prescribe i.e. to make its law applicable to particular persons and circumstances, whether by legislation, by executive act or order, by administrative rule or regulation, or by determination of a court.

2. Jurisdiction to adjudicate i.e. to subject persons or things to the processes of its courts or administrative tribunals, whether in civil or criminal proceedings, whether or not the state is a party to the proceedings.

3. Jurisdiction to enforce i.e. to induce or compel compliance or to punish noncompliance with its laws or regulations, whether through the courts or by use of executive, administrative, police or other non-judicial action.

The overlapping relationship between these three categories of jurisdiction is shown diagrammatically, in stylized form, in Figure 2, based on the discussion in the Third Restatement.

The Institute notes that it does not divide exercises of authority by a state into discrete conceptual categories - although it also notes that the three categories resemble the division of government authority into legislative, executive and judicial branches. Instead, the three-way division is a pragmatic one: it identifies "different aspects of the

\footnotetext{
${ }^{102}$ See American Law Institute, 1987, Volume 1, Part IV.

${ }^{103}$ American Law Institute, Vol. 1, pp. 230-231.

${ }^{104}$ American Law Institute, Vol. 1, p. 232. The Institute also makes a distinction, with respect to jurisdiction to adjudicate, between general and specific jurisdiction. Specific jurisdiction is limited to adjudicating claims arising out of conduct or activity in the forum state, while general jurisdiction is not so limited.
} 


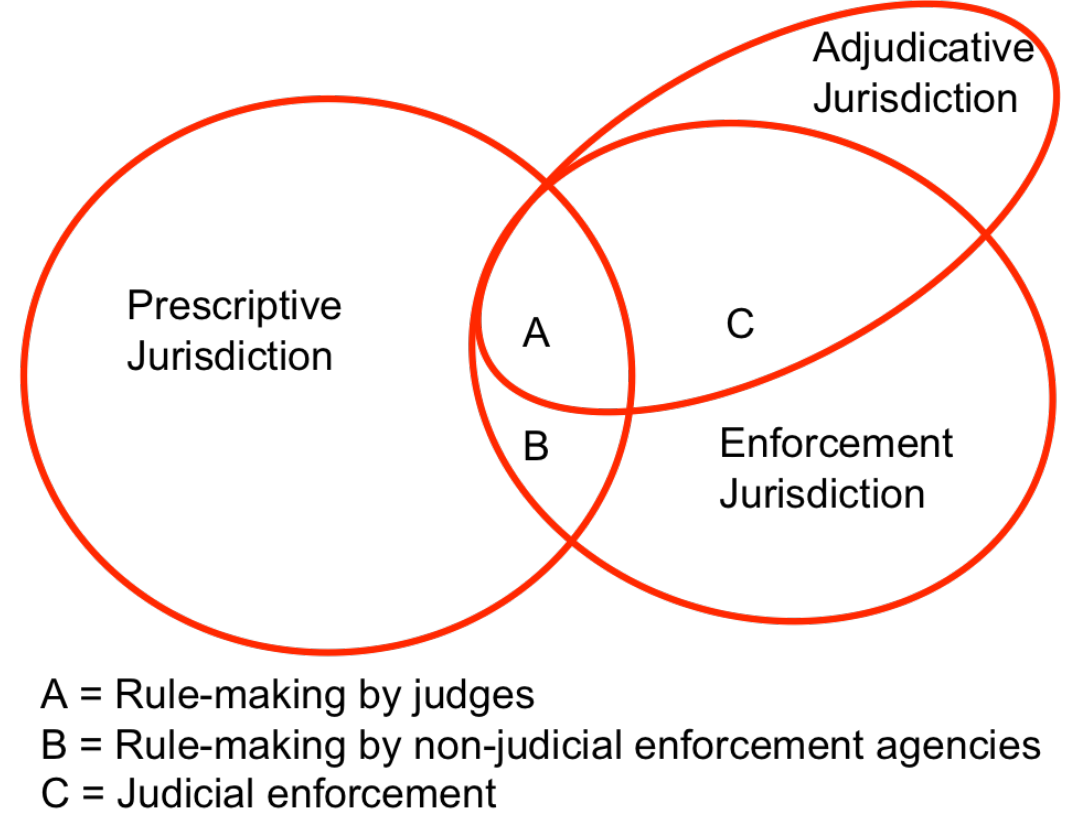

exercise of authority that, because they employ different means and have different consequences, have led to different rules of international law."105

Because international law gives states wide discretion in the exercise of jurisdiction, and does not generally provide for exclusive jurisdiction for one state, there is considerable scope for overlapping jurisdiction. For instance, territoriality and nationality are the principal bases of jurisdiction to apply laws to a person or activity, and will often lead to overlap or conflict between the state of nationality and the territorial state i.e. the state where the conduct took place.

Increasing economic integration means that there is increasing scope for such overlapping jurisdiction, particularly with respect to jurisdiction over juridical persons e.g. companies such as multi-national corporations. In response, international economic agreements have increasingly moved beyond concepts of negative coordination, on which the international law approach to state jurisdiction is founded, to concepts of positive coordination.

${ }^{105}$ American Law Institute, Vol. 1, pp. 232-233. 
The significant increase in the number, scope and depth of international economic agreements requires new conceptual tools to capture the emerging reality. This is the genesis of the concept of jurisdictional integration, introduced in the next section.

First, however, some pragmatic adaptations and refinements are proposed to the categories in the Third Restatement, to take into account the full range of international economic cooperation, and to reflect how different types of cooperation are effected in practice. This suggests the following categories and sub-categories of state jurisdiction:

1. Prescriptive jurisdiction. The authority to make rules by legislation, executive acts or administrative regulation, or by the ruling of a court.

2. Jurisdiction to enforce. For some purposes it may be desirable to subdivide the enforcement jurisdiction into judicial enforcement and non-judicial enforcement - for example, to help identify and analyse options available to policy-makers for increased enforcement cooperation. Non-judicial approaches are more readily amenable to change by executive action. On the other hand, non-judicial and judicial enforcement often work in tandem, and it may be difficult to disentangle them when analysing international cooperation in practice. For example, a regulatory agency may need a court order to obtain evidence; and enforcement action by a regulatory agency may be subject to appeal through the judicial system.

3. Jurisdiction to adjudicate. For some purposes it may be desirable to subdivide this into public law and private law spheres. Adjudication with respect to private activities that has the character of judicial enforcement is incorporated in category 2 above. However, in customary international law, states are immune from the jurisdiction of the courts of other states, when conducting activities of a governmental character. ${ }^{106}$ The issue of rules to regulate adjudication of inter-state disputes of a governmental character has not therefore traditionally arisen in international law. In practice, however, dispute settlement mechanisms, to resolve inter-state disputes of a governmental character, are an increasingly common feature of international relations. Therefore a separate category of adjudication jurisdiction, referred to here as inter-state adjudication jurisdiction, will at times be a useful

\footnotetext{
106 "The immunity of a state from the jurisdiction of the courts of another state is an undisputed principle of customary international law" - except with respect to claims arising from activities, such as commercial activities, that can also be carried on by a private person. American Law Institute, 1987, p. 390 .
} 
category, and is employed in Part Three of this thesis with respect to international competition policy cooperation (see Chapter 10).

4. Executive implementation jurisdiction. A final category of state authority that is relevant to international economic cooperation is the authority of a state to design and deliver public services to its resident population. Where these are regulatory or policy development services, they may be incorporated in the enforcement jurisdiction and the prescriptive jurisdiction respectively. However, there are other public services, such as transport or other infrastructure services that span state borders, or services associated with the production of regional public goods, that are delivered directly to residents through international cooperative arrangements. In a territorially based international system this authority is not one that has been challenged or that needed constraining in international law. States nevertheless voluntarily enter into international arrangements and commitments that constrain their autonomy to varying degrees in this sphere. At the simplest level are agreements between neighbouring countries establishing physical inter-connection standards for transport or infrastructure services that span state borders. A higher level of jurisdictional integration is represented by jointly provided services, such as a regionally owned shipping line or airline.

The approach taken to measuring international cooperation in competition policy in Part Three of the thesis is based on an assessment of which of the above categories and subcategories of state jurisdiction best reflect the nature of cooperation in that particular policy domain. Ordinal indices are developed of increasing depth of cooperation with respect to the prescriptive, non-judicial enforcement, judicial enforcement, and interstate adjudication jurisdictions. These four categories of state authority best distinguish the different types of cooperation. However, in Chapter 13, when measuring a large number of international competition cooperation agreements, judicial and non-judicial enforcement are collapsed into a single category of enforcement jurisdiction. This is because, in most of the competition policy agreements, non-judicial enforcement is by far the predominant means of cooperation, and because, as noted above, the two dimensions of jurisdiction are closely linked in practice. 


\subsection{JURISDICTIONAL INTEGRATION}

Jurisdictional integration can now be defined as:

A process by which a state chooses, through entering formal agreements with another state or states, to restrict its recognized authority to autonomously make, and/or to enforce, and/or to adjudicate decisions in a specific domain or domains.

By juxtaposition, jurisdictional disintegration is a process by which a state augments its formal authority by amending formal agreements with other countries e.g. by withdrawing from a Treaty.

Jurisdictional integration between states takes place by direct agreement between two or more states, with no intervening international organization, or indirectly through an official international organization comprised of member states.

Jurisdictional integration therefore excludes all types of unilateral action that "import" or (attempt to) "export” jurisdiction across state boundaries. For instance, in the field of international regulatory coordination, unilateral recognition of the standards of another state, while an important policy option for effecting economic integration, does not constitute jurisdictional integration as defined here, because the recognizing state is completely free to reverse its policy without the formal need to amend an international agreement or explain its actions to another state. Similarly, neither unilateral assertions of jurisdiction by a state, nor the unilateral imposition of sanctions by one state on another, constitute jurisdictional integration.

As with the term "integration" itself, jurisdictional integration can also be viewed as the end result of such an integration process at a particular point in time. However, the focus here is on jurisdictional integration as a process, to highlight the diverse range of phenomena involved - although Chapter 6 also introduces a taxonomy of international economic cooperation types that includes horizontal and vertical integration as specific points on a spectrum. 
Jurisdictional integration is contrasted here with full political integration (or what Deutsch termed amalgamation), ${ }^{107}$ in which a country is fully subsumed under, or fully merges with the jurisdiction of another country to produce a new state under a single national government with a new and permanent international legal personality. Jurisdictional integration thus measures the impacts of formal international agreements on state authority, short of arrangements that extinguish the international legal personality of the state, and thereby create a single unified jurisdiction.

This definition differs from Nye's definition of jurisdictional integration, which was limited to measuring the extent to which regional institutions can make binding decisions. ${ }^{108}$ Nye's definition did not incorporate collective action at stages of the policy process prior to decision-making e.g. consultation, or the many types of decisions or instruments that are non-binding, or that do not involve a regional organization.

As defined here, jurisdictional integration does not include the involuntary foregoing of national autonomy, through coercive means or colonial-type relationships. The concept is therefore essentially the same as Krasner's concept of 'compromises of Westphalian sovereignty by invitation.' Perhaps the only difference is that Krasner states that voluntary compromises of Westphalian sovereignty are never inconsistent with international legal sovereignty (Krasner 1999, p. 22). In principle, however, the international community could withdraw recognition of a state if it considered it no longer existed as a separate sovereign entity as a result of an association it had voluntarily entered with another state(s). The concept of jurisdictional integration, therefore, is defined here to cover compromises of Westphalian sovereignty by invitation consistent with maintenance of international legal sovereignty. However, there is a strong presumption in international law against the extinction of an already established state (Crawford 2006, p. 70), so that in practice there is very little difference between the two terms.

\footnotetext{
${ }^{107}$ See Deutsch 1957.

${ }^{108}$ Nye 1968, pp. 867-868. Olson also used the term jurisdictional integration to refer to the creation of a larger area of free trade and factor mobility, as well as a shift in the institutions and locations that make some important decisions about economic policy (Olson 1982, p. 121). This definition combines economic integration and policy integration. Wolf used the term also, based on the Olson definition (source: email communication with the author, 2 September 2006). See Wolf, 2006, p.315.
} 
Jurisdictional integration incorporates what Trachtman has described as "transactions in jurisdiction', agreements by states to reduce barriers to trade. 109 "When states regulate, they cause and encounter regulatory externalities... while not all regulatory externalities will be worth internalising, due to transactions costs, [their] existence...suggests the evaluation of the utility of transactions in regulatory authority.",110

The focus on de jure authority is not to deny that in many instances, many states may have little realistic choice but to sign an international treaty, or to adopt a foreign standard, due to their lack of influence and limited unilateral options. Even powerful states are no longer able to achieve all their objectives without entering some international cooperative agreements that limit their freedom of action in some way. However, these are very different to the situation where a state lacks the formal legal authority to pursue independent action.

Jurisdictional integration as conceived here incorporates the horizontal sharing or transfers of authority between sovereign states, and the vertical sharing or transfer of authority with international organizations comprised of member states. ${ }^{111}$ It does not include the allocation of decision rights and powers between institutions or levels of government within a country. ${ }^{112}$ It also excludes delegation of decision-making to private or non-official entities - except to the extent that the standards promulgated by or decisions taken by such non-official entities are validated or formalized by state action. For instance, the concept incorporates the various ways in which non-state entities are given standing to play roles in developing, monitoring, or enforcing official international rules.

Because the powers to make and enforce decisions bear a relationship to the powers of the three branches of government, jurisdictional integration incorporates what Slaughter has termed "transgovernmentalism," or the disaggregation of the state into its

\footnotetext{
${ }^{109}$ Trachtman 1996, p. 16.

${ }^{110}$ Trachtman, 2007, p. 644.

${ }^{111}$ It also incorporates non-state entities that possess full autonomy in the conduct of their external economic relations, such as customs unions that are full members of the WTO but do not possess international legal sovereignty - for example, Hong Kong China.

112 The issue does arise, however, of whether a national government authorises sub-national governments to enter international agreements, such as cross-border economic zones, and this could be incorporated within the definition of jurisdictional integration.
} 
components - branches of government and individual government agencies - and their cooperation across state lines. ${ }^{113}$

Note that some writers argue that globalisation has created gaps in state governance that the private sector, NGOs, and sub-state actors have moved in to fill - see for example Scholte 2000. ${ }^{114}$ However, the contention here, in line with that of Slaughter, is that states have also moved in many and diverse ways to address the emerging gaps in governance. ${ }^{115}$ This thesis is intended to contribute to better conceptualisation, measurement, research, and policy development with respect to this phenomenon.

Jurisdictional integration focuses on formal agreements. Formal agreements have a particular salience in international law, and in the field of international economic law have largely supplanted general international law due to the requirement of states for reciprocity. ${ }^{116}$ Formal agreements are generally more easily observable than informal understandings or customary international law, which makes the concept of jurisdictional integration easier to operationalize for research purposes.

State autonomy is the baseline, or counterfactual against which jurisdictional integration is assessed. ${ }^{117}$ Non-interference in the affairs of other states is considered to be one of the fundamental legal rules that structure the international system, being reflected in Article 2 of the UN Charter, and has become part of general international law. State autonomy has also been adopted as the baseline by a number of writers, including

\footnotetext{
${ }^{113}$ See Slaughter 2004.

${ }^{114}$ Scholte 2000 , p. 144.

${ }^{115}$ Slaughter 2004.

${ }^{116}$ As argued by Petersmann, 1996/97, p. 400.

${ }^{117}$ Skelcher, 2005, p. 93, has referred to state autonomy as "boundary (or external) integrity. Complete boundary integrity would mean that the jurisdiction was not subject to intrusion by other agencies of government, whether at higher or equivalent spatial scales and therefore that its authority could be exercised autonomously." Skelcher defines boundary integrity as an element of "jurisdictional integrity", a concept he introduces for the purpose of developing a general theory of network governance applicable to subnational, national, and supranational scales. Skelcher uses the term jurisdiction in the same way as it is used here, and as noted, boundary jurisdictional integrity has the same meaning as state autonomy, or the absence of jurisdictional integration.
} 
Keohane and Nye 1989, Kahler 1995, Chayes and Chayes 1995, Trachtman 1996, Sandholtz and Sweet 1998, and Cohen 2001. ${ }^{118}$

It is recognized, however, that this conception of state autonomy is one that may be limited by customary international law - what Abbott et. al. 2001 describe as "the background operation of the international legal system" (p. 404). For instance, the norm of pacta sunt servanda - that treaties are binding and should be observed - has been described as the basis for all other international law, and is logically prior to treaties or formal agreements. On the other hand, Jackson has argued that there are few customary laws in international economic law. ${ }^{119}$ Furthermore, while states may be able to contract out of some customary international law, customary law is generally not subject to policy choice, whereas policy choice is a central focus of jurisdictional integration. In any case, customary international law does not involve formal agreements, and therefore lies outside the definition of jurisdictional integration.

It is also recognized that, in practice, state sovereignty does not mean absolute freedom from external interference in internal matters. States have long concerned themselves with the treatment of their nationals living as minorities within the territories of other states. Powerful states have always exerted influence over the internal affairs of less powerful states. Increasingly salient norms of human rights are coming increasingly into conflict with the norm of non-interference, and the international system has no mechanism for deciding between conflicting norms. As Krasner has analysed in detail, the international system of state sovereignty can be well characterised as one of "organised hypocrisy," in which conformity with the norm of non-interference is often violated in the pursuit of national self-interest.

Finally, the dualist theory of law holds that international and domestic law operate in completely separate spheres. "When municipal law provides that international law applies in whole or in part within the jurisdiction this is merely an exercise of the

\footnotetext{
${ }^{118}$ Schiff and Winters identify most favoured nation treatment as the baseline, but it is hard to see this as anything other than a policy that states may or may not decide to commit themselves to. Schiff and Winters 2003, p. 181.

${ }^{119}$ Jackson 2006, p. 42.
} 
authority of municipal law..."120 In practice, treaties are only part of domestic law in Britain and most Commonwealth countries if an enabling Act of Parliament has been passed. ${ }^{121}$ In the USA, Petersmann notes that foreign trade legislation generally declares international trade agreements not to be self-executing i.e. they require the passage of specific domestic legislation to have legal force. ${ }^{122}$ Brownlie states that it is probably also the case in the majority of countries outside the Commonwealth that specific legislative incorporation is required before treaties have domestic force. ${ }^{123}$ In dualist legal systems, therefore, a state cannot, through signing an international treaty, fully restrict its de jure legal authority to make and enforce laws, because ultimately the legislature has the legal authority to enact domestic laws, now or in the future, that are inconsistent with the state's international obligations. Technically, therefore, in dualist systems the definition of jurisdictional integration is confined to restrictions on de jure authority within the meaning of international law. ${ }^{124}$

\footnotetext{
${ }^{120}$ Brownlie, 1998, p. 32. Monists, on the other hand, view international and domestic law as being part of the same system, and some monists consider international law to be supreme over domestic law.

${ }^{121}$ Although note that a state cannot in general point to the fact its domestic legislation restricts its ability to comply with its international obligations in order to limit the scope of its international obligations unless the legal conflict was "manifest and concerned a rule of its internal law of fundamental importance" (article 46 of the Vienna Convention on the Law of Treaties). Note also that in some states national courts may have the power to overrule domestic legislation on the ground that it is contrary to international law (Brownlie, 1998, p. 41). The Constitutions of Fiji, Hungary, Russia, South Africa, India and East Timor all give international law a formal role in the domestic legal system (Charlesworth et al, 2005, p. 6)

${ }^{122}$ Petersmann, 1996-97, p. 416.

${ }^{123}$ Brownlie, 1998.

${ }^{124}$ My thanks to an anonymous reviewer for this point.
} 


\section{Chapter 6}

A STYLIZED SPECTRUM OF JURISDICTIONAL INTEGRATION.

\subsection{CRITERIA For Locating PoINTS ON THE SPECTRUM}

Jurisdictional integration, then, is conceived of as a spectrum running from complete policy autonomy through to, but stopping short of, full political integration. Krasner suggested that coercion of one state by another could be represented along a continuum, with the location determined by the costs of refusal for the target state. He did not similarly suggest that compromises of Westphalian sovereignty by invitation could be represented along a continuum. ${ }^{125}$

Other observers have done so, however. Charlesworth et. al. note that there is no longer a rigid dichotomy between international and domestic law, and that they are better understood as part of a continuum. ${ }^{126}$ As noted in Chapter 2, Schiff suggests that the level of policy integration within RTAs can be more fruitfully thought of as a continuum, ${ }^{127}$ while the 2005 Report by the Consultative Board to the WTO Director General argued that state sovereignty in the WTO context is not all or nothing, but rather consists of disaggregated slices. ${ }^{128}$

Viewing jurisdictional integration as a spectrum is based on a view that it is valid, at least for some purposes, to array different types of policy interventions along a single

\footnotetext{
${ }^{125}$ Krasner 1999, p. 36.

${ }^{126}$ Charlesworth et. al. 2005, p. 2.

${ }^{127}$ Schiff, 2000, p.8.

${ }^{128}$ WTO 2005a.
} 
continuum. From this perspective, legal rules are a particular form in which policy is expressed, rather than a qualitatively different phenomenon. ${ }^{129}$

Intrusions into the domestic policy process are associated with changes to the fora in which policy debate and implementation take place. Even a requirement to notify current policies to an external actor implies a subtle shift from complete policy autonomy. At successively higher levels of jurisdictional integration, external actors may be authorized to require prior consultation over policy change, to lodge objections, to monitor and assess performance, to recommend broad or specific policy changes, to adjudicate disputes, or to promulgate new binding rules.

Such interventions represent increasing levels of intrusion, and progressively raise the political cost to a state of non-cooperation or non-compliance. As Chayes and Chayes have argued, engagement between states in explanation, justification, and persuasion is an important factor in determining state behaviour. ${ }^{130}$ The spectrum can also be seen as running from "soft power" to "hard power." As defined by Nye, soft power lies in the ability to co-opt other states by the power of persuasion and example, whereas hard power originates in rewards and threats that induce other states to act in certain ways. ${ }^{131}$

What are some of the discrete points as one moves to the right on the spectrum? What are some of the criteria that assist in identifying these discrete points?

Starting with legal theory, a distinction (due to Hart) has been drawn between primary and secondary rules. ${ }^{132}$ Primary rules are laws bearing directly on individuals or entities requiring them to do or refrain from doing certain acts, while secondary rules do not impose obligations but regulate the making of primary rules e.g. constitutions and rules of procedure. While Hart's positivist concept of law has been challenged from various

\footnotetext{
${ }^{129}$ Alvarez notes that: "To the strict positivist, the possibility that law can exist along a spectrum of binding authority...is anathema...soft-law is an oxymoron...' (p. 48). He himself argues, however, the difficulty of differentiating between binding and non-binding international rules (p. 224). He notes that the Yale School of international law description of authoritative decision-making processes '...is more receptive to accepting as legally relevant processes of interaction among the various actors in international society, especially when these were solidified in growing expectations of legitimate authority.' Alvarez 2005, p. 52.

${ }^{130}$ Chayes and Chayes 1995, pp. 25-26.

${ }^{131}$ Nye 1990.

${ }^{132}$ Hart, 1961, p. 79, cited in Abbott et. al. 2000, p. 403, on which this paragraph draws.
} 
perspectives, for the purpose of this application it seems useful to distinguish between specific laws, on the one hand, and underpinning framework laws that regulate how specific laws are made, on the other. Delegating authority to enact the latter, which in principle are wider in scope, is likely to evince more concern than delegating authority to enact the former.

This broad perspective of the nature of the decisions being delegated is important in assessing the degree of jurisdictional integration.

The criteria identified by international lawyers for determining the extinction of international legal sovereignty are particularly relevant to identifying high levels of jurisdictional integration. The key criteria in practice are majority decision-making, direct effect, the protection of individual rights, and the supremacy of treaty law over domestic law. In addition, Crawford considers the degree of discretion of an international organization to be an indicator of the level of integration. ${ }^{133}$

A further consideration is the distinction in the public policy literature between policies aimed primarily at promoting efficiency, and policies aimed primarily at promoting equity (or inter-personal redistribution). ${ }^{134}$ In principle, only decision-makers directly accountable to the electorate should adopt policies that have the primary purpose of redistribution. Efficiency-enhancing policies that have the primary objective of improving the aggregate welfare of the community are in principle more amenable to legitimate delegation - for instance to entities that conduct technical activities such as regulatory functions.

In addition, one class of laws that are typically introduced only by legislatures, and that are enforced only by direct executive action, are those entailing the use of the coercive powers of the state, such as the power to tax, and the power to define and enforce criminal laws.

Other criteria that may be used to identify points of increasing integration are taken from the literature review in Chapter 4, and include whether the functions are non-rule

\footnotetext{
${ }^{133}$ If there is considerable discretion, “... an association of states created with a view to international cooperation would be indistinguishable from a federation." Crawford 2006, FN 70.

${ }^{134}$ The discussion in this paragraph draws on Majone 1996, pp. 13-15.
} 
directed, rule-oriented, or rule enforcing (after Stein); ${ }^{135}$ the scope of the legal rights and obligations created, whether they are between states (and international organizations) only, or also between states and other parties; Lindberg's scale of decision stages; ${ }^{136}$ Nye's levels of supranationality of decision-making; ${ }^{137}$ Cooper's and Leebron's indicators of increasing depth of regulatory coordination; ${ }^{138}$ Smith's levels of legalism in dispute resolution mechanisms; ${ }^{139}$ and Abbott et. al.'s indicators of obligation, precision, and delegation. ${ }^{140}$

\subsection{A GENERIC SPECTRUM OF JURISDICTIONAL INTEGRATION}

Figure 3 presents a stylized generic spectrum of jurisdictional integration, comprising simple cooperation, coordination, horizontal integration, and vertical integration. The object is to identify key generic points representing increasing depth of international cooperation - where depth of cooperation is measured in terms of degree of constraint on de jure state authority.

The spectrum combines the main dimensions of state jurisdiction discussed in Chapter 5 viz. prescriptive jurisdiction, enforcement jurisdiction, and jurisdiction to adjudicate. The three dimensions of jurisdiction are arrayed in a single diagram here to attempt to capture some generic cooperation types that transcend the three dimensions, and for ease of exposition.

The spectrum is parsimonious. Because it combines international cooperation of very different types, discrete points on the spectrum can only be defined in broad terms rather than on a definitive basis. At this level of generality, the spectrum is intended only to be broadly indicative of increasing impact on state autonomy. Within each

\footnotetext{
${ }^{135}$ Stein 2001, p. 494.

${ }^{136}$ Lindberg 1970, pp. 670-671.

${ }^{137}$ Nye 1968 , pp. $867-868$.

${ }^{138}$ Cooper 1987, p. 183, and Leebron 1996, pp. 43-50.

${ }^{139}$ Smith 2000, pp. 139-143.

${ }^{140}$ Abbott et. al. 2000, pp. 408-417.
} 
category, the sub-categories incorporate a variety of cooperation mechanisms, so that the sub-categories are to some extent overlapping in terms of depth of cooperation.

\section{Figure 3: A Stylized Spectrum of Jurisdictional}

\section{Integration}

\begin{tabular}{|l|l|l|l|l|}
\hline $\begin{array}{l}\text { Uni- } \\
\text { lateralism }\end{array}$ & $\begin{array}{l}\text { Simple } \\
\text { Cooperation }\end{array}$ & Coordination & $\begin{array}{l}\text { Horizontal } \\
\text { Integration }\end{array}$ & $\begin{array}{l}\text { Vertical } \\
\text { Integration }\end{array}$ \\
\hline & $\begin{array}{l}\text { Information } \\
\text { exchange }\end{array}$ & $\begin{array}{l}\text { Technical } \\
\text { cooperation }\end{array}$ & $\begin{array}{l}\text { Mutual } \\
\text { recognition }\end{array}$ & $\begin{array}{l}\text { Third-party rule } \\
\text { making }\end{array}$ \\
\hline & Consultations & $\begin{array}{l}\text { Jurisdictional } \\
\text { interface rules }\end{array}$ & $\begin{array}{l}\text { Joint service } \\
\text { delivery }\end{array}$ & $\begin{array}{l}\text { Third party } \\
\text { enforcement }\end{array}$ \\
\hline & $\begin{array}{l}\text { Information } \\
\text { networks }\end{array}$ & $\begin{array}{l}\text { Institutionalised } \\
\text { mechanisms for } \\
\text { policy development }\end{array}$ & $\begin{array}{l}\text { Third party } \\
\text { adjudication }\end{array}$ \\
\hline & & $\begin{array}{l}\text { Agreed policy or } \\
\text { enforcement } \\
\text { guidelines }\end{array}$ & $\begin{array}{l}\text { Policy } \\
\text { unification }\end{array}$ & \\
\hline & & $\begin{array}{l}\text { Sanctioned self- } \\
\text { enforcement }\end{array}$ & & \\
\hline & & $\begin{array}{l}\text { Third party } \\
\text { monitoring and/or } \\
\text { review }\end{array}$ & & \\
\hline & & & & \\
\hline & & & & \\
\hline & & & & \\
\hline & & & & \\
\hline & & & & \\
\hline
\end{tabular}

Figure 3 is based on a simple taxonomy of the depth of international economic policy cooperation, to aid the identification, analysis, and discussion of broad alternatives. At the first level the taxonomy distinguishes between unilateral and cooperative approaches. It then sub-divides cooperative approaches into simple cooperation; coordination; horizontal integration; and vertical integration. Box 1 contains further discussion of the taxonomy.

Because international integration of state authority to make and to enforce rules is embodied in substantially different phenomena, and often in separate agreements, any 


\section{Box 1: A Taxonomy of the Depth of International Economic Policy Cooperation}

The taxonomy in Figure 3 is intended to enhance the framework developed by Banting, Hoberg, and Simeon to differentiate policy convergence from the effects of international economic integration (Banting et. al., 1997, as cited in Hoberg, 2001, p. 127). Banting et. al.'s framework identifies four major forces behind international policy convergence:

1. Parallel domestic pressures.

2. Emulation.

3. International legal constraints - "when countries enter into international agreements that involve some (voluntary) giving up of national sovereignty" (Hoberg 2001, p. 127).

4. International economic integration.

The taxonomy put forward here fleshes out the third category, in view of the increasing variety and depth of policy constraints embodied in international economic agreements. It distinguishes at the first level between unilateralism and cooperation, the former not being defined as a form of jurisdictional integration. Unilateralism includes all forms of noncooperative policy convergence, such as common responses to parallel domestic pressures, and policy emulation, as identified by Banting et. al. It also includes unilateral recognition or adoption of a foreign regulatory standard, and developing domestic policy on the basis of an appreciation of the policy settings in other countries or as advocated by international organisations. Finally, unilateralism incorporates traditional comity, the passive deference accorded by one state to the acts of another state unless the state judges such deference to be not in its own interests (Slaughter 2004, p. 250).

International cooperation is then divided into sub-categories, comprising simple cooperation; coordination; horizontal integration; and vertical integration. There are no hard boundaries between these categories, and they require tailoring to any particular policy domain.

In general, however, simple cooperation connotes information sharing and discussion, whereas coordination connotes working together, and in particular that some aspect of the ordering or timing of activities or elements is jointly discussed, planned, or implemented.

Integration adds the further dimension that some elements or parts of separate systems are combined, at least for some purposes, into a single system.

Integration is divided into two categories. Horizontal integration occurs when two states agree to unify their otherwise separate national jurisdictions in some dimension of policy or practice. Vertical integration, on the other hand, occurs when state jurisdictions cooperate to create an entity with supra-national authority of some form. That is, states cede some measure of formal authority to an international entity. Vertical integration comprises analytically distinct sub-categories, depending on the nature of the inter-face between the national and supranational jurisdictions. For instance, in international cooperation in enforcing competition policies, vertical integration may comprise concurrent jurisdiction between the two levels, or exclusive jurisdiction for the supranational level (see Chapter 10.1).

The distinction between horizontal and vertical jurisdictional integration is similar in concept to Slaughter's distinction between horizontal and vertical international networks - except that Slaughter's horizontal networks are disaggregated here into networks that cooperate, coordinate, or are horizontally integrated; and vertical networks can also be disaggregated into analytically distinct sub-groups. 
in-depth analysis of jurisdictional integration requires a focus on a specific instrument type or policy domain. ${ }^{141}$ This allows a more precise identification of discrete points of increasing jurisdictional integration, and the development of ordinal scales to measure the depth of international policy cooperation. This in turn provides a more robust basis for research, using the depth of international policy cooperation as a dependent or independent variable.

This is the approach taken by Smith in his impressive analysis of the design of dispute settlement mechanisms in RTAs. Smith developed a five point ordinal scale of "legalism," or the depth of dispute settlement mechanisms, which he used in statistical analysis of the factors "predicting" shallow or deep legalism. ${ }^{142}$

For these reasons, Part 3 of the thesis, starting at Chapter 7, contains in-depth, instrument-specific and domain-specific analyses of jurisdictional integration, first in RTAs, and then, more extensively, in international competition policy cooperation.

\subsection{Populating THE JURISDictional InTEGRATION SPECTRUM}

To illustrate the discrete points as one moves from simple cooperation, through coordination, to horizontal and vertical integration, examples will be drawn from a range of international economic agreements and arrangements. The examples represent all the dimensions of state jurisdiction discussed in Chapter 5.2 viz. prescriptive jurisdiction, enforcement jurisdiction, jurisdiction to adjudicate, and executive implementation jurisdiction. In general, the discussion within each sub-section (simple cooperation, coordination, integration) proceeds from shallower to deeper cooperation.

\subsubsection{Simple Cooperation}

Starting with simple cooperation, there is a diverse range of arrangements for information exchange. For instance, there is what Chayes and Chayes have termed "regime participation" i.e. agreements to participate in international meetings (such as the annual members' meeting of an official international organisation), and to respond

\footnotetext{
${ }^{141}$ Instrument type would include both different types of international agreements (such as RTAs, Bilateral Investment Treaties, multilateral conventions and so on), and different government functions (such as regulation, taxation, monetary policy, and service delivery).

${ }^{142}$ Smith 2000. pp. 155-159.
} 
to ad hoc requests for information from other governments or from international organisations.

Also included here is the regular reporting of information on current policies, either to an international organisation, or to counterpart agencies in other governments. Such reporting may or may not be on the basis of internationally agreed standard definitions of policy or enforcement terms and concepts - for example, the World Customs Organisation's Harmonized System of Customs Classification, and the IMF's Manual on Government Finance Statistics.

In an adjudicative setting, simple cooperation consists of international agreements providing for consultations in the event of a dispute between the parties.

Simple cooperation also consists of bilateral, regional, or multilateral networks of government agencies or officials that discuss policy, service delivery, or enforcement issues. These networks fall short of permanent organisations with a standing secretariat (which constitute either coordination or integration, depending on their functions and mandate). Examples include networks of regulators and enforcement officials, in which norms of acceptable policies and enforcement behaviour are discussed and inculcated for example, the International Competition Network established in 2001 to promote convergence amongst anti-trust agencies, and the networks of officials established under the auspices of various OECD Committees. Discussion of enforcement issues in these fora is confined to non-case specific issues. Sharing information between regulators on cases under investigation represents coordination rather than simple cooperation, and is discussed further below.

Simple cooperation is designed to provide foreign governments, government agencies, and international organisations with the minimum information on domestic policies and practices to enable common policy discussion and debate. Many international agreements go well beyond this, and contain provisions that are defined here as constitution coordination or integration.

\subsubsection{Coordination}

The first generic form of coordination is technical cooperation intended to help recipients meet international standards and norms. Technical cooperation is provided to 
states by technical specialists from government agencies in other states, or from international organisations. Examples include cross-border technical cooperation between regulatory agencies, technical assistance provided by the International Financial Institutions, the WTO and UNCTAD, and the committees established to promote economic and technical cooperation in the Asia Pacific Economic Community (APEC).

A second generic form of coordination is jurisdictional inter-face rules. These include agreements on trans-border interconnection standards e.g. for transport, communications or energy infrastructure, or conventions on international transactions formulated by the United Nations Convention on International Trade Law (UNCITRAL). Conceptually similar are agreed interface rules for the taxation of income subject to two national tax jurisdictions, and for the payment of social security pensions of persons who migrate from one country to another. These are found in a large number of bilateral tax treaties and bilateral social security agreements.

Further examples of jurisdictional interface rules arise in the field of enforcement. For example, agreements to allocate regulatory responsibility between jurisdictions, such as those devised by the Bank for International Settlements allocating responsibility for banking supervision between the authorities of a bank's home country and the countries where the bank operates. ${ }^{143}$

Finally, jurisdictional interface rules also arise with respect to the jurisdiction to adjudicate. The Agreement on the European Economic Area (EEA), which is an RTA between the EC and the European Free Trade Area (EFTA), provides that the European Court of Justice, not the EFTA Court, will decide cases involving both EFTA and EC parties. The International Convention on the Settlement of Investment Disputes (ICSID) provides for international arbitration as the exclusive remedy unless otherwise provided between the parties in the event of disputes between an investor and a host state.

\footnotetext{
${ }^{143}$ See http://www.bis.org/publ/bcbs100.htm A further example of allocation of enforcement jurisdiction, but from outside the economic sphere, is that of "complementarity", in which the jurisdiction of the International Criminal Court is triggered only if the national legal system is unwilling or unable to exercise jurisdiction. See R. Teitel, The Law and Politics of Contemporary Transitional Justice, 2005, cited in Howse, 2008, p. 66.
} 
A third generic form of coordination is institutionalised mechanisms for policy development. At the shallowest level, these include regular agency-to-agency forums for discussion of policy, service delivery, or enforcement issues. They also include permanent international organisations with a range of functions. At the shallowest level are organisations such as APEC that have only limited secretariat and coordination roles. Beyond this are international organisations with a mandate to conduct policy studies and research, to advocate particular policy or enforcement approaches, to draft policy guidelines or model laws, and at times to develop proposals for legally binding conventions e.g. the OECD, the International Labor Organization. ${ }^{144}$ A further important example is the WTO, which has the authority to coordinate large-scale binding international trade policy negotiations amongst member countries.

A fourth generic form of coordination is agreed policy or enforcement guidelines. These may be non-binding (shallower), or binding (deeper) obligations. They include statements of policy objectives, voluntary guidelines, statements of agreed policy principles, ${ }^{145}$ standard operating procedures, codes of conduct, and model laws. Examples include UNCTAD's Model Law on Competition Policy, the OECD's Model Double Tax Treaty, and non-binding policy principles promulgated by APEC.

A further example of a non-binding policy principle at this level of coordination is Slaughter's suggested norm of "legitimate difference." She suggests that state agencies and officials working in transgovernmental networks should defer to foreign laws or regulations unless they violate values of constitutional significance. "Note that, thus formulated, the principle of legitimate difference lies midway on the spectrum from comity to mutual recognition."

Binding policy obligations may be either general or specific. General obligations impose a broad measure of discipline over domestic policy, but either lack specificity or provide for significant escape clauses or opt-outs. In general, and as noted in the

\footnotetext{
${ }^{144}$ See Egeberg, 2006, for a discussion of the impact that different features of international organisations, such as the existence and structure of a secretariat, have on the degree of political integration among states.

${ }^{145}$ Braithwaite and Drahos have observed that "principles are the infrastructure of global regulation they pattern the complex regulatory superstructures that follow them.” Braithwaite and Drahos, 2000, p. 9.

${ }^{146}$ Slaughter, 2004, pp. 247-249.
} 
legalization literature, they therefore leave a margin for state discretion compared to more specific obligations. Examples include the obligation to comply with the principle of "least restrictive measure" in the WTO Agreement on Technical Barriers to Trade, and the requirement in the NAFTA side agreements to enact "high labor standards."

More specific policy obligations representing increasing impact on state autonomy include commitments to enforce existing domestic legislation e.g. in NAFTA; commitments not to take specific measures, such as general prohibitions on non-tariff border measures in Article XI of the WTO Agreement; and legally binding international instruments requiring the adoption and maintenance of specific policies, such as obligations in IMF Article VIII(2)(a) to keep current account transactions free from exchange restrictions, and commitments in the WTO or in RTAs to bind tariffs at specific (maximum) levels.

Also included here are arrangements that make the receipt of financial assistance conditional on the adoption of particular policies by recipient member states. Examples include conditional lending by the IMF, the World Bank, and the regional multilateral development banks. The actual depth of coordination here will vary widely according to the nature and duration of the particular financial arrangement concerned. ${ }^{147}$

This level of integration also includes what Chayes and Chayes have termed the "authoritative" interpretation by a treaty organisation of the level of conduct required to comply with a treaty. ${ }^{148}$ A typical example of this is determinations over assessed membership contributions and other internal administrative arrangements.

A fifth generic form of coordination is coordinated enforcement. This goes beyond discussion or sharing of information on general enforcement issues, and includes sharing of information on individual cases under investigation. For example, in the field of competition policy, there are a number of international agreements providing for notification by one Competition Authority to another Authority of enforcement action it is taking that may impact on the other country's interests (see Chapter 12).

\footnotetext{
${ }^{147}$ See Brimsmead, undated, who discusses the varying degrees of intrusiveness of different types of IMF conditionality, pp. 11-14.

${ }^{148}$ Chayes and Chayes 1995, p. 24.
} 
Coordinated enforcement also includes self-enforcement measures that are specifically legitimated by a treaty body. An agreement may identify specific circumstances in which a member state may take proportionate action to protect its interests in response to failure by another member state to bring measures into compliance with its obligations under a treaty. For example, the WTO 1994 sanctions proportional crossretaliation by a member state, if authorised by a WTO Dispute Resolution Body.

The final generic form of coordination considered here is third party monitoring and review. These measures have the effect of bringing increased international attention to bear on individual state conduct. This generally takes the form of monitoring and review by an official international organisation, taking a variety of forms. Examples, in increasing levels of intrusion, include self-reporting by states to an international body; peer review mechanisms, such as that established in the New Partnership for Africa's Development, and the open method of coordination in the EC; and dissemination amongst member states of monitoring reports produced by a Treaty body. An example of the latter is the regular IMF Article IV surveillance report on individual member countries.

Traditionally third party review was conducted on a confidential basis. However, some organisations, such as the OECD and the WTO, publish their monitoring reports, and others, such as the IMF, are moving increasingly in this direction. ${ }^{149} \mathrm{~A}$ further step is the explicit "naming and shaming" of non-complying states, which was the approach adopted by the OECD's Financial Action Task Force with respect to states considered to be not cooperating over anti-money laundering measures. ${ }^{150}$

Third party monitoring is generally undertaken by official entities, but in some instances non-government entities are given standing to inject information into formal monitoring processes. An example is the formal role accorded to Transparency International and

\footnotetext{
${ }^{149}$ The OECD's annual Economic Surveys are published (at http://www.oecd.org/findDocument/0,3354,en_2649_37443 1 119663_1_1_37443,00.html), as are the WTO's Trade Policy Reviews (at http://www.wto.org/english/tratop e/tpr_e/tpr_e.html). IMF Article IV reports were traditionally confidential. They are now published with the consent of the member state concerned, and an increasing number of countries are consenting to publication (see http://www.imf.org/external/ns/cs.aspx?id=51)

${ }^{150}$ See the 2005 Annual and Overall Review of Non-cooperative countries or territories, at http://www.oecd.org/dataoecd/41/26/34988035.pdf
} 
other NGOs to provide information on compliance by signatories to the committee monitoring implementation of the OECD Anti-bribery Convention. ${ }^{151}$

All the examples of coordination cited above can be characterised as representing forms of cooperation between either the separate jurisdictions of two or more states, or the separate jurisdictions of states and international organisations. Some international agreements go further, and establish, to varying degrees, a unified jurisdiction. It is to these forms of jurisdictional integration - defined here as constituting integration rather than cooperation or coordination - that we now turn.

\subsubsection{Horizontal and Vertical Integration}

The first generic form of integration, mutual recognition, comprises agreements between two or more countries to recognise each other's policies or enforcement practices as equivalent to their domestic policies or practices. For instance, with respect to regulation, mutual recognition arrangements entail the acceptance by one country of the conformity assessment and/or regulatory standards of another country(s) as equivalent to its own e.g. the 1998 US-EU Mutual Recognition Agreement Umbrella Agreement. Mutual recognition of standards effectively creates an integrated jurisdiction over the scope of the agreement.

Procedural mutual recognition, on the other hand, comprises agreements in which two (or more) states agree to recognise, for example, the rules of evidence and the procedural rules of each other's courts. ${ }^{152}$ For instance, Australia and New Zealand permit certain evidential rules and legal procedures to be recognised in each other's domestic courts for certain competition actions. ${ }^{153}$ The same two countries have agreed to what might be described as an arrangement for overlapping jurisdiction, or the mutual extension of the jurisdiction of courts into the legal systems of signatories, by agreeing to allow courts to sit in each other's territories to hear competition cases.

\footnotetext{
${ }^{151}$ See http://www.oecd.org/dataoecd/21/15/40896091.pdf, p. 32.

${ }^{152}$ Taylor, 2006, p. 381, uses the term procedural mutual recognition.

153 Taylor, 2006, p. 119.
} 
Unification of policies represents a second generic form of integration. ${ }^{154}$ This includes regulatory unification i.e. identical standards implemented by separate national regulatory institutions. It also includes the establishment of a common external tariff in a Customs Union. At this level, regulatory unification still provides states with some discretion over how to translate the unified policy or standard into national legislation.

In practice, unification may be combined with mutual recognition, so that some minimum standards are harmonized, and mutual recognition applies to standards beyond the minimum.

Mutual recognition and unification can be characterised as horizontal integration between two separate national systems. The remaining forms of integration are better characterised as vertical integration between a national level policy and enforcement system, and a regional system.

A third generic form of integration, then, comprises an international or trans-national organisation possessing an element of delegated rule-making, implementation, or enforcement authority. Perhaps the most common example is regional central banks, which are entrusted with the conduct of monetary policy across a monetary union. ${ }^{155}$

Outside monetary unions, the outstanding examples of delegated rule making and enforcement in economic policy are provided by the EC. For example, the authority of the EC Commission to:

- $\quad$ Promulgate regulations in specific fields that are binding on all member states.

- Initiate proposals for regional expenditure programs designed to redistribute from wealthier to poorer regions within member states.

- Initiate financial sanctions on member states in breach of the fiscal deficit and debt limits in the Stability and Growth Pact.

\footnotetext{
${ }^{154}$ The term unification is used here to avoid the ambiguity inherent in the term "harmonisation." Harmonisation is at times used to refer to a process of convergence towards uniform policies or practices, and at times it is used to refer to the end point of such a process i.e. a situation where policies or practices are identical.

${ }^{155}$ See Cohen, Chapter 6 in Kahler and Lake (Ed.s) 2003, for a description of monetary unions in different regions.
} 
- $\quad$ Sign treaties with third countries on behalf of member states with respect to some functions or policy domains.

In addition, the European Parliament, a directly elected trans-national legislative body, plays a formal role in decisions that are binding on member states e.g. it has the formal right to be consulted by the European Council prior to some decisions, and the right of co-decision with respect to the EC budget.

At the highest level of integration are arrangements where a single trans-national or regional body has the power to issue rules or regulations that have direct effect in member states, and/or where decisions on new policies in some areas are subject to a majority vote among member states with no (or very limited) provision for opt-out or national veto. Direct effect eliminates, or at least sharply reduces the scope for national discretion because decisions require no translation into national law. ${ }^{156}$ Majority voting occurs in the EC Council of Ministers, while direct effect is also a feature of EC law.

At this level also are mechanisms that can be described as effecting the vertical integration of the legal systems of member states and an international court. These mechanisms include the provision of standing to non-state parties (Treaty bodies and/or private individuals or firms) to file complaints against states for failure to comply with their treaty obligations; the mandate to issue preliminary rulings to national courts on request; and the rulings of courts having direct effect in the domestic law of member states. All of these features are found in the dispute settlement mechanisms in four RTAs (the EC, EFTA, the ANDEAN Group, and the Caribbean Community (CARICOM)).

Finally, the EC provides the only current instance of a regional arrangement in which supranational law has supremacy over domestic law in the event of conflict. This is associated with the European Court of Justice claiming a doctrine of implied powers where treaties are not definitive as to whether a particular power has been devolved to the EU level.

\footnotetext{
${ }^{156}$ Although a member state may still be entitled to request a review of a regulation promulgated by a trans-national regulatory body prior to its coming into effect, or may have the authority to unilaterally modify or (temporarily) exclude its application under specified circumstances e.g. exceptional health or safety concerns.
} 


\subsection{Policy Trade-Offs in Moving Along The SpeCtrum}

The spectrums serve to highlight some critical trade-offs between competing public policy objectives.

First is the trade-off between flexibility, on the one hand, and efficiency and commitment on the other. Efficiency gains from jurisdictional integration can arise from a reduction in transactions costs for businesses due to differences in behind the border policies; from the reduction of trans-national 'market failures;' from the provision of trans-national public goods; or from reduction in the power of domestic cartels. Box 2 in Chapter 7 contains a more extended discussion of the potential economic benefits from jurisdictional integration.

Credibly committing to a sustained reduction in these costs can yield additional efficiency gains. Time consistency problems come into play here in the same way they do with respect to domestic policies, creating an international relations equivalent of the rules versus discretion trade-off in domestic policy. Smith has labelled this a trade-off between treaty compliance and policy discretion. ${ }^{157}$

On the other hand, uncertainty is pervasive, and policy flexibility in the face of changing circumstances and preferences is therefore of real value to states - as emphasized by a number of writers e.g. Kahler 1995, Rosendorff and Milner 2001. Extricating a country from an international agreement is not necessarily straightforward. There may be requirements for prior consultation stipulated in the original agreement, required notice periods, or provision for procedures to determine matters requiring settlement in the event of withdrawal e.g. financial implications. For agreements covering a wide range of issues, such as many RTAs, it may also be the case that withdrawing from the agreement in order to reclaim autonomy or flexibility in one policy domain may entail the loss of major benefits in other domains covered by the agreement.

\footnotetext{
${ }^{157}$ Smith, 2000, pp. 143-150. See also Majone 1996, pp. 2-6 for discussion of the application of the rules versus discretion trade-off to the design of international institutions.
} 
As Yarbrough and Yarbrough have observed: “...flexibility, the capacity to credibly commit oneself, and the ability to recognize whether flexibility or commitment is needed in a particular situation, are all essential elements of state capacity."158

On the other hand, international cooperation can also reduce uncertainty. "The framework [for EU-US cooperation in competition policy] emphasizes dispute prevention as a corrective to the uncertainty and political tensions arising from dispute resolution through extraterritoriality and retaliatory countermeasures."

The second key policy trade-off in moving along the spectrum is between the adoption of foreign or internationally recognized standards, and the possibility of tailoring standards and policies more finely to an individual country's particular circumstances. This can be thought of as a trade-off between commitment and "policy fit." This tradeoff is illustrated by the distinction that is drawn between international regulatory harmonization and regulatory competition. Full harmonization of regulations reduces the ability of each country to tailor regulations to distinctive national circumstances or preferences, whereas mutual recognition provides some scope for competition between different regulatory regimes - albeit often on the basis of some minimum level of harmonization. The theory is that a country whose regulations are more cost effective will reduce compliance costs for businesses subject to, or choosing to meet its standards, creating an incentive for other countries to make their regulations more cost effective.

Related to this is the constraint that jurisdictional integration can place on the use of the first-best policy intervention. For example, lack of monetary policy autonomy in a monetary union removes the possibility of autonomous changes in interest rates for macroeconomic management at the national level. In addition, the constraints on fiscal policy that are associated with a monetary union - because of concerns about the external effects of excessive fiscal deficits, or the difficulty of achieving a coordinated fiscal expansion - may also restrict somewhat the ability to use the instrument of fiscal policy for macroeconomic management.

\footnotetext{
${ }^{158}$ Yarbrough and Yarbrough, 1990, p. 258.

${ }^{159}$ Damro, 2005, p. 63.
} 
Finally, unwillingness to cede taxing authority to the regional level may result in regulatory instruments being used when fiscal instruments, such as taxes and transfers, may be more effective and efficient. This is arguably the case with respect to the EC's Common Agricultural Policy, which uses regulations but which could in principle be replicated by a tax and transfer system. Whether fiscal instruments would achieve the policy objectives at lower economic and social cost to the EC, and to the rest of the world, is a moot point given the EC's lack of authority to employ them. This factor may also help to explain Alesina and Spolaore's finding that the EU has been very active in policy domains where international spill-overs are low and heterogeneity of preferences is high, such as agriculture. ${ }^{160}$

Third is the impact of increasing jurisdictional integration at the higher ends of the spectrums on legitimacy. Two aspects of legitimacy are important here, representativeness legitimacy and performance legitimacy. Jurisdictional integration can reduce or constrain opportunities for citizens to make direct representations to decision makers on the content of the rules and standards, or to hold decision makers and enforcement agencies directly accountable because of the lack of institutional safeguards often found at the national level, such as parliamentary oversight, judicial review, and transparency. ${ }^{161}$ These concerns underlie the principle of subsidiarity, that government functions should be undertaken by the lowest possible level of government.

This can be thought of as a trade-off between commitment and representativeness legitimacy. This trade-off might, however, be reduced by any efficiency improvements associated with higher levels of jurisdictional integration. A government's perceived success in economic management can result in improvements in performance legitimacy.

As one moves along the jurisdictional integration spectrum from left to right, a country increasingly constrains its flexibility to change policies, constrains its ability to tailor policies, rules, and enforcement practices to distinctive national circumstances, and may

\footnotetext{
${ }^{160}$ Alesina and Spolaore 2003, Chapter 12.

${ }^{161}$ Petersmann has observed that: 'Discretionary regulatory powers at the international level require no less constitutional safeguards than at the national level in order to limit abuses of national and international bureaucracies.' Petersmann, 1996-97, p. 457. See also Alvarez, 2005, Chapter 4.3 for discussion of accountability in the "emerging global administrative law" of standard-setting activities of international organisations.
} 
risk diminishing the legitimacy of decision-making and enforcement in the eyes of its citizens. On the other hand, an increase in jurisdictional integration can reduce the costs of doing business across national borders, reduce trans-national 'market failures', lower the costs of designing and supplying public goods such as regulatory regimes and economic infrastructure, and increase the credibility of a country's commitment to particular policies and rules.

Central questions in contemporary international relations are the nature of these tradeoffs, the reasons different countries choose different degrees and forms of policy cooperation, and the impacts these different forms have on international economic integration. Of interest also is how the different dimensions of jurisdictional integration e.g. of prescriptive, enforcement, and adjudicative jurisdiction, should or do co-vary, and whether in practice particular clusters or patterns of points across the different dimensions are common.

The concept of jurisdictional integration and the spectrums of integration developed in this thesis are intended to contribute to progress in answering these questions. As noted by Summers, economic integration is critical to economic welfare, but requires both a larger role for government and more constraints on state sovereignty, and there are reasons in general to prefer less government intervention in the economy and fewer constraints on sovereignty. "The profoundly important question is how to reconcile the three legs of the trilemma [economic integration, management, and national sovereignty]."162

${ }^{162}$ Summers, 1999, pp. 3, 7, 9-10, and 17. 


$$
\text { PART } 3
$$

Empirical Analysis of Jurisdictional Integration:

\author{
Measuring the Depth \\ of International Policy Cooperation
}




\section{OVERVIEW}

Part 3 of the thesis will apply the concept of jurisdictional integration to specific policy domains and international agreements, to demonstrate the practicality of the concept, and its potential contribution to more accurate measurement of and research on international policy cooperation.

The next chapter discusses competing theories of the causes of international economic policy cooperation, and identifies general hypotheses of the key variables influencing decisions by states over the extent to which they will constrain or relinquish their jurisdiction.

Chapter 8 then analyses the changing depth of jurisdictional integration in RTAs. It does so by applying the concept of jurisdictional integration to existing WTO data on non-tariff provisions in RTAs, which allows some testing of competing hypotheses about whether the depth of policy cooperation in RTAs increases or decreases with multilateral trade liberalization. WTO data also allows some limited testing of the hypothesis put forward here that jurisdictional integration is a complement to the increase in the number of countries.

Existing datasets have severe limitations, however, in terms of measuring the depth of international economic policy cooperation. They were primarily compiled, not to measure the depth of cooperation, but to measure phenomena such as the legal form of an agreement, the simple presence or absence of specific agreement features, or the extent to which provisions are compatible with the multilateral trading system. Measuring jurisdictional integration satisfactorily therefore requires construction of a purpose-built dataset.

To that end, the remaining chapters in Part 3 apply the concept of jurisdictional integration to international cooperation in competition policy, as follows:

- Chapter 9 provides an overview of the evolution of international cooperation in competition policy, the instruments through which it is effected, and existing taxonomies of international competition policy cooperation. 
- In Chapter 10, ordinal indices of jurisdictional integration of competition policy are then derived, that measure increasing depth of international policy cooperation in its various dimensions.

- Chapter 11 sets out research questions specific to international competition policy cooperation, to be tested along with the general hypotheses of the causes of international economic cooperation in Chapter 7.

- In Chapter 12 a dataset of international competition policy agreements is compiled, comprising both stand-alone competition enforcement agreements, and competition policy chapters in RTAs.

- Agreements are then ranked on the jurisdictional integration indices, allowing the generation in Chapter 13 of summary statistics on the depth of international cooperation in enforcing competition policies.

- In Chapter 14, statistical analysis is conducted of variables that may or may not predict the depth of international cooperation in enforcing competition policies. 


\section{Chapter 7}

\section{THE DETERMINANTS OF INTERNATIONAL ECONOMIC COOPERATION}

\subsection{COMPETING THEORIES}

At the outset it is useful to identify two broad categories of factors that need to be addressed by theories of the causes of international policy cooperation. Theories need to address:

1. Both the demand from various interests for governments to enter international policy cooperation arrangements, and the supply of policy cooperation by governments (Mattli, 1999)

2. Both the determination of preferences within each state, and the outcome of bargaining between states (the so-called two level game, after Putnam, 1988)

From the literature, nine broad determinants of international economic policy cooperation can be identified. These are:

1. Economic integration

2. Security and foreign policy considerations

3. Domestic political factors

4. Domestic "cultural" factors

5. Strategic inter-state bargaining

6. Geographic proximity

7. Regulatory competition

8. Elite norm diffusion

9. System-level drivers

Turning first to economic integration, the theoretical framework in which this research is embedded is that there is a two-way interaction between international economic integration and international policy cooperation. Policy-makers focus on the expected impact of policy cooperation on economic integration. For instance, discussions of policy with respect to membership of RTAs, or on international regulatory coordination, 
are typically framed around the possibilities that such agreements will increase levels of trade and economic exchange. The few empirical studies in this area find some support for an impact of policy cooperation on economic integration (Dorrucci et al 2002, 2004, Vlachos 2004). Appendix 1 contains a summary table of selected empirical studies of international economic policy cooperation.

On the other hand, it is also possible that, in some circumstances at least, economic integration creates a demand for increased policy cooperation. This is in line with the perspective of Lawrence who observed that: "Free trade areas may well be an endogenous variable - that is, a response to, rather than a cause of large trade flows....Presumably [governments] are more likely to form free trade areas, since the benefits outweigh the costs. ${ }^{\text {"163 }}$ Mansfield, Milner and Rosendorff note that many observers have argued that increasing economic exchange between states promotes domestic political support for international agreements that act to promote further integration and provide protection for private interests against opportunistic behaviour by foreign governments. ${ }^{164}$ This is a form of "economic functionalism" analogous to Haas' (1958) functionalist perspective on European integration.

Consistent with the overall focus of the thesis on re-conceptualizing the impact of economic integration on state sovereignty, the perspective that will be adopted here will be to treat jurisdictional integration primarily as the dependent variable, and to begin to explore the conditions influencing states to sign up to international economic cooperation arrangements entailing varying depths of cooperation.

This will contribute to the small empirical literature on the causes of international policy cooperation, which at present is largely confined to studies looking at a binary choice of cooperation versus no cooperation e.g. Mansfield, Milner and Rosendorff 2002, Baier and Bergstrand 2002, or studies that use a combined measure of economic and policy integration (the stage of economic integration) as the dependent variable e.g. Wu 2004.

Why does increasing economic integration create a demand for deeper international policy cooperation? As firms become more extensively and intensively involved in

\footnotetext{
${ }^{163}$ Lawrence, 1998, cited in Baier and Bergstand, 2002, p. 1.

${ }^{164}$ Mansfield, Milner and Rosendorff, 2003, p. 32
} 
transacting across national borders, there is an increasing mismatch between the domain of their activities and the jurisdiction of their home states. They are therefore increasingly subject to the jurisdiction of foreign governments, which creates both new risks and new opportunities for them. This creates a demand for their governments to enter cooperative arrangements with foreign jurisdictions to manage these risks and to realise opportunities.

This is based on a theory of policy cooperation in which absolute increases in economic integration are the driving force, not relative increases. That is, if Country A increases trade with Country B by $20 \%$ in a particular period, and its trade with the rest of the world increases by $50 \%$ over the same period, there will still be a demand for policy cooperation with Country B, even though A's exports to B have declined relative to the rest of the world. This is in contrast to the theory of relative integration propounded by Deutsch and others, which measures economic integration on a relative trade shares basis. $^{165}$

Box 2 sets out the specific sources of potential economic gains from international policy cooperation.

Once economic integration associated with the removal of border restrictions e.g. quotas and tariffs, has reached a certain stage, impediments to exchange due to differences in "behind the border" policies come into focus, and result in a demand for deeper integration. ${ }^{166}$ Governments may indulge in "policy shifting" (Kahler), ${ }^{167}$ for example using non-tariff barriers, as they are increasingly constrained from using tariff barriers. Trachtman has referred to this as "...the first law of trade dynamics: the law of conservation of protection....It thus appears that domestic regulation may be the next frontier of protection." 168

\footnotetext{
${ }^{165}$ See Caporaso 1971, p. 249, for discussion.

${ }^{166}$ Baldwin has likened this to "draining a swamp - the lower water level has revealed all the snags and stumps of non-tariff barriers that still have to be cleared away." Baldwin, 1970, p. 2.

${ }^{167}$ Kahler 1995.

${ }^{168}$ Trachtman, 2007, pp. 632-633.
} 


\section{Box 2: The Potential Economic Gains from International Economic Policy Cooperation}

What economic factors lead to demands that governments sign up to arrangements entailing international economic policy cooperation? The following discrete factors can be identified:

1. Transactions cost economies - for example, trade facilitation (such as cooperation between customs agencies) can reduce costs for exporters of moving goods across borders; and regulatory cooperation can reduce costs by reducing the need for multiple product testing and certification.

2. Economies of scale - mutual recognition and/or harmonization can increase economies of scale by allowing larger production runs through eliminating the need to tailor products slightly differently for different national markets (Kobrin, 1997).

3. Safeguards for specific assets (Yarbrough and Yarbrough 1990) - foreign direct investment is exposed to the risk of loss from the capricious actions of host governments, creating a demand for mechanisms to constrain host governments e.g. Bilateral Investment Treaties, investment, competition policy and dispute resolution mechanisms in RTAs. Firms are argued to have limited ability to manage these risks through other means such as insurance or hedging (Schiff and Winters 2003).

4. Reduction in policy risk - by increasing the transparency and predictability of the overall policy environment in partner countries e.g. through establishing monitoring mechanisms including regional institutions, policy cooperation increases the expected profitability of future investments in export capacity and foreign direct investment.

5. Trade insurance - by creating a more secure "regional" market, policy cooperation reduces the losses that would occur if exporters were to be squeezed out of wider export markets, for example by a trade war between rival trade blocs. This suggests smaller countries would seek insurance by cooperating with bigger countries, not other small countries.

6. Reduction in business cycle uncertainty - to the extent that the business cycles of regional economies are not closely synchronized, increased regional integration fostered by greater policy cooperation can help to reduce demand volatility ( $\mathrm{Wu}, 2004$, p. 10).

7. Increased competition in domestic markets - lower barriers to entry from cooperative liberalization, and regulatory cooperation e.g. with respect to enforcement of competition policy on businesses operating in multiple national markets, may create price, quality and variety benefits for domestic consumers.

8. Increased cost-effectiveness of public goods - international economic integration has seen an increase in the number of policy issues beyond the effective control of individual states, and a demand from the private sector for governments to ensure their activities are cost-effective by allocating some regulatory public goods production to the supranational level (in line with the theory of fiscal federalism). Given increased factor mobility, governments perceive a need for taxation to be competitive in order to compete for financial and human capital.

9. Facilitating or locking in domestic policy reforms - jurisdictional integration provides a mechanism for governments to make credible commitments both to domestic and foreign interests with respect to a range of behind the border policies that can impede trade and economic integration - as argued by Whalley (1996), pp. 15-16, with respect to Mexico and NAFTA). Attempts to entrench unilateral commitments e.g. through constitutional amendments, or the creation of independent institutions, may be less credible or feasible, in part because of the high cost of exit from an RTA. 
A different form of "spill-over" (Haas) occurs where the effects of previous policy integration measures increase the attractiveness of further policy integration steps - for example, a monetary union can create pressure for some convergence of fiscal policies. ${ }^{169}$ The increasing intensity of economic integration - in the form of foreign direct investment, intra-industry trade, and the activities of multinational enterprises forming themselves into transnational networks - can also be expected to result in greater awareness of behind the border impediments to trade and exchange, and more scope for trans-national anti-competitive activity.

This suggests a possible change in the direction of causality running from economic integration to jurisdictional integration over time. Shallow jurisdictional integration (focused on removal of impediments at the border) generates economic integration in the initial phase, but at some point deeper jurisdictional integration may be a precondition for further economic integration.

This is in contrast to two alternative hypotheses advanced on the relationship between economic integration and policy cooperation. Smith hypothesized that the depth of intended economic integration would influence states to agree to deeper - more legalized - forms of dispute resolution mechanisms in RTAs. ${ }^{170} \mathrm{He}$ did not use measures of actual economic integration.

Secondly, Kahler hypothesized that there is a curvilinear relationship between the level of international economic integration, and the degree of centralization of institutions. When economic integration is shallow and information about government policy preferences is scarce, substantial information gathering is required before stronger and more centralized institutions can emerge. Decentralization can re-emerge at the other end of the "arc of information," when information about preferences is plentiful and cheap, and decentralized, reputation-based systems may again be sufficient. Centralized institutions with greater monitoring and enforcement capabilities might be expected in intermediate situations where transparency has increased but

\footnotetext{
${ }^{169}$ Haas 1976.

${ }^{170}$ Smith 2000, pp. 161-163. That is, his dependent variable (legalism), which as previously noted is a form of jurisdictional integration, was hypothesized to depend on the form of an RTA i.e. whether it is "shallow" (FTA, Customs Union) or "deep" (Common Market or Economic Union). His independent variable therefore included both economic integration and policy integration.
} 
uncertainty remains about government preferences. ${ }^{171}$

Some empirical support for an impact of economic integration on policy cooperation is provided by Simmons 2000, and Wu 2004 (see Appendix 1).

The gains from international policy cooperation identified in Box 2 come at a cost, however. For instance, depending on the depth of policy cooperation, international agreements can restrict the ability of governments to use the best policy instrument, to tailor a particular policy to unique national circumstances, or to change policies as circumstances change. They also expose the government to the risk that partner governments will replace border protection with disguised protectionism in the form of domestic regulations, or that private restraints of trade will replace government protection. There are often also adjustment costs for domestic groups e.g. workers in, and owners of firms exposed to increased competition, and losses of government tariff revenues, that lead to domestic opposition to international policy cooperation. The adjustment costs are often immediate and concentrated, while benefits are more dispersed and longer term. And international agreements that constrain the autonomy of domestic authorities can challenge notions of political legitimacy by attenuating the links between citizens and those who make and/or implement and enforce policies.

Why do governments nevertheless sign up to international economic policy cooperation? First, the expected economic gains - which will often (although not necessarily) be more than sufficient to compensate losers (whether or not compensation is actually paid) - are a potential source of electoral support. A government's perceived success in managing the economy and delivering economic growth helps its prospects of re-election. The increasing difficulty of governments in unilaterally influencing economic outcomes also means they are likely to respond to pressure to be seen to be taking action to achieve policy goals. Economic performance is believed to be an important influence on median voter behaviour, and hence on government behaviour.

Secondly, by requiring reciprocity from partner countries (as opposed to liberalizing unilaterally), a government may both reduce the economic costs of liberalization -

\footnotetext{
${ }^{171}$ Kahler 1995, suggests that the shift from regulatory harmonization to mutual recognition within the EC, and the Closer Economic Relations Agreement between Australia and New Zealand (which has not created any centralised institution or secretariat), are evidence that decentralized institutions may appear at high levels of economic integration.
} 
because export markets are opening at the same time that import restrictions are being lowered - and at the same time help to build support for economic liberalization from domestic exporters.

Thirdly, an international trade agreement may signal to domestic and foreign businesses that a government will pursue and maintain liberal economic policies. The signal could arise from the fact that entering an RTA is politically costly up-front. ${ }^{172}$ In addition, an international trade agreement typically results in foreign governments and/or international organizations monitoring the trade policy performance of each signatory government. This improves the ability of governments to signal to voters what their trade policy choices are, by lowering voter information costs compared to unilateral trade policies that can be quietly made more protectionist without arousing foreign public comment. ${ }^{173}$

Fourthly, certain features of international agreements e.g. monitoring and dispute resolution provisions, and competition policy provisions, reduce the risk that foreign governments will renege on their commitments. This reduces the government's political risk from signing up to the agreement (a type of specific asset for the government).

Fifthly, a liberal government may want to tie the hands of an alternative future protectionist government. ${ }^{174}$

Returning to the broad determinants of international economic cooperation, the second broad theory of the determinants is security and foreign policy considerations. States may enter economic policy cooperation agreements with the main intention of achieving non-economic objectives, such as reducing regional tensions, building regional stability, cementing political alliances, spreading democracy, and reducing the risk of negative spill-overs from neighbouring countries e.g. large-scale illegal immigration. Security considerations were clearly a key motivation for the formation of the EC in 1957, and have also been a factor in other regions e.g. in South East Asia, Latin America, Australasia. US interest in NAFTA was in part due to its non-economic interests in a

\footnotetext{
${ }^{172}$ Fernandez and Portes 1998, p. 204.

${ }^{173}$ Mansfield, Milner and Rosendorff 2002, p. 8.

${ }^{174}$ Fernandez and Portes 1998, p. 207.
} 
stable southern neighbour. The EC's more recent expansions have also been motivated in part by security concerns, and the objective of building democracies in the former Soviet Union. These considerations have been incorporated in empirical studies through the inclusion of variables measuring whether countries are allies, former colonies, geographic neighbours, and the number of military disputes between them.

A third hypothesized determinant of international economic policy cooperation is domestic political factors. Regime type e.g. democracy, authoritarian, may influence the proclivity to enter international economic cooperation agreements - although a priori it is not clear what the direction of influence would be. For instance, democratic governments may be more likely to respond to the electoral pay-offs from the economic benefits of international cooperation. On the other hand, democracies may be more concerned about the distributional implications i.e. groups who lose, and the legitimacy costs of constraining their policy autonomy. Empirically, Mansfield, Milner and Rosendorff found that democratic countries are twice as likely to form a Preferential Trading Agreement (PTA) than autocratic countries, and that pairs of democratic countries are around four times as likely to form a PTA. ${ }^{175}$ On the other hand, Simmons found that democracy had a negative effect on compliance by states with their IMF Article VIII obligations to maintain current account convertibility. ${ }^{176}$

It does seem plausible, however, as suggested by Stein, that states with the same or comparable political systems are more likely to accept higher levels of integration than states with substantially different systems of governance. ${ }^{177}$ This is because international cooperation, especially deeper cooperation, requires a degree of trust in the ability and willingness of the other parties to abide by their commitments, and in the ability of their systems of governance to deal with foreign nationals (exporters, investors) on an acceptable basis. This would also suggest that deeper cooperation is more likely amongst countries with higher quality governance.

The strength of the domestic rule of law is a further domestic political variable that may impact on international economic cooperation. Authoritarian regimes may be sceptical

\footnotetext{
${ }^{175}$ Mansfield, Milner, and Rosendorff 2002. They defined a PTA as an FTA, Customs Union, Common Market or other commercial agreement.

${ }^{176}$ Simmons 2000.

${ }^{177}$ Stein 2001, p. 494.
} 
of international cooperation involving deeper (more 'legalized") forms of cooperation. ${ }^{178}$ Simmons found that compliance with IMF obligations was more likely amongst countries that placed a high value on the domestic rule of law. ${ }^{179}$ Other domestic political indicators that have been used in empirical studies are corruption, and the index of economic freedom. ${ }^{180}$

A fourth hypothesized determinant of international economic policy cooperation is domestic cultural factors, specifically domestic legal cultures. A distinction has been drawn between "Western-style" legal cultures and "the Asian way." The former are considered to rely on formal commitments and adversarial forms of dispute resolution, while the latter rely on informal, non-binding commitments, consensus, and negotiated dispute resolution. These domestic legal cultures may influence the degree to which states are willing to enter international arrangements entailing formal, more binding policy commitments, and formal (especially binding third party) dispute resolution. ${ }^{181}$ Other cultural factors incorporated in empirical studies are language, religious beliefs, and ethnicity.

Geographic proximity has long been regarded as an important contributor to international cooperation. "Spill-overs" between countries are, in some policy domains, likely to be greater amongst geographic neighbours. For example, the risk of trade diversion to take advantage of different customs duties on third country imports, which is greater amongst countries sharing a land border, can create an incentive to harmonize external tariffs in a Customs Union. Similarly, adoption of a common currency in a currency union is more common amongst neighbouring countries than in countries that are geographically distant. More generally, there is greater scope for aligning the territorial scope of state jurisdiction with the territorial scope of policy effects amongst countries in the same region. In addition, proximity is associated with common language, which reduces the costs of cooperation. The widespread phenomenon of Regional Trade Agreements reflects these effects of geography on international

\footnotetext{
${ }^{178}$ Kahler 1995 , pp. $26-28$.

${ }^{179}$ Simmons 2000.

${ }^{180} \mathrm{Wu} 2004$, p. 9.

${ }^{181}$ See Kahler 2000 for a detailed discussion and analysis of the theory in relation to APEC, the ASEAN Free Trade Area, and the ASEAN Regional Forum.
} 
economic cooperation. However, the more recent wave of RTAs includes many that are between countries that are geographically distant. ${ }^{182}$

Regulatory competition constitutes a sixth hypothesis. Major economies with large domestic markets have scope to influence the regulatory laws and standards of their trading partners, and it is to the advantage of their firms that they do so. They can also hope to establish their specific regulatory regimes as the de facto or de jure international/multilateral standard. The US and the EC pursue a strategy of regulatory export to varying degrees across different economic policy domains, and even smaller developed countries pursue this in their region. ${ }^{183}$ The EC, through agreements with countries seeking to join the EU, and to a lesser extent with other neighbouring countries, includes provisions for convergence or harmonization with EC standards.

The seventh broad hypothesized determinant of international economic policy cooperation is elite norm diffusion. Participation in trans-national policy communities, such as those facilitated by the OECD, can promote a broad convergence of views in specific policy domains. For instance, Kahler points to a knowledge-based model of national preference formation. Ideas and shared beliefs amongst policy makers and trans-national epistemic communities may provide focal points for international cooperation. ${ }^{184}$ Slaughter discusses the ways in which government networks, such as the Basel Committee of central bankers, can induce adherence to collective norms through socialisation arising from repeated interactions in small groups. ${ }^{185}$ Waller has pointed out that cooperation among competition agencies creates a community of officials who have been trained and socialised to speak, write and think about competition issues in a similar way. ${ }^{186}$

The eighth broad theory of the determinants of international economic policy cooperation is strategic inter-state bargaining. International cooperation is a two-level game. What factors determine outcomes at the second level of the game, inter-state

\footnotetext{
${ }^{182}$ See Crawford and Fiorientino 2005, p. 2.

${ }^{183}$ See the discussion generally in Raustiala 2002.

${ }^{184}$ Kahler 1995.

${ }^{185}$ Slaughter 2004, pp. 198-199.

${ }^{186}$ Waller, 1999, p. 1125, cited in Slaughter 2004, p. 253.
} 
bargaining? The outcome of international negotiations based on unanimity is assumed to be determined by the larger economies, who have more unilateral policy options, are less dependent on international economic exchange, are more heterogeneous and therefore suffer more "policy fit" costs (Alesina and Spolaore 2003), and who therefore have less to lose from failing to reach agreement. This perspective suggests that a key factor at this level of the game in determining the level of policy cooperation is the degree of economic asymmetry between parties to international agreements.

The level of asymmetry per se is hypothesized to have an ambiguous impact on cooperation. On the one hand, a large economy may successfully impose a high level of policy integration on a small economy e.g. require adoption of the large country's regulatory standards, as has occurred in bilateral agreements between the EC and neighbouring countries. This may be particularly true in a bilateral relationship, where power leverage is greatest. It has also been suggested that successful regional integration requires that a group is led by a country able to serve as an institutional focal point and regional pay-master. ${ }^{187}$

On the other hand, a large economy is likely to successfully resist constraints on its enforcement authority, preferring to retain unconstrained capacity for unilateral action. ${ }^{188}$ It may be hypothesized, therefore, that asymmetry will impact positively on the depth of enforcement cooperation when cooperation is measured as integration of prescriptive jurisdiction, and that this effect will be stronger in bilateral agreements than in agreements involving larger numbers of states. It may also be hypothesized that asymmetry will impact negatively on cooperation when cooperation is measured as integration of enforcement jurisdiction. ${ }^{189}$

The ninth and final hypothesized determinant of international economic policy cooperation is system-level drivers. Four separate elements can be identified:

\footnotetext{
${ }^{187}$ Mattli 1999, p. 64.

${ }^{188}$ Smith 2000, p. 149.

189 The hypothesized negative impact of asymmetry on integration of enforcement jurisdiction is consistent with the findings of Smith, who found, in an analysis of the dispute settlement provisions in RTAs, a strongly negative relationship between economic asymmetry and the level of legalism. Smith 2000, pp. 163-170.
} 
1. The number of countries: demand for international cooperation is hypothesized to be higher the larger the number of countries. This is because when there are more countries, there are more and longer international borders, and therefore a greater number of "behind the border" policies impacting on trade and investment. In addition, average country size has fallen with the large increase in the number of countries in the post-World War II period, and smaller countries are likely to seek deeper international agreements because they are more economically integrated, have less scope for exploiting economies of scale, ${ }^{190}$ have fewer unilateral options, and are more in need of "trade insurance." The hypothesis therefore is that the large increase in the number of countries in recent decades will lead both to a larger number of international economic agreements, and a demand for deeper levels of international policy cooperation.

2. The global hegemonic system: the existence of a bi-polar or uni-polar hegemonic system is theorized to be an influence on the behaviour of states in the economic realm. For instance, the end of the Cold War has clearly had an influence on the behaviour of states in eastern and central Europe, many of which have joined the EU since the fall of the Berlin wall. Wu hypothesized that the end of the Cold War resulted in a change in the structure of global trading alliances, and created an incentive for countries to increase their participation in regional and multilateral integration arrangements to alleviate augmented risks. ${ }^{191}$ To test for this she disaggregated her analysis into pre-1987 and post-1987 sub-periods. A different concept of hegemony - economic hegemony - was used by Mansfield, Milner and Rosendorff who included, as an independent variable, the percentage of global trade accounted for by the largest trader. ${ }^{192}$

3. The rise of the "regulatory state:" on this view, government regulation has become more pervasive in many countries over the course of the twentieth century as governments intervene in markets more extensively in pursuit of policy goals. Step increases in the pervasiveness of economic regulation are seen to have occurred at various points, such as the 1930s depression, and more recently with the need to regulate formerly state-owned enterprises after privatisation in the 1980s and 1990s. Raustiala has argued that, as a result,

\footnotetext{
${ }^{190}$ Alesina and Spolaore, 2003.

${ }^{191} \mathrm{Wu}, 2004$, p. 7.

${ }^{192}$ Mansfield, Milner, and Rosendorff 2002, p. 33.
} 
“...modern states look functionally similar...regulators in State A usually have a functional counterpart in State B...."193 This has also resulted in an increase in the potential for "behind the border" barriers or impediments to trade, and therefore an incentive for governments to seek means of reducing the negative effects of such regulations, when imposed by foreign governments, on their exporters and investors.

4. The relationship between multilateral and bilateral economic cooperation: While multilateral agreements, such as the WTO, are a type of international economic cooperation, the WTO is, to an important extent, part of the wider context in which regional and bilateral economic cooperation takes place. To that extent it can be considered a system-level effect. Ethier developed a theory in which multilateral trade liberalization leads to more RTAs, because lower tariff levels create an incentive for developing countries to compete for foreign direct investment, and therefore to enter into an RTA with a developed country. ${ }^{194}$ On the other hand, it has been theorized that multilateral and regional agreements are to some extent substitutes. For instance, Kahler suggested that there will be less demand for regional policy integration if the same type of integration has been achieved at the multilateral level. ${ }^{195}$ Drawing on Ethier, and on the unrelated hypothesis of Alesina and Spolaore 2003 that multilateral trade liberalization results in an increase in the number of countries (political disintegration), Schiff hypothesized that multilateral trade liberalization will result in more, but less politically integrated RTAs. ${ }^{196}$ Schiff did not set out a theory on which this hypothesis was based.

\subsection{Hypotheses of the CAUSES OF INTERNATIONAL ECONOMIC POLICY}

\section{COOPERATION}

The above discussion has pointed to or suggested a number of hypotheses about the general causes of international economic policy cooperation. Testing the above hypotheses requires confronting them with data on international economic policy

\footnotetext{
${ }^{193}$ Raustiala 2002, p. 4.

${ }^{194}$ Ethier 1998.

${ }^{195}$ Kahler argued that the introduction of the WTO dispute settlement mechanism in 1995 meant that APEC members saw less need for such a mechanism within APEC. Kahler 2000, p. 39.

${ }^{196}$ Schiff 2000, p. 9.
} 
cooperation from specific policy domains. This, in turn, requires some adaptation of the general hypotheses to fit the particular circumstances of each application. Some policy domains and datasets will be suitable for testing some hypotheses, but not others.

This section gathers together the general hypotheses from section 7.1 that it is proposed to test empirically in this thesis. The primary dataset that will be used is a specially constructed dataset of international competition policy cooperation agreements described in Chapter 12. With this data in mind, it is proposed to test the following general hypotheses of the causes of international economic policy cooperation:

1. There will be a strong positive relationship between countries' depth of international economic policy cooperation and their level of international economic integration.

2. The depth of policy cooperation in RTAs increases over time, measured both in aggregate terms and per agreement, due to increases in international economic integration, the shift in focus to behind the border issues as impediments at the border are removed, and the rise of the regulatory state. This is in contrast to Schiff's hypothesis that multilateral policy integration will result in less politically integrated RTAs i.e. RTAs with less policy integration (Schiff 2000).

3. International economic policy cooperation is a complement to the increase in the number of countries; that is, there is a positive relationship between the number of countries and both the number and average depth of international economic agreements. ${ }^{197}$ An increase in the number of countries results in an increase in the number of international borders, and a concomitant increase in behind the border costs. An increase in behind the border costs suggests, in turn, a greater demand for jurisdictional integration to reduce them.

4. There will be a strong positive relationship between countries' depth of international economic policy cooperation and their quality of governance.

5. The effect of economic asymmetry on the depth of enforcement cooperation will be strongly negative.

6. Enforcement cooperation between two countries will be much deeper the more similar are their substantive laws in the policy domain concerned.

7. There will be a strong positive relationship between countries' depth of international economic policy cooperation and their geographic proximity.

${ }^{197}$ This is an extension of Alesina and Spolaore 2003. 
The hypotheses are expressed as a "strong relationship" because a weak relationship has almost no information content, given the likely margin of error.

Chapter 11 describes some additional propositions and hypotheses specific to international competition policy cooperation, derived from a review of that literature in Chapter 9. These, together with the general hypotheses above, will then be tested using the dataset of international competition policy agreements.

First, however, there is one existing dataset that allows testing of Hypothesis 2, and a limited testing of Hypothesis 3. This is a WTO dataset on the presence of selected nontariff provisions in RTAs. This is the subject of the next chapter. 


\section{Chapter 8}

\section{MEASURING THE CHANGING DEPTH OF POLICY COOPERATION IN REGIONAL TRADE AGREEMENTS}

This chapter utilises existing data to measure the depth of jurisdictional integration in RTAs. This allows testing of competing hypotheses about the depth of policy cooperation in RTAs. First is hypothesis 2 in the previous chapter, suggesting that the number and average depth of policy cooperation in RTAs increases over time. The rival hypothesis is that of Schiff, suggesting that multilateral trade liberalization will result in less policy integration in RTAs. ${ }^{198}$

\subsection{MeAsuring By PROXY: Simple RATIO ANALYSIS By RTA-TYPE}

Historically, the legal focus of trade policy with respect to RTAs has been on the distinction between an FTA and a Customs Union. And in terms of trade policies at the border, the distinction between FTAs and Customs Union remains an important indicator of the level of policy and institutional integration. A Customs Union represents a higher level of goods trade policy integration because, in contrast to an FTA, member countries agree to the objective of harmonizing their tariffs with nonmember countries - although in practice many Customs Union remain well short of a common external tariff in practice, and the EC did not achieve a unified external tariff until 1968. In addition to deeper prescriptive jurisdictional integration, tariff harmonization also entails institutional cooperation with respect to the collection of tariff revenues.

However, in a world in which RTAs are increasingly covering behind the border policies, and the overwhelming majority of RTAs are FTAs, the FTA/ Customs Union

\footnotetext{
${ }^{198}$ Schiff 2000, p. 9.
} 
distinction fails to capture other, non-border dimensions of policy integration. ${ }^{199}$ Failure to measure and recognize this can result in incorrect conclusions about trends in international economic policy cooperation.

For instance, as noted in Chapter 7, Schiff drew on the implications of two unrelated hypotheses to suggest that multilateral trade liberalization will result in more, but less politically integrated RTAs. The two hypotheses were, first, Alesina and Spolaore's political disintegration hypothesis - the equilibrium size of countries falls and the number increases as international economic integration proceeds - and secondly, Ethier's hypothesis that multilateral trade liberalization results in more RTAs. ${ }^{200}$ Schiff did not define political integration, but from his discussion it is clear he is referring to policy and institutional integration, or to forms of jurisdictional integration as defined here. $^{201}$

Schiff's hypothesis was under-theorized, however, in that he did not present any suggested channels or mechanisms through which the hypothesized outcome would be brought about. And while his empirical work found support for his hypothesis, there are serious weaknesses in his approach.

Schiff tested his hypothesis by simply assigning all FTAs to a low level of political integration, and all Customs Union to a high level, based on the persistent traditional trade view that Customs Unions are deeper. Crawford and Fiorentino appear to make a similar assumption in stating: "The predominance of FTAs over customs unions is probably due to the fact that they are faster to conclude and require a lower degree of policy coordination... harmonization of external trade policies implying a greater loss of autonomy over the parties' commercial policies... ${ }^{202}$ However, many FTAs contain provisions entailing a loss of policy autonomy in areas outside tariff policy. In a world of progressively lower tariffs as a result of successive GATT Rounds, the increasing preponderance of FTAs seems more likely to be due to the fact that the net benefits

\footnotetext{
${ }^{199}$ Crawford and Fiorentino 2005, pp. 3-4, state that, of the 131 RTAs in force notified to the WTO as at February 2005, $109(84 \%)$ are FTAs, and only $11(8 \%)$ are Customs Unions. The dominance of FTAs over Customs Unions was even more pronounced amongst RTAs signed but not yet in force at that time 96\% were FTAs and there were no Customs Unions not yet in force.

${ }^{200}$ Alesina et. al. 1997, Alesina and Spolaore 2003, and Ethier 1998, pp. 1149-1161.

${ }^{201}$ See Schiff 2000, pp. 9-11.

${ }^{202}$ Crawford and Fiorentino 2005, pp. 3-4.
} 
from moving to harmonize third party tariffs are less than the net benefits from cooperation with respect to non-tariff policies.

Schiff measured the level of political integration in RTAs by whether they were a Customs Union, or were an FTA but not a Customs Union. He measured international economic integration by the openness ratio (the ratio of world exports to GDP).

Schiff found that the ratio of FTAs to Customs Unions had increased in recent decades - see Table 1a - but concluded incorrectly that this supported his hypothesis. What his methodology missed is the variation in the depth of policy cooperation across different FTAs, together with the significant increase in the average level of jurisdictional integration in FTAs in the last 15 years or so.

Table 1: Alternative Measures of the Depth of Regional Trade Agreements

1a: Ratio of Customs Unions to Free Trade Areas (Reproduced from Schiff 2000)

\begin{tabular}{|c|c|c|c|c|}
\hline Period & $\begin{array}{c}\text { Openness } \\
\text { (X:GDP in \%) }\end{array}$ & $\begin{array}{c}\text { Customs } \\
\text { Unions }\end{array}$ & FTAs & $\begin{array}{c}\text { FTAs/Customs } \\
\text { Unions }\end{array}$ \\
\hline $1949-59$ & 9.03 & 2 & 2 & 1.00 \\
\hline $1960-69$ & 9.73 & 5 & 7 & 1.40 \\
\hline $1970-79$ & 16.7 & 2 & 3 & 1.50 \\
\hline $1980-89$ & 15.5 & 3 & 4 & 1.33 \\
\hline $1990-98$ & 18.8 & 8 & 76 & 9.50 \\
\hline
\end{tabular}

1b: Ratio of Customs Unions plus Economic Integration Agreements to FTAs

\begin{tabular}{|c|c|c|c|c|}
\hline Period & $\begin{array}{c}\text { Openness } \\
\text { (X:GDP in \%) }\end{array}$ & $\begin{array}{c}\text { Customs } \\
\text { Unions+ EIAs }\end{array}$ & $\begin{array}{c}\text { Remaining } \\
\text { FTAs }\end{array}$ & $\begin{array}{c}\text { FTAs/ Customs } \\
\text { Unions+EIAs }\end{array}$ \\
\hline $1949-59$ & 9.03 & 2 & 0 & 0 \\
\hline $1960-69$ & 9.73 & 1 & 1 & 1.00 \\
\hline $1970-79$ & 16.7 & 2 & 8 & 4.00 \\
\hline $1980-89$ & 15.5 & 3 & 2 & 0.66 \\
\hline $1990-98$ & 18.8 & 13 & 36 & 2.77 \\
\hline
\end{tabular}

1c: as for $b$, but different time periods

\begin{tabular}{|c|c|c|c|}
\hline Period & $\begin{array}{c}\text { Customs } \\
\text { Unions+ EIAs }\end{array}$ & $\begin{array}{c}\text { Remaining } \\
\text { FTAs }\end{array}$ & $\begin{array}{c}\text { FTAs/ Customs } \\
\text { Unions+EIAs }\end{array}$ \\
\hline $1955-64$ & 3 & 1 & 0.33 \\
\hline $1965-74$ & 2 & 5 & 2.50 \\
\hline $1975-84$ & 1 & 4 & 4.00 \\
\hline $1985-94$ & 6 & 14 & 2.33 \\
\hline $1995-04$ & 29 & 91 & 3.14 \\
\hline
\end{tabular}

One simple way to use the database of RTAs notified to the WTO to illustrate this is to assign all FTAs that cover trade in services to a higher level of integration than 
FTAs that cover trade in goods only. The justification for this is that trade in services brings into play a wide range of often-sensitive domestic regulatory settings.

For instance, agreements covering services trade - classified by the WTO as Economic Integration Agreements - contain, at the least, specific conditional commitments to national treatment in schedules to the agreements. Many Economic Integration Agreements go well beyond this, however, and provide for unconditional national treatment, and guaranteed right of establishment. Many agreements contain provisions designed to encourage the development of mutual recognition of regulatory regimes, and a few contain explicit Mutual Recognition Agreements. Some Economic Integration Agreements also contain disciplines on government procurement, and the temporary entry of business people. The most comprehensive treatment of services occurs in a number of FTAs e.g. the EEA, CER, NAFTA, and western hemisphere agreements modeled on NAFTA, whereas some Customs Unions have covered services in a less comprehensive manner e.g. MERCOSUR. ${ }^{203}$

A more accurate measure of the level of "political integration" hypothesized by Schiff that is, of jurisdictional integration as developed in this thesis - would therefore be the ratio of Customs Unions plus Economic Integration Agreements to remaining FTAs.

Table $1 \mathrm{~b}$ shows the different results this approach produces. ${ }^{204}$ The ratio still increases in the period 1990-98 over 1980-89, but much less so. And in contrast to 1a, the ratio is lower in 1990-98 than for the period 1970-79.

Up-dating the analysis to include more recent RTAs, and redefining the periods to reduce the small numbers problem, produces still more contrasting results. For instance, when the periods are redefined to mid-decade intervals and data is included up to 2004 - see Table 1c - the above pattern is repeated, a lower ratio in the most recent decade than for two decades earlier. Now, however, there is an even smaller increase 1995-04 over the previous decade, and the average ratio over the last four decades (3.00) is little different from the ratio in the most recent decade (3.14).

\footnotetext{
${ }^{203}$ See Stephenson 1999. See also Crawford and Fiorentino 2005, pp. 5-6.

${ }^{204}$ The data in Tables 1(b) and 1(c) are based on notified RTAs in force as at 22/11/05. These numbers are substantially lower than the numbers that Schiff used. Schiff may have used total RTAs notified to the WTO, whether currently in force or not, but he does not explain his RTA data.
} 
These results do not support Schiff's hypothesis that economic integration - which, with the exception of a dip 1980-89 over 1970-79, was increasing throughout the period leads to less politically integrated RTAs. Indeed, they would appear to refute the hypothesis, by suggesting that RTAs have not in fact become less "politically integrated" since 1975-1984.

However, using broad categories of RTAs as proxies for the depth of international policy cooperation has serious limitations. For instance, FTAs not covering services may themselves have exhibited an increasing or declining level of policy integration over the period; and some FTAs are deeper in some respects than some Customs Unions. This needs to be investigated directly by looking at the substantive content of individual RTAs to assess the depth of policy cooperation in each agreement.

\subsection{A Direct Measure of The Depth of Policy CoOperation in RTAs}

An inventory of non-tariff provisions in a large number of RTAs, compiled by WTO staff in 1998, makes such an analysis possible. ${ }^{205}$ The inventory contains detailed information on a number of parameters, and allows estimation of a direct measure of the changing depth of policy cooperation in RTAs.

The inventory was based on information extracted from a total of 69 RTAs notified to the GATT/WTO that were in force in 1998. It is described as covering all main types of non-tariff provisions found in the texts of the agreements and, where possible, in annexes, protocols or other related legal texts. ${ }^{206}$ A database was developed by the WTO that categorized each agreement by whether it:

- Was a Customs Union or an FTA.

- Was signed before or after 1990 (as a rough indication of whether it was contemporary to the GATT or the WTO 1994).

- Pertained to a particular geographical region.

- Had two or more parties.

\footnotetext{
${ }^{205}$ Available on the WTO web site http://www.wto.org/english/tratop_e/region_e/region_e.htm.

${ }^{206}$ With the exception of best-endeavour or unspecific provisions. Instances of where the status of some provisions was unclear were signalled in the text of the note.
} 
In addition, non-tariff provisions were organized under eight categories:

- Scope.

- Institutional and procedural provisions.

- General and security exceptions.

- Rules on quantitative restrictions.

- Rules on subsidies/state aids.

- Contingency instruments.

- Standards.

- Other provisions related to trade in goods.

To make additional comparisons between RTAs possible, the inventory also created sub-categories of these eight categories. Results were presented in the form of statistical frequency tables.

An important feature of the inventory for current purposes is that, in a number of cases, the underlying criterion used to organise the categories and sub-categories appears to be some concept of the depth of policy cooperation.

For instance, the category "Institutional and Procedural Provisions" contained three subcategories directly relevant to measuring the depth of policy cooperation: Institutional Structure; Dispute Settlement Provisions; and Approximation of Laws.

Institutional Structure focuses on the authorities delegated to the new body created in nearly all RTAs to facilitate implementation of the agreement. These authorities are generally arrayed in increasing depth of delegation, as follows:

- Whether the body is charged with largely procedural functions e.g. convening meetings.

- Whether it can grant a slow-down in liberalization e.g. authorizing safeguards.

- Whether it can mandate further liberalization e.g. deciding to increase harmonization.

- Whether it is endowed with separate legal personality.

Similarly, Dispute Settlement Provisions are arrayed according to whether the agreement provides merely for consultations between the parties, or for a generally 
consultative process for authorizing retaliation, or also provides for an optional binding process.

Finally, the sub-category Approximation of Laws arrays agreements by whether they contain provisions for the approximation of legislation relating only to trade-related matters, or go beyond trade legislation to include a broader range of economic policies.

Other categories and sub-categories that are designed in a way that enables estimation of the depth of policy cooperation are: rules of origin; rules on subsidies and state aid; countervailing duties; standards; and rules on state monopolies.

In order to provide an initial measure of the changing depth of policy cooperation over time in this sample of 69 RTAs, each of these categories/sub-categories is divided here into two levels, labelled for convenience shallow cooperation and deep cooperation. The dividing line in most cases corresponds to that used by WTO staff, who for many subcategories identified just two "levels." ${ }^{207}$ In some cases there are three or four discrete "levels" identified by WTO staff, and the binary division selected here is in terms of a natural or qualitative break point. ${ }^{208}$

Table 2 presents a frequency count of the number of RTAs containing the selected provisions corresponding to deep cooperation, categorized by whether the RTA was signed before 1990 or in the period 1990-1998. The table shows that the aggregate level of policy cooperation in RTAs signed between 1990-1998 was over six times higher than in pre-1990 RTAs. For only one of the categories (rules on state aid) is the total frequency higher in pre-1990 RTAs than 1990-1998 RTAs (and here the sample size is small).

An alternative measure is the average frequency of occurrence of the deep cooperation provisions per RTA. This again shows a large increase in the depth of policy cooperation, from an average frequency of 1.7 occurrences per RTA prior to 1990 , to 3.7 occurrences per RTA 1990-1998 (a 118 per cent increase).

\footnotetext{
${ }^{207}$ There were just two levels for the following categories: approximation of laws; countervailing duties; and whether there were provisions restricting policy flexibility with respect to standards, state monopolies, and state aids respectively.

208 "Deep" was defined as whether the authority of the "secretariat" was more than just procedural; and whether the dispute settlement mechanism offers an optional binding process.
} 
The results in Table 2 constitute evidence that appear to refute the hypothesis that trade liberalization leads to less politically integrated RTAs. RTAs in fact became more “politically integrated" in the period 1990-1998 compared to the decades prior to 1990 , when measured in terms of the concept of jurisdictional integration. This lends support for hypothesis 2 in Chapter 7.

Table 2: Increasing Depth of Jurisdictional Integration in RTAs

\begin{tabular}{|l|c|c|}
\hline \multicolumn{1}{|c|}{ Provision in RTA } & $\begin{array}{c}\text { No. of pre-1990 } \\
\text { RTAs } \\
\text { in which present }\end{array}$ & $\begin{array}{c}\text { No. of 1990-1998 } \\
\text { RTAs } \\
\text { in which present }\end{array}$ \\
\hline $\begin{array}{l}\text { Authority of RTA body: more than just } \\
\text { procedural }\end{array}$ & 10 & 42 \\
\hline $\begin{array}{l}\text { Dispute settlement: optional binding } \\
\text { process }\end{array}$ & 6 & 26 \\
\hline $\begin{array}{l}\text { Approximation of laws: beyond just trade- } \\
\text { related }\end{array}$ & 1 & 42 \\
\hline $\begin{array}{l}\text { Countervailing duties: only after } \\
\text { consultations/referral }\end{array}$ & 4 & 20 \\
\hline $\begin{array}{l}\text { Standards: provisions covering TBT and } \\
\text { SPS 209 }\end{array}$ & 1 & 44 \\
\hline $\begin{array}{l}\text { State monopolies: provisions to prevent } \\
\text { discrimination }\end{array}$ & 5 & 40 \\
\hline $\begin{array}{l}\text { Rules of origin: bilateral and diagonal } \\
\text { cumulation }\end{array}$ & 3 & 3 \\
\hline $\begin{array}{l}\text { Rules of state aid: prohibition on export } \\
\text { subsidies }\end{array}$ & 5 & 224 \\
\hline Total & 35 & 3.7 \\
\hline Average frequency of occurrence per RTA & 1.7 & 42 \\
\hline
\end{tabular}

The results in Table 2, combined with WTO data on the growth in the number of RTAs, also provide limited support for the hypothesis that international economic policy cooperation is a complement to the increase in the number of countries (hypothesis 3 in Chapter 7). That is, there is a positive correlation between the number of countries and both the number and average depth of international economic cooperation agreements. ${ }^{210}$ The large growth in the number of RTAs in recent decades occurred at the same time as an increase in the number of countries, driven by decolonisation and the disintegration of the Soviet Union. There were 74 countries in 1948, 89 in 1950, and

\footnotetext{
${ }^{209}$ Technical Barriers to Trade, and Sanitary and Phytosanitary Measures.

${ }^{210}$ This is an extension of Alesina and Spolaore 2003.
} 
by 2001 the number had increased to $193 .{ }^{211}$ However, the limited nature of the WTO data on non-tariff provisions in RTAs - restricted to just two time periods (pre-1990 and 1990-1998) - does not provide a full test of the hypothesized relationship.

Unfortunately, WTO staff are not able to locate the detailed information that presumably underpinned the summary statistics contained in their 1998 inventory - such as the staff's ranking of non-tariff provisions in each individual $R T A .^{212}$ This would have enabled testing of further hypotheses in Chapter 7, through statistical analysis of the relationship between predictor variables and each participating country's level of jurisdictional integration. Nor is there, to the author's knowledge, any other existing dataset of the provisions of a substantial number of international economic agreements that would allow ranking countries or agreements by the depth of policy cooperation.

Therefore, to test additional hypotheses from Chapter 7, and to provide further evidence of the practicality and utility of the concept of jurisdictional integration, a new dataset is constructed by applying the concept of jurisdictional integration to international cooperation in competition policy. This is the subject of the next six chapters.

\footnotetext{
${ }^{211}$ Alesina and Spolaore, 2003, p. 197.

${ }^{212}$ Source: email communications with, and a meeting on 15 August 2006 at the WTO between the author and staff in the Regional Trade Agreements Section of the WTO (Jo-Ann Crawford and Roberto Fiorentino).
} 


\title{
Chapter 9
}

\section{AN OVERVIEW OF INTERNATIONAL COOPERATION IN COMPETITION POLICY}

\author{
“...negative externalities arise because at the same time that markets \\ become more internationalised market governance remains in the scope \\ of national competition authorities having limited territorial \\ jurisdiction."
}

Jenny, 2003.

\subsection{INTRODUCTION}

Competition (or anti-trust) policy is a good domain in which to measure levels of international cooperation. ${ }^{213}$ The number of international agreements has grown rapidly in the last two decades. This reflects both the rapid expansion in the number of countries that have domestic competition laws, and the need, in the face of increasing economic globalisation, to manage jurisdictional conflict and close gaps between territorially based regulatory regimes. The international agreements are of diverse types, including bilateral, regional, and multilateral instruments covering all the main dimensions of state jurisdiction. There is substantial variability in the depth of provisions in the agreements. Furthermore, the texts of the agreements are in the public domain and available to researchers.

\footnotetext{
${ }^{213}$ The term competition policy is used here in the narrow sense of competition law, or in US-parlance, anti-trust law. While the term is also used to refer to a broader set of policies that promote competitive markets - including trade policies and market de-regulation - the focus here is solely on generic, economy-wide laws that directly regulate the structure of markets and the behaviour of firms in the market.
} 
In the following six chapters, the concept of jurisdictional integration will be applied to international competition policy cooperation. In this chapter, a brief overview is presented of the spread of domestic competition laws, the practice of extra-territorial enforcement of domestic laws, and the evolution of international cooperation. The main international instruments are briefly outlined, and previous studies of international cooperation in competition policy summarised.

In Chapter 9, ordinal indices of the different dimensions of jurisdictional integration of competition policy are then derived. Chapter 10 sets out research questions and hypotheses specific to international competition policy cooperation, identified in the course of reviewing this literature, to be tested together with the general hypotheses of the causes of international economic policy cooperation in Chapter 7. They are tested using a dataset of international agreements compiled in Chapter 12. Selected agreements are then ranked on the jurisdictional integration indices, focusing in particular on agreements covering cooperation in enforcing competition laws. In Chapter 12, statistical analysis is conducted of the relationship between levels of enforcement jurisdictional integration (as the dependent variable), and predictor variables. Chapter 14 also considers the relationship between depth of jurisdictional integration and the form of bilateral agreement - specifically whether the level of jurisdictional integration is a good predictor of whether an agreement is a transgovernmental or an “intergovernmental” agreement.

\subsection{ECONOMIC GLOBALISATION AND UNILATERAL EXTRATERRITORIAL}

\section{ENFORCEMENT}

While laws regulating competition are many centuries old, the modern era of competition laws is regarded as commencing with the US Sherman Act in 1890, and the similar Canadian law that preceded it in $1889 .{ }^{214}$ It is perhaps surprising, however, that the expansion of such laws to other developed economies has been relatively recent. The United Kingdom only supplemented its long-standing reliance on the common law to regulate monopolies, with the passage of the Monopolies Act 1948 and the Restrictive Trade Practices Act 1956. At the signing of the Treaty of Rome in 1957, which introduced supranational competition policies and enforcement amongst the original six

\footnotetext{
${ }^{214}$ This and the next two sentences are based on Braithwaite and Drahos 2000, pp. 186-187.
} 
member countries of the European Community, most of the member states had no domestic competition law. ${ }^{215}$ In Germany's case, the existence of a national competition law was the result of pressure from the USA in the post-World War II reconstruction to promulgate laws regulating industrial concentrations (the same occurred in Japan).

By 1980 approximately thirty countries had domestic competition laws. There then followed a rapid expansion in the last two decades of the twentieth century, and by 2005 there were approximately one hundred countries that had such laws (around two-thirds of WTO members). ${ }^{216}$ For instance, starting in the early $1990 \mathrm{~s}$, all twelve members of the Commonwealth of Independent States (CIS) enacted competition laws as an important part of the transition to a market economy. ${ }^{217}$ Note, however, that there can be a lag of years between passage of a competition law and the establishment of the institutions to enforce it. ${ }^{218}$

In addition to increased international economic integration, other reasons for the spread of competition laws include an increased focus on the welfare benefits of competitive markets, economic transition following the end of the Cold War, privatisation and deregulation, regulatory competition between the US and the EC, the rapid growth in the number of RTAs, EU expansion, and pressure by the International Financial Institutions on borrowing countries.

It has long been recognised that anti-competitive activities that span national borders create problems for national competition authorities. Firms increasingly operate in multiple national markets, and are able to conduct anti-competitive activities in one country that have effects in another country. For instance, an international cartel, or a multinational firm indulging in anti-competitive practices, may operate from country A, and affect consumers in country B. ${ }^{219}$ Because the jurisdiction of competition authorities is territorially-based, the Competition Authority in country B cannot use its

\footnotetext{
${ }^{215}$ Jenny, 2005, p. 284.

${ }^{216}$ Bloom, 2005, p. 2, cited in Ewing, 2006, p. 1.

${ }^{217}$ Yacheivstova 2000, p.1.

${ }^{218}$ See Mehta, Agarwal and Singh 2007.

${ }^{219}$ Or a multinational enterprise may conduct business in multiple jurisdictions through legally distinct business units in each jurisdiction.
} 
investigative powers to obtain evidence in country A. And if the anti-competitive practice does not have an impact in country A, that country's Competition Authority lacks jurisdiction to investigate. ${ }^{220}$ Jenny has characterised the result as being one in which Competition Authorities are unable "to exercise their operational sovereignty."221

A further type of economic activity that creates difficulties for Competition Authorities is a merger involving firms from more than one country. The increasing volume and complexity of international mergers and acquisitions means that, in some cases, the same transaction needs to be notified in many countries, because it impacts on competition in many national markets. ${ }^{222}$ Multiple filings create the possibility that the same merger will be approved in one jurisdiction and prohibited in another. This may be for entirely legitimate reasons, reflecting the fact that the relevant market conditions are different in the two countries. However, it creates the potential for jurisdictional conflict, because one Competition Authority's decision to approve a merger can be undone by another Competition Authority's decision to prohibit it. Depending on the economic interests involved, suspicion may be aroused that one Competition Authority is "over-enforcing" its laws while another is "under-enforcing" its laws in order to protect the commercial interests of their respective national firms. The significance of this sort of tension was seen in the fall-out from the diverging views the US and EC competition authorities took to the merger of Boeing and McDonnell Douglas. ${ }^{223}$

Historically, the first response of Competition Authorities to foreign practices that impact on their domestic markets has been to try to extend their "jurisdictional reach" through extra-territorial enforcement of their domestic laws. The US led the way in this approach following the decision in the 1945 Alcoa case, through the development of the “effects doctrine." Braithwaite and Drahos assert that "antitrust has been the main

\footnotetext{
${ }^{220}$ The Competition Authority in country A may also lack the incentive to investigate its own firms (indeed in some cases governments have encouraged the formation of export cartels operating from their territory). See Jenny, 2003, pp. 611-613, on the US government's encouragement of an aluminium cartel in the 1990s; and the encouragement of the uranium cartel by a number of governments in the 1970s (Zanettin, 2002, pp. 35-36).

${ }^{221}$ Jenny 2003, p. 617.

${ }^{222}$ Zanettin 2002, p. 15 notes that: "In the late 1970s, the FTC [US Federal Trade Commission] reviewed only one transaction with an international dimension. By contrast, from 1987 to 1997, merger filings in the United States involving a foreign acquiring person or a foreign acquired one ranged from 15.5 per cent to 51 per cent. In 1999, there were no fewer than 849 such notifications..."

${ }^{223}$ See Taylor 206, p. 51.
} 
battleground of the post-war extraterritorial reach of US law..."224 In that case, the US Department of Justice prosecuted foreign companies involved in an aluminium cartel affecting the US market. ${ }^{225}$ The effects doctrine is based on subject matter jurisdiction being satisfied by the fact that the activities have substantial consequences in the country asserting jurisdiction, and personal jurisdiction being satisfied by the existence of some minimum level of contact between the foreign firm and that country. ${ }^{226}$

More recently, the EC has also taken enforcement action against foreign anticompetitive practices that are implemented within the EC. ${ }^{227}$ While states such as the United Kingdom and Canada were initially hostile to the effects doctrine as being contrary to international law, they too have subsequently acted to investigate practices conducted in other countries that have an effect on their domestic markets. Zanettin argues that the effects doctrine is now "widely, if not universally recognised as a legitimate extension of the jurisdictional scope of national competition laws."228 Braithwaite and Drahos, however, note that weaker states tend to be opposed to the effects doctrine, and have not attempted to take action extra-territorially. ${ }^{229}$

There are two main problems with extra-territorial action. First, it means that two or more states have jurisdiction over the same conduct or transaction. This is compounded by the fact that each state may well have different policies or attitudes towards the conduct or transaction. Inconsistent standards create the possibility that even though a number of Competition Authorities conclude that a transaction is not anticompetitive, a single jurisdiction with sufficient connection to the transaction can block it (Muris has termed this the "most restrictive enforcer" problem). ${ }^{230}$ In addition to creating an uncertain regulatory environment and additional transactions costs for firms, it has

\footnotetext{
${ }^{224}$ Braithwaite and Drahos 2000, p. 188

${ }^{225}$ US v Aluminium Co. of America 148 F2d 416 (1945).

${ }^{226}$ As noted by Zanettin 2002, pp. 9-10.

${ }^{227}$ Zanettin (p. 19) argues that the EU approach is widely regarded as a version of the effects doctrine, although the European Court of Justice uses a different rationale and terminology.

${ }^{228}$ Zanettin, p. 7. He argues this with respect to action to remedy foreign practices that affect domestic consumers, but considers it is much less true of action used to promote exporters' interests in market access cases (what Zanettin calls outbound extraterritoriality).

${ }^{229}$ Braithwaite and Drahos 2000, p. 188.

${ }^{230}$ Cited in Ewing, 2006, p. 27.
} 
resulted in a number of international disputes in which the "home" state has resisted (usually) US assertions of extra-territoriality. In some instances states have enacted blocking legislation to frustrate US anti-trust enforcement action in their country e.g. by preventing the discovery of documents by foreign authorities and the enforcement of foreign antitrust judgments by their national courts. Zanettin argues that, in recognition of the legitimate tensions involved, US courts and Competition Authorities have also at times exercised restraint in asserting extra-territorial jurisdiction. ${ }^{231}$

The second problem with extra-territorial enforcement is a practical one: the evidence required by a Competition Authority in such cases is typically located in another country, and it is also difficult to apply penalties to non-resident companies. Under international law, state jurisdiction to take enforcement action is strictly territorial. The Permanent Court of International Justice has stated that "the first and foremost restriction imposed by international law upon a state is that, failing the existence of permissive rule to the contrary, it may not exercise its power in any form in the territory of another state. ${ }^{232}$ Even those states having domestic legislation that enables the Competition Authority to serve notice abroad and to impose remedies abroad (such as the US and EC), are not able to compel compliance, which is a serious restriction on their ability to investigate anti-competitive conduct.

These inherent limitations on the unilateral assertion of extra-territorial jurisdiction have resulted in a long-standing interest in cooperative approaches to addressing transnational anti-competitive conduct.

\subsection{THE EVOLUTION OF INTERNATIONAL COOPERATION IN COMPETITION POLICY}

International cooperation in competition policy emerged in the second half of the twentieth century, although there were earlier unsuccessful attempts at cooperation. The deepest form of cooperation to date was also amongst the earliest, the competition policy provisions in the 1957 Treaty of Rome. The next important developments took place at a plurilateral level with a series of OECD Recommendations on Restrictive

\footnotetext{
${ }^{231}$ Zanettin 2002, pp. 12-13. Zanettin cites Picciotto, 1996, to the effect that “.... developing legal doctrine of "moderation and restraint" in the exercise of concurrent jurisdiction, originally developed in US case law, has received some international endorsement through the OECD."

${ }^{232}$ Lotus case, 7 November 1927, PCIJ Reports, Series A, no. 10, p. 18, cited in Zanettin 2002, p. 41.
} 
Business Practices, starting in 1967. Bilateral agreements providing for enforcement cooperation between Competition Authorities first emerged in 1959, grew in the 1980s, and then expanded rapidly in number from the 1990s, as did regional arrangements on competition in the context of the burgeoning growth of RTAs in the same decade. In the following paragraphs, the evolution of cooperation is briefly discussed through analysis by instrument type.

\subsubsection{Plurilateral and Multilateral Instruments ${ }^{233}$}

The first attempt at global regulation of Restrictive Business Practices was at the 1927 League of Nations Economic Conference. The US wanted action to break down cartels, but was unsuccessful due to opposition from European states. ${ }^{234}$ US interest in a multilateral approach to competition was again reflected during the negotiations in 1944 to establish an International Trade Organisation as the third Bretton Woods Institution. The initial US proposal was in fact for a very deep level of cooperation, providing for common international competition rules and an international organisation with authority to investigate cases and issue binding rulings. ${ }^{235}$ Opposition within the US led to a more modest set of proposals in the 1948 Havana Charter, but which involved obligatory international competition rules. Although ratified by over fifty countries, the Havana Charter was abandoned in 1950 principally due to the failure of the US Congress to ratify it. ${ }^{236}$ To date, there remains no binding multilateral instrument on competition policy.

The next important developments took place through the OECD and its Competition Law and Policy Committee, which is widely regarded as having played a critical role in

\footnotetext{
${ }^{233}$ Bilateral agreements generally involve just two states, but there are a small number of agreements between Competition Authorities from three or more countries, that are not in the same region, that are referred to as bilateral agreements in the literature because their content is the same as bilateral agreements. In addition, some bilateral agreements (and some RTAs) have a regional institution (such as the EC) as one of the parties. RTAs, on the other hand, are regional agreements on trade that may or may not contain competition provisions. RTAs may or may not be between countries in the same geographic region, and are between two or more countries. Plurilateral agreements involve a substantial number of countries spanning more than one geographic region e.g. the OECD Recommendations, and the APEC Principles on Competition. Finally, multilateral agreements are essentially global in scope, such as the WTO, and the agreements establishing the IMF, and the World Bank. In practice, the boundaries between these categories may be somewhat blurred, rather than hard and fast.

${ }^{234}$ Braithwaite and Drahos 2000, p.187.

${ }^{235}$ See Taylor 2006, pp. $151-153$.

${ }^{236}$ Havana Charter for an International Trade Organisation, UN Doc. E/Conf.2/78 (1948).
} 
the promotion of international cooperation in this field. Concerns about US extraterritorial enforcement, in a context of increasing economic integration, rekindled interest in the 1960s in international cooperation, culminating in the 1967 OECD Council Recommendation. ${ }^{237}$ This recommendation introduced the central concept of notification - that a member state should notify another member when enforcement action it is taking may impact on the important interests of the other state, and should take account of the views expressed by the other state. ${ }^{238}$ The Recommendation also called for basic case coordination and information sharing to the extent permitted by existing laws. Compliance with this and subsequent OECD Recommendations is voluntary.

A further Recommendation in 1973 added the important provision that where companies are engaging in Restrictive Business Practices that harm the interests of a state, that state should request consultations with other member states; and the state so addressed is recommended to take whatever remedial action it deems appropriate. The 1973 Recommendation also introduced an arbitration procedure involving an OECD Committee of Experts.

These two Recommendations were supplemented in 1986 by the addition of principles to guide when and how notification should take place, the ways in which information could be requested, and how the arbitration procedure should be implemented. ${ }^{239}$

A further Recommendation in 1995 added detailed articles on case coordination and assistance with case investigation. ${ }^{240}$ For instance, it provided for sharing information on investigation timetables, and factual and analytical information; and it provided for Competition Authorities to request the subjects of investigation to voluntarily permit information sharing, and coordination of discussions or negotiations on remedies. Two

\footnotetext{
${ }^{237}$ OECD Council Recommendation Concerning Cooperation between Member Countries on Restrictive Business Practices Affecting International Trade, 5 October 1967.

${ }^{238}$ Notification may also be with respect to requests for documents or attempts to obtain information from potential witnesses located in another jurisdiction.

${ }^{239}$ OECD Council Recommendation Concerning Cooperation between Member Countries on Restrictive Business Practices Affecting International Trade, C(86)44(Final). The main body of the 1986 Recommendation is identical to the 1967 and 1973 Recommendations, with the new guiding principles being added in an annex.

${ }^{240}$ Revised recommendation of the OECD Council concerning cooperation between member countries on anti-competitive practices affecting international trade (27-28 July 1995 (C(95)130/FINAL).
} 
deeper forms of cooperation were also covered. First, a member state may use its coercive powers to obtain information on behalf of another member. Secondly, it recommended that, when a member learns of an anticompetitive practice occurring in the territory of another state that could violate the laws of the latter, the former should consider informing the latter.

Finally, a 1998 Recommendation on Hard-Core Cartels encourages cooperation and comity specifically in respect of enforcement against cartels. ${ }^{241}$ The 1998

Recommendation provides that members should ensure that their competition laws provide effective sanctions against cartels, and improve international cooperation by positive comity. Positive comity and negative (or traditional) comity are key principles in international competition policy. In a 1999 OECD publication, negative comity was defined as "a country's consideration of how it may prevent its law enforcement actions from harming another country's important interests." Notification is an instance of negative comity. Positive comity, on the other hand, “....involves a country's consideration of another country's request that it open or expand a law enforcement proceeding in order to remedy conduct that is substantially and adversely affecting another country's interests." 242

Reflecting international concern in the 1970s over the activities of multi-national corporations, the main multilateral agreement to date on competition was enacted in 1980. Referred as the "UNCTAD Set", ${ }^{243}$ it recommends competition norms of a general nature to be applied by member states, and enforcement cooperation in the form of consultations and information exchange. It also established an Intergovernmental Group of Experts that has met every five years since to review implementation of the Set.

There has been no comprehensive agreement on competition within the GATT or WTO. The GATT did adopt a Resolution in 1960 recommending that each contracting party

\footnotetext{
${ }^{241}$ Recommendation of the OECD Council concerning effective action against hard-core cartels. There was a also a revised set of Guidelines for Multinational Enterprises adopted by OECD member governments in 2000, Section IX of which urges enterprises to refrain from specified anticompetitive activities.

${ }^{242}$ See OECD 1999.

${ }^{243}$ The full title is the Set of Multilaterally Agreed Equitable Principles and Rules for the Control of Restrictive Business Practices 1980, adopted by General Assembly resolution 35/63 of 5 December 1980.
} 
should, on request, enter bilateral negotiations on the harmful effects of any Restrictive Business Practices to which its residents were a party. ${ }^{244}$ However, the Resolution did not define Restrictive Business Practices, nor provide any basis for investigation or dispute resolution. Taylor concludes that the Resolution had little legal weight. It is in fact seldom referred to. ${ }^{245}$

Some limited competition provisions have been incorporated into the GATT/WTO system, particularly in the Uruguay Round that established the WTO e.g. in the General Agreement on Trade in Services, and the Agreement on Financial Services. ${ }^{246}$ However, the provisions apply to behaviour by governments rather than firms, and most apply only to limited sectors e.g. telecommunications. Taylor concludes that these "....are relatively ad hoc and limited in nature....There is no generic obligation [in the WTO] regulating cross-border anticompetitive conduct." 247

The Uruguay Round did, however, result in agreement that a WTO Working Party must consider whether the agreement on Trade Related Investment Measures should be complemented by an agreement on competition policy. ${ }^{248}$ Subsequently, competition policy was one of the so-called "Singapore issues", on which it was agreed to explore the possible modalities of an agreement in the current Doha Round of Multilateral Tariff Negotiations. A substantial amount of effort was devoted to this in a Working Group on the Interaction Between Trade and Competition Policy. Among the proposals by member governments was an agreement providing for commitment to a core set of broad principles (including transparency, non-discrimination, and due process); measures against hardcore cartels; modalities for voluntary cooperation on policy and enforcement; a commitment to technical assistance; and the establishment of a Standing

\footnotetext{
${ }^{244}$ The GATT Decision on Arrangements for Consultations on Restrictive Business Practices, 18 November 1960, now incorporated in GATT 1994. See UNCTAD 2003, p. 18.

${ }^{245}$ Taylor, 2006, pp. 156-158. Taylor does identify the Resolution as the first multilateral commitment to combat anticompetitive practices (as does Joelson, p. 559). Taylor notes that it was invoked by the US in the Fuji-Kodak Film Dispute in the 1980s. UNCTAD (2003, p. 16), on the other hand, describes the Set as the "sole universally applicable multilateral instrument in this area."

${ }^{246}$ Dumping, one of the Restrictive Business Practices targeted in the Havana Charter, was subjected to global regulation under the GATT 1967 Anti-Dumping Code (Braithwaite and Drahos, 2000, p. 188).

${ }^{247}$ Taylor 2006, pp. 159-163.

${ }^{248}$ Article 9, Trade Related Investment Measures, Annexe 1A: Multilateral Agreement on Trade in Goods, Final Act.
} 
WTO Committee on Competition Policy. ${ }^{249}$ However, a possible agreement on competition policy in the WTO was taken off the agenda following the Cancun Ministerial Meeting in 2003, with much of the opposition coming from developing countries that feared overly intrusive antitrust enforcement. ${ }^{250}$

In parallel with the post-Uruguay Round discussions on competition policy in the WTO, a less legalistic approach was initiated within APEC. This has focused on discussion and information exchange, a training programme, and the promulgation of non-binding APEC Principles to Enhance Competition Policy and Regulatory Reform. ${ }^{251}$ The Principles call for countries to introduce or maintain effective and transparent competition laws and enforcement.

Finally, an International Competition Network (ICN) was established in 2001. This is a network of Competition Authorities, not an international organisation or an international agreement. Its functions are to help build capacity amongst Competition Authorities through the exchange of information and experience, brokering of Technical Assistance, and development of non-binding good practice guidelines. By 2008 Competition Authorities from around 80 countries were members of the ICN. ${ }^{252}$

\subsubsection{Regional Trade Agreements}

An increasing number of RTAs contain a chapter on competition policy. The overriding motivation for this is to prevent the trade liberalization benefits of the RTA being eroded by anti-competitive behaviour. That is, the focus is on the trade-limiting effects of anti-competitive behaviour, rather than on the broader objectives of competition policy (competitive markets to promote consumer welfare). RTAs that incorporate competition policy focus mainly on policy cooperation although a number also contain provisions on enforcement cooperation (see Chapter 13).

\footnotetext{
${ }^{249}$ See Jenny 2003, pp. 621-623. There was a lack of support for requiring the exchange of confidential information, or compulsory positive comity. There was also debate over whether the WTO Dispute Settlement System should apply in some limited manner to competition, or whether instead a system of voluntary peer reviews might provide a less intrusive approach to compliance.

${ }^{250}$ Elhauge and Geradin 2007, pp. 1107-1108.

${ }^{251}$ The Principles can be found at http://www.apec.org/apec/leaders declarations/1999/attachment _apec.html

${ }^{252}$ See www.internationalcompetitionnetwork.org
} 
The treatment of competition in RTAs can be divided into two broad groups. First, the large majority of RTAs containing competition provisions provide for horizontal cooperation between national jurisdictions through a variety of forms. Secondly, a small number of RTAs give effect to vertical integration through the creation of supranational competition law and supranational enforcement institutions e.g. the EC, the EEA, WAEMU, and CARICOM. The competition provisions in RTAs are discussed in detail in Chapters 10 - 14.

\subsubsection{Stand-alone Competition Enforcement Agreements ${ }^{253}$}

In contrast to RTAs, these agreements only cover competition policy, and focus on cooperation in enforcing competition laws, not the substantive laws themselves. They are often referred to as bilateral agreements because many of them are between two parties. The first of these agreements dates from 1959, when the US Attorney General and the Canadian Minister of Justice agreed to some principles to guide cooperation between their antitrust agencies, including notification of enforcement action. ${ }^{254}$ Zanettin describes this as the forerunner to the first (1967) OECD Recommendation. Following a 1976 agreement between the US and Germany, there was a further gradual spread in the number of agreements in the 1980s, many still involving the US as one partner, before a very rapid growth in the 1990 s and the first decade of the $21^{\text {st }}$ century.

These competition enforcement agreements are heavily based on the concepts developed in OECD Recommendations, and draw explicitly on the structure, provisions, and language in the Recommendations - although the 1991 and 1998 EC-US bilateral agreements went beyond what was in the Recommendations at that time.

As with competition chapters in RTAs, there is variety of provisions across the different agreements. Again, these agreements will be considered in detail in Chapters 10 - 14.

\footnotetext{
${ }^{253}$ Agreements specifically on competition policy were preceded by Friendship, Commerce and Navigation (FCN) Treaties between the USA and a number of other countries containing provisions relating to competition policy enforcement e.g. the 1954 FCN Treaty between the US and Germany provided that each would consult on request over Restrictive Business Practices. "However, it is now many years since FCN Treaties were signed between the US and other countries." UNCTAD, 2003, p. 10.

${ }^{254}$ Zanettin, 2002, FN 3, p. 53.
} 


\subsubsection{Other Instruments of International Cooperation}

A small number of countries have enacted general domestic legislation authorizing the exchange of confidential information in international antitrust enforcement cases. For instance, the US International Antitrust Enforcement Assistance Act 1994 (IAEAA), which allows the US competition authorities to sign reciprocal international agreements authorizing the sharing of private sector confidential information, but only where the US is confident of the other party's ability to maintain confidentiality. Taylor suggests that the stringency of the confidentiality protection provisions is in part responsible for their being only one agreement to date under the IAEAA, the 1999 Agreement with Australia. ${ }^{255}$ Australia has amended its domestic laws to allow the sharing of confidential information, as have Denmark, Iceland and Norway. ${ }^{256}$ New Zealand introduced legislation to Parliament in September 2008 to enable sharing of confidential information (see Chapter 9.4 for further discussion).

There are also Mutual Legal Assistance Treaties, which provide for cooperation between states in the investigation and prosecution of criminal offences. Following a request from one central executive authority e.g. a Minister of Justice to their counterpart, the judiciary is asked to provide assistance through the use of coercive instruments such as subpoenas and search warrants. However, in the majority of states with competition laws, offences are treated as civil rather than criminal offences. A Mutual Legal Assistance Treaty cannot be invoked by such states. Furthermore, very few Mutual Legal Assistance Treaties explicitly cover competition policy (those that do include Canada-US 1985, and UK-US since an amendment in 2001), ${ }^{257}$ while some explicitly exclude competition policy. In general, Mutual Legal Assistance Treaties are motivated by objectives other than competition policy enforcement. While they have proved very useful to a small number of Competition Authorities - especially in facilitating cooperation between the US and Canada - they are likely to be relevant to international cooperation in competition policy only in a limited number of cases.

A further instrument that may be used to facilitate international cooperation is letters of request (or letters rogatory). This is a request from one court to another, requesting the

\footnotetext{
255 Taylor, 2006, p. 115.

${ }^{256}$ On Australia, see Holmes et. al., undated, pp. 71 -73; on the Nordic countries, see Marsden 2005, p. 26 .

${ }^{257}$ See Holmes et. al. 2005, p. 69.
} 
performance of a judicial act, such as taking evidence or serving a subpoena. Like Mutual Legal Assistance Treaties, they are not specific to antitrust enforcement. Letters of request are honoured or not on the basis of international judicial comity, not on the basis of treaty. While they have on occasion been of practical use in international antitrust cases (mainly to the benefit of the US authorities), restrictions imposed by most nations on the assistance they will provide in response to a request mean the instrument has little value in facilitating international cooperation in antitrust enforcement. $^{258}$

Finally, the Hague Evidence Convention is also potentially relevant to international competition cooperation. This Convention covers letters of request. However, after a careful assessment of its possible application to antitrust cases, Zanettin concludes that it is “...wholly inadequate for international assistance in the field of antitrust enforcement.",259

\subsection{Previous Studies of InTERnATIONAL COMPETITION COOPERATION}

There is a considerable literature on international cooperation in competition policy, with agencies such as the OECD and UNCTAD in particular having devoted substantial resources to the field. The large increase in the number of international agreements has prompted growing interest in clearer identification of what they contain, as a precursor to studying their possible causes and effects.

To that end, various classifications have been produced of the competition provisions in international agreements. These taxonomies have, in the main, been produced to enable an initial "mapping" of the provisions in selected international agreements. Motivations include assessing the extent to which the agreements are compatible with each other, whether they are "WTO-plus", and the relationship between competition provisions and other provisions such as anti-dumping measures and subsidies. ${ }^{260}$ Empirical work in this area, in terms of measuring levels of cooperation and using this as an input to statistical analysis, is at an early stage.

\footnotetext{
${ }^{258}$ This paragraph is based on Zanettin, 2002, pp. $146-147$.

${ }^{259}$ Zanettin, 2002, p. 148.

${ }^{260}$ See for instance Hoekman 1998; Holmes et. al. 2005, and Teh, Prusa and Budetta 2007.
} 
This section will briefly describe existing taxonomies of competition provisions in international agreements, starting with those that apply to a single type of international agreement, and moving on to those that are intended to apply across two or more instruments.

Some observers have categorised Competition Enforcement Agreements into two broad types: soft cooperation, and hard cooperation, adopting a similar binary approach to that in the international law and international relations literatures (where the terms used are soft and hard international law). For instance, the OECD Global Forum on Competition defines soft cooperation as constituting information sharing that is confined to information not subject to confidentiality restrictions. ${ }^{261}$

A similar binary approach is adopted by observers who identify first and second generation agreements, the latter providing for the sharing of confidential information, and the use of compulsory powers to obtain evidence for another jurisdiction e.g. Schaub. ${ }^{262}$ Holmes et. al., on the other hand, define second-generation agreements both in terms of their substantive provisions (whether they contain "hard law" binding obligations) and whether the agreement was preceded by an earlier agreement. ${ }^{263}$

Zanettin identifies three generations of agreements. The first are what he calls soft cooperation, confining information exchange to publicly available information, and operating solely within the confines of existing law. ${ }^{264}$ Zanettin defines secondgeneration agreements as providing for positive comity, and for the exchange of confidential information via the courts as intermediary i.e. through letters of request or Mutual Legal Assistance Treaties. Third-generation agreements, on the other hand, provide for direct exchange of confidential information between Competition Authorities, using their own discovery instruments on behalf of a foreign agency, or

\footnotetext{
${ }^{261}$ OECD 2004, p. 70.

${ }^{262}$ Schaub 1998.

${ }^{263}$ Holmes et. al. undated, p. 10.

${ }^{264}$ Within first generation agreements, Zanettin identifies two distinct sub-types: "defensive agreements" such as those between Australia and the US in 1982 and Canada and the US in 1984, with provisions reflecting the preoccupation of Canada and especially Australia at that time with restricting US extraterritorial enforcement; and "weak cooperation" such as the limited provisions in the US-Germany agreement 1976.
} 
sharing the confidential information they have on file. He identifies the 1994 Cooperation and Coordination Agreement between the Australian and New Zealand Competition Authorities - since replaced by a 2007 Agreement which does not contain these features - as the first third generation Agreement, and the 1999 US-Australia Agreement as a further example.

The demise of the 1994 Australia-New Zealand Agreement is interesting because it illustrates the practical difficulties entailed in sharing confidential information. Experience with the 1994 Agreement was that the sharing of confidential information, including that obtained through the use of compulsory powers, had to be facilitated by legislative change. The New Zealand government introduced a Bill to Parliament in September 2008 (The Commerce Commission (International Cooperation and Fees Bill) which proposes to allow the Commerce Commission to use its statutory powers to provide investigative assistance to overseas competition regulators, and to share compulsorily acquired information with them, subject to certain conditions. The 2007 Cooperation Agreement between the Australian and New Zealand Competition Authorities provides for further protocols to be appended, and it is anticipated that, following passage of the Bill, a protocol to this effect will be added to the Agreement. ${ }^{265}$

In similar vein to Zanettin, Taylor identifies four distinct evolutionary phases of agreements over the past thirty years: "passive cooperation" agreements from 1976; "negative comity" agreements from 1988; "positive comity" agreements from 1995; and “extension of jurisdiction" agreements, which are rare (see Chapter 10.2 for a description of the arrangement between Australia and New Zealand). ${ }^{266}$

Three further single-instrument taxonomies of competition provisions, this time in RTAs, have been published by OECD 2006, Cernat 2005, and UNCTAD 2005. In OECD 2006, a taxonomy was created and applied to the competition provisions in 86 selected RTAs. ${ }^{267}$ The study did not attempt to cover all types of RTAs. While it included some deep regional integration agreements for reference purposes (such as CARICOM, WAEMU, and the Andean Community), it noted that: "the institutional and

\footnotetext{
${ }^{265}$ Source: email communication with Peter Taylor, General Counsel, New Zealand Commerce Commission, 29 September, 2008.

${ }^{266}$ Taylor 2006, p. 108.

${ }^{267}$ OECD 2006, p. 19.
} 
legal complexities of these organisations goes beyond the general categorization adopted here, and requires more detailed analysis." The taxonomy comprised three categories:

1. Adopting, maintaining and applying competition measures. This is a broad catchall category, picking up the presence of general provisions, with more specific cooperation provisions being captured under the following two categories.

2. Coordination and cooperation provisions. This covers the presence of a range of elements, including notification, information exchange, consultation, negative comity, and positive comity.

3. Provisions addressing anti-competitive behaviour. This covers the horizontal policy scope of the agreements, capturing the presence of provisions prohibiting specific types of anti-competitive conduct, general policy commitments such as transparency and non-discrimination, recourse to trade measures, and anti-dumping. It also covers dispute settlement (with three sub-categories: exclusion of competition policy from the Dispute Settlement Mechanism; consultation; and arbitration).

This OECD taxonomy creates a checklist of whether elements are present or absent in selected agreements. It does not provide a basis for measuring the depth of cooperation given the presence of an element. In general, no attempt is made to order the elements within the categories according to any particular metric. While the second category resembles enforcement jurisdictional integration, and the third contains elements of prescriptive jurisdictional integration, the latter also contains dispute resolution mechanisms, resulting in a category that lacks conceptual coherence. Sokol used a similar taxonomy in analysing the competition policy chapter provisions in Latin American RTAs (see Sokol 2007a).

A second taxonomy of competition provisions in RTAs was created by Cernat. Focusing on the linkages between trade, competition, and economic development, Cernat categorized RTAs containing competition provisions into three groups:

1. The trade dimension: whether the RTA is a bilateral FTA; a plurilateral FTA; a Customs Union; an EU Association Agreement; or a Common Market/Economic Union. 
2. The level of development of RTA members. Here Cernat recorded whether agreements were between developed countries (North-North agreements), or were South-South, North-South, East-East (between transition economies), East-North, or East-South agreements.

3. The competition dimension. The presence of key competition provisions, such as "general provisions against anti-competitive practices, adoption of national competition law requirements, harmonization of national competition rules, consultation provisions, comity principles, sectoral exemptions, dispute settlement and so on. ${ }^{, 268}$

Like the OECD taxonomy, Cernat's taxonomy is capable of measuring only the presence or absence of selected provisions, not the varying depth of cooperation.

The third taxonomy of competition provisions in RTAs is in a 2005 UNCTAD publication, which identifies a spectrum of provisions, from shallow obligations to deep obligations. The points on the spectrum, representing increasing depth, are:

- $\quad$ Best endeavours in cooperation.

- $\quad$ Legally binding cooperation.

- $\quad$ Positive and negative comity.

- Resort to dispute resolution.

- Supra-national authority acting on private entities.

- $\quad$ Limitations to trade remedies.

A diagram representing this spectrum, reproduced from UNCTAD 2005, is in Figure 4.

The UNCTAD spectrum appears to combine the different types of jurisdictional integration: integration of prescriptive and enforcement jurisdiction, and inter-state adjudication jurisdiction. This is because all these types are found to some extent in RTAs - although, as we shall see in Chapter 13, enforcement cooperation in RTAs is usually limited compared to that found in stand-alone Competition Enforcement Agreements.

\footnotetext{
${ }^{268}$ Cernat 2005, p. 15.
} 


\section{Shallow obligations}

\section{Deep obligations}

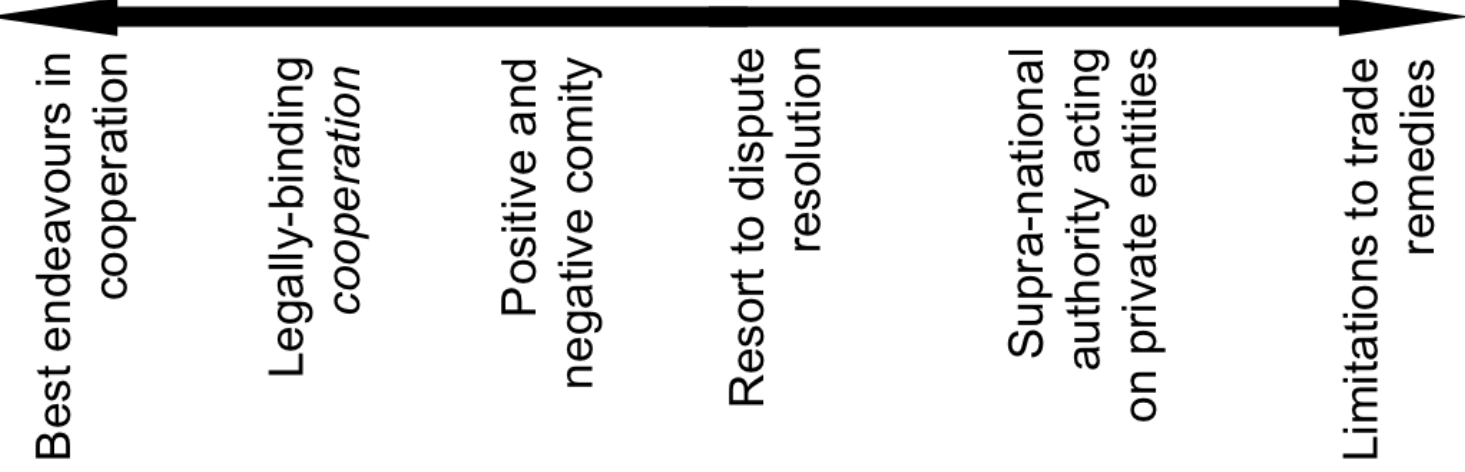

Illustrative only: actual positioning would depend upon specific wording in the agreement

From UNCTAD 2005, p. viii.

However, the UNCTAD spectrum is very limited in its coverage of policy cooperation, and does not differentiate between different types of dispute resolution. Furthermore, the ordering principle is not clear. Positive comity is regarded as significantly deeper than negative comity (as discussed in Chapter 10), and neither is legally binding. Dispute resolution provisions come in many forms, many of which are not legally binding. The placement of limitations to trade remedies at the deepest end of the spectrum seems to reflect a focus on trade policy, rather than a more general focus on the depth of cooperation. Limitations to trade remedies are hardly as intrusive of policy autonomy as EC-style supranational institutions involving majority voting on new competition laws, binding third party adjudication, or direct effect of the actions of supranational legislative or enforcement bodies in national legal systems.

The fourth taxonomy of competition provisions in RTAs is by Holmes et al. ${ }^{269}$ The authors usefully distinguish between competition-related provisions relating to policy harmonization, enforcement cooperation, and dispute settlement mechanisms. For each

${ }^{269}$ Holmes et. al. 2005, pp. 108-109. 
of these categories they classify sub-categories. Harmonization provisions are classified in three levels: no provisions; very loose harmonization; and firm/hard harmonization. Cooperation provisions are classified in two levels: soft but symmetrical rules providing for cooperation, including any procedures for consultations, notification, or comity at all; and asymmetric de facto obligation of the "junior" partner to cooperate, which essentially applies to EC candidate countries. Dispute settlement mechanisms are classified simply by whether there are any rules on dispute settlement mechanisms or not.

In each of the three categories, the sub-categories are arrayed in order of degree of intrusion on state autonomy - although the two enforcement cooperation levels mix de jure obligations and de facto obligations. The other two categories involve only two or three levels.

An alternative approach to classification is taken by studies that span more than one instrument-type. For instance, the International Competition Network Cartel's Working Group classifies cooperation between competition agencies in cartel investigations into the following categories:

- "informal co-operation (based inter alia on the 1995 OECD

Recommendation on Restrictive Business Practices);

- co-operation based on competition-specific provisions in agreements covering other subjects too (FTAs);

- co-operation based on competition-specific agreements between jurisdictions;

- $\quad$ "co-operation within the European Competition Network;

- $\quad$ co-operation based on waivers; ${ }^{270}$

- $\quad$ co-operation based on MLATs [Mutual Legal Assistance Treaties]; and

- co-operation based on letters rogatory." 271

This classification is based primarily on the type of instrument containing a provision on cooperation. It does not attempt to differentiate between similar types of cooperation

\footnotetext{
${ }^{270}$ This is presumed to refer to agreements to seek a waiver of confidentiality from the subject who provided confidential information, so as to enable the exchange of confidential information between Competition Authorities.

${ }^{271}$ International Competition Network, 2006, p. 32.
} 
irrespective of the instrument in which they appear, nor does it order cooperation activities within each type according to any metric.

A second multi-instrument study, in which the same classification is applied to the competition provisions in RTAs, stand-alone agreements, and Mutual Legal Assistance Treaties, is that by Holmes et al. ${ }^{272}$ The authors develop a series of questions covering policy cooperation, enforcement cooperation, and dispute resolution. In addition to horizontal scope, some questions explore depth of cooperation e.g. soft/hard law; substantive agreements on policy principles, or rules on specific Restrictive Business Practices or policy harmonization; and whether dispute resolution is of a binding character. The taxonomy is intended to enable completion of checklists of the presence/absence of features, as a starting point for research. The authors do not attempt to identify increasing levels of cooperation, and the checklist is in the form of a series of questions by topic rather than being classified into categories representing conceptually distinct cooperation types.

One attempt to apply a taxonomy on international competition cooperation across all instrument types is that in an earlier UNCTAD paper, which identifies three broad categories of international competition cooperation. ${ }^{273}$ The categories are:
A. Case-specific cooperation.
B. Substantive provisions.
C. Technical assistance and dispute avoidance or resolution.

The fourteen different elements the paper identifies under case-specific cooperation are not described as being arranged in any particular order. In some instances the ordering appears to be by depth of cooperation e.g. exchange of non-confidential information appears before exchange of confidential information; notification is listed first, supranational enforcement is listed $12^{\text {th }}$. In other instances, however, no particular ordering is apparent. For instance, the $13^{\text {th }}$ and $14^{\text {th }}$ elements are grounds for noncooperation, and preferential or differential treatment for developing countries, respectively; and coordination of merger notifications $\left(11^{\text {th }}\right)$ is listed after coordinated enforcement $\left(6^{\text {th }}\right)$. The latter would seem to be a more intrusive form of cooperation.

\footnotetext{
${ }^{272}$ Holmes et. al. undated.

${ }^{273}$ UNCTAD, 2003.
} 
The second broad category, substantive provisions, does appear to be ordered somewhat from less intrusive to more intrusive, running from having an effective competition law, through having laws proscribing specific identified Restrictive Business Practices, to alignment of rules, and finally to common regional rules. However, the final two categories are exclusions, and preferential treatment for developing countries, respectively, which do not fit the same ordering logic. Furthermore, some substantive policy provisions - such as transparency, due process, and non-discrimination - are included in category $\mathrm{C}$, raising the question of how category $\mathrm{B}$ is defined.

The final category - technical assistance and dispute resolution - is a curious mixture of policy rules, technical assistance, and elements relating to dispute resolution. While the three categories of dispute resolution provisions are related to the degree of intrusiveness (consultations; good offices/conciliation/mediation; arbitration or adjudication), this category lacks coherence.

In summary, this 2003 UNCTAD taxonomy is interesting in that it is intended to apply to competition provisions in all types of instruments. However, while the categories bear some resemblance to a prescriptive/ enforcement/adjudication jurisdiction split, and there is to some extent an ordering of elements according to degree of intrusiveness, ultimately the taxonomy resembles a simple list of provisions, organized into categories lacking in coherence.

Finally, Taylor sets out a continuum of approaches to the cross-border regulation of international competition, from non-cooperative to fully cooperative approaches. The points on Taylor's continuum are unilateral extra-territorial application; $1^{\text {st }}$ generation bilateral agreements; $2^{\text {nd }}$ generation bilateral agreements; regional plurilateral agreements; and finally, global multilateral agreements. Taylor's continuum is reproduced in Figure 5. 


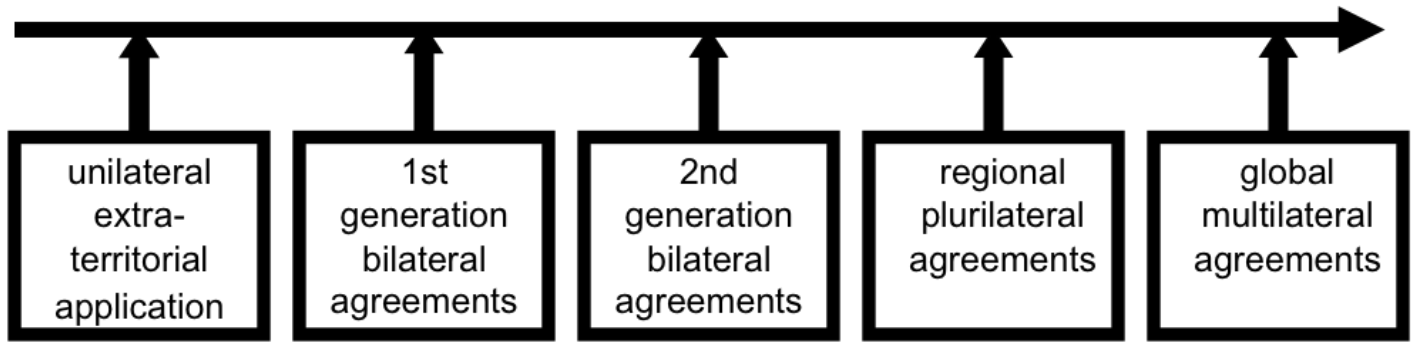

From Taylor 2006, p. 107.

While covering all instrument types, Taylor's continuum is based on the geographic scope of cooperation, not the depth of cooperation. The deepest competition cooperation agreements in existence to date are those regional agreements entailing vertical integration. The type of multilateral agreement that Taylor advocates is not as deep as this - and indeed it is extremely difficult to envisage a global agreement of the depth of the EC Competition Articles being feasible. Only in the sense of number of signatories, therefore, does a progression from bilateral, through regional to global multilateral agreements represent successively higher levels of international cooperation.

\subsection{CONCLUSIONS}

Existing taxonomies of competition provisions in international agreements suffer from a number of shortcomings as coherent measures of the depth of international cooperation - although it must be recognised that none of the taxonomies appear to have been developed with this purpose in mind. The shortcomings can be summarised as follows:

- Taxonomies relating to a single instrument, such as Zanettin's relating to enforcement cooperation in CEAs, are coherent within their scope. However, they do not attempt to cover the full spectrum of enforcement cooperation features, nor to incorporate the substantive policy and dispute resolution dimensions of international competition cooperation.

- The taxonomy developed in UNCTAD 2005 with respect to the depth of cooperation in RTAs does not contain a coherent ordering of elements by depth 
of cooperation. It is also very limited in its coverage of substantive policy cooperation, and does not differentiate between different types of dispute resolution.

- Taxonomies such as those developed in UNCTAD 2003 are intended to apply to cooperation across all instrument types. However, the categories of cooperation lack coherence, nor is there a coherent ordering of elements within each category.

- Taylor's continuum of cooperation types uses geographic scope as the unit of measure, not depth of cooperation.

- The taxonomies all leave out the vertical integration arrangements found in some RTAs. No taxonomy attempts to incorporate the full range of cooperation types, from shallow to deepest.

In a few cases, the taxonomies are used to provide an initial mapping of the territory, enabling checklists to be developed of the presence/absence of features. In a few cases, the extra step is taken of qualitative discussion of the range of provisions within each element (OECD 2006), and to identify broad "families" of agreements by comparing the checklists across all the elements (UNCTAD 2005, OECD 2006, Teh, Prusa and Budetta 2007).

As yet, the classifications have been used as the starting point for research, rather than to enable a more or less precise measurement of the depth of cooperation, for use in description and statistical analysis. The empirical literature is at an early stage. There is a range of approaches to classification, and a lack of quantitative measures of the depth of cooperation to enable measurement and statistical research.

In the next chapter, measures of jurisdictional integration in competition policy in each of the dimensions of state jurisdiction are developed. These ordinal indices are intended to provide coherent measures of the depth of international competition policy cooperation, for use in measurement and research. 


\section{MEASURING THE DEPTH OF INTERNATIONAL COOPERATION: INDICES OF JURISDICTIONAL INTEGRATION IN COMPETITION POLICY}

This chapter derives ordinal indices of the depth of international cooperation in competition policy. It does so through applying the concept of jurisdictional integration to competition policy cooperation, and classifying the elements of international agreements into different dimensions of state jurisdiction: the jurisdiction to make rules (prescriptive jurisdiction); jurisdiction to enforce rules through non-judicial and judicial action respectively (enforcement jurisdiction); and jurisdiction to adjudicate inter-state disputes.

The focus will be on international cooperation between Competition Authorities in enforcing competition laws. As a result of the influence of the OECD

Recommendations, and of key stand-alone Competition Enforcement Agreements (such as those between the US and the EC), there is a high degree of clarity around the concepts and terminology in this area, and a high degree of uniformity of substantive provisions across different international agreements containing provisions on enforcement cooperation. This facilitates the identification of discrete levels of jurisdictional integration and the reliable coding of agreements against the indices.

The index of enforcement jurisdictional integration derived in this chapter will then be used to rank the agreements in the dataset of international agreements compiled in Chapter 12. Summary measures are presented in Chapter 13 of the level of jurisdictional integration in those agreements, and the level of jurisdictional integration is used as a variable in statistical analysis in Chapter 14.

Ordinal indices are also developed of integration of prescriptive jurisdiction, and of inter-state adjudication jurisdiction with respect to competition policy. Selected 
international agreements are also ranked informally against these indices in Chapter 13, and a vector approach is used to identify and describe families of agreements.

\subsection{AN INDEX OF NON-JUDICIAL ENFORCEMENT COOPERATION IN COMPETITION} POLICY

Turning first to cooperation between Competition Authorities in enforcing competition laws, recall that the baseline against which jurisdictional integration is assessed is that of state autonomy, reflecting the fundamental international system norm of noninterference in the affairs of other states. For instance, as noted in Chapter 5, under international law a state's law enforcement officials may only exercise their functions in another state with the consent of the other state. ${ }^{274}$ Departures from this baseline occur through formal agreements between states or state agencies that introduce expectations, of increasing strength, that states will cooperate in enforcing competition laws. These expectations intrude progressively on de jure state autonomy.

Box 3 contains the index of non-judicial enforcement cooperation.

Level 1 on the index, informal cooperation, is the default in the absence of any formal agreement. A lot of cooperation occurs at this level between Competition Authorities, but it takes place outside any formal instrument (although it may be "in the shadow" of the OECD Recommendations on Restrictive Business Practices, or of the International Competition Network).

The second level on the index, cooperation short of notification, represents formal agreements to cooperate through discussing general enforcement issues or enforcement research, or exchanging experience, or engaging in technical cooperation, exchanging staff, or similar activities unrelated to individual cases. At its simplest, level 2 includes an agreement that provides no more than that the parties will cooperate with each other in enforcing their competition laws.

${ }^{274}$ American Law Institute, 1987, p. 329. 


\section{Box 3: The Index of Non-Judicial Enforcement Cooperation in Competition Policy}

Level 1: Informal cooperation: cooperation between Competition Authorities in the absence of any formal agreement between them.

Level 2:Cooperation short of notification: agreements to exchange views on general enforcement issues, to engage in technical cooperation, the development of model enforcement practices, and similar activities unrelated to individual cases.

Level 3: Basic notification: the existence of a basic agreement on the part of a Competition Authority that it should notify or inform another Competition Authority when some aspect of its competition policy enforcement activities may affect the other party's interests.

Level 4: Detailed mutual enforcement cooperation: in addition to a brief reference to notification of enforcement action (level 3), at least some specification of the circumstances surrounding when or how notification should take place e.g. circumstances in which notification would normally occur, its timing, the information to be provided; or assistance with gathering of voluntary evidence on behalf of a foreign Competition Authority, and with seeking waivers for the release of confidential information; or a reference to possible coordination of parallel investigations, with at least some fleshing out of what this might entail; or provision that one Authority will notify the other of information it is aware of concerning anti-competitive activities relevant to the other party's interests.

Level 5: Positive comity: the existence of a provision that an affected Competition Authority may request another Authority to open or expand an investigation, and an obligation that the requested Authority should (carefully) consider such a request.

Level 6: Advanced jurisdictional interface rules: in addition to basic positive comity (level 5), identification of the circumstances when an Authority requesting another to initiate an investigation may defer or suspend its own investigation in the meantime; or the use of compulsory powers to obtain evidence for a foreign Competition Authority; or sharing of confidential information without waiver; or an agreement to provide assistance whether or not the conduct being investigated is an offence under the laws of the requesting Authority.

Level 7: Third party enforcement (vertical integration): the establishment of a supra-national enforcement authority with jurisdiction of any kind to enforce area-wide laws on competition policy.

Level 2 also includes the development of "model enforcement practices", such as the "Framework for a Notification and Report Form for Concentrations" developed by the OECD Competition Committee in 1999 in an attempt to promote harmonization in trans-national merger notification requirements; and the Best Practices for the Formal Exchange of Information Between Competition Authorities in Hard Core Cartel Investigations, developed by the ICN.

Level 2 excludes cooperation on specific cases that are, or may come under investigation - with only a small number of limited exceptions, discussed in Box 9, that 
do not involve case notification. Case-specific cooperation is considered to represent a clear threshold in international enforcement cooperation.

For instance, Melamed (1999) discusses three levels of international regulatory cooperation in competition policy: exchange of ideas including technical assistance; case-specific cooperation, including detailed mutual enforcement cooperation; and agreed principles and positive comity. ${ }^{275}$ The inclusion of technical assistance in level 2 of the enforcement cooperation index, and basic notification starting at level 3 , is consistent with Melamed's approach. UNCTAD 2003 also separates technical assistance from case-specific cooperation. A 2002 WTO paper states: “...cooperation in a WTO setting would be essentially incremental in nature, and would be achieved in a step-by-step manner. The first phase of the exercise would be largely educational, concentrating on the development of enforcement capacity [technical cooperation]. The second phase would have as its primary feature the development and implementation of notification procedures....More meaningful steps towards enhancing international cooperation would be the coordination of enforcement actions against international cartels and the development of a common approach with respect to procedural issues in merger review."276

Level 3 on the index of non-judicial enforcement cooperation is basic notification. There is a bright line between agreements that provide in any way for notification of enforcement action, and those that do not. Basic notification may simply comprise a one-word reference in an agreement along the following lines: “...the parties shall cooperate, including through the exchange of information, notification..." It may also comprise just a sentence providing for notification when the enforcement actions of one Competition Authority may impact on the interests of another. Any provisions that go beyond the above and that set out any details with respect to how notification should operate would be at least level 4 on the index.

Level 4 comprises agreements providing for detailed mutual enforcement cooperation. In addition to basic notification (level 3), these agreements contain one or more of the following provisions:

\footnotetext{
${ }^{275}$ Melamed 1999, p. 424.

${ }^{276}$ See WTO 2002, p. 7.
} 
- Some specification of the circumstances surrounding when or how notification should take place e.g. circumstances in which notification would normally occur, or its timing, or the information to be provided.

- Assistance with gathering of voluntary evidence on behalf of a foreign Competition Authority.

- Seeking waivers for the release of confidential information.

- A reference to possible coordination of parallel investigations, with at least some fleshing out of what this might entail, such as the factors relevant to deciding whether to coordinate, or the modalities of coordination i.e. more than just a sentence saying the parties may coordinate enforcement activities which, because it is generally accompanied by a notification clause, would be level 3 .

Notification sometimes goes beyond the standard provision for notification of enforcement action by a Competition Authority that may affect the interests of another state, to include notification when one authority becomes aware that anticompetitive activities themselves are taking place that may affect the other party's interests. This could involve reporting conduct by firms resident in the notifying country, and an agreement containing this more active form of notification should therefore be regarded as level 4 (as argued for instance by Mathis, 2005).

Level 5, positive comity, represents another key international cooperation threshold. Positive comity refers to an agreement that a Competition Authority affected by anticompetitive conduct may request another Competition Authority to open or expand an investigation, and an obligation that the requested Authority should consider such a request. There is a bright line between negative or traditional comity, which is included in levels 3 or 4, and positive comity at level 5 (see for instance OECD 1999, Zanettin 2002, Mathis 2005). Traditional comity refers to a country considering avoiding taking an action because it may harm another country's interests, while positive comity entails a country being asked to take action it might not otherwise take.

At level 6 is a small number of more recent agreements that contain advanced jurisdictional interface rules. An agreement at this level will include one or more of the following:

- In addition to the basic positive comity clause, identification of the circumstances when an authority requesting another Competition Authority to 
initiate an investigation may defer or suspend its own investigation in the meantime. Taylor refers to this as "allocative positive comity.",277

- The use of compulsory powers to obtain evidence for a foreign Competition Authority.

- Sharing of confidential information without waiver for its release from those who provided it.

- An agreement to provide assistance whether or not the conduct being investigated is an offence under the laws of the requesting Authority. This amounts to using another jurisdiction's laws to attack conduct that is not covered by domestic laws.

In the recent literature these are viewed as clearly representing a deeper level of cooperation. For example, the new positive comity provisions introduced in the 1995 EC-US agreement are referred to as "advanced positive comity" by some, ${ }^{278}$ while a number of other analysts e.g. Taylor 2006, distinguish between "second generation" agreements and "third generation" agreements, the latter including sharing of confidential information, and the use of compulsory powers to obtain evidence.

From a slightly different perspective, Zanettin (2002) identifies agreements that provide for the exchange of confidential information directly between Competition Authorities i.e. not involving the courts through the use of Mutual Legal Assistance Treaties or letters of request, as being "third generation" agreements. He regards this as a deep form of cooperation because Competition Authorities have generally taken a very restrictive view of their authority to exchange non-public information on their files, even if the information is not explicitly confidential. An agency-to-agency agreement to this effect is likely to significantly increase the exchange of information, and to that extent increases expectations of cooperation. Any agreement providing for this type of cooperation is therefore also included at level 6 on the index.

Level 7 includes agreements that establish third party non-judicial enforcement (vertical integration). There is a clear threshold between the previous levels, entailing horizontal cooperation between country-level Competition Authorities, and agreements

\footnotetext{
${ }^{277}$ Taylor, 2006, p. 117. He contrasts this with "cooperative positive comity", in which the requesting agency may participate in the enforcement action.

${ }^{278}$ Holmes et. al. 2005, p. 60.
} 
that establish a supra-national Competition Authority to enforce competition law. This category includes distinct sub-categories, but because there are only a small number of agreements at this level, they are combined in one level on the index. Drawing on Jenny and Horna (2005), the following distinct types of vertical integration of enforcement jurisdiction can be identified, arranged below in order of increasing jurisdictional integration:

a. "Invited or negotiated jurisdiction:" where the regional enforcement authority may only exercise jurisdiction where it has been requested to do so by a member state or a firm with standing e.g. ANDEAN Group, or after a negotiated agreement has been reached with member state(s) e.g. in CARICOM.

b. Concurrent jurisdiction: where both the regional enforcement authority and member state enforcement authorities have jurisdiction e.g. the EC with respect to anti-competitive practices. This involves rules for allocating jurisdiction; provisions for the exchange of information; and the right of the EC Commission to pre-empt jurisdiction if it so wishes. ${ }^{279}$

c. Exclusive jurisdiction: where only the regional enforcement body has jurisdiction over regional rules e.g. the EC Commission with respect to merger control; the WAEMU Commission with respect to the WAEMU Treaty provisions on competition law.

d. "Delegated jurisdiction:" where enforcement of the regional competition laws is delegated down in some circumstances by the regional enforcement authority to the Competition Authorities of member states. The only example of delegated jurisdiction is the EC since the "Modernization Package" in Council Regulation 1/2003, creating the European Competition Network (ECN) with effect from May 2004. This includes provisions that compel member states to enforce EC law; to notify the EC Commission when they commence action; to provide investigatory assistance; and that provide for sharing of confidential information notwithstanding anything to the contrary in domestic law. The EC Commission can remove the delegation of competence.

Compared to the binary (soft/hard cooperation) distinction, and the taxonomies described in the previous chapter, this seven-level index attempts to provide a clear

\footnotetext{
${ }^{279}$ A further example of rules allocating jurisdiction, this time involving two RTAs, is found in the EEA, which has rules on when the EC Commission or the EFTA Surveillance Authority has jurisdiction in competition policy cases involving both jurisdictions.
} 
ordering of more or less distinct and increasing levels of enforcement cooperation. It also provides a comprehensive measure of the depth of enforcement cooperation across the two main types of international agreements e.g. stand-alone agreements and chapters in RTAs. The index is intended to allow more precise measurement, description, and statistical analysis of international competition policy enforcement cooperation applicable to whichever instruments such cooperation is contained in.

In terms of the international cooperation taxonomy developed in Chapter 6, levels 1-3 constitute simple cooperation, level 4 represents coordination, levels 5-6 constitute horizontal integration, and level 7 constitutes vertical integration.

\subsection{AN INDEX OF PRESCRIPTIVE JURISDICTIONAL INTEGRATION IN COMPETITION} POLICY

This index covers more or less discrete points of increasing restriction on state authority to make rules with respect to competition policy. Departures from a baseline of state autonomy are associated with progressive changes to the fora in which policy debates and decisions take place. Even an agreement to notify existing policies to another state or international organisation implies a subtle shift from complete state autonomy. At successively higher levels of integration, internationally-agreed principles may frame policy choices; domestic policies may be formally reviewed by international organisations; the introduction of new policies may be subject to prior notification; policies may be unified with those of another country; or, at the deepest level, a supranational institution may be authorized to promulgate binding rules.

Box 4 contains the index of prescriptive jurisdictional integration in competition policy.

Level one, general information exchange, covers the ad hoc or regular provision of information and/or discussion of current policy settings. A number of multilateral arrangements and instruments provide for general information exchange on current policies, including the OECD Global Forum on Competition, which provides for information exchange amongst both OECD members and non-members; and databases of competition policies and laws maintained by APEC and the Free Trade Agreement of 
the Americas. ${ }^{280}$ Some RTAs and CEAs also provide for the general exchange of information on current policies e.g. NZ-Singapore, EC-Mexico.

\section{Box 4: The Index of Prescriptive Jurisdictional Integration in Competition Policy}

Level 1: General information exchange: the ad hoc or regular provision of information and/or discussion of current policies.

Level 2: Common policy definitions: internationally greed definitions of key concepts, principles, and terms.

Level 3: Agreed policy guidelines or non-specific policy undertakings: broad policy undertakings e.g. to maintain laws proscribing anti-competitive activities; non-binding policy obligations, such as agreements on policy objectives, or policy principles; and non-binding multilateral guidelines.

Level 4: Institutionalised mechanisms to promote policy compatibility: a range of features, such as requirements to notify prospective policies, or regular consultations or standing bodies to discuss policies; peer review by multilateral organisations; resourcing an international organisation to produce a continuing stream of research and policy papers.

Level 5: Specific policy obligations: in addition to broad undertakings proscribing anticompetitive activities at level 3 above, a variety of further specific obligations, including obligations such as to provide national treatment and due process in competition policy, to enact a competition law by a specific date, or to ensure the independence of the Competition Authority.

Level 6: Policy convergence: obligations to progressively adopt the competition policy settings of another jurisdiction; or arrangements to align specific aspects of competition policy between jurisdictions.

Level 7: Policy unification: agreements that countries will adopt the same policies in some dimension(s) of competition policy.

Level 8: Single trans-national rule-maker: a trans-national body with the authority to promulgate new competition policies to apply in member states.

At level two are common policy definitions. These start to frame policy discourse, and the ways in which policy options are identified and assessed. Common definitions may cover concepts, terms, or classification systems, or put forward policy objectives or principles. For example, the UNCTAD Model Law on Competition, ${ }^{281}$ and the OECD Recommendations on Restrictive Business Practices define key terms in competition

\footnotetext{
${ }^{280}$ The APEC Competition Policy and Law Database, maintained by Chinese Taipei, at www.epeccp.org.tw/about.html; the SICE which is an inventory of international competition agreements in the region compiled as part of the negotiations toward a Free Trade Agreement of the Americas, at www.ftaa-alca.org/ngroups/NGCP/Publications/Treaty e.asp.

281 “Model Law on Competition", UNCTAD Series on Issues in Competition Law and Policy, United Nations, New York and Geneva, 2004.
} 
law and international cooperation (they also go beyond this, and are therefore referred to below in relation to subsequent levels of the index). The WTO Working Group on Competition worked on clarifying the core principles of transparency, nondiscrimination, and due process (which have since been incorporated in the Competition Policy Chapter some RTAs).

Level 3 comprises agreed policy guidelines, or non-specific policy undertakings. These include general non-specific policy undertakings, agreements on policy objectives, or commonly agreed policy principles; and non-binding multilateral guidelines on competition policy. The former are found in a number of RTAs, such as non-specific and brief obligations to enact or maintain laws that make anti-competitive acts illegal e.g. as found in a number of RTAs between countries of the Former Soviet Union. Multilateral guidelines include guidelines promulgated by multilateral institutions, such as the 1998 OECD Recommendation Concerning Effective Action Against Hard Core Cartels, the UNCTAD Set, the UNCTAD Model Law on Competition, and the APEC non-binding Principles on Competition Policy and Regulatory Reform. A further example is the International Competition Network's Eight Guiding Principles for Merger Notification and Review, which includes the principles of non-discrimination and procedural fairness. ${ }^{282}$

Level 4 comprises institutionalised mechanisms to promote policy compatibility. This covers a range of phenomena, such as:

- Requirements to notify prospective policies e.g. notification of designation of new monopolies in RTAs

- The provision of technical assistance to help with drafting competition laws

- Regular competition policy consultations established under RTAs or CEAs

- Standing bodies to discuss competition policies e.g. the Association or Cooperation Councils established in a number of RTAs between the EC and neighbouring countries; the Committees or other standing bodies on competition policy established in a number of RTAs, such as the Chile-Mexico Agreement; the OECD Competition Policy and Law Committee, the UNCTAD Intergovernmental Group of Experts on Competition Law and Policy, the WTO

\footnotetext{
282 See http://www.internationalcompetitionnetwork.org/media/library/conference 5th capetown_2006/Impleme ntationHandbookApril2006.pdf
} 
Working Group on Competition Policy, and the APEC Competition Policy and Deregulation Group

- Coordinated self-assessment by APEC members of the implementation of agreed competition policy principles

- Peer review of current competition policies e.g. as conducted by the OECD Competition Policy and Law Committee (since 1998), and the UNCTAD Intergovernmental Group of Experts on Competition Law and Policy.

At level 5 are specific policy obligations. This comprises a variety of more specific policy obligations found in RTAs going beyond the broad anti-competition provisions at level 2. Examples include providing national treatment and due process in competition policy; ensuring that state enterprises do not discriminate on the basis of nationality (in many RTAs involving the EC and neighbouring countries); enacting a competition law or establishing a Competition Authority (as in Article 12 of the Singapore-US RTA). The Competition Chapter of the 2005 EC-South Africa CEA provides that South Africa will develop competition laws within three years, publish laws within 60 days, provide the better of national treatment and Most Favoured Nation treatment, and provide the same treatment to the $\mathrm{EC}$ as it provides in any subsequent agreements.

Level 6 comprises policy convergence. This includes obligations to progressively adopt the competition laws of another jurisdiction, as found in a relatively small number of RTAs between the EC and neighbouring countries. ${ }^{283}$ In addition, policy convergence would include softer agreements to progressively align specific aspects of competition policy, such as has taken place between New Zealand and Australia. Under a 1998 Memorandum of Understanding, the two governments undertook to consult each other over changes to their competition regimes with a view to appropriate harmonization. ${ }^{284}$ Subsequently, the anti-dumping remedy was abolished on trans-Tasman trade, and in 1990 a "Trans-Tasman competition provision" was introduced into each national law. This established the concept of a "Trans-Tasman market" in respect of proscribed conduct by dominant firms i.e. the jurisdiction of each competition authority was

\footnotetext{
${ }^{283}$ See Holmes et. al. undated, pp. 89-101, for a description of some of these agreements.

${ }^{284}$ The 1998 Memorandum of Understanding on Harmonisation of Business Law.
} 
extended to take account of the effects of proscribed conduct on the combined Australian and New Zealand markets. ${ }^{285}$

Level 7 is policy unification, defined as the mutually agreed adoption of identical policies to that of another jurisdiction. ${ }^{286}$ For example, agreements in RTAs that countries will adopt a uniform set of competition policies, as found in a relatively small number of agreements such as the EC Treaty of Rome, the European Economic Area (between the EFTA states minus Switzerland, and the EC), the ANDEAN Group (following the adoption of Decision 285 of 1991), CARICOM (following the adoption of Protocol VIII in 2000), and bilateral agreements between the EC and candidate countries for EC accession. The EEA agreement could be described as providing for dynamic policy unification, in the sense that new EC competition laws, or secondary competition rules are legally binding as integrated into the EEA by decision of the EEA Joint Committee.

At level 8 is a single trans-national rule maker, that is, a trans-national body with the authority to promulgate new competition policies or rules to apply in member states upon adoption in domestic law. Such a supranational authority may also have the authority to introduce new rules on the basis of majority voting rather than unanimity, and/or whose rulings have direct effect in member states. While conceptually distinct and deeper forms of jurisdictional integration, they are included in level 8 because these features are found only in the EC.

This ranking of elements in order of increasing intrusion on national autonomy is consistent with a number of previous experts on international policy cooperation. For instance, Cooper (1987), as previously noted in Chapter 4.6, identified the following levels of international policy cooperation: exchange of information on existing policies; agreed common definitions; agreed norms and objectives; and exchange of information on prospective actions. The ordering of levels 1 - 4 in the index in Box 2 is consistent with Cooper's approach. Leebron's (1996) levels of harmonization of general policy objectives, of policy principles, of specific rules, and of institutional structures and procedures is consistent with the ordering of levels 3, 5, and 8 (see earlier discussion in

\footnotetext{
${ }^{285}$ See Bollard and Vautier 1998, pp. 143-155, on which this is drawn, for a fuller discussion.

${ }^{286}$ Note that this excludes unilateral adoption of the policies of another jurisdiction. Unilateral actions do not comprise jurisdictional integration as defined here.
} 
chapter 4.6). Similarly, Abbot et. al. 2000 identify the degree of precision of rules as a key dimension of the "legalization of international relations." More determinate rules with less room for interpretation are more legalised, and therefore impinge to a greater degree on state sovereignty. The same authors place non-binding norms and guidelines at an earlier point on their legalism spectrum than specific obligations and binding instruments. This is consistent with the ordering of levels 3 and 5.

This index is used in Chapter 13 to broadly rank the level of prescriptive jurisdictional integration found in RTAs, CEAs, and multilateral instruments.

In terms of the international cooperation taxonomy developed in Chapter 6, levels 1-2 constitute simple cooperation, levels 3-5 represent coordination, levels 6-7 constitute horizontal integration, and level 8 constitutes vertical integration.

\subsection{AN INDEX OF JUDICIAL ENFORCEMENT COOPERATION IN COMPETITION POLICY}

This is an ordinal index of increasing international intrusion on the autonomy of judicial authorities of a state in enforcing competition laws. A Competition Authority may undertake enforcement action within its jurisdiction, but may not be able to obtain evidence, enforce court orders, or enforce judgments against enterprises in another jurisdiction. In contrast to prescriptive jurisdiction - where international law allows a wide measure of discretion to states - the basis of enforcement jurisdiction in international law is strictly territorial, particularly where it involves the use of forcible restraint. $^{287}$

Box 5 contains the index of judicial enforcement cooperation in competition policy.

Level 1 on the index, judicial comity, is the informal regard courts have for the judicial processes of other countries. ${ }^{288}$ It is the default in the absence of any formal agreement. Jurisdictional disputes may arise as to which law should apply to a particular activity, and procedural disputes may arise due to differences between the evidential and procedural rules of different jurisdictions. The domestic court in which the case is

\footnotetext{
${ }^{287}$ As argued by Zanettin, 2002, p. 41.

${ }^{288}$ See Slaughter 2000, pp. 1112-1115 for a discussion of judicial comity.
} 
heard will attempt to resolve the dispute. ${ }^{289}$ A Court may also address a letter rogatory (or letter of request) to a court in another state requesting assistance e.g. to gather evidence. Compliance is voluntary.

\section{Box 5: The Index of Judicial Enforcement Cooperation in Competition Policy}

Level 1: Judicial comity

Level 2: Serve process, take evidence, and enforce foreign judgments in civil or commercial matters.

Level 3: Use of compulsory judicial powers to obtain evidence on behalf of another jurisdiction

Level 4: Procedural mutual recognition

Level 5: Overlapping jurisdiction

Level 6: Vertical integration of legal systems

At level 2 are formal international agreements to serve process, take evidence without compulsion, or to enforce foreign judgments in civil or commercial matters. A regional example is the Brussels Convention on Jurisdiction and Enforcement of Judgments in Civil Matters, while at the multilateral level, the Hague Service and Evidence Conventions fulfil some of these functions. While Zanettin has concluded that the Hague Evidence Convention is inadequate for international assistance in anti-trust enforcement, these conventions are included here for completeness, as they are at least potentially available for use.

At level 3 are agreements that provide an expectation that the judiciary will use compulsory powers to obtain evidence on behalf of another jurisdiction. Examples of this level of cooperation are found in the few Mutual Legal Assistance Treaties between states that cover competition policy. Under a Mutual Legal Assistance Treaty, the judiciary undertakes to use coercive instruments such as subpoenas and search warrants to obtain evidence on behalf of another state. As discussed in Chapter 9.3.4, limitations on the use of this instrument mean that it is relevant to international cooperation in competition policy between relatively few countries.

${ }^{289}$ The discussion in the last two sentences draws on Taylor, 2006, pp. 378-379. 
Level 4, procedural mutual recognition, comprises agreements in which two (or more) states agree to recognise the rules of evidence and the procedural rules of each other's courts with respect to competition policy. ${ }^{290}$ For example, Australia and New Zealand permit certain evidential rules and legal procedures to be recognised in each other's domestic courts for certain competition actions. ${ }^{291}$

Level 5, overlapping jurisdiction, refers to agreements that provide for the mutual extension of the jurisdiction of competition courts into the legal systems of signatories. For instance, in 1990 Australia and New Zealand amended their laws to allow courts to sit in each other's territories to hear specific competition cases. ${ }^{292}$

Level 6, vertical integration of legal systems, is found only in a small number of deep integration RTAs, such as the EC, EFTA, EEA, WAEMU, and the ANDEAN Group. These agreements provide standing to private parties, and direct effect of the rulings of regional judicial institutions in national law.

The levels in this index are consistent with Trachtman 1996, whose options to promote international cooperation range from less binding to more binding, and include rules of jurisdiction, rules of recognition of foreign regulations, and institutions that will adjudicatively conduct these tasks in future.

In terms of the international cooperation taxonomy developed in Chapter 6, levels 1-2 constitute simple cooperation, level 3 represents coordination, levels 4-5 constitute horizontal integration, and level 6 constitutes vertical integration.

\subsection{AN INDEX OF COOPERATION IN INTER-STATE ADJUDICATION IN COMPETITION} POLICY

The final category of jurisdiction relevant to international competition policy cooperation is the jurisdiction to adjudicate inter-state disputes. Recall that the default position under international law is that a state is immune from the jurisdiction of the courts of another state when it is acting governmentally. The index in Box 6 draws on

\footnotetext{
${ }^{290}$ Taylor, 2006, p. 381, uses the term procedural mutual recognition in this context.

${ }^{291}$ Taylor, 2006, p. 119.

${ }^{292}$ Bollard and Vautier 1998, p. 144.
} 
Smith's index of legalism in dispute settlement mechanisms in RTAs, although, unlike Smith's index, the index in Box 6 is confined to inter-state disputes.

\section{Box 6: An Index of International Cooperation in Adjudicating Inter-State Competition Policy Disputes}

Level 1: Consultations: but no right to third party review - as applies with respect to many competition chapters in RTAs e.g. those signed by the US and Canada, and in many standalone competition enforcement agreements.

Level 2: Conciliation or mediation: for example, there is a provision for OECD arbitration in some EU-Euro-Med agreements.

Level 3: Non-binding adjudication: a number of bilateral agreements involving the EC provide for arbitration of competition-related disputes if the political Council established under the RTA, comprising representatives from both parties, cannot reach agreement. ${ }^{293}$

Level 4: Binding adjudication: as in the WTO Dispute Settlement Mechanism. There are currently no international competition policy agreements containing this provision.

Level 5: A standing regional court: with jurisdiction in competition policy to rule on the legality of the actions of states. This is found in the deepest RTAs such as the EC, EFTA, and WAEMU.

In terms of the international cooperation taxonomy developed in Chapter 6, level 1 constitutes simple cooperation, levels 2-3 represent coordination, level 4 constitutes horizontal integration, and level 5 constitutes vertical integration.

\footnotetext{
${ }^{293}$ Holmes et. al. undated, pp. 35-36.
} 


\section{Chapter 11}

\section{RESEARCH QUESTIONS SPECIFIC TO INTERNATIONAL COMPETITION POLICY COOPERATION}

Chapter 7 set out a number of general hypotheses about the causes of international economic policy cooperation. The literature on international cooperation in competition policy reviewed in Chapter 9 points to a number of more specific propositions about the nature and causes of international cooperation in this domain. This chapter sets out these additional propositions in a systematic manner.

These competition policy-specific propositions have most often been derived from analysis of selected agreements, either of RTAs containing competition-related provisions e.g. Cernat 2005; Holmes et. al. 2005, or of selected stand-alone Competition Enforcement Agreement (CEAs) e.g. Zanettin 2002. In Chapter 12, a large dataset is compiled both of RTAs containing competition-related provisions, and of CEAs. While some previous studies have included a large number of RTAs with competition-related provisions, no previous study has included such a large number of CEAs, nor combined the competition-related provisions in RTAs and CEAs into a single dataset for statistical analysis. This expanded dataset provides a good opportunity to test the propositions on a more complete multi-instrument dataset. A combined dataset of RTAs and CEAs also suggests in some cases a modification of a hypothesis originally formulated with respect to RTAs only.

Competition policy-specific propositions advanced in the literature can be divided into descriptive propositions and hypotheses. 


\subsection{DESCRIPTIVE PROPOSITIONS}

1 The proportion of enforcement cooperation agreements (CEAs) that are between OECD member countries is declining. ${ }^{294}$

2 The "vast majority of bilateral agreements signed so far have the US as one of the parties." 295

3 RTAs with competition provisions signed by the EC focus on the adoption by partner countries of competition rules similar or identical to EC laws, but, with few exceptions, do not include detailed enforcement cooperation provisions. $^{296}$

4 Agreements signed by developed economies other than the EC mostly pursue enforcement cooperation rather than policy convergence. ${ }^{297}$

5 It is "virtually impossible" for developing countries to sign a CEA with developed countries, there are "only a handful.,"298

6 There are no "hard cooperation" agreements involving developing countries. $^{299}$

7 Comity principles are rarely found in RTAs. ${ }^{300}$

8 Some competition chapters in RTAs are as advanced, if not more advanced, in their provisions to foster cooperation between competition authorities on enforcement matters as second generation inter-agency agreements (CEAs) between competition authorities. ${ }^{301}$

\footnotetext{
${ }^{294}$ UNCTAD 2003, p. 7, which stated: "The concentration of cooperation agreements among OECD countries is not quite as heavy as before..., virtually all observers and invitee jurisdictions at the Global Forum which were active in competition policy had entered into cooperation agreements with one or more jurisdictions (often with those which were geographically close and or close trading partners).

${ }^{295}$ Zanettin 2002, p. 57. Similarly Braithwaite and Drahos 2000, p. 189, state that bilateral MOUs [CEAs] are mainly between the US and other states.

${ }^{296}$ Holmes et. al. 2005, p. 72.

${ }^{297}$ Holmes et. al. 2005, p. 73.

${ }^{298}$ Jenny 2003, p. 620

${ }^{299}$ Holmes et. al. 2005, p. 64.

${ }^{300}$ Cernat 2005, p. 28.

${ }^{301}$ This is a finding put forward by Anderson and Evenett on the basis of analysis of Competition-related provisions in 11 RTAs and some CEAs. See Anderson and Evenett, 2006, p. 28.
} 


\subsection{HYPOTHESES}

1 A high proportion of North-South RTAs that contain enforcement cooperation provisions, and a high proportion of North-South CEAs, are likely to provide only for shallow cooperation, while North-North agreements will on average be deeper. The term North in this context refers to developed countries, and South to developing countries. Cernat hypothesized that developing countries would seek to include provisions in RTAs with developed countries on enforcement cooperation ("for example consultation, notification, and so on") in an attempt to restrict anti-competitive practices by developed country firms in their markets. ${ }^{302}$ This same logic would apply to CEAs between developed countries and developing countries. Cernat found that approximately $80 \%$ of NorthSouth RTAs contain consultation provisions, and $38 \%$ contained notification provisions, while only $31 \%$ of North-North agreements contained notification provisions. However, many competition enforcement cooperation agreements are in the form of stand-alone agreements (CEAs) rather than in RTAs, and this is especially true of agreements between developed economies. Testing the hypothesis only on RTAs may therefore produce incorrect results. A priori, it seems unlikely that developed countries would sign up to meaningful reciprocal enforcement cooperation with less developed countries i.e. going beyond consultation, when many of the latter countries lack credible enforcement capacity, and some lack a Competition Authority or even a competition law altogether. Furthermore, developed countries lack the incentive to enter such agreements when the provisions are more likely to be invoked by less developed countries with respect to the activities of developed country firms in their markets, than vice versa (as argued by Jenny). ${ }^{303}$ While less developed countries might seek to include such provisions, as Cernat hypothesized, it is not clear how they might induce developed countries to agree to them. Therefore it is hypothesized that a high proportion of North-South RTAs and North-South CEAs that

\footnotetext{
${ }^{302}$ Cernat 2005, p. 13.

${ }^{303}$ Jenny, 2003, p. 614
} 
contain enforcement cooperation provisions are likely to provide only for shallow cooperation, while North-North agreements will on average be deeper.

2 Competition policy enforcement cooperation agreements, whether in RTAs or CEAs, will be deeper between countries that are party to a Customs Union or more advanced stage of economic integration agreement, and shallower where "only" a Free Trade Agreement is in place; but this relationship will have weakened over time. Cernat hypothesized that RTAs characterized by a higher level of (intended) trade integration are more likely to contain competition-related provisions, because, as the level of ambition of an RTA increases, the more serious are the potential negative effects of anti-competitive conduct. ${ }^{304}$ Puri went one step further and suggested: "The expected level of trade integration intended for an RTA tends to dictate the existence and depth of its competition provisions." ${ }^{\text {305 }}$ The same logic suggests that CEAs will be deeper where the parties are also party to an RTA that is a Customs Union or deeper agreement. However, as noted in Part Two and Chapter 7, the traditional sharp distinction between shallow FTAs and deep Customs Unions has broken down, with FTAs increasingly containing relatively deep policy cooperation. This suggests the hypothesized relationship will be less strong in more recent periods.

3 There is a positive relationship between the presence or depth of enforcement cooperation provisions, and the similarity of competition laws. It seems plausible, a priori, that enforcement officials will find it easier to cooperate where the legal regimes under which they operate are more similar e.g. where offences are similarly defined, where enforcement practices, particularly involving information sharing, are compatible - as suggested by Taylor. ${ }^{306}$ Jenny has commented that:"cooperation in specific cases can be successful only among countries which have relatively similar legal systems [and] common

\footnotetext{
${ }^{304}$ Cernat 2005, p. 10. Cernat tested this with respect to the existence of competition-related provisions, but not with respect to their depth.

${ }^{305}$ Puri, in UNCTAD 2005, p. x.

${ }^{306}$ Taylor 2006, pp. 121-122.
} 
economic experience and trust each other." ${ }^{, 307}$ An alternative perspective is put forward by Papadopoulos, who suggests that enforcement cooperation has been used as an alternative/substitute for harmonisation of national competition laws. ${ }^{308}$ While this suggestion is not strictly antithetical, because it may be referring only to cooperative convergence of laws from a low base, rather than a high degree of similarity, the implication is that enforcement cooperation and similarity of laws are inversely related.

4 Successful enforcement cooperation requires a progressive approach, such as starting with a simple cooperation agreement, and evolving more complex arrangements over time (drawing on UNCTAD 2003, p. 22) In similar vein, Cernat 2005 suggested that competition-related harmonization, policy transfer and convergence provisions contained in RTAs lead to increased cooperation among national competition agencies. While an assessment of the actual implementation of agreements is outside the scope of this thesis, it will be possible to examine how many instances there are of a cooperation agreement between two countries (whether in an RTA or a CEA) being replaced by a subsequent and deeper agreement. This would provide limited support for the hypothesis, on the basis that succeeding shallower with deeper enforcement cooperation agreements is more likely than not to be followed by more successful cooperation - because the subsequent agreement is itself evidence of goodwill, trust, and an expectation of an increase in cooperation, and/or due to the specific additional cooperation provisions it contains.

\footnotetext{
${ }^{307}$ Cited in Melamed 1999, p. 429.

${ }^{308}$ Cited in Holmes et. al. undated, FN 106.
} 


\section{Chapter 12}

\section{THE DATASET OF INTERNATIONAL COMPETITION POLICY AGREEMENTS}

\subsection{Datasets in PREVIOUS StUdies}

The objectives of this research are to measure the depth of international economic policy cooperation at a point in time, to measures changes over time, and to undertake exploratory analysis of some of the factors influencing state decisions over whether to sign shallow or deep cooperation agreements. The unit of analysis will be both the international agreement, and the country that is signatory to an agreement.

To test the hypotheses in Chapter 7, the ideal dataset would comprise:

- Data on the depth of international policy cooperation in a specific policy domain(s) or of a specific type, for all or most states in the world

- Within that policy domain, complete data on all forms of international policy cooperation e.g. bilateral, regional, or multilateral agreements, and whether embodied in government-to-government treaties, in agency-to-agency agreements, or in any other formal instrument.

- The dataset would be sufficiently large, detailed, and representative, that multiple levels of jurisdictional integration could be robustly specified and used in statistical analysis to test relationships for a large number of countries.

Unfortunately, currently available data falls far short of this ideal, for a number of reasons. First, and most importantly, there is no conceptually coherent basis for measuring the depth of international policy cooperation, which is an obvious obstacle to data collection.

For instance, the World Bank's Development Indicators includes a Chapter on "Globalization and Global Links," in which the Bank notes that: "The growth of crossborder economic activity has changed the structure of economies and the political and social organization of countries. Not all effects of globalization can be measured 
directly." 309 The Bank monitors the scope and pace of change along four important channels: trade in goods and services; financial flows; the movement of people; and the diffusion of technology and knowledge. No attempt is made to directly measure changes to the "political organization" of countries - for instance, the depth of their international policy commitments.

Policy and research in the field of international economic cooperation remains somewhat focused on the stages of economic integration e.g. Schiff 2000, Wu 2004, which is a combined measure of economic and policy integration, and, as discussed in Chapters 4.4 and 8 , is less and less useful as a proxy measure of the depth of policy cooperation. Many researchers record whether selected economic provisions are present or not in a sample of agreements, but not the varying depth of the provisions e.g. OECD 2006, Cernat 2005.

Alternatively, a widely known measure of a country's level of international policy cooperation - the A.T.Kearney/Foreign Policy measure of international political engagement - merely measures the number of selected Treaties signed, and membership of selected international organisations, irrespective of the varying depth of cooperation these engagements entail. ${ }^{310}$ The KOF Globalisation Index, and the Centre for the Study of Globalisation and Regionalisation's Globalisation Index take a similar approach. Each proxies the degree of political globalization by counting the number of foreign embassies in a country, the number of international organisations of which the country is a member, and the number of UN Peace Missions a country participated in. ${ }^{311}$

Secondly, international economic policy cooperation - even that confined to official cooperation - is effected by a large number of entities, using a wide range of instruments. There is typically no centralized repository of information on the extent of international policy cooperation, either within a single country across all agencies and policy domains, or - more importantly for current purposes - across countries by a single policy domain.

\footnotetext{
${ }^{309}$ World Bank 2007, p. 313.

${ }^{310}$ See the A.T.Kearney Globalization Index at http://www.atkearney.com/main.taf?p=5,4,1,127

${ }^{311}$ See http://globalization.kof.ethz.ch/; and http://www2.warwick.ac.uk/fac/soc/csgr/
} 
Thirdly, the increasing depth of policy integration within FTAs is a relatively recent (post-1990 or so) phenomenon, and data classification and research have not yet caught up with this. For instance, the WTO retains its primary, historical legal classification of RTAs as either FTAs or Customs Unions, making no distinctions within the increasingly large variety of FTAs.

For these reasons, cross-country quantitative research on international economic policy cooperation has focused on RTAs as the source of information. RTAs, along with the WTO agreement itself, are probably the single most important vehicle for international economic policy cooperation. There has been a large increase in the number of RTAs in the last ten years. This has been well documented. Crawford and Fiorentino identify the following key stylized facts: ${ }^{312}$

1 There was an unprecedented increase in the number of RTAs in the period 1995-2005, with 43 new RTAs being notified to the WTO between January 2004 and February 2005 alone.

2 As at February 2005, all but one WTO member (Mongolia) was party to at least one RTA.

3 RTAs are becoming increasingly complex, in many cases establishing regimes that go beyond WTO and other multilateral requirements.

4 An increasing number of RTAs are between developing and developed countries - so-called North-South agreements - with over half of these involving either the EC or EFTA as one party - and between developed countries (North-North).

5 An increasing number of RTAs are between non-contiguous countries, including cross-regional RTAs and RTAs where one of the parties is itself an RTA e.g. the EC, EFTA.

6 There is an increasing preponderance of FTAs compared to Customs Unions, and of bilateral compared to plurilateral agreements.

RTAs function as a coordinating and umbrella mechanism in a wide range of policy areas. More recent RTAs typically go well beyond trade issues to incorporate a range of provisions on behind the border issues such as investment, competition, domestic regulation, and so on. They therefore have some validity as a source of information on

\footnotetext{
${ }^{312}$ Crawford and Fiorentino 2005, pp. 1-6.
} 
signatory countries' depth of international economic policy cooperation. Box 7 describes the WTO's dataset on RTAs.

\section{Box 7: The WTO's Dataset on Regional Trade Agreements}

Member countries have been required to notify the GATT/WTO of RTAs that they enter, under Article XXIV, because RTAs constitute a sanctioned departure from the Most Favoured Nation principle in which trade concessions granted by one WTO member to another member must be available to all other member countries. The WTO maintains a database of notified RTAs in force. "RTAs in force" includes accessions by new members to existing agreements. It excludes agreements that have been superseded by more recent agreements between the same signatories, or that have been consolidated into wider groupings.

Historically, the focus has been on the distinction between an FTA and a Customs Union, reflecting the predominant focus of the GATT in reducing barriers to trade at the border. With the extension of the GATT to include trade in services, there has also been, since 1994, a requirement for members to notify the WTO of services agreements. A country entering a single RTA that covers both goods and services trade is required to lodge two separate notifications.

The WTO's main categorization of RTAs is according to whether the RTA is a Customs Union, a Free Trade Agreement (FTA), a Services Agreement - also referred to as an Economic Integration Agreement - or a Preferential Arrangement. A Preferential Arrangement is one involving the non-reciprocal exchange of obligations (typically between developed and developing countries).

In addition, RTAs in force are categorized by date of entry into force, and by which legal provision they were notified under e.g. GATT Article XXIV, the "Enabling Clause" - which applies to less developed countries, or GATS Article V for agreements covering trade in services.

Not all RTAs actually in operation have been notified to the WTO. For instance, as at January 2005,312 RTAs had been notified to the GATT/WTO - of which 170 were then in force - and WTO staff estimated there were a further 65 RTAs in operation, but not notified to the WTO. ${ }^{313}$ As at 1 March 2007 the WTO web site indicated there were 194 RTAs in force, comprising 114 FTAs and 7 Customs Unions notified under Article XXIV, 20 RTAs notified under the Enabling Clause, and 42 notified under GATS Article V.

Links to just over half of the notified RTAs in force are on the WTO web site.

However, RTAs by no means capture the full extent of any particular country's level of international economic policy cooperation - nor the full extent in any particular policy domain covered in the agreement. In the field of competition policy cooperation, as outlined in Chapter 9, a key instrument, in addition to RTAs, is the stand-alone Competition Enforcement Agreement (CEA).

${ }^{313}$ See Crawford and Fiorentino 2005, pp. 2-3. 
To fully measure the depth of competition policy cooperation by country, therefore, it is necessary to assemble a dataset across all of the instruments in which international cooperation is embodied. This is taken up in the remaining sections of this chapter.

\subsection{COMPETITION POLICY CHAPTERS IN RTAS}

RTAs are often long and complex documents, and until relatively recently there had been little attempt to systematically extract and compile information on the detailed provisions in them. However, the recent upsurge in the number of, and interest in, RTAs has started to result in the extraction and classification of detailed information on their provisions.

With respect to competition policy, there are two existing large-scale datasets on the competition-related provisions in RTAs:

1. A dataset compiled by the OECD comprising 86 selected RTAs, covering approximately 130 countries. ${ }^{314}$ The RTAs include those that were notified to the WTO from 2001 - July 2005. Some earlier agreements, as well as some non-notified agreements, were also included by reason of their competition provisions, their importance to trade, or because they involve groups of developing countries. Of the 86 agreements, 59 (68\%) are between developing or emerging countries, 23 (27\%) are between developed and developing countries, and only 4 (5\%) are between developed countries, reflecting the OECD's interest in this particular exercise in the development aspects of trade and competition. "Because there are more than 200 RTAs currently in force, the Table is not exhaustive. It is hoped nevertheless that the Table both covers the recent agreements and gives a fair sampling of the range of competition-related provisions in RTAs." 315

2. A dataset compiled by Cernat comprising 141 RTAs containing various competition-related provisions. ${ }^{316}$ The dataset was compiled from an analysis of more than 300 RTAs, drawing on the WTO database of notified

\footnotetext{
${ }^{314}$ OECD 2006.

${ }^{315}$ OECD 2006, p. 6.

${ }^{316}$ Cernat 2005.
} 
RTAs, supplemented with information from various sources on non-notified RTAs, as well as agreements between some non-WTO members. ${ }^{317}$

In addition, Sokol (Sokol 2007a) has compiled a dataset of 24 Latin American RTAs containing competition policy chapters.

There are a significant number of RTAs (43) in the OECD dataset that are not in the Cernat dataset. This means that the total number of RTAs containing competitionrelated provisions in these two datasets is 184 .

In order to retrieve the relevant texts of these RTAs, the Tuck Trade Agreements Database was used. ${ }^{318}$ This database claims to be the most comprehensive collation of bilateral and regional FTAs and Customs Unions available on a single online site. It claims to contain the text of all RTAs notified to the WTO up to June 1, 2003, plus many that have not been notified to the WTO. However, it also contains a number of post-2003 RTAs, including a number that contain competition-related provisions.

The database is text-searchable by keyword, or by seventy, indexed provision fields including a field for "rules of competition" - defined as "provisions dealing with national laws, regulations etc related to anti-trust, anti-monopoly, anti-predatory practices etc."

The search methodology adopted, using the text search facility, was as follows:

1. The database was searched by keyword "competition." This retrieved 192 RTAs. $^{319}$

2. For each of these RTAs, the search tool provided the text of every indexed provision field of the RTA that contained the word "competition." Not all of the references to competition were relevant to competition law. For example, there were many references to competition or unfair competition in the context of anti-dumping or

\footnotetext{
${ }^{317}$ Because EU enlargement led to the abrogation of a large number of RTAs with competition-related provisions signed by former Central and Eastern European countries prior to EU accession, Cernat's subsequent analysis was based only on those RTAs that were currently in force.

${ }^{318}$ www.dartmouth.edu/ $\sim$ tradedb/

${ }^{319}$ Web site last visited 26 March 2008.
} 
safeguards provisions, government procurement, state-owned enterprises, or intellectual property, or relating only to a specific sector such as telecommunications. RTAs that contained only these types of provisions were excluded from further consideration. Excluding competition-related provisions that relate only to a specific sector is warranted because the focus here is on international cooperation with respect to general, economy-wide competition laws - and more specifically, on cooperation between Competition Authorities in enforcing such laws. ${ }^{320}$

3. For RTAs in which the Competition Policy chapter covers both general competition/anti-trust law and other issues, such as state aid and dedicated monopolies (typical of US RTAs), or consumer protection or government procurement, only those provisions in the Sub-section on general competition law are incorporated.

4. Some agreements involved one party that is not a fully independent state i.e. a member of the UN. These agreements include 8 in which one signatory was the Faroe Islands, the Palestinian Authority, or the OCT (Overseas Countries and Territories of the EC). These were excluded, as the definition of jurisdictional integration in this thesis is confined to state-to-state cooperation.

5. The MERCSOUR Protocol of the Defence of Competition was excluded because it was not ratified. $^{321}$

6. For the purpose at hand, there is some duplication and redundancy in the 192 RTAs retrieved. For instance, in a small number of cases, both the English and original language version of an RTA were retrieved, or both the original and up-dated version of an RTA were retrieved. Only the English language versions, and the most recent agreements were included for further analysis.

\footnotetext{
${ }^{320}$ Although it should be noted that one or two competition policy chapters in RTAs limit some aspects of enforcement cooperation to specific sectors. For instance, Chapter 5 of the 2002 Implementing Agreement between Japan and Singapore unusually limits case notification and information exchange to the sectors of telecommunications, electricity and gas (Article 22). This agreement is included in the dataset.

${ }^{321}$ MERCOSUR is the Customs Union of the Southern Cone between Argentina, Brazil, Paraguay, and Uruguay.
} 
Some RTAs are not available on the Tuck web site, but were located on the WTO web site, on the web site of the Organisation of American States, or on the web site of the EC's Directorate General of Competition. ${ }^{322}$

Finally, the EC has entered a number of bilateral agreements with countries in its region that contain competition provisions. Not all of these agreements are on the WTO or Tuck web sites. These agreements are with candidates or potential candidates for EC membership, or with neighbouring countries in Euro-Mediterranean Agreements. These agreements are primarily confined to provisions on substantive policies. For instance, candidate countries must demonstrate that they have national competition laws reflecting the principles of EC law, have a national competition authority to implement these laws, and have a credible enforcement record. There is generally no requirement for international enforcement cooperation, although there are enforcement cooperation provisions in one or two Euro-Mediterranean agreements e.g. EC-Algeria 2002.

This search yielded information on the competition-related provisions in 174 RTAs. Analysis of these RTAs reveals that, while most of them are confined to provisions covering competition policy settings, a sub-set of them - nearly one quarter - contain provisions relating to enforcement cooperation. This will be elaborated in Chapter 13, but, because the focus of the statistical analysis will be on enforcement cooperation, the 41 RTAs providing for enforcement cooperation are identified in Table 3 . These will be combined with a dataset of Stand-alone Competition Enforcement Cooperation Agreements (CEAs) to produce a composite set of agreements providing for international enforcement cooperation (see 12.4 below).

Appendix 2 contains a list of the remaining 133 RTAs that contain competition provisions other than enforcement cooperation, again indicating which of these are in the OECD and Cernat datasets.

\footnotetext{
${ }^{322}$ http://www.wto.org/english/tratop_e/region_e/region_e.htm; http://www.sice.oas.org/tradee.asp; http://ec.europa/comm/competition/
} 
Table 3: The Dataset of RTAs Containing Enforcement Cooperation by Period

\begin{tabular}{|c|l|c|}
\hline Period & \multicolumn{1}{|c|}{ Agreements } & Total \\
\hline $1957-$ & EC 1958; EFTA 1960 & 2 \\
1989 & & \\
\hline $1990-$ & ANDEAN Community Decision 285 1991; EEA 1994; NAFTA 1994; & 4 \\
1994 & WAEMU 1994 & 5 \\
\hline $1995-$ & EC-Turkey 1996; Canada-Israel 1997; Canada-Chile 1997; Chile-Mexico & \\
1999 & 1999; CEMAC 1/99 & 18 \\
\hline $2000-$ & CARICOM Protocol VIII 2000; EC-Mexico 2000; Israel-Mexico 2000; \\
2004 & EC-South Africa 2000; EFTA-Mexico 2001; NZ-Singapore 2001; Japan- & \\
& Singapore- 2002; Canada-Costa Rica 2002; SACU 2002; Algeria-EC & \\
& 2002; Chile-EC 2003; EFTA-Singapore 2003; Australia-Singapore 2003; & \\
& Chile-EFTA 2004; Chile-Korea 2004; Chile-US 2004; Singapore-US & \\
\hline $2005-$ & Australia-US 2005; Japan-Mexico 2005; Australia-Thailand 2005; NZ- & 12 \\
2007 & Thailand 2005;Brunei-Chile-NZ-Singapore 2006; Korea-Singapore 2006; & \\
& Panama-Singapore 2006; EFTA-Korea 2006; EFTA-Lebanon 2006; & \\
\hline & Japan-Philippines 2006; Japan-Thailand 2007; Chile-Japan 2007 & 41 \\
\hline
\end{tabular}

\subsection{ENFORCEMENT COOPERATION AGREEMENTS BETWEEN COMPETITION}

\section{AUTHORITIES}

The only significant dataset of Competition Enforcement Agreements (CEAs) published to date is that compiled by Holmes et. al., who listed 22 agreements. ${ }^{323}$ These have been supplemented through targeted searches of the OECD, UNCTAD, and ICN web sites. ${ }^{324}$

In addition, two regional initiatives have compiled information on the RTAs and CEAs containing competition provisions signed by member countries, and these yielded copies of and/or references to further agreements:

1. The APEC Competition Policy and Law Database, which is maintained by Taiwan. ${ }^{325}$ One of the categories of information is "International and/or

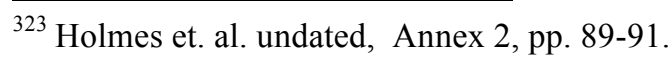

${ }^{324}$ See http://www.oecd.org/topic/0,3373,en_2649_37463_1_1_1_1_37463,00.html; http://www.unctad.org/Templates/StartPage.asp?intItemID=2239\&lang=1;www.internationalcompetition network.org.

${ }^{325}$ See Introduction to the APEC Competition Policy and Law Database, at www.epeccp.org.tw/about.html
} 
bilateral cooperation arrangements", including "agreements, arrangements, memoranda, letters of understanding, and other relevant documents."

2. A Free Trade Agreement of the Americas Inventory of Competition Agreements in the Americas, dated March 22, 2002, submitted by the OAS Trade Unit to the FTAA Negotiating Group on Competition Policies. ${ }^{326}$

In addition, publications describing competition policy in specific regions were drawn on. First were two publications by Yacheivstova (2000a, 2000b) on competition policy cooperation amongst members of the Commonwealth of Independent States. Secondly, a recent book by Dabbar on competition law in the Middle East concluded that: "A noticeable absence from the Middle East competition law scene is specific bilateral cooperation agreements. ${ }^{, 327}$ Dabbar states that Israel has only one bilateral agreement, the 1999 Agreement with the US, and that Turkey has no such agreements (p. 69 and 107). The dataset compiled in this chapter includes the US-Israel agreement, and it seems unlikely, therefore, that there are additional CEAs in the Middle East that have been omitted.

Finally, a search was conducted on the web sites of key node countries - the USA, EC, Canada, Japan, Mexico, Russia, Australia, Korea, and New Zealand - that yielded additional agreements.

A small number of agreements were located that were not available to the author in English. These are virtually all amongst members of the Commonwealth of Independent States, and include the 1993 CIS Treaty on the Implementation of a Coordinated Competition Policy, and the 1999 CIS Regulations on the Mechanism of Cooperation in Competition Policy. On the basis of descriptions in Yacheivstova 2000a and 2000b, the 1999 Regulations have been included in the dataset. The 1993 Treaty appears to be primarily concerned with rapprochement of antimonopoly laws, and it is not clear whether it extends to enforcement cooperation; it has not, therefore, been included.

With respect to bilateral agreements amongst CIS members, the APEC Competition Policy and Law Database, and the Russian Federal Antimonopoly Service refer to 21

\footnotetext{
${ }^{326}$ See www.ftaa-alca.org/ngroups/NGCP/Publications/Treaty_e.asp

${ }^{327}$ Dabbar, 2007, p. 316. Dabbar states that Israel has only one bilateral agreement, the 1999 Agreement with the US (p. 69), and that Turkey has no such agreements (p. 107).
} 
CEAs that Russia is party to, only 8 of which are available in English and have been included in the dataset. There are also a small number of other CEAs amongst CIS members referred to by Yacheivstova that are not part of this database. ${ }^{328}$

In compiling a composite dataset from all these sources, one of the issues is a lack of independence among agreements. In a number of instances, more than one agreement is listed between the same pair of signatories (e.g. EC-US, Canada-US, Australia-New Zealand). In nearly all cases, the later agreement supplements rather than replaces the earlier agreement, so both are included. In a small number of cases, however, this is not the case. Following Smith (2000), in order not to increase the lack of independence, agreements that have subsequently been superseded or encompassed by later agreements have been excluded. These include two agreements signed by New Zealand - the 1994 Australia-New Zealand agreement, and the 1997 New Zealand-Taiwan agreement - that have been explicitly replaced by later agreements. In addition, three agreements amongst countries that later joined the EC have also been omitted. These are the 1996 agreements between Estonia-Lithuania-Latvia; Latvia-Lithuania; and Lithuania-Poland. It is presumed that the cooperation these agreements provided for which was at level 3 and 4 - has been overtaken by these countries' membership of the European Competition Network and the much deeper level of cooperation this entails.

Finally, in a few cases, an RTA contains some basic references to competition enforcement cooperation, but details are contained in an Implementing Agreement promulgated at the same time e.g. the Economic Partnership Agreements between Japan and Mexico, and Japan and the Philippines. Only the Implementing Agreements have been included in the dataset.

The final dataset compiled for this research comprises a total of 51 CEAs. These are listed in Table 4, grouped by five year time period (with the exception of the initial period, which covers 1970-1989 due to the paucity of agreements prior to 1990). They are also listed in Table 5 at the end of this chapter, which indicates which of the CEAs was included in the Holmes et. al. dataset.

\footnotetext{
${ }^{328}$ Yacheivstova 2000b, p. 5.
} 
Table 4: The Dataset of Competition Enforcement Agreements by Period

\begin{tabular}{|c|c|c|}
\hline Period & Agreements & Total \\
\hline $\begin{array}{l}1970- \\
1989\end{array}$ & Germany-US 1976; Australia-US 1982 & 2 \\
\hline $\begin{array}{l}1990- \\
1994\end{array}$ & EC-US 1991 & 1 \\
\hline $\begin{array}{l}1995- \\
1999\end{array}$ & $\begin{array}{l}\text { Canada-US 1995; Australia-Taipei 1996; China-Russia 1996; Lithuania- } \\
\text { Ukraine 1996; Hungary-Russia 1997; EC-US 1998; Australia-US 1999; } \\
\text { Brazil-US 1999; Israel-US 1999; Japan-US 1999; Canada-EC 1999; } \\
\text { Australia-PNG 1999; China-Kazakhstan 1999; Korea-Russia 1999; CIS } \\
\text { Regulations } 1999\end{array}$ & 15 \\
\hline $\begin{array}{l}2000- \\
2004\end{array}$ & $\begin{array}{l}\text { Mexico-US 2000; Australia-Canada-NZ 2000; Canada-Mexico 2001; } \\
\text { Denmark-Iceland-Norway 2001; }{ }^{329} \text { Canada-Chile 2001; Brazil-Russia } \\
\text { 2001; Australia-Korea 2002; Australia-NZ-Taiwan 2002; }{ }^{330} \text { Australia-Fiji } \\
\text { 2002; ECA Mergers Guide 2002; Australia-NZ-UK 2003; Canada-UK } \\
\text { 2003; CIS-Korea-Latvia-Romania 2003; EC-Japan 2003; ECN (Reg } \\
\text { 1/2003); Mexico-Russia 2003; Bolivia-Russia 2003; Canada-US 2004; } \\
\text { France-Taiwan 2004; Korea-Mexico 2004; EC-Korea 2004; Russia- } \\
\text { Sweden 2004; China-EC 2004 }\end{array}$ & 23 \\
\hline $\begin{array}{l}2005- \\
2007\end{array}$ & $\begin{array}{l}\text { Canada-Japan 2005; Korea-Turkey 2005; Romania-Turkey 2005; } \\
\text { Australia-NZ 2006; Canada -Korea 2006; Albania-Greece 2006; } \\
\text { Armenia-Moldova 2007; Australia-New Zealand 2007; Mongolia-Taiwan } \\
\text { 2007; Portugal-Turkey 2008 }\end{array}$ & 10 \\
\hline & & 51 \\
\hline
\end{tabular}

\subsection{A BLENDED DATASET OF INTERNATIONAL COMPETITION ENFORCEMENT}

\section{AGREEMENTS}

In order to measure the depth of cooperation by country, in the presence of more than one relevant type of international agreement, it is necessary to aggregate across instruments. Therefore, a combined dataset has been produced of agreements providing for international cooperation in enforcing competition policies - a simple combination of the agreements listed in Tables 3 and 4 above.

A possible objection to combining enforcement cooperation provisions in RTAs with similar provisions in CEAs is the different status of RTAs and (some) CEAs in international law. For instance, Slaughter notes that there is a fundamental difference between intergovernmental cooperation - formal state-to-state Treaties that can create

\footnotetext{
${ }^{329}$ Sweden joined the agreement in 2004.

${ }^{330}$ Supersedes the 1997 NZ-Taipei agreement.
} 
binding obligations - and transgovernmental cooperation - agreements between government agencies rather than between states themselves. ${ }^{331}$ Slaughter states that agency-to-agency agreements have no formal recognition in international law. RTAs are clearly intergovernmental agreements. CEAs, on the other hand, may or may not be. While it might be assumed that a CEA is an agency-to-agency agreement, in fact - as discussed in Chapter 14 (section 14.7) when analyzing the relationship between depth of cooperation and the legal form of the agreement - a number of CEAs appear to be government-to-government agreements. Clearly, from this perspective, it is valid to combine these CEAs with RTAs in a single dataset.

Furthermore, in nearly all cases, the competition policy chapter of an RTA is specifically excluded from the dispute resolution provisions in that RTA. Even where this is not the case, such as in the EC-Turkey RTA, the positive comity clause in Article 43 states that nothing in that Article limits the discretion of the parties. ${ }^{332}$ Some agreements provide for consultations in the event of disputes, but no binding mechanism. Only in the deepest agreements providing for vertical integration, are the competition provisions subject to resolution through a regional court e.g. the EC, EFTA, and WAEMU. This renders the competition provisions in nearly all RTAs of a nonbinding character. No CEA contains these types of deep cooperation. There is also the fact that Competition Authorities, at least, appear to take CEAs more seriously than competition chapters in RTAs. ${ }^{333}$ This is likely due to the fact that Competition Authorities are actively involved in negotiating CEAs, and in many or all cases will have initiated the agreement. Competition chapters in RTAs, on the other hand, are typically negotiated by trade officials, and Competition Authorities may at times have little involvement.

Therefore, where enforcement cooperation in a CEA and in an RTA is described in similar terms, such as in a notification or a positive comity clause, it is valid to consider them to be an equivalent indication of the depth of cooperation. Both are typically soft-

\footnotetext{
${ }^{331}$ Slaughter 2004. International Competition Network 2006, p. 7, labels them as either "agency to agency agreements" or "jurisdiction to jurisdiction agreements."

${ }^{332}$ The Japan-Mexico Implementing Agreement on Competition states in Article 12.3: "Nothing in this Agreement shall be construed to prejudice the policy or legal position of either Party regarding any issue related to jurisdiction."

${ }^{333}$ See for instance International Competition Network 2006, p.15; and UNCTAD 2005, p. xvi.
} 
law, not hard law instruments. In recognition of the difference between soft and hard law instruments, in some of the statistical analysis in Chapter 14, level 7 agreements (as a proxy for hard law instruments) are both included and omitted to test the sensitivity of the results.

Turning to the dating of agreements, for CEAs the date of the agreement is taken from the date of signature, and for RTAs it is the date the agreement entered into force. The date of signature can typically be found in the text of each CEA. This is not the case for RTAs, and the most readily available data is entry into force e.g. as found on the WTO's web site. However, because CEAs generally enter into force on the date of signature, in practice the two treatments converge. For RTAs, the fact that there is generally a lag between date of signature and entry into force reflects the fact that in many countries RTAs can only enter into force following domestic legislative authorisation.

Mutual Legal Assistance Treaties have not been incorporated directly in this dataset. As discussed in Chapter 9, many countries do not have criminal sanctions for anticompetitive conduct, and few Mutual Legal Assistance Treaties explicitly cover competition policy. In general, Mutual Legal Assistance Treaties are motivated by broader criminal justice objectives rather than competition policy enforcement, and it is appropriate therefore not to incorporate them as a generic category in this dataset. A small number of RTA Competition Chapters briefly refer to cooperation by means of mutual legal assistance. ${ }^{334}$ However, it is not clear from the text whether there is a Mutual Legal Assistance Treaty in place between them, and these references have not influenced the rating of these agreements.

The 92 agreements are considered likely to comprise a high proportion of all the agreements in existence. For RTAs, the visibility of these instruments, and the existence of multiple databases that attempt to compile complete inventories, provides confidence that few RTAs containing provisions on competition enforcement cooperation are not included in this dataset.

The dataset of CEAs is not as complete. This is the first attempt the author is aware of to compile a complete inventory. As noted in the previous section, there are at least 13

${ }^{334}$ For example, NAFTA, Canada-Israel 1997, Canada-Chile 1997, and Chile-Mexico 1999. 
CEAs Russia is party to, and a small number of agreements involving other CIS members, that are omitted because the text is not available in English. However, because of the existence of regional inventories in Asia-Pacific and the Americas, of Competition Authority web sites, of the activities of the OECD, UNCTAD, and the ICN, and of a large literature on international competition policy cooperation, we can be reasonably confident that the dataset is fairly complete outside the CIS countries. It may not be unreasonable to suggest that the total number of RTAs and CEAs providing for competition enforcement cooperation is in the range of $125-150$. This would mean the sample compiled here represents $61 \%-74 \%$ of all agreements.

This dataset will be used in the next two chapters both to measure international cooperation in this domain, and to conduct statistical analysis of the relationship between depth of enforcement cooperation and predictor variables, in order to test the propositions and hypotheses set out in Chapters 7 and 11.

\subsection{MUlTILATERAL INSTRUMENTS}

As described in Chapter 9, there are a number of plurilateral and multilateral agreements and instruments providing for international cooperation in competition policy although there is no multilateral agreement imposing general obligations in competition law. The term multilateral is used here as shorthand, and includes plurilateral agreements signed by countries outside the context of an RTA (or CEA).

The multilateral instruments assembled here are not intended to be comprehensive, although they are intended to be representative of the complete set of such instruments. The purpose of including them is to provide a broad indication of the type and depth of cooperation they contain, and to allow a point of comparison with the depth of cooperation in RTAs and CEAs. More fine-grained analysis of these instruments is possible, but is left for a future exercise.

The multilateral instruments comprise:

1. Successive OECD Recommendations on Restrictive Business Practices and on Hard Core Cartels - specifically, the 1967, 1973, 1986, and 1995

Recommendations on Restrictive Business Practices, the 1998

Recommendation on Hard-Core Cartels, and the 2000 Guidelines for Multinational Enterprises. 
2. The UNCTAD Set.

3. The UNCTAD Model Competition Law.

4. The 1960 GATT Decision on Arrangements for Consultations on Restrictive Business Practices.

5. The OECD Competition Law and Policy Committee.

6. The OECD's "Competition Assessment Toolkit" which provides a general methodology for identifying unnecessary restraints and developing alternative, less restrictive policies that still achieve government objectives; and the APEC-OECD Integrated Checklist for self-assessment on competition (and regulatory and market openness) policies. ${ }^{335}$

7. OECD and UNCTAD peer review of competition policies.

8. The OECD Global Competition Forum.

9. The APEC non-binding Principles to Enhance Competition Policy and Regulatory Reform. ${ }^{336}$

10. The WTO Committee on Competition Policy.

11. Good Practice Guidelines promulgated by the International Competition Network, such as those relating to merger notification and review. ${ }^{337}$

In the next chapter, the competition-related provisions in RTAs and CEAs are ranked against the indices of jurisdictional integration with respect to competition policy described in Chapter 10. The focus is on measuring the depth of international cooperation in enforcing competition laws. In addition, some preliminary analysis is presented of the depth of integration of prescriptive jurisdiction in RTAs, and of the depth of the different dimensions of jurisdiction in multilateral instruments.

\footnotetext{
${ }^{335}$ The toolkit is at http://www.oecd.org/document/38/0,3343,en_2649 $40381664 \quad 39680550 \quad 1 \quad 1 \quad 1 \quad 37463,00 . h t m l$ The checklist is at APEC-OECD Integrated Checklist for self-assessment on regulatory, competition and market openness policies, to implement the APEC and OECD principles.

${ }^{336}$ See http://www.apec.org/apec/leaders_declarations/1999/attachment__ apec.html

${ }^{337}$ See

http://www.internationalcompetitionnetwork.org/media/library/conference_5th_capetown_2006/Impleme ntationHandbookApril2006.pdf
} 
Table 5: Comparison of Datasets of International Agreements Containing General Competition Law Provisions

\begin{tabular}{|c|c|c|c|c|}
\hline Agreement & Year $^{338}$ & $\begin{array}{c}\text { In } \\
\text { Holmes } \\
\text { et al } \\
\text { undated }\end{array}$ & $\begin{array}{l}\text { In OECD } \\
2006\end{array}$ & $\begin{array}{c}\text { In } \\
\text { Cernat } \\
2005\end{array}$ \\
\hline \multicolumn{5}{|l|}{$\begin{array}{c}\text { A. Competition Enforcement } \\
\text { Agreements }\end{array}$} \\
\hline Germany-US & 1976 & $\sqrt{ }$ & & \\
\hline Australia-US & 1982 & $\sqrt{ }$ & & \\
\hline EC-US & 1991 & $\sqrt{ }$ & & \\
\hline Canada-US & 1995 & $\sqrt{ }$ & & \\
\hline Australia-Taipei & 1996 & $\sqrt{ }$ & & \\
\hline China-Russia & 1996 & & & \\
\hline Lithuania-Ukraine & 1996 & & & \\
\hline Hungary-Russian Federation & 1997 & & & \\
\hline EC-US & 1998 & $\sqrt{ }$ & & \\
\hline Australia-US & 1999 & $\sqrt{ }$ & & \\
\hline Brazil-US & 1999 & $\sqrt{ }$ & & \\
\hline Israel-US & 1999 & $\sqrt{ }$ & & \\
\hline US-Japan & 1999 & $\sqrt{ }$ & & \\
\hline Canada-EC & 1999 & $\sqrt{ }$ & & \\
\hline Australia-Papua New Guinea & 1999 & $\sqrt{ }$ & & \\
\hline China-Kazakhstan & 1999 & & & \\
\hline Korea-Russia & 1999 & & & \\
\hline CIS Regulations & 1999 & & & \\
\hline Mexico-US & 2000 & & & \\
\hline Australia-Canada- NZ & 2000 & & & \\
\hline Canada-Mexico & 2001 & $\sqrt{ }$ & & \\
\hline Denmark-Iceland-Norway & 2001 & & & \\
\hline Canada-Chile & 2001 & $\sqrt{ }$ & & \\
\hline Brazil-Russia & 2001 & $\sqrt{ }$ & & \\
\hline Australia-Korea & 2002 & $\sqrt{ }$ & & \\
\hline Australia-NZ-Taiwan & 2002 & & & \\
\hline Australia-Fiji & 2002 & $\sqrt{ }$ & & \\
\hline ECA Mergers Guide & 2002 & & & \\
\hline Australia-NZ-UK & 2003 & & & \\
\hline Canada-UK & 2003 & $\sqrt{ }$ & & \\
\hline CIS-Korea-Latvia-Romania & 2003 & & & \\
\hline EC-Japan & 2003 & $\sqrt{ }$ & & \\
\hline $\begin{array}{l}\text { European Competition Network } \\
\text { (Regulation 1/2003) }\end{array}$ & 2003 & & & \\
\hline Mexico-Russian Federation & 2003 & & & \\
\hline Bolivia- Russian Federation & 2003 & & & \\
\hline Canada-US & 2004 & $\sqrt{ }$ & & \\
\hline France-Taiwan & 2004 & & & \\
\hline Korea -Mexico & 2004 & & & \\
\hline EC-Korea & 2004 & & & \\
\hline
\end{tabular}

\footnotetext{
${ }^{338}$ While CEAs are dated by their date of signature, for RTAs the date of entry into force is the more usual method of recording, and is more readily available e.g. on the WTO and Tuck web sites.
} 


\begin{tabular}{|c|c|c|c|c|}
\hline Agreement & Year & $\begin{array}{c}\text { In } \\
\text { Holmes } \\
\text { et al } \\
\text { undated }\end{array}$ & $\begin{array}{l}\text { In OECD } \\
2006\end{array}$ & $\begin{array}{l}\text { In } \\
\text { Cernat } \\
2005\end{array}$ \\
\hline Russian Federation-Sweden & 2004 & & & \\
\hline China-EC & 2004 & & & \\
\hline Canada -Japan & 2005 & & & \\
\hline Korea -Turkey & 2005 & $\sqrt{ }$ & & \\
\hline Romania-Turkey & 2005 & & & \\
\hline Australia-NZ & 2006 & & & \\
\hline Canada-Korea & 2006 & & & \\
\hline Albania-Greece & 2006 & & & \\
\hline Armenia-Moldova & 2007 & & & \\
\hline Australia-New Zealand & 2007 & & & \\
\hline Mongolia-Taiwan & 2007 & & & \\
\hline Portugal-Turkey & 2008 & & & \\
\hline $\begin{array}{c}\text { TOTAL Competition Enforcement } \\
\text { Agreements }\end{array}$ & 51 & $21^{339}$ & - & - \\
\hline $\begin{array}{l}\text { B. RTAs Containing Provisions on } \\
\text { Competition Enforcement } \\
\text { Cooperation }\end{array}$ & & & & \\
\hline $\mathrm{EC}$ & 1958 & & & $\sqrt{ }$ \\
\hline EFTA & 1960 & & $\sqrt{ }$ & \\
\hline $\begin{array}{l}\text { ANDEAN Group } \\
\text { (Decision 285) }\end{array}$ & 1991 & & $\sqrt{ }$ & $\sqrt{ }$ \\
\hline EEA & 1994 & & $\sqrt{ }$ & \\
\hline NAFTA & 1994 & & $\sqrt{ }$ & \\
\hline WAEMU & 1994 & & $\sqrt{ }$ & \\
\hline EC-Turkey & 1996 & & & $\sqrt{ }$ \\
\hline Canada-Israel & 1997 & & & \\
\hline Canada-Chile & 1997 & & $\sqrt{ }$ & \\
\hline Chile-Mexico & 1999 & & $\sqrt{ }$ & $\sqrt{ }$ \\
\hline CEMAC Reg. 1/99 & 1999 & & & \\
\hline CARICOM Protocol VIII & 2000 & & & $\sqrt{ }$ \\
\hline EC-Mexico & 2000 & & $\sqrt{ }$ & \\
\hline Israel-Mexico & 2000 & & $\sqrt{ }$ & $\sqrt{ }$ \\
\hline EC-South Africa & 2000 & & $\sqrt{ }$ & \\
\hline EFTA-Mexico & 2001 & & $\sqrt{ }$ & $\sqrt{ }$ \\
\hline NZ-Singapore & 2001 & & $\sqrt{ }$ & \\
\hline Japan-Singapore & 2002 & & $\sqrt{ }$ & $\sqrt{ }$ \\
\hline Canada-Costa Rica & 2002 & & $\sqrt{ }$ & $\sqrt{ }$ \\
\hline SACU & 2002 & & & $\sqrt{ }$ \\
\hline Algeria-EC & 2002 & & & $\sqrt{1}$ \\
\hline Chile-EC & 2003 & & $\sqrt{ }$ & \\
\hline EFTA-Singapore & 2003 & & $\sqrt{ }$ & $\sqrt{ }$ \\
\hline Australia-Singapore & 2003 & & $\sqrt{ }$ & $\sqrt{ }$ \\
\hline Chile-EFTA & 2004 & & & $\sqrt{ }$ \\
\hline Chile-Korea & 2004 & & $\sqrt{ }$ & $\sqrt{ }$ \\
\hline Chile-US & 2004 & & $\sqrt{ }$ & \\
\hline Singapore-US & 2004 & & $\sqrt{ }$ & $\sqrt{ }$ \\
\hline
\end{tabular}

339 The twenty-second agreement in Holmes et al, NZ-Taipei 1996, was replaced by the 2002 AustraliaNZ-Taiwan agreement. 


\begin{tabular}{|l|l|c|c|c|}
\hline \multicolumn{1}{|c|}{ Agreement } & Year & $\begin{array}{c}\text { In } \\
\text { Holmes } \\
\text { et al } \\
\text { undated }\end{array}$ & $\begin{array}{c}\text { In OECD } \\
\mathbf{2 0 0 6}\end{array}$ & $\begin{array}{c}\text { In } \\
\text { Cernat } \\
\mathbf{2 0 0 5}\end{array}$ \\
\hline COMESA Regs & 2004 & & & \\
\hline Australia-US & 2005 & & $\sqrt{ }$ & \\
\hline Japan-Mexico & 2005 & & $\sqrt{ }$ & $\sqrt{ }$ \\
\hline Australia-Thailand & 2005 & & $\sqrt{ }$ & \\
\hline NZ-Thailand & 2005 & & & \\
\hline Brunei-Chile-NZ-Singapore & 2006 & & $\sqrt{ }$ & \\
\hline Korea-Singapore & 2006 & & & \\
\hline Panama-Singapore & 2006 & & & \\
\hline EFTA-Korea & 2006 & & & \\
\hline Japan-Philippines & 2006 & & & \\
\hline EFTA-Lebanon & 2007 & & & \\
\hline Japan-Thailand & 2007 & & & \\
\hline Chile-Japan & 2007 & & & \\
\hline & & & & \\
\hline & 41 & & & \\
\hline $\begin{array}{l}\text { TOTAL CEAs and RTAs containing } \\
\text { provisions on Competition } \\
\text { Enforcement Cooperation }\end{array}$ & 92 & & & \\
\hline
\end{tabular}




\section{Chapter 13}

\section{MEASURING THE DEPTH OF INTERNATIONAL COOPERATION IN COMPETITION POLICY}

In this chapter, international competition policy cooperation agreements are ranked against the indices of jurisdictional integration derived in chapter 10. This allows the generation of summary descriptive statistics on the depth of policy cooperation in international competition policy.

The focus is on enforcement cooperation, utilizing the combined dataset of 92 CEAs and RTA Competition Policy Chapters compiled in Chapter 12. The texts of these 92 agreements are ranked on an index of enforcement cooperation.

In four instances, the texts of the agreements were unavailable in English, and publications by recognized competition policy experts were used to rate them. With respect to WAEMU, a detailed description of its provisions in Jenny and Horna 2005, which clearly indicates its vertically integrated character, was used to rate this agreement at level 7 on the index of enforcement cooperation. Similarly, for the 1999 CEMAC Regulations, and the 2004 COMESA Regulations on competition, the descriptions in UNCTAD 2008 of the competencies of the regional enforcement bodies indicates these are level 7 agreements. For the 1999 CIS Regulations, descriptions of their provisions in Yacheivstova (2000a, 2000b) were drawn on. In addition, through email communication with the author, Yacheivstova indicated that in her view the 1999 Regulations, while containing a clause resembling positive comity, fall short of OECDstyle positive comity, and the agreement should be rated at level 4 on the index - and it has been rated accordingly. ${ }^{340}$

Summary descriptive statistics are presented in this chapter, and the dataset is used to test the descriptive propositions concerning international competition policy

\footnotetext{
${ }^{340}$ Email communication with Nataliya Yacheivstova of 25 August 2008.
} 
cooperation that were identified in Chapter 11. In Chapter 14, statistical analysis is conducted using depth of enforcement cooperation primarily as the dependent variable to test selected hypotheses about the causes of international economic policy cooperation.

Limited measurements are also reported in this chapter of the depth of prescriptive jurisdictional integration in RTAs and CEAs, and the depth of cooperation in multilateral instruments, in order to illustrate how the concept of jurisdictional integration enables the identification and comparison of new "families" of agreements.

\subsection{RANKING AGREEMENTS BY DEPTH OF ENFORCEMENT COOPERATION}

Recall that Chapter 10 developed separate indices of non-judicial and judicial enforcement cooperation with respect to competition policy. Because in practice, the agreements are largely confined to non-judicial enforcement measures, for practical purposes it is easier to collapse the two indices into a single index of enforcement cooperation. The main examples of judicial enforcement cooperation are the RTAs that establish a regional court with jurisdiction in competition policy cases - these are included here in a redefined level 7 on the enforcement cooperation index. The blended enforcement cooperation index is reproduced in summary form in Box 8 .

\section{Box 8: The Index of International Enforcement Cooperation in Competition Policy}

Level 1: Informal cooperation

Level 2: Cooperation short of notification

Level 3: Basic notification

Level 4: Detailed mutual enforcement cooperation

Level 5: Positive comity

Level 6: Advanced jurisdictional interface rule.

Level 7: Third party enforcement (non-judicial and judicial)

As noted previously, the influence of the OECD Recommendations, and of key bilateral agreements, has resulted in a high degree of clarity around the concepts and terminology in this area, and a degree of uniformity across different international agreements. This 
facilitates the identification of discrete levels of jurisdictional integration, and the reliable coding of agreements against the indices. For instance, the concepts of notification, and of positive comity, are well defined, and there are standard clauses in many agreements that implement these forms of cooperation.

In addition, there is a consistent progression of cooperation provisions in these agreements. That is, in nearly all cases, agreements coded level 5 or 6 contain cooperation provisions from all the lower cooperation levels as well - such as notification (level 3) and case coordination (level 4). With one exception (the DenmarkIceland-Norway Agreement of 2001), all agreements in the dataset rated at level 6 contain a positive comity clause (level 5).

Nevertheless, as is inevitable when ranking a large number of examples on a single scale, there are instances where boundary issues arise and where some further clarification of category definitions is required. Box 9 contains some further notes on the coding of the 92 agreements. 


\section{Box 9: Notes on Coding Agreements by Depth of Enforcement Cooperation}

- In practice, a key cooperation threshold is a provision that one Competition Authority will notify another of enforcement action it is taking that may impact on the interests of the other Competition Authority (level 3). If an agreement does not provide for notification, it is coded level 2 - with just two exceptions, EC-Turkey and EC-South Africa, each of which contains a positive comity clause, and which are coded level 5.

- Most agreements at level 2 provide for forms of cooperation that are clearly not casespecific, such as technical cooperation, or sharing of information on laws and enforcement concepts. In a small number of cases, however, an agreement that is coded level 2 suggests a limited form of case cooperation - such as "exchanging investigation cases if possible" (China-Russia), or "exchanging experience in handling cases" (China-Kazakhstan, Korea-Russia, and Australia-Fiji). However, none of these agreements refers to notification, and they are therefore coded level 2.

- As noted in chapter 10, any agreement that goes beyond a one word or one sentence reference to notification of enforcement action, or to case coordination, and provides some details with respect to how or when notification or case coordination should occur, is coded at least at level 4.

- To be rated level 5 an agreement must contain the standard positive comity clause.

- A small number of agreements contain a three-word reference to "mutual legal assistance" e.g. NAFTA, and the Canada-Chile, Canada-Israel, and Chile-Mexico RTAs; or refer to the existence of an MLAT between the signatories e.g. AustraliaUS 2004. The references to mutual legal assistance have not influenced the ratings for the reasons discussed in Chapter 9.3.4.

- While the language in agreements varies, for example from "shall notify" or "will notify" to "may notify", these are regarded as representing a broadly similar level of obligation, given that virtually all these agreements are explicitly non-binding e.g. not subject to the dispute resolution provisions in the RTA.

- No agreements are rated at level 1, which by definition means the absence of any formal cooperation agreement. Level 1 may be useful for other research purposes, and is in the index for completeness.

- Provisions for non-discrimination in enforcing competition laws, or to establish or ensure the independence of a Competition Authority, are considered to be policy commitments (prescriptive jurisdictional integration), not enforcement cooperation.

\subsection{SUMMARY DESCRIPTIVE StATISTICS}

Figures 6 and 7 are relative frequency bar graphs of the two instrument types, showing the distribution of agreements across levels 2-7 on the index of enforcement jurisdictional integration (EJI). 

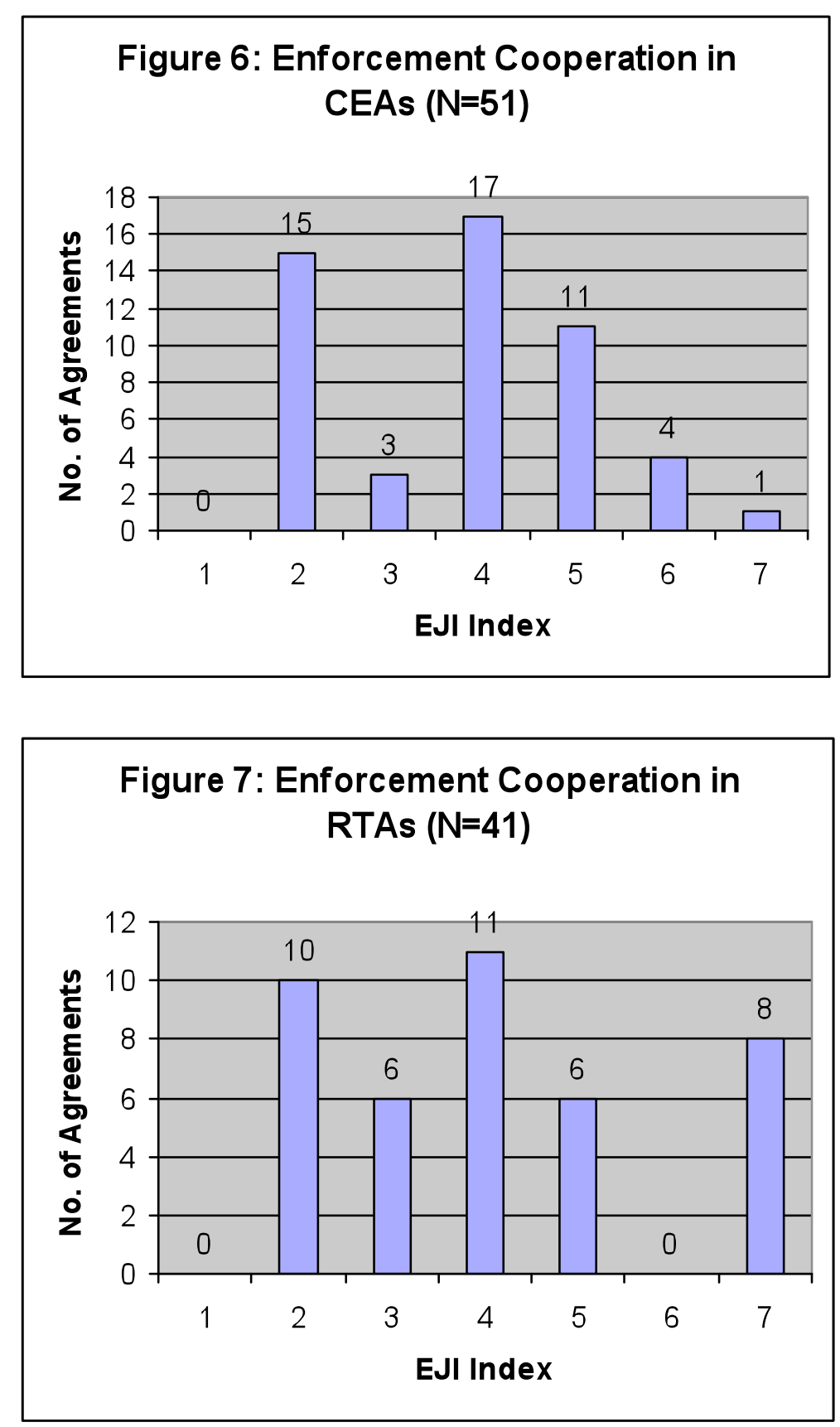

In each case, the mode of the distribution is level 4, the median is also level 4, and the range is the same (levels 2-7).

The distribution of CEAs is more peaked at level 4, however, and the right tails of the distributions are radically different. There are no RTAs at level 6, a level that entails deep cooperation between officials in national anti-trust agencies of a kind that is difficult to agree to in multi-sector negotiations led by trade and foreign affairs officials.

There are, however, 8 RTAs at level 7 (third party enforcement). This reflects the fact that these RTAs are intended to achieve particularly deep and broad economic 
integration. Concern that private impediments to trade may frustrate this objective led these governments to sacrifice significant formal autonomy in competition policy enforcement.

In practice, however, there was a lack of national enforcement capacity in common markets and economic unions at the time they were first negotiated. Even with respect to the EC, at the time of the Treaty of Rome most member states lacked a national competition authority (see Jenny 2005, p. 285). It remains the case today that, in the vertically integrated RTAs amongst developing countries, most of the member states lack competition authorities at the national level, and many also do not have a national competition law (Jenny 2005). Agreement to supranational law in these situations is not a substitute for national law, but fills a gap. As capacity in competition law enforcement is developed at the national level, the nature of the relationship between national and regional jurisdictions in these RTAs will need to be resolved.

Stand-alone agreements between Competition Authorities, however, are carefully negotiated within existing domestic legal mandates, and, with only one exception, do not entail third party enforcement. The one exception proves the rule: the European Competition Network, which is a competition-policy specific agreement between Competition Authorities and the EC Competition Directorate (and therefore classified here as a CEA rather than an RTA), is an extension of a prior level 7 RTA.

There is a variety of relationships between RTAs and CEAs, as follows: There are many instances where there is an RTA between two signatories that contains enforcement cooperation provisions, but no CEA between them.

- There are many instances where there is an RTA between two signatories that contains enforcement cooperation provisions, but no CEA between them.

- There are some instances where enforcement cooperation between two or more signatories is dealt with both in an RTA and a subsequent CEA e.g. EC Treaty of Rome and the ECN; the EEA 1994 and the 2002 European Competition Association Mergers Protocol; NAFTA and the three bilateral CEAs between the US, Canada, and Mexico; the 1997 Canada-Chile RTA and 2001 CEA.

- There are some instances where an RTA contains limited provisions on competition policy, but nothing on enforcement cooperation, leaving the latter to an Implementing Agreement e.g. Japan-Singapore, Japan-Thailand, Japan- 
Mexico, Japan-Philippines. The Implementing Agreements have been rated as RTAs rather than CEAs because they appear to have been negotiated in most cases at the same time as the RTA and they cover other policy domains as well.

- There are a number of instances where there is a CEA between two signatories, but no RTA e.g. eight of the CEAs are between G7 countries such as the US, Japan, and Canada, or between such countries and the EC, but there is only one RTA (NAFTA) involving these parties.

- For only one country pair, a CEA preceded an RTA containing competition enforcement provisions - the CEAs between the US and Australia of 1982 and 1999 preceded the 2004 RTA.

Table 6 displays all 92 agreements by type, by depth of enforcement cooperation (Enforcement Jurisdictional Integration, or EJI), and by whether or not the agreement was prior to the year 2000 .

The depth of enforcement cooperation in the aggregate, as measured by this index of jurisdictional integration, has increased over time. There are 63 agreements in the nine years from 2000-2008, whereas there were only 29 agreements in the entire period prior to 2000 i.e. since the 1957 Treaty of Rome, the earliest agreement in the dataset. CEAs are somewhat unevenly distributed across the two time periods - 18 CEAs pre-2000 and 33 in 2000-2008, an increase of $83 \%$. However, there was an increase of $173 \%$ in the number of RTAs containing competition enforcement provisions between the two periods (30 compared to 11 pre-2000), reflecting the large increase in the overall number of RTAs negotiated over the last decade (Crawford and Fiorentino 2005).

In terms of the average depth of agreements, there was a reduction in the later period. In the period prior to 2000, the median agreement was level 5 and the mode was level 4, while in 2000-2008 the median was level 4 and the mode was level 2. RTAs accounted for nearly all this change, reflecting in particular the large number of shallow FTAs in the most recent period, and to a lesser extent, the larger number of deep level 7 agreements in the earlier period.

However, while the average depth fell, there is a clear tendency for earlier agreements to be supplemented or replaced by deeper agreements between the same signatories. In every case except two, where an initial CEA or RTA chapter has been supplemented by 
Table 6: Competition Agreements by Type, Depth of Cooperation, and Year

\begin{tabular}{|c|c|c|}
\hline $\begin{array}{l}\text { Depth } \\
\text { of EJI }\end{array}$ & Competition Enforcement Agreements & RTA Chapters \\
\hline 2 & $\begin{array}{l}\text { Pre-2000: China-Russia; Hungary-Russia; } \\
\text { China-Kazakhstan; Korea-Russia } \\
\text { 2000 and later: Brazil-Russia; } \\
\text { CIS-Korea-Latvia-Romania; } \\
\text { Australia-Fiji; Mexico-Russia; } \\
\text { Bolivia-Russia; Russia-Sweden; } \\
\text { China-EC; Romania-Turkey; } \\
\text { Albania-Greece; } \\
\text { Mongolia-Taiwan; Portugal-Turkey }\end{array}$ & $\begin{array}{l}\text { 2000 and later: Australia-Singapore; } \\
\text { EFTA-Singapore; NZ-Singapore; } \\
\text { SACU; Korea-Singapore; } \\
\text { Singapore-US; Chile-Japan; } \\
\text { Panama-Singapore; } \\
\text { Japan-Philippines; EFTA-Lebanon }\end{array}$ \\
\hline 3 & $\begin{array}{l}\text { Pre-2000: Lithuania-Ukraine } \\
\mathbf{2 0 0 0} \text { and later: EC-Korea; } \\
\text { France-Taiwan; Korea-Turkey }\end{array}$ & $\begin{array}{l}\text { Pre-2000: US-Canada-Mexico } \\
\text { (NAFTA); Canada-Israel; Canada- } \\
\text { Chile } \\
2000 \text { and later: Australia-Thailand; } \\
\text { US-Chile; NZ-Thailand; } \\
\text { EFTA-Korea; Japan-Thailand }\end{array}$ \\
\hline 4 & $\begin{array}{l}\text { Pre-2000: Germany-US; Australia-US } \\
\text { 1982; Australia-Taipei; Australia-Papua } \\
\text { New Guinea; CIS Regs } \\
2000 \text { and later: Canada-Chile; Australia- } \\
\text { Korea; Australia-NZ-Taiwan; ECA } \\
\text { Mergers Guide; Canada-Korea; Australia- } \\
\text { NZ 2006; Canada-UK; Australia-Canada- } \\
\text { NZ; Australia-NZ-UK; Armenia- } \\
\text { Moldova; Australia-New Zealand }\end{array}$ & $\begin{array}{l}\text { Pre-2000: } \\
2000 \text { and later: Canada-Costa Rica; } \\
\text { Algeria-EC; Chile-EC; Chile-Korea; } \\
\text { EC-Mexico; Israel-Mexico; Brunei- } \\
\text { Chile-NZ-Singapore; Japan- } \\
\text { Singapore (implementing agreement) }\end{array}$ \\
\hline 5 & $\begin{array}{l}\text { Pre-2000: EC-US 1991; Canada-US } \\
\text { 1995; Brazil-US; Israel-US; Japan-US; } \\
\text { Canada-EC } \\
2000 \text { and later: Canada-Japan; EC-Japan; } \\
\text { Mexico-US; Canada-Mexico; Korea- } \\
\text { Mexico }\end{array}$ & $\begin{array}{l}\text { Pre-2000: EC-Turkey } \\
\text { 2000 and later: Australia-US; EC- } \\
\text { South Africa; Chile-EFTA; EFTA- } \\
\text { Mexico; Japan-Mexico }\end{array}$ \\
\hline 6 & $\begin{array}{l}\text { Pre-2000: EC-US 1998; Australia-US } \\
1999 \\
2000 \text { and later: Denmark-Iceland- } \\
\text { Norway; }{ }^{341} \text { Canada-US } 2004\end{array}$ & $\begin{array}{l}\text { Pre-2000: } \\
2000 \text { and later: }\end{array}$ \\
\hline 7 & 2000 and later: EC (ECN 2003) & $\begin{array}{l}\text { Pre-2000: EC 1957; EFTA; } \\
\text { ANDEAN Group Decision 285; } \\
\text { EEA; WAEMU; } \\
\text { CEMAC Reg. } 1 / 99 \\
\text { 2000 and later: CARICOM Protocol } \\
\text { VIII; COMESA Regs } 2004\end{array}$ \\
\hline TOTAL & 51 & 41 \\
\hline
\end{tabular}

\footnotetext{
${ }^{341}$ Sweden joined in 2004.
} 
a subsequent CEA, the later agreement is as deep, or deeper, than the original. For instance:

- The 1982 Australia-US CEA was level 3, the 1999 CEA was level 6.

- NAFTA 1994 was level 3, while Canada-US 1995 was level 5, Canada-US 2004 was level 6, and Mexico-US 2000 and Canada-Mexico 2001 were both level 5.

- $\quad$ EC-US 1991 was level 5, and their 1998 agreement was at level 6.

- The Australia-Taiwan agreement of 1996 was level 4, as was the tripartite agreement in 2002 between Australia, Taiwan and New Zealand.

- The New Zealand-Singapore agreement of 2002 is level 2, while the fourcountry agreement that New Zealand and Singapore signed in 2005 is level 4.

- The 2002 Japan-Singapore RTA is level 2, while the Implementing Agreement of 2004 is level 4 .

The first exception to this rule, that subsequent agreements are at least as deep, is the Australia-New Zealand Agreement of 2007. For reasons explained in Chapter 9.4, the deep cooperation provisions in the 1994 Agreement were not incorporated in the 2007 Agreement that replaced it. However, the intention is to amend New Zealand legislation in order to make the deep cooperation envisaged in the 1994 Agreement possible in practice, and then to amend the 2007 Bilateral Agreement accordingly.

The second exception to the "later is deeper" rule is the 2004 Australia-US RTA, which broadened the range of competition cooperation between the two countries, without limiting the level of cooperation in their 1999 CEA.

It is also interesting to look at the case of Singapore, which did not have a competition law at all until 2007, entering force in August 2008. Prior to that time, Singapore preferred to rely on openness to international trade to ensure competitive markets. Partly due to international pressure from trading partners, it has, however, negotiated seven RTAs containing provisions on competition policy enforcement cooperation since its first agreement with New Zealand in 2002. The Singapore-US RTA of 2004 obliged Singapore to enact general competition legislation by January 2005 (Article 12.2:1). While most of Singapore's agreements are at level 2, it has negotiated two agreements at level 4 (the Agreement between Japan and Singapore implementing the 2002 RTA, and the 2006 Brunei-Chile-New Zealand-Singapore RTA). 
Some agreements explicitly foreshadow the possibility of deepening cooperation over time by referring to possible future extensions to the agreement e.g. the reference to a possible positive comity clause in the Japan-Thailand RTA, suggesting that this trend for formal cooperation to deepen over time may well continue.

Finally, Table 6 also reveals the varying practices of countries in terms of the depth of agreements they sign. The US has the highest proportion of deep agreements -12 out of the 17 agreements it has signed are level 5 or higher on the EJI index. Corresponding proportions for other signatories are the EC (8 out of 17); EFTA (5 out of 8); Japan (4 out of 8); Canada (5 out of 13); Australia (2 out of 14); Korea (1 out of 8); Chile (1 out of 8); and Russia ( 0 out of 8). The reasons for the varying practice of countries in signing shallow or deep agreements are explored in Chapter 14.

The relationship between the increasing number of international competition policy agreements and their depth is discussed further in Chapter 14.4.

Figure 8 is a relative frequency bar graph of the combined dataset of 92 agreements by the level of enforcement cooperation. This dataset will be used, in the remainder of this chapter and in Chapter 14, to conduct exploratory tests of the descriptive propositions and inferential hypotheses about international competition policy cooperation.

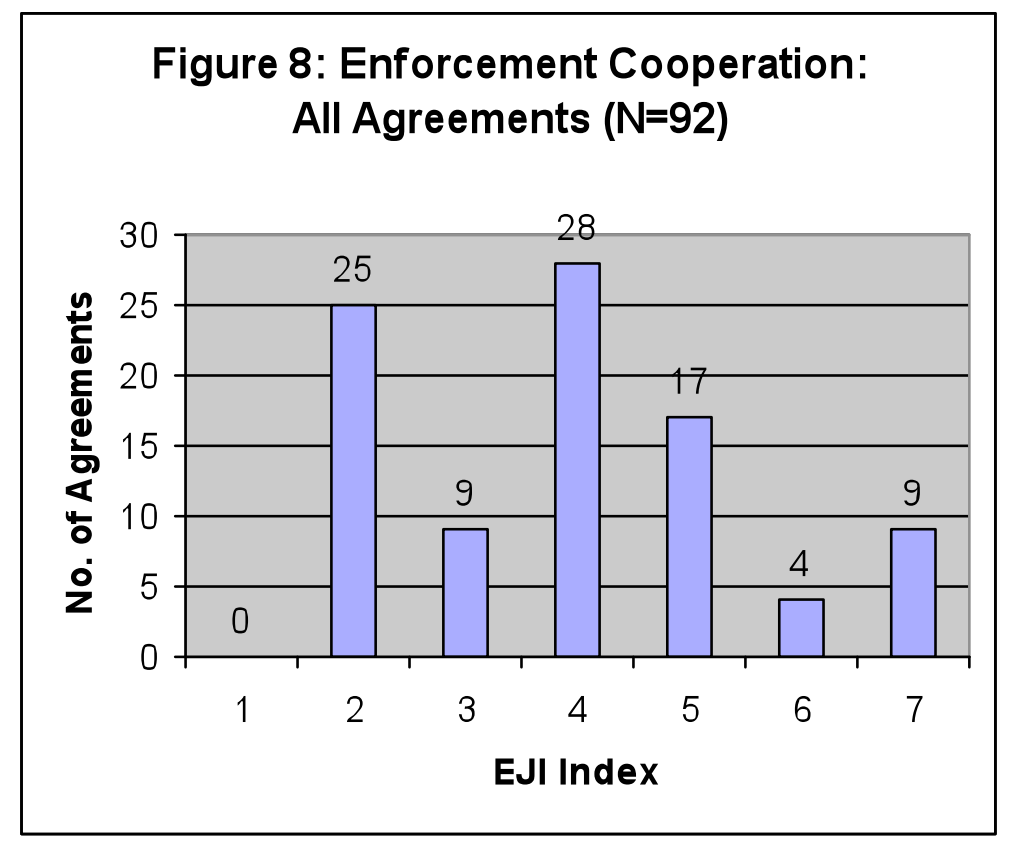




\subsection{IDENTIFYING "FAMILIES" OF AGREEMENTS: A VeCtOR APPROACH}

The main approach used in the literature to identify "families" of RTAs containing competition provisions is to distinguish between "EC-style" agreements and "US-style" agreements (OECD 2006). The former are said to contain substantive policy cooperation provisions rather than enforcement cooperation provisions, while the reverse is the case for US-style agreements - although the two categories are intended to be flexible, with some overlap between them. This proposition will be tested in Section 13.4 below. UNCTAD 2005 (p.x) similarly identifies Canadian and US RTAs, on the one hand, and EU RTAs on the other hand.

Other approaches used to identify "families" of RTAs containing competition provisions include:

- By depth of trade integration i.e. stages of economic integration (see Cernat 2005, pp. 9-11).

- By country level of development (Cernat 2005, pp. 11-14).

- By whether an RTA entails horizontal or vertical integration of competition policy enforcement (Jenny and Horna 2005).

- By whether an RTA contains specific substantive competition law provisions (Hoekman 1998, The, Prusa and Budetta 2007).

The concept of jurisdictional integration and its different dimensions offers an alternative method to identify related families of agreements. First, agreements can be classified by whether they predominantly entail cooperation with respect to prescriptive jurisdiction, enforcement jurisdiction, or inter-state adjudication jurisdiction, or some mix of these. This is broader than the current split between policy cooperation and enforcement cooperation families in RTAs.

For example, families could be defined by whether they:

- Contain provisions solely, or mainly, relating to prescriptive jurisdiction e.g. most RTA competition policy chapters.

- Relate only to enforcement cooperation - virtually all CEAs. 
- Contain any provisions on inter-state adjudication cooperation beyond consultations - a small number of deep RTAs only.

- Contain all three types of jurisdictional integration - again, a small number of deep RTAs only.

Secondly, and more precisely, a vector of the three dimensions can be used to summarise the key provisions, provide a new basis for comparison across agreements of all types, and identify new "families."

To this end, an initial assessment of the depth of prescriptive jurisdictional integration, and of inter-state adjudication cooperation, has been conducted on all 176 RTAs in Table 5 and Appendix 2, on all CEAs, and on the 11 multilateral instruments listed in Chapter 12. References in the following paragraphs to the "typical" depth of the different dimensions of jurisdictional integration in these instruments should be regarded as indicative only, and the individual rating of agreements is not therefore reported. The mode of these ratings seems likely to be sufficiently accurate, however, for the purposes of identifying essential differences in the way the different dimensions of jurisdictional integration are treated in the various instruments.

For example, a vector approach could be used as follows with respect to international competition policy cooperation: $(6,4,1)$ describes the level of integration of prescriptive jurisdiction, enforcement cooperation, and inter-state adjudication, ranked respectively against the indices in Box 4 (p.149), Box 8 (p. 182), and Box 6 (p. 156). This is how the Australia-New Zealand arrangements on competition policy would rank on the three indices. This rating incorporates the CEAs between the two countries, as well as the 1998 Memorandum of Understanding between the Government of Australia and the Government of New Zealand on Harmonisation of Business Law, including competition law.

The vector summary for the EC would be $(8,7,5)$, illustrating that the $\mathrm{EC}$ is at the highest level of integration on each of these three integration vectors. NAFTA's rating would be $(3,4,1)$.

Similarly:

- A "typical" CEA - i.e. the modal CEA - would rank $(1,4,1)$. 
- A “typical” RTA, of those RTAs containing any competition provisions, would rank $(4,2,1)$.

- A "typical" multilateral instrument would rank $(2,1,1)$.

Note that, while the median RTA, of those RTAs containing competition enforcement cooperation provisions, is level 4 on the index of enforcement cooperation, the majority of RTAs with a competition policy chapter contain no provisions on enforcement cooperation (only $41 / 176$, or $23 \%$, do so). The vector summaries $(4,4,1)$ and $(4,1,1)$ respectively describe this more precisely.

A vector summary also provides a more precise method of describing the key differences between RTAs across regions, such as comparing NAFTA, the EC, CER, WAEMU, SACU, APEC, and the ANDEAN Group. It also allows more ready comparisons between the same types of international policy cooperation irrespective of the instrument in which they are contained. This helps to avoid approaches that purport to measure policy cooperation at the country level but which do not incorporate the variety of types of international instrument a country may have signed.

It would then be possible to combine the three measures to produce a single quantitative rating of the level of international competition policy cooperation. This could prove useful for research purposes, with the three elements weighted according to the purpose at hand.

\subsection{Testing Descriptive Propositions About International Competition} POLICY COOPERATION

Chapter 11 set out 8 descriptive propositions about international competition policy enforcement cooperation. These are now tested in turn.

1 The proportion of enforcement cooperation agreements that are between OECD member countries is declining (UNCTAD 2003). Using the full set of 92 agreements, and dividing it into two time periods (pre-2000 and 2000-2008), the proportion of agreements where all signatories were OECD members at the time of signing was $13 / 29$ pre-2000 (45\%), and 
$23 / 63(37 \%)$ in $2000-2008 .{ }^{342}$ The proposition is correct, although the fall in the proportion is relatively small. Subdividing by instrument type, however, reveals a different picture. The proportion of CEAs involving only OECD members actually increased between the two periods, from $44 \%(8 / 18)$ to $55 \%(18 / 33)$, while there was a large fall in the proportion of RTAs involving only OECD members (from $45 \%, 5 / 11$, to $17 \%$, 5/30). These statistics reflect the fact that RTAs are increasingly between countries at different levels of development, intended to exploit different areas of comparative advantage, while it remains difficult for Competition Authorities in non-OECD countries to sign cooperation agreements with OECD countries, for reasons discussed further in chapter 14. If one were to measure, instead, the proportion of these RTAs and CEAs where at least one signatory was an OECD member, there was an increase between the two time periods (from $71 \%$ (20/28) to $88 \%$ $(56 / 64)$.

From a different perspective, it has been stated that most OECD countries have no international competition policy cooperation agreement (OECD 2004, pp. 57-58). However, when both CEAs and RTAs are considered, 18 of the current 30 members of the OECD are party to either a CEA or an RTA with provisions on competition enforcement cooperation. This does not include OECD members belonging to the EC that are indirectly party to agreements signed by the EC. A number of OECD countries are party to multiple agreements, including Australia (14 agreements), the US (13), Canada (13), Korea (8), and Japan (8).

2 The vast majority of bilateral agreements (CEAs) signed so far have the US as one of the parties. Over the whole sample, there are only 11/51 $(22 \%)$ of CEAs where the US is one of the signatories. If the data is divided into three sub-periods (1957-1998, 1999-2002, and 2003-2008), the corresponding proportions are $56 \%, 26 \%$, and $4 \%(5 / 9,5 / 19$, and $1 / 23)$. The statement is therefore incorrect, although the proportion of agreements prior to 1999 involving the US did exceed one half. In the

\footnotetext{
${ }^{342}$ The Treaty of Rome is coded as an agreement where all signatories are OECD members, despite the fact that the OECD was not established until 1960, because all of the original six EC members were founding members of the OECD.
} 
most recent period, only a very small proportion of CEAs involve the US.

It is interesting to note, however, the preponderance of the deepest bilateral agreements (levels 5 and 6) that involve the US as one of the signatories. Of the total of 14 such agreements, the US is party to 9 of them. Other signatories that are party to more than one such deep agreement are Canada (5 agreements), the EC (4), and Japan and Mexico (3 each).

3 RTAs with competition provisions signed by the EC focus on the adoption by partner countries of competition rules similar or identical to EC laws, but, with few exceptions, do not include detailed enforcement cooperation provisions. There are only 7 RTAs with the EC as signatory, in the dataset of 41 RTAs containing any competition enforcement provisions. There are, however, a total of 37 RTAs signed by the EC that contain competition provisions of any kind (including agreements with countries that subsequently joined the EC), so that only $19 \%$ of these contain any enforcement cooperation provisions. The statement is therefore accurate.

4 Agreements signed by developed economies other than the EC mostly pursue enforcement cooperation rather than policy convergence. There is a total of 52 RTAs, in the combined dataset of 176 RTAs, signed by at least one developed country other than the EC (developed economy is defined here as corresponding to the 30 advanced economies defined by the International Monetary Fund). ${ }^{343}$ Of these, 27 (52\%) contain enforcement cooperation of any kind, and 25 RTAs (48\%) contain policy cooperation provisions but no enforcement cooperation. Given the margin of error here, it is probably more accurate to say that agreements signed by developed economies other than the EC are approximately equally likely to contain provisions on enforcement cooperation and policy cooperation. However, it is certainly correct that, compared to RTAs signed by the EC, those signed by other developed countries place more emphasis on enforcement cooperation compared to policy cooperation ( $52 \%$ compared to $19 \%)$.

${ }^{343}$ See the World Economic Outlook, 2007, Statistical Appendix, pp. 208-213, at www.imf.org/ 
5 It is virtually impossible for Less Developed Countries to sign a CEA with Developed Countries, there are "only a handful. 15/51 (29\%) of CEAs are between a developed country and a less developed country. ${ }^{344}$ There were none in the period prior to $1999(0 / 9)$, but $37 \%(7 / 19)$ of the CEAs signed 1999-2002, and 39\% (9/23) of those signed 2003-2008 were between a developed country and a less developed country. This suggests that, while the statement was very much correct prior to 2000 , it is not correct in the post-2000 period. An interesting question, however, is whether there is a relationship between the depth of enforcement cooperation and the level of country development of the signatories, rather than just the existence or absence of an agreement. This will be investigated in Chapter 14.

6 There are no "hard cooperation" agreements involving less developed countries. The literature on hard cooperation, and on second-generation competition cooperation agreements, focuses on CEAs, and does not typically consider competition policy chapters in RTAs. Hard cooperation is defined in at least two ways. The OECD Global Forum on Competition defines it as the sharing of confidential information (level 6), while Zanettin (2002) defines it as either sharing confidential information or positive comity i.e. levels 5 and 6 . On the more restrictive definition, one of the 26 CEAs where at least one of the signatories was a less developed country provides for sharing of confidential information the European Competition Network. ${ }^{345}$ This reflects the unique role of EC expansion as a mechanism for modernising less advanced neighbouring countries. In addition, hard cooperation arguably should be defined to include vertical integration of enforcement (level 7). There are 5 RTAs that are level 7 agreements between less developed countries, and which should therefore be considered to constitute hard cooperation. When the definition is expanded to include positive comity (level 5), there are 4 CEAs and 5 RTAs signed by less developed countries that

\footnotetext{
${ }^{344}$ The 15 agreements are Brazil-US; Australia-PNG; Korea-Russia; Mexico-US; Canada-Mexico; Canada-Chile; Australia-Fiji; CIS-Korea-Latvia-Romania; the European Competition Network; KoreaMexico; Russia-Sweden; China-EC; Korea-Turkey; Albania-Greece; and Mongolia-Taiwan.

${ }^{345}$ While Regulation 1/2003 establishing the ECN was signed in 2003, prior to the 2004 expansion of the EU that brought in a number of developing countries, it came into effect in 2004 and applied immediately to the ten new member countries.
} 
contain this provision. ${ }^{346}$ Overall, the proposition is correct if hard cooperation is defined as the sharing of confidential information within a stand-alone competition agreement. However, it is incorrect when vertically integrated agreements are taken into consideration, and is further from the mark when a broader definition of hard cooperation is employed that includes positive comity.

7 Comity principles are rarely found in RTAs. Of the 41 RTAs, only 6 contain a positive comity clause, so the proposition is correct. However, $5 / 30(17 \%)$ of the RTAs signed in the period 2000-2007 contain the clause, or one in six, so the proposition is perhaps not correct in the most recent period.

8 Some competition chapters in RTAs are as advanced, if not more advanced, in their provisions to foster cooperation between competition authorities on enforcement matters as second generation inter-agency agreements between competition authorities i.e. CEAs. There are 9 agreements providing for vertically integrated enforcement (level 7). Of these, 8 are RTAs, and the ninth, the ECN, is an extension of a prior level 7 RTA. At this, deepest level of enforcement cooperation, the proposition is clearly correct - in fact, it is an understatement. However, there are no RTAs at level 6, while there are 4 CEAs at this level. If vertical integration is left to one side, the proposition is incorrect.

\footnotetext{
${ }^{346}$ The 4 CEAs signed by a developing country that contain a positive comity clause are Brazil-US, Mexico-US, Canada-Mexico, and Korea-Mexico. Note that three of these involve Mexico, an OECD member, while Brazil was offered enhanced engagement with the OECD in 2007 with a view to possible membership. The five RTAs signed by developing countries that contain positive comity are EC-Turkey, EC-South Africa, EFTA-Mexico, Chile-EFTA, and Japan-Mexico. Note that three of these involve Mexico or Turkey, both OECD members. Chile was invited in 2007 to open discussions for OECD membership, and South Africa was offered enhanced engagement at the same time with a view to possible membership.
} 


\section{Chapter 14}

\section{PREDICTING THE DEPTH OF INTERNATIONAL COMPETITION POLICY COOPERATION}

The apparatus constructed in the thesis so far is now used to conduct some initial tests of hypotheses about the causes of international competition policy cooperation.

That is, the new concept of jurisdictional integration, in its different dimensions, has been used to construct indices of the depth of international policy cooperation, in terms of the impact of cooperation on states' recognized authority to make and enforce their own competition policies independently of other states. A new dataset of international agreements containing competition policy provisions has been assembled. The sub-set of agreements providing for cooperation in enforcing competition policies has been ranked on these indices, and summary descriptive statistics derived on the depth of international policy cooperation. Descriptive propositions about international policy cooperation from the existing literature have been tested using this data, and a number have been found to be less than accurate.

The final step is to conduct exploratory statistical analysis of the relationship between the depth of international competition policy cooperation and a range of variables that are hypothesized to be good predictors of the depth of international cooperation. This is the subject of this chapter.

Recall that a number of general hypotheses about international policy cooperation were identified in Chapter 7. Additional hypotheses relating specifically to competition policy cooperation were set out in Chapter 11. These hypotheses are now confronted with the data.

The unit of analysis is either the international agreement, or the signatory country. 


\subsection{EnForcement COOPERATIOn, OeCD MeMBership, AND LEVEl OF DEVELOPMENT}

The hypothesis in Chapter 7 was that there is a strong positive correlation between a country's depth of international economic policy cooperation and its quality of governance.

Recall also that the hypothesis advanced in Chapter 11 was that:

A high proportion of North-South RTAs that contain enforcement cooperation provisions, and a high proportion of North-South CEAs, are likely to provide only for shallow cooperation, while North-North agreements will on average be deeper.

These hypotheses will be tested using two different variables: first, the effect of OECD membership on the depth of enforcement cooperation; and secondly, the effect of advanced economy status (as defined by the IMF). For an agreement to qualify as a North-North agreement, all the signatories will have to be OECD members (in the first specification) or advanced economies (in the second specification). Both OECD membership and advanced economy status are plausibly correlated with country quality of governance, and specifically with the existence and capacity of a country's competition enforcement authority.

Table 7 displays the data with respect to OECD membership. High enforcement cooperation is defined initially as a score of 4 and above on the EJI index.

Table 7: Competition Enforcement Cooperation and OECD Membership

Enforcement Cooperation

\begin{tabular}{|l|c|c|c|c|}
\hline & Low Cooperation & High Cooperation & Total & $\begin{array}{c}\text { Probability of } \\
\text { high cooperation }\end{array}$ \\
\hline $\begin{array}{l}\text { At least one non- } \\
\text { OECD signatory }\end{array}$ & 35 & 22 & 57 & .39 \\
\hline $\begin{array}{l}\text { OECD-only } \\
\text { agreements }\end{array}$ & 4 & 31 & 35 & .89 \\
\hline $\begin{array}{l}\text { Total No. of } \\
\text { agreements }\end{array}$ & 39 & 53 & 92 & \\
\hline
\end{tabular}

The estimated conditional probability that enforcement cooperation is high, where both or all signatories to an agreement are OECD members, is 0.89 . On the other hand, the 
estimated conditional probability of high enforcement cooperation when at least one signatory is a non-OECD member, is only 0.39 .

OECD membership, therefore, is a very good predictor of the depth of enforcement cooperation. The difference of proportions is .5 (.89-.39), with a standard error of .08. A $95 \%$ confidence interval for the true difference is $(.34, .66)$. In other words, we can be $95 \%$ confident that the true difference of proportions is between .34 and .66 .

But this confidence interval assumes that the population from which the sample data is drawn is very large, in fact infinite, whereas we can be confident that $n=92$ is a large proportion of the total number of relevant agreements in existence. From the discussion in Chapter 12.4, we assume the "true" population to be 150. Adjusting for the finite population correction factor $(\sqrt{ } \mathrm{N}-\mathrm{n} / \mathrm{N}-1)$, the adjusted $95 \%$ confidence interval for the true difference is $(.4, .6)$. It is highly probable that the difference of proportions is at least 40 percentage points.

A further consideration is that, for the confidence interval to be reliable, there needs to be a large number of observations, so that we can assume that the data are normally distributed. The total number of agreements in the dataset is 92 , and when sub-divided into OECD-only agreements and other agreements, the sample sizes are only 35 and 57 respectively. It is sometimes suggested that a sample size of 30 is the minimum required for the central limit theorem to hold, and therefore for standard large sample statistical methods to be employed. However, in order to test the robustness of the apparently very strong relationship between OECD membership and the depth of enforcement cooperation, it is prudent to employ an additional statistical technique that does not rely on an assumption that the data are normally distributed.

The 92 agreements are therefore assumed to be a sample from a hypergeometric distribution. In formal terms, the hypergeometric distribution is a discrete probability distribution that describes the number of successes in a sequence of $n$ draws from a finite population without replacement. In layman's terms, the hypergeometric distribution is from a finite population in which there are two possible outcomes, "success" and "failure" - or in this case, "OECD-only agreement" and "other agreement" - and where the probability of success/failure is different in each case. 
In this case, we know the observed distribution, but not the total population of agreements or the "true" distribution. In this situation, a Bayesian approach is used. An assumption is made about the distribution of each of the two types of agreement in the total population of agreements. The actual observed probability is then used to compute the posterior probability that the number of OECD-only agreements equals a specific value, using Bayes' Theorem. In this case, the a priori assumed distribution is the flat distribution i.e. each of the possible combinations of OECD-only and other agreements is assumed to be equally likely. This "non-informative prior" is the appropriate prior to use, because it is generally felt that it "lets the data speak the loudest" i.e. imposes prior beliefs on the actual data less than other approaches.

In this case, we cannot compute the mean and other parameters, and simulation must be used. We again assume that the total population of agreements in existence is 150, and we further assume they are distributed 60/90 between OECD-only agreements and other agreements, which approximates the relative number of the two types in the actual sample. We use Bayes' Theorem to compute the posterior probabilities that the number of OECD-only agreements equals a specific value. If we let:

$\mathrm{P}($ hi $)=$ the conditional probability that enforcement cooperation is high when all signatories are OECD members

$\mathrm{Q}(\mathrm{hi})=$ the conditional probability that enforcement cooperation is high when at least one signatory is not a member of the OECD

then we can compute the posterior probability that $\mathrm{P}(\mathrm{hi})>\mathrm{M} * \mathrm{Q}$ where $\mathrm{M}$ is a multiplier.

Using Bayes' Theorem, the result obtained is that there is a probability of 0.992 that $\mathrm{P}(\mathrm{hi})$ is $75 \%$ larger than $\mathrm{Q}(\mathrm{hi})$; and a probability of .884 that it is twice as large.

That is, we can be over $99 \%$ confident that the conditional probability of enforcement cooperation being high when all signatories are OECD members, is $75 \%$ greater than the conditional probability of enforcement cooperation being high when at least one signatory is not a member of the OECD. 
The odds ratio is an alternative way to demonstrate the strength of the relationship between the depth of enforcement cooperation and OECD membership. From Table 7, the odds ratio can be calculated as follows: $(35 \times 31) /(22 \times 4)=12.3$.

This means that the estimated odds of high enforcement cooperation in agreements between countries that are both or all members of the OECD, is 12.3 times higher than when at least one of the signatories is not an OECD member.

Taken together, these results point to a very strong relationship between OECD membership and the depth of competition enforcement cooperation.

Turning to the level of country development, while there is a high degree of overlap between developed economies and OECD members, there are some important differences. For instance, Mexico and Turkey are OECD members, but are not advanced economies, while the reverse is true for Singapore, Taiwan and Israel. Table 8 displays the data on the relationship between depth of enforcement cooperation and country level of development.

Table 8: Competition Enforcement Cooperation and Level of Development

Enforcement Cooperation

\begin{tabular}{|l|c|c|c|c|}
\hline & Low Cooperation & High Cooperation & Total & $\begin{array}{c}\text { Probability of } \\
\text { high } \\
\text { cooperation }\end{array}$ \\
\hline $\begin{array}{l}\text { At least one non- } \\
\text { advanced signatory }\end{array}$ & 30 & 25 & 55 & .45 \\
\hline $\begin{array}{l}\text { Advanced } \\
\text { economy-only } \\
\text { agreements }\end{array}$ & 9 & 28 & 37 & .76 \\
\hline $\begin{array}{l}\text { Total No. of } \\
\text { agreements }\end{array}$ & 39 & 53 & 92 & \\
\hline
\end{tabular}

The estimated conditional probability that enforcement cooperation is high, where both or all signatories to an agreement are advanced economies, is 0.76 . On the other hand, the estimated conditional probability of high enforcement cooperation when at least one signatory is a non-advanced economy, is 0.45 .

The difference of proportions is only 0.31 (.76-.45), compared to 0.5 for OECDmembership. The adjusted $95 \%$ confidence interval is $(.19, .43)$. Using the Bayesian simulation approach, we can be $99 \%$ confident that the conditional probability of 
enforcement cooperation being high when all signatories are advanced countries, is $20 \%$ greater than the conditional probability of enforcement cooperation being high when at least one signatory is not an advanced country.

The marginal odds ratio here is only 3.7. This means that the estimated odds of high enforcement cooperation in agreements between countries that are both or all advanced economies, is 3.7 times higher than when at least one of the signatories is not an advanced economy.

Comparing the two odds ratios, the marginal odds of enforcement cooperation being high in agreements between OECD countries (at 12.9) is 3.3 times greater than in agreements between advanced economies (3.7).

These results indicate a much weaker relationship between advanced economy status and depth of enforcement cooperation than that for OECD membership.

When high enforcement cooperation is redefined as level 5 on the EJI index, the odds ratios are uniformly lower, at 7.1 with respect to OECD countries, and 1.8 for advanced economies. The odds of enforcement cooperation being high in agreements between OECD countries is then nearly 4 times greater than in agreements between advanced economies.

Disaggregating by instrument type reveals that all of the difference between OECD membership and advanced economy status arises from RTAs (when high cooperation is defined as level 4 and above). For CEAs, the numbers in the four cells, showing the relationship between the level of enforcement cooperation and OECD membership or advanced economy status respectively, are identical. This produces the same odds ratio of 21.7 in each case.

However, for RTAs, the estimated odds of high enforcement cooperation in OECD-only agreements is 5.5, while for agreements between advanced economies only, it is 0.6. In the latter case, less than half of the 12 RTAs (42\%) between advanced economies entail high enforcement cooperation, while more than half (55\%) of agreements involving at least one non-advanced economy entail high cooperation. This result is heavily 
influenced by the fact that Singapore, an advanced economy that is not a member of the OECD, has signed five RTAs involving low-level cooperation.

Overall, all signatories to an agreement being members of the OECD is a very strong (89\%) predictor of whether international competition enforcement cooperation will be high. It is a much stronger predictor than whether all signatories are advanced economies. However, for stand-alone competition enforcement agreements, OECD membership and advanced economy status are equally strong predictors of depth of enforcement cooperation. For RTAs that contain enforcement cooperation provisions, on the other hand, advanced economy status is a poor predictor of depth of enforcement cooperation.

\subsection{ENFORCEMENT COOPERATION AND ECONOMIC INTEGRATION}

From Chapter 7, the hypothesis to be tested is that there is a strong positive correlation between a country's depth of international economic policy cooperation and its level of international economic integration.

The most commonly used measure of international economic integration is the total trade: GDP ratio. This measures total exports and imports as a percentage of GDP. This is a good measure of the overall level of international economic exchange. It is plausible that increases in this ratio will be associated with increased potential for anticompetitive behaviour, such as cartels, abuse of dominant position, and mergers. However, the overall ratio by country contains no information on the distribution of trade flows between different partner countries. The theoretical model in this thesis is that the pattern of trade flows between countries will influence the depth of policy cooperation between countries. Therefore the appropriate data to use is trade flow statistics at the country level.

An alternative measure of international economic integration is the ratio of foreign direct investment (FDI) to GDP. It is plausible that an increase in FDI will be associated with an increase in some types of potentially anti-competitive behaviour, such as mergers and acquisitions. Using FDI to test the hypothesis would be consistent with Babones (2007), who suggests that it is appropriate to use foreign investment as an indicator of economic globalisation where the theoretical model is explicitly concerned 
with issues of economic control. However, FDI statistics are not yet available at the country level. ${ }^{347}$

The IMF's Direction of Trade Statistics records trade between individual country pairs, and also shows trade flows to and from the EU as a whole. This allows an assessment of the relationship of trade flows between pairs of countries and their depth of cooperation in competition policy. Specifically, the data are total merchandise trade (exports plus imports) between each signatory in the year prior to the agreement, as a percentage of each country's total global merchandise trade in that year, averaged over the number of countries. $^{348}$

There are 11 agreements where the ratio exceeds .2, but most of the agreements (63\%) line in the range $0.0-0.1$, with a median of approximately 0.05 . Simply splitting the agreements into high and low trade integration according to whether the ratio is greater than or equal to 0.05 , or below 0.05 , results in 42 agreements rated high trade integration, and 43 rated low. Table 9 shows the relationship between depth of enforcement cooperation and level of trade integration - with high enforcement cooperation defined initially as level 4 or above on the EJI index.

Table 9: Competition Enforcement Cooperation and Trade Integration

\begin{tabular}{|l|c|c|c|c|}
\hline & $\begin{array}{c}\text { Eow } \\
\text { Cooperation }\end{array}$ & $\begin{array}{c}\text { High } \\
\text { Cooperation }\end{array}$ & Total & $\begin{array}{c}\text { Probability of high } \\
\text { cooperation }\end{array}$ \\
\hline $\begin{array}{l}\text { Low trade } \\
\text { integration }\end{array}$ & 25 & 20 & 45 & .44 \\
\hline $\begin{array}{l}\text { High trade } \\
\text { integration }\end{array}$ & 11 & 33 & 44 & .75 \\
\hline $\begin{array}{l}\text { Total No. of } \\
\text { agreements }\end{array}$ & 36 & 53 & 89 & \\
\hline
\end{tabular}

The estimated conditional probability that enforcement cooperation is high, when trade integration is high, is 0.75 . On the other hand, the estimated conditional probability of high enforcement cooperation when trade integration is low, is 0.44 . High trade

\footnotetext{
${ }^{347}$ Note however that the IMF has initiated a Coordinated Direct Investment Survey to collect data on the source and destination of direct investment by individual country. See IMF Survey on line, August 1, 2008 at http://www.imf.org/external/pubs/ft/survey/so/home.aspx

${ }^{348}$ The data cover 89 agreements. In a small number of cases, the trade data precede the agreement by two or three years rather than one, due to post-2004 Direction of Trade Statistics data not being freely available. Data for some RTAs are from UNCTAD (Intra-trade of groups as a percentage of total exports of each group). See UNCTAD Handbook of Statistics, various years.
} 
integration is a fairly good predictor of the depth of enforcement cooperation. However, the difference of proportions is only 0.31, with a standard error of 0.099. An adjusted $95 \%$ confidence interval for the true difference is $(.19, .43)$.

The marginal odds ratio is $(25 \times 33) /(11 \times 20)=3.8$. This means that the estimated odds of high enforcement cooperation between countries with high trade integration, is 3.8 times higher than the odds where trade integration is low. When high enforcement cooperation is redefined as level 5 or above, the odds ratio is 3.7 .

If the agreements are separated into two groups (RTAs and CEAs), the marginal odds ratios are 2.9 and 4.6 respectively. CEAs between countries with high trade integration are somewhat more likely to be deeper than are RTAs between countries with high trade integration. This is also true when high enforcement cooperation is redefined as level 5 and above.

Finally, if the nine deep agreements at level 7 are excluded - on the basis that vertically integrated enforcement cooperation is of a sufficiently different character to not be fully comparable with horizontal agreements - then the odds ratios are slightly lower. The odds ratio when high enforcement cooperation is defined as level 4 and above is 3.3 (compared to 3.8), and when it is set at level 5 and above, is 3.1 (compared to 3.7).

Overall, these results suggest only a moderate positive relationship between the level of trade integration between countries and their depth of enforcement cooperation.

\subsection{ENFORCEMENT COOPERATION AND ECONOMIC ASYMMETRY}

Recall that the hypothesis advanced in Chapter 7 was that the effect of economic asymmetry on the depth of enforcement cooperation is strongly negative. That is, large economies are less likely to agree to constrain their enforcement jurisdiction in agreements with small countries.

The methodology used to measure economic asymmetry between signatories to an agreement is based on that used in Smith (2000), who measured the level of economic asymmetry between signatories of RTAs. Smith calculated country shares of "trade area GDP," using GDP data in US dollars in the year the agreement was signed. Smith used 
two methods to rank agreements into low and high asymmetry. The methods produced almost identical results, and the simpler of his methods is used here. A bilateral agreement is defined as being asymmetric where one country's share exceeds $70 \%$ of joint GDP. ${ }^{349}$ For a plurilateral agreement, asymmetry is defined as the largest country share being more than two times larger than the second largest economy. The signatories include only those countries that were party to the agreement at the time it was signed, or at the date it first entered force in the case of RTAs. Table 10 displays the data, for 90 agreements.

Table 10: Competition Enforcement Cooperation and Economic Symmetry

\begin{tabular}{|l|c|c|c|c|}
\hline \multicolumn{5}{|c|}{ Enforcement Cooperation } \\
\hline & Low Cooperation & High Cooperation & Total & $\begin{array}{c}\text { Probability of } \\
\text { high } \\
\text { cooperation }\end{array}$ \\
\hline Low symmetry & 29 & 35 & 64 & .55 \\
\hline High symmetry & 8 & 18 & 26 & .69 \\
\hline $\begin{array}{l}\text { Total No. of } \\
\text { agreements }\end{array}$ & 37 & 53 & 90 & \\
\hline
\end{tabular}

The estimated conditional probability that enforcement cooperation is high when economic symmetry is high i.e. when asymmetry is low, is 0.69 , and when economic asymmetry is high it is 0.55 , yielding a difference of proportions of 0.14 . The marginal odds ratio is 1.9 , and the $95 \%$ confidence interval, adjusted by the Finite Population Correction Factor, is $(0, .28)$. There is a slightly higher probability that enforcement cooperation will be high when the economies of signatories are of a similar size. When high cooperation is redefined as level 5 and above, the difference of proportions is only $.04,(.35 \mathrm{v} .31)$, and the odds ratio is 1.2

When CEAs are compared to RTAs, it turns out that the difference is mainly due to RTAs, which are 2.7 times more likely to feature high cooperation when economic symmetry is high than when it is low.

Overall, these results suggest only a weak positive relationship between the depth of enforcement cooperation and the similarity of size of signatories' economies.

\footnotetext{
${ }^{349}$ The source of GDP data for most countries is the Groningen Total Economy Database as at October 2008. GDP is expressed in 1990 US dollars. For 8 agreements, the Groningen dataset does not have data for the signatory countries, and the World Bank's World Development Indicators dataset was used (GDP in current US \$).
} 


\subsection{ENFORCEMENT COOPERATION AND THE STAGES OF ECONOMIC INTEGRATION}

The hypothesis advanced in Chapter 11 was that:

Competition policy enforcement cooperation agreements, whether in RTAs or CEAs, will be deeper between countries that are party to a Customs Union or more advanced stage of economic integration agreement, and shallower where only an FTA is in place; but this dichotomy will have weakened over time.

In effect there are two hypotheses here. The first is that RTAs that are Customs Unions or deeper will have deeper enforcement cooperation than RTAs that are FTAs, but this will be less so over time. The second is that CEAs between countries that are part of a Customs Union or deeper trade arrangement, will be deeper than CEAs where the parties have signed an FTA, but this will also be less so over time. Table 11 displays the data on enforcement cooperation in different types of RTA.

Table 11: Competition Enforcement Cooperation in Customs Unions and FTAs

\begin{tabular}{|c|c|c|c|c|}
\hline & Customs Unions & $\begin{array}{c}\text { Depth of } \\
\text { Cooperation }\end{array}$ & FTAs & $\begin{array}{c}\text { Depth of } \\
\text { Cooperation }\end{array}$ \\
\hline $\begin{array}{c}1957- \\
1989\end{array}$ & $\mathrm{EC}$ & Level 7 & EFTA & Level 7 \\
\hline $\begin{array}{c}1990- \\
1999\end{array}$ & $\begin{array}{c}\text { ANDEAN Group } \\
\text { WAEMU } \\
\text { EC-Turkey } \\
\text { CEMAC } 1 / 99\end{array}$ & $\begin{array}{l}\text { Level } 7 \\
\text { Level } 7 \\
\text { Level } 5 \\
\text { Level } 7\end{array}$ & $\begin{array}{c}\text { EEA } \\
\text { NAFTA } \\
\text { Canada- } \\
\text { Israel } \\
\text { Canada- } \\
\text { Chile } \\
\text { Chile- } \\
\text { Mexico }\end{array}$ & $\begin{array}{l}\text { Level } 7 \\
\text { Level } 3 \\
\text { Level } 3 \\
\text { Level } 3 \\
\text { Level } 2\end{array}$ \\
\hline $\begin{array}{l}2000- \\
2007\end{array}$ & $\begin{array}{c}\text { CARICOM } \\
\text { SACU } \\
\text { COMESA Regs. } \\
2004\end{array}$ & $\begin{array}{l}\text { Level } 7 \\
\text { Level } 2 \\
\text { Level } 7\end{array}$ & 27 FTAs $^{350}$ & $\begin{array}{c}\text { Range from level } \\
2-5\end{array}$ \\
\hline Totals & 8 & & 33 & \\
\hline
\end{tabular}

\footnotetext{
${ }^{350}$ See Table 25 for details of the individual agreements.
} 
Of the eight Customs Unions, six are level 7 agreements, one is level 5, and one is level 2. Of the 33 FTAs, only two are level 7 agreements, while the remaining 31 range from levels 2-5. Clearly, enforcement cooperation is, in general, much deeper in Customs Unions than in RTAs, in line with the hypothesis. There are only two Customs Unions at less than level 7, and only two FTAs that are deeper than level 5 (there are also 5 FTAs that are at level 5).

The small number of agreements involved makes accurate measurement of trends difficult. In the period prior to 1990, there were only three RTAs with competition policy enforcement cooperation provisions. Two were Customs Unions and one was an FTA, and all three of these agreements were level 7 agreements. There was thus no difference in depth of enforcement cooperation between Customs Unions and FTAs in the first period.

In the period 1990-1999, there were only nine relevant RTAs. Four were Customs Unions (three level 7, one level 5), and five were FTAs (one level 7, three level 3, and one level 2). Overall, the second period saw the appearance of a gap between the average depth of Customs Unions and of FTAs (the latter being less deep than the former), rather than the narrowing of a gap.

In the period 2000-2007, there was a large increase to 30 RTAs with enforcement cooperation provisions. Of these, 27 were FTAs, ranging from levels 2-5, and three were Customs Unions; in all three cases these represented the addition of competition provisions to an already existing Customs Union. Two of the three are level 7 agreements. The third, the 2002 SACU Agreement, is only a level 2 agreement, the parties merely agreeing that: "Member States shall cooperate with each other with respect to the enforcement of competition laws and regulation"(Article 40). In the latest period, enforcement cooperation remained deeper on average in Customs Unions than in FTAs. However, in the aggregate, there is much more de jure international competition enforcement cooperation taking place in FTAs than in Customs Unions, because there are 27 FTAs containing such provisions and only 3 Customs Unions.

Overall, the data do not support the hypothesis - that the dichotomy between deep Customs Unions and shallow FTAs would become less pronounced over time. There are 
two factors at play here. The first, as noted, is the small number of agreements, especially of Customs Unions, making it very difficult to establish trends.

Secondly, the deepening of FTAs has been accompanied by a significant broadening in the number of countries signing FTAs with enforcement cooperation provisions. For instance, the large increase in the number of FTAs after 1999 comprises two subsets: an increasing number of deep FTAs - of the six level 5 FTAs, five are post-1999 - and an increasing number of shallower FTAs involving countries newly active in international competition policy enforcement cooperation. For example, Singapore signed its first FTA with enforcement cooperation provisions in 2002, and had signed six more agreements by 2006. Of these, five agreements were at levels 2 and 3, and two were level 4.

The overall data therefore masks two sub-trends: an increasing number of deeper FTAs, in combination with a broadening in the number of countries signing FTAs with provisions on competition enforcement cooperation.

Turning to the depth of cooperation in CEAs between signatories that are also party to an RTA, Table 12 displays the data. Where there is more than one CEA between the same signatories, the agreement cited is the deepest agreement.

There are only two CEAs between countries that are signatories to a Customs Union or deeper trade arrangement, both in the post-1999 period. One agreement is at level 7, the other at level 4. For FTA-signatories, in the post-1999 period there are three level 6 agreements, three at level 5, and five at level 4. Customs Unions are associated with slightly deeper enforcement cooperation than FTAs in the most recent period. 
Table 12: Competition Enforcement Cooperation in CEAs by Form of Associated RTA

\begin{tabular}{|c|c|c|c|c|}
\hline $\begin{array}{l}\text { Date of } \\
\text { CEA } 351\end{array}$ & $\begin{array}{c}\text { CEA and a } \\
\text { Customs Union }\end{array}$ & $\begin{array}{l}\text { Depth of } \\
\text { Cooperation in } \\
\text { CEA }\end{array}$ & CEA and an FTA & $\begin{array}{c}\text { Depth of } \\
\text { Cooperation in } \\
\text { CEA }\end{array}$ \\
\hline $\begin{array}{l}1957- \\
1989\end{array}$ & None & & None & \\
\hline $\begin{array}{l}1990- \\
1999\end{array}$ & None & & $\begin{array}{l}\text { Australia-US } \\
\text { Israel-US } \\
\text { Australia-Papua } \\
\text { New Guinea } \\
\text { CIS Regs }\end{array}$ & $\begin{array}{l}\text { Level } 6 \\
\text { Level } 5 \\
\text { Level } 4 \\
\text { Level } 4\end{array}$ \\
\hline $\begin{array}{l}2001- \\
2007\end{array}$ & $\begin{array}{l}\text { European } \\
\text { Competition } \\
\text { Network (ECN) } \\
\text { Australia-New } \\
\text { Zealand } 2006^{352}\end{array}$ & $\begin{array}{l}\text { Level } 7 \\
\text { Level } 4\end{array}$ & $\begin{array}{l}\text { ECA } \\
\text { Denmark-Iceland- } \\
\text { Norway }{ }^{353} \\
\text { Mexico-US } \\
\text { Canada-Mexico } \\
\text { Canada-Chile } \\
\text { Canada-US } \\
\text { Armenia- } \\
\text { Moldova }\end{array}$ & $\begin{array}{l}\text { Level } 4 \\
\text { Level } 6 \\
\text { Level } 5 \\
\text { Level } 5 \\
\text { Level } 4 \\
\text { Level } 6 \\
\text { Level } 4\end{array}$ \\
\hline
\end{tabular}

Disaggregating by time period, the average level of cooperation in FTAs remained approximately the same over the two time periods, but it is not possible to draw conclusions on the relative depth of FTAs and Customs Unions due to the small number of agreements. Table 13 displays the comparative data.

\footnotetext{
${ }^{351}$ There are two CEAs between Australia and New Zealand (2006, 2007), and both are level 4 agreements.

352 The CER Agreement between Australia and New Zealand is not a Customs Union, but it has many features of a Common Market, and so is coded here as an agreement that is a "Customs Union or deeper RTA", rather than as an FTA. While the WTO classifies CER as an FTA, this is an artefact of the WTO's legally determined definition of RTAs as either FTAs or Customs Unions. That is, the WTO's categories are defined solely by the signatories' tariff policies with respect to the rest of the world, and ignore the varying depth of all other economic policies. The WTO does not recognize Common Markets or Economic Unions as being deeper than FTAs, unless they are also Customs Unions. It would be inappropriate for the purpose at hand to classify CER as an FTA.

${ }^{353}$ These three countries are members of the EEA.
} 
Table 13: Competition Enforcement Cooperation in CEAs by Form of Associated RTA and by Period

\begin{tabular}{|c|c|c|c|c|c|}
\hline & $\begin{array}{c}\text { Customs } \\
\text { Unions }\end{array}$ & FTAs & FTAs & FTAs & FTAs \\
\hline & & Level 4 & Level 5 & Level 6 & Level 7 \\
\hline $\begin{array}{c}1990- \\
1999\end{array}$ & None & 2 & 1 & 1 & 0 \\
\hline $\begin{array}{c}2000- \\
2007\end{array}$ & $\begin{array}{c}1 \text { at level 7 } \\
1 \text { at level 4 }\end{array}$ & 3 & 2 & 2 & 0 \\
\hline
\end{tabular}

Overall, the data do not support the hypothesized reduction in the dichotomy between shallower CEAs amongst FTA-signatories and deeper CEAs between signatories to Customs Unions.

\subsection{ENFORCEMENT COOPERATION AND THE SiMILARITY OF COMPETITION LAWS}

This section explores the relationship between the depth of enforcement cooperation between countries and the similarity of their competition laws.

Recall from Chapter 10 that there are two hypotheses of the sign of this relationship. On the one hand, the more plausible hypothesis is that cooperation between Competition Authorities is facilitated by a degree of similarity of substantive laws or doctrines and enforcement practices. The alternative view is that there is a negative relationship between the presence or depth of enforcement cooperation provisions, and provisions relating to convergence or harmonization of competition laws. On this view, countries have pursued enforcement cooperation as an alternative/substitute for policy convergence.

These hypotheses can be tested using a dataset on the similarity of the competition laws of 11 APEC economies compiled by Bollard. ${ }^{354}$ Bollard's index of similarity is an unweighted aggregation of scores for 22 elements under 7 broad areas of competition law (the treatment of mergers, dominant firm behaviour, horizontal agreements, vertical restraints, unfair trading, and judicial and enforcement characteristics). The result is a score of between 0 (totally different competition laws) and 100 (an identical pair of laws), for 55 country pairs, as shown in Table 14 (reproduced from Bollard and Vautier 1998, Table 6.4, p. 142). ${ }^{355}$ Bollard calculated the index based on information in an

\footnotetext{
${ }^{354}$ In Bollard and Vautier, 1998, pp. 129-143.

355 Vautier and Lloyd, 1997, p. 52.
} 
unpublished 1994 survey undertaken by the New Zealand government for APEC, and cites a number of qualifications in using it, two of which are relevant here: information may not be completely up to date as at 1994; and it is subject to different interpretations and translations of terms. ${ }^{356}$

To compare these country pair scores with the depth of enforcement cooperation between the same pairs of countries, the similarity index scores are divided into two categories, low similarity and high similarity. The range of scores is 14-77, suggesting a mid-point around 45. Inspection shows that a dividing line of 45 results in a low category with 35 observations and a high category with 20 observations, whereas a dividing line of 40 results in a low category with 28 observations, and a high category with 27 observations. In the initial analysis below, a dividing line of 45 is used, although analysis is also conducted in which high similarity is defined as a score over 40 , to test the sensitivity of the results to this specification.

Of the 55 country pairs for which a legal similarity index is available, there are 19 country pairs for which an enforcement cooperation score is also available in the dataset. In three cases the country pair score for jurisdictional integration is obtained from a trilateral enforcement cooperation agreement. The NZ-Canada enforcement cooperation score is obtained from the NZ-Canada-Australia agreement of 2000; the Australia-Canada score is obtained from the same agreement; and the New ZealandTaiwan score is obtained from the Australia-NZ-Taiwan agreement. Where there is more than one agreement between the same country pair, the score used is the deepest agreement involving each country pair.

\footnotetext{
${ }^{356}$ See Bollard and Vautier 1998, p. 141.
} 
Table 14: Measures of Similarity of Competition Laws Between APEC Country Pairs

\begin{tabular}{|c|c|c|c|c|c|c|c|c|c|c|c|}
\hline & Australia & Canada & China & $\begin{array}{c}\text { Chinese } \\
\text { Taipei }\end{array}$ & Japan & Korea & Mexico & NZ & Philippines & Thailand & US \\
\hline Australia & 0 & & & & & & & & & & \\
\hline Canada & 67 & 0 & & & & & & & & & \\
\hline China & 17 & 17 & 0 & & & & & & & & \\
\hline Chinese Taipei & 41 & 46 & 17 & 0 & & & & & & & \\
\hline Japan & 41 & 47 & 17 & 47 & 0 & & & & & & \\
\hline Korea & 43 & 44 & 17 & 53 & 54 & 0 & & & & & \\
\hline Mexico & 47 & 50 & 17 & 31 & 41 & 41 & 0 & & & & \\
\hline $\mathrm{NZ}$ & 77 & 70 & 17 & 53 & 53 & 56 & 59 & 0 & & & \\
\hline Philippines & 20 & 20 & 29 & 21 & 31 & 31 & 14 & 23 & 0 & & \\
\hline Thailand & 17 & 16 & 22 & 26 & 29 & 27 & 23 & 14 & 23 & 0 & \\
\hline US & 51 & 53 & 17 & 43 & 61 & 46 & 47 & 47 & 36 & 29 & 0 \\
\hline
\end{tabular}

From Bollard and Vautier, 1998, Table 6.4, p. 142. 
With high cooperation defined as level 5 or above on the EJ Index, and high legal similarity defined as 45 and over on the Bollard index, these 19 cases are distributed as follows:

\section{Table 15: Competition Enforcement Cooperation and Similarity of Competition Laws $(n=19)$}

\begin{tabular}{|l|c|c|c|c|}
\hline & Eow & High & Total & $\begin{array}{c}\text { Probability of } \\
\text { high cooperation }\end{array}$ \\
\hline Low similarity of laws & 7 & 2 & 9 & .22 \\
\hline High similarity of laws & 4 & 6 & 10 & .60 \\
\hline Total No. of agreements & 11 & 8 & 19 & \\
\hline
\end{tabular}

The estimated conditional probability that enforcement cooperation is high, where competition laws are similar, is 0.6 , while when competition laws are not similar it is 0.22 . Having similar competition laws does not appear to be a very good predictor of deep enforcement cooperation, while the absence of similar laws is not a particularly strong predictor of low cooperation. The marginal odds ratio is 5.3.

Given the search techniques used to compile the dataset, however, including searches on node country web sites and drawing on the APEC Competition Law and Policy Database and the Free Trade of the Americas Inventory, we can have some confidence that few or even possibly none of the remaining 36 country pairs has any formal competition policy enforcement cooperation agreement at all. There is, therefore, a need to incorporate these country pairs in the analysis. Of the 36 country pairs with no formal agreement in our dataset, 10 pairs rank high on the legal similarity index, while 26 pairs rank low on that index.

If we make the strong assumption that none of these 36 country pairs has a CEA or RTA containing competition enforcement cooperation provisions, and defining high enforcement cooperation and high legal similarity in the same way as in Table 15 above, the resulting contingency table is shown in Table 16. 


\section{Table 16: Competition Enforcement Cooperation and Similarity of Competition Laws $(n=55)$}

Enforcement Cooperation
\begin{tabular}{|l|c|c|c|c|}
\hline & No/Low & High & Total & $\begin{array}{c}\text { Probability of high } \\
\text { cooperation }\end{array}$ \\
\hline Low similarity of laws & 33 & 2 & 35 & .06 \\
\hline High similarity of laws & 14 & 6 & 20 & .30 \\
\hline Total No. of agreements & 47 & 8 & 55 & \\
\hline
\end{tabular}

Now, the estimated conditional probability that enforcement cooperation is high, where competition laws are dissimilar, is only 0.06 . This means that we can be very confident that enforcement cooperation will be low when legal similarity is low. The marginal odds ratio is $(33 \times 6) /(2 \times 14)=7.1$, which means that the estimated odds of enforcement cooperation being high between a country pair where the competition laws are similar, is 7 times greater than the odds for a country pair with dissimilar competition laws. The difference of proportions is .24.

On the other hand, when legal similarity is high, the estimated conditional probability that enforcement cooperation is high is only 0.3 . Not surprisingly, these results suggest that similarity of substantive competition laws is a necessary, but not a sufficient condition, for high enforcement cooperation.

While these results are an upper bound, given the strong assumption that the dataset includes all the CEAs that exist between these country pairs, it seems unlikely that any missing agreements are high enforcement cooperation agreements. A CEA of level 5 or above is more likely to be on a web site, or at least referenced in the public domain, than is a lower cooperation agreement. This is because a high cooperation agreement is likely to involve an OECD node country, such as the USA, Canada, Japan, Korea, Mexico, Australia, or New Zealand. All these countries post their CEAs in English on official web sites, their agreements attract attention in the competition policy community and amongst academics, and they comprise 7 of the 11 countries in the Bollard index. Any deep enforcement cooperation agreement involving one of these node countries and any one of the other 4 countries in the Bollard index seems likely to be posted on the node country's web site (or failing that, to perhaps have been included either in the APEC inventory, or, with respect to the USA, Canada, and Mexico, in the FTAA inventory).

While it is quite possible that there is a small number of low cooperation agreements involving these country pairs that are missing from the dataset, any that were between 
countries with dissimilar competition laws would only further strengthen the association between low legal similarity and low enforcement cooperation. Alternatively, while an omitted low cooperation agreement that was between countries with high legal similarity would lower the odds ratio, this would not weaken the result that we can be very confident that enforcement cooperation will be low when legal similarity is low.

To test the sensitivity of this result to the specification of legal similarity, high legal similarity is redefined as a score of 40 or above on the Bollard index (instead of a score of 45). As a result, seven country pairs shift from low legal similarity to high similarity. The revised contingency table is:

Table 17: Competition Enforcement Cooperation and Similarity of Competition Laws (legal similarity redefined)

\begin{tabular}{|l|c|c|c|c|}
\multicolumn{1}{|c|}{ Enforcement Cooperation 357} \\
\hline & No/Low & High & Total & $\begin{array}{c}\text { Probability of } \\
\text { high cooperation }\end{array}$ \\
\hline Low similarity of Laws & 28 & 0 & 28 & $.02^{358}$ \\
\hline High similarity of laws & 19 & 8 & 27 & .30 \\
\hline Total No. of agreements & 47 & 8 & 55 & \\
\hline
\end{tabular}

The estimated conditional probability that enforcement cooperation is high, where competition laws are dissimilar, is even lower, at 0.02 , while, when legal similarity is high, it remains at 0.3 . The marginal odds ratio is much higher, at 24.8 , indicating a much stronger relationship between depth of enforcement cooperation and similarity of competition laws.

Clearly, the relationship between legal similarity and depth of enforcement cooperation is sensitive to the specification of legal similarity. Furthermore, the Bollard index is subject to the limitations noted, the sample size is small - 11 countries and 55 country pairs - and the legal similarity index is calculated at a single point in time (1994), while the depth of enforcement cooperation is measured over the period $1996-2006$. The similarity of laws of these countries may have changed somewhat over this period, and it is possible that there are a few formal cooperation agreements involving these country pairs that are not in the dataset.

\footnotetext{
${ }^{357}$ High cooperation is defined as level 5 or above on the EJI index.

${ }^{358}$ Calculated by adding 0.5 to the two cells in the row, so they read 28.5 and 0.5 .
} 
However, the strength of the association between low legal similarity and low enforcement cooperation, and the size of the odds ratios, which range from $5.3-24.8$ across all specifications, provides clear support for the hypothesis that enforcement cooperation between competition authorities is facilitated by a degree of similarity of substantive competition laws; and that enforcement cooperation is not a substitute for convergence of substantive competition laws.

\subsection{ENFORCEMENT COOPERATION AND GEOGRAPHY}

Recall from Chapter 10 the hypothesis that there will be a strong positive correlation between countries' depth of international economic policy cooperation and their geographic proximity.

To test this, two measures of geographic proximity have been employed. The first is whether the signatories share a common land border. In the case of agreements with multiple signatories, the test is whether half or more of the signatories share a common border. The second measure is whether signatories belong to the same sub-regional grouping, as defined by UNCTAD (see UNCTAD 2008). In the few cases where countries that share a common border are defined by UNCTAD as belonging to different regional groupings e.g. China and Russia, they are defined here as belonging to the same region.

Table 18 shows the relationship between depth of enforcement cooperation and whether signatories share a common land border, with high cooperation defined as level 4 or above on the EJI index.

\section{Table 18: Competition Enforcement Cooperation And Common Land Border}

Enforcement Cooperation

\begin{tabular}{|l|c|c|c|c|}
\hline & Low & High & Total & $\begin{array}{c}\text { Probability of } \\
\text { high } \\
\text { cooperation }\end{array}$ \\
\hline Non-contiguous & 34 & 40 & 74 & .54 \\
\hline Contiguous & 5 & 13 & 18 & .72 \\
\hline Total No. of agreements & 35 & 57 & 92 & \\
\hline
\end{tabular}

The estimated conditional probability that enforcement cooperation is high, where countries share a common land border, is 0.72 , while for non-contiguous 
countries it is 0.54 , a difference of proportions of only 0.18 . The $95 \%$ confidence interval, after adjusting for the finite population, is $(.05, .31)$, and the marginal odds ratio is only 2.2. This means that the estimated odds of high enforcement cooperation between countries sharing a common land border is only slightly more than two times higher than the odds where countries are non-contiguous. However, when high enforcement cooperation is redefined as level 5 or above, the odds ratio is 4.5 , indicating a somewhat stronger relationship at deeper levels of cooperation.

Turning to the relationship between depth of enforcement cooperation and whether signatories are in the same region, Table 19 displays the data.

\section{Table 19: Competition Enforcement Cooperation and Common Region}

\begin{tabular}{|l|c|c|c|c|}
\multicolumn{1}{l}{ Enforcement Cooperation } \\
\hline Low & High & Total & $\begin{array}{c}\text { Probability of } \\
\text { high } \\
\text { cooperation }\end{array}$ \\
\hline Different region & 29 & 34 & 63 & .54 \\
\hline Common region & 10 & 19 & 29 & .66 \\
\hline Total No. of agreements & 39 & 53 & 92 & \\
\hline
\end{tabular}

The estimated conditional probability that enforcement cooperation is high, where countries are in the same region, is 0.66 , while for non-regional countries it is 0.54 , giving a difference of proportions of only 0.12 . The $95 \%$ confidence interval, after adjusting for the finite population, is $(-0.02,0.26)$, and the marginal odds ratio is only 1.6, lower than in the contiguous case. This means that the estimated odds of high enforcement cooperation between countries in the same region is only one and a half times higher than the odds where countries are in different regions. When high enforcement cooperation is redefined as level 5 or above, the odds ratio is 2.7 .

However, when the data is disaggregated by instrument type, it shows a marked difference between CEAs and RTAs. There is a very weak relationship between depth of cooperation in CEAs and geographic proximity, and a strong relationship between RTAs and proximity.

For CEAs, the conditional probability of cooperation being high is almost the same for countries sharing a land border and countries that do not (.67 and .62). Common land 
border and depth of enforcement cooperation are close to being independent variables with respect to CEAs.

The conditional probability of cooperation being high in CEAs where countries are in the same region is 0.59 , while for countries in different regions it is higher, at 0.65 . Being in the same region is clearly not associated with deeper enforcement cooperation.

For RTAs, however, the conditional probability of enforcement cooperation being high when signatories share a common land border is 0.78 , and when they do not it is 0.44 , a difference of proportions of 0.34 . The adjusted $95 \%$ confidence interval is $(0.12,0.56)$. For the relationship between enforcement cooperation and shared region, the corresponding conditional probabilities are 0.75 and 0.41 , a difference of proportions of .34 .

Using the Bayesian approach from 14.1, and letting $\mathrm{P}(\mathrm{hi})=$ the conditional probability that Enforcement Cooperation is high when half or more signatories to an RTA share a land border, and $\mathrm{Q}(\mathrm{hi})=$ the conditional probability that Enforcement Cooperation is high when less than half do so, there is a probability of .986 that $\mathrm{P}(\mathrm{hI})$ is $20 \%$ larger than Q(hi).

That is, we can be over 98\% confident that the conditional probability of enforcement cooperation being high when half or more of the signatories of an RTA share a common land border, is $20 \%$ greater than the conditional probability of enforcement cooperation being high when fewer than half of the signatories share a common border.

The marginal odds ratio for the relationship in RTAs between high enforcement cooperation and common land border is 4.5 , and for common region it is 4.3 . When high cooperation is redefined as level 5 and above, the marginal odds ratios are 12.5 and 14.4 respectively.

To test the extent to which there results are driven by the inclusion of the 8 deep RTAs at level 7, these 8 agreements were omitted. For the remaining 33 RTAs, the relationship between common land border and depth of cooperation was negative. The same was true for the relationship with common region. 
In conclusion, geographic proximity appears to play little role in influencing the depth of cooperation in stand-alone competition enforcement agreements. For RTAs, geographic proximity is a good predictor of the depth of cooperation, but only when the eight level 7 agreements are included in the dataset.

\subsection{ENFORCEMENT COOPERATION AND TRANSGOVERNMENTALISM}

As noted in Chapter 12, Slaughter states that there is a fundamental difference between intergovernmental cooperation - formal state-to-state Treaties that can create binding obligations - and transgovernmental cooperation - agreements between government agencies rather than between states themselves. ${ }^{359}$ Slaughter states that agency-to-agency agreements have no formal recognition in international law.

In making this distinction, Slaughter builds on earlier work in international relations by Keohane and Nye (1971), who defined transgovernmental relations as "sets of direct interactions among sub-units of different governments that are not controlled or closely guided by the policies of the cabinets or chief executives of those governments." The concept is an alternative to the predominant view that international relations consist of formal treaties between unitary states.

A small number of international legal scholars have recently applied the concept of transgovernmentalism to the qualitative analysis of international competition policy cooperation (Raustiala 2002, Slaughter 2004, Whytock 2005). These studies all conclude, on the basis of an assessment of CEAs only, that the level of transgovernmentalism in international competition policy cooperation is high.

However, the empirical study of transgovernmentalism is in its infancy. As discussed in Box 10, there is a tension between the definitions of transgovernmentalism used in some of this research, and the authors' subsequent categorization of some legally binding CEAs as transgovernmental.

The framework developed in this thesis, together with the dataset compiled in Chapter 12 , allows some in-depth, cross-country, and multi-instrument exploration of the concept of transgovernmentalism in international competition policy cooperation.

${ }^{359}$ Slaughter 2004, p. 33. 


\section{Box 10: Transgovernmentalism as a Dependent Variable}

As defined by Keohane and Nye (1971), transgovernmental relations are "sets of direct interactions among sub-units of different governments that are not controlled or closely guided by the policies of the cabinets or chief executives of those governments." In the last ten years, a small number of scholars have applied this definition of transgovernmentalism to the analysis of the growing networks of direct interactions between government agencies across state borders. Slaughter (2004) introduced the concept of transgovernmental networks, identifying three types: government networks within international organizations; government networks within the framework of agreements negotiated by heads of state; and spontaneous government networks that arise without interstate agreement, comprising either formal regulatory organizations, or agreements between counterpart regulatory agencies that can be implemented by the regulators themselves.

Slaughter, Raustiala (2002) and Whytock (2005) call for research on transgovernmentalism, and both Raustiala and Whytock define transgovernmentalism for the purpose of case study research on international competition policy cooperation. The definitions lack clarity however. For instance, Slaughter's categories of government networks negotiated by heads of state, and spontaneous government networks without inter-state agreement, need to be refined when attempting to actually measure transgovernmentalism. There is a gray area between agreements negotiated by heads of state, and agreements purely on an agency-to-agency basis - as Keohane and Nye's definition allows for e.g. in international competition policy cooperation, some apparently agency-to-agency agreements are legally binding e.g. some agreements signed by the US Department of Justice, which have the status of executive agreements in US law. Raustiala acknowledges their legally binding nature, yet describes them as "informal agreements", and categorizes them as transgovernmental on the basis that they resemble informal MOUs in several respects, and that the use of a legally binding instrument in international competition cooperation, rather than an MOU, may be a historical accident (Raustiala 2002, FN 173). Whytock, in discussing one of these agreements (the 1999 EC-US CEA), distinguishes it from a treaty because, unlike treaties, executive agreements do not override any provisions of US law with which they may be inconsistent, and because the particular agreement was not signed by the President, unlike many other executive agreements (Whytock 2005, FN 167).

The categorization of these binding US agreements as transgovernmental by Raustiala and Whytock does not sit well with their definitions of transgovernmentalism, or with Slaughter's definition of a spontaneous government network. While there may be a basis for distinguishing between a treaty and an executive agreement, both are legally binding and therefore appear to fit Whytock's definition of an intergovernmental agreement. While they may resemble an MOU in some respects, and may, but for historical accident have been cast in the form of an MOU, they are in fact legally binding.

Whytock uses a qualitative measure of the relative levels of transgovernmentalism and intergovernmentalism in his case study "because of the difficulty of establishing a baseline with reference to which absolute levels of interstate and transgovernmental cooperation could be assessed..." The concept of jurisdictional integration put forward in this thesis is such a baseline. Whytock notes that: "improvements need to be made in the operationalisation of the concept of transgovernmentalism...improvement that will depend on further theoretical and empirical work." (Whytock 2005, p. 117). 
The starting point is the natural distinction between agreements embodied in a chapter of an RTA, and stand-alone competition policy agreements. Using Keohane and Nye's definition, RTAs are high profile instruments that are "controlled or closely guided" by governments. Even allowing for the fact that Competition Policy Chapters are typically not subject to the dispute settlement provisions in the RTA, they certainly would seem to have more of an inter-governmental character than a CEA signed only by the respective heads of the Competition Authorities. The second step is to recognize that not all CEAs are purely agency-to-agency agreements. While many of them are explicitly between, and signed by the heads of, the respective Competition Authorities, many of them are not. As noted by Holmes et. al., some CEAs are explicitly agreements between governments, not between agencies, and are signed by representatives of governments. ${ }^{360}$ This arguably lends them considerably more of an intergovernmental character than an agency-to-agency agreement. Zanettin concludes, from an analysis of four or five CEAs, that, with the exception of a 1984 Memorandum of Understanding between the US and Canada, the parties to the agreements were the governments of the relevant states, not their competition authorities. ${ }^{361}$

It may be legitimate, therefore, to group Competition Chapters in RTAs, with CEAs that are explicitly government-to-government agreements. Whether these agreements should be classified as intergovernmental, or as a deep form of transgovernmental agreement, is a moot point at this stage. They will be referred to here as "intergovernmental", to distinguish them from transgovernmental agreements (the remaining CEAs that are agency-to-agency agreements).

Having made this distinction, it is possible to explore the relationship between the depth of enforcement cooperation, and the form of the agreement. The hypothesis would be that deeper agreements are much more likely to be "intergovernmental." A state is likely to be less willing to delegate authority to its Competition Authority to sign international commitments that impinge more on the state's enforcement jurisdiction. ${ }^{362}$ For this

\footnotetext{
${ }^{360}$ Holmes et. al. undated, p. 51. In the case of agreements involving the EC, they are agreements by the EC, or the European Commission, not the Directorate General responsible for competition. In fact, the European Court of Justice held in 1994 that the Competition Commissioner was not competent to conclude the 1991 EC-US agreement.

${ }^{361}$ Zanettin, 2002, p. 77.

${ }^{362}$ See Sokol for a short discussion of principal-agent issues in the relationship between the executive and the anti-trust agency with respect to international competition cooperation. Sokol, 2007b, p.78.
} 
purpose, deep enforcement cooperation is defined as agreements containing positive comity or beyond i.e. levels 5, 6, or 7 on the EJI Index. Positive comity is judged to represent a significant threshold in international competition policy cooperation. Any relationship between depth of cooperation and form of agreement is more likely to be apparent at higher levels of the index.

Table 20 presents the data.

Table 20: Competition Enforcement Cooperation and Transgovernmentalism

\begin{tabular}{|l|c|c|c|c|}
\hline $\begin{array}{l}\text { Enforcement } \\
\text { Cooperation }\end{array}$ & Transgovernmental & "Intergovernmental" & Total & $\begin{array}{c}\text { Probability of } \\
\text { high cooperation }\end{array}$ \\
\hline $\begin{array}{l}\text { Low } \\
\text { Cooperation }\end{array}$ & 29 & 33 & 62 & .53 \\
\hline $\begin{array}{l}\text { High } \\
\text { Cooperation }\end{array}$ & 2 & 28 & 30 & .93 \\
\hline $\begin{array}{l}\text { Total No. of } \\
\text { agreements }\end{array}$ & 31 & 61 & 92 & \\
\hline
\end{tabular}

The first result that can be read from Table 20 is that, on this definition of transgovernmentalism, international competition policy cooperation is predominantly an "intergovernmental" phenomenon: 66\% (61/92) of agreements are "intergovernmental." This is due in part to the inclusion of RTAs in the dataset, and partly due to the classification of 20 CEAs as "intergovernmental."

Secondly, $93 \%$ of the agreements where enforcement cooperation is high, are “intergovernmental" agreements, while only $53 \%$ of the agreements where enforcement cooperation is low are "intergovernmental." This produces a difference of proportions of .4 , and an odds ratio of 12.3 .

Because Competition Chapters in RTAs are by definition classified here as "intergovernmental", it is interesting to look just at the stand-alone competition agreements. Table 21 presents the data.

More than half $(61 \%$, or $31 / 51)$ of agreements are now transgovernmental. The more interesting result, however, is that the difference of proportions is now $0.71(.88-.17)$.

\footnotetext{
${ }^{363}$ High cooperation is defined as level 5 or above on the EJI index.
} 
Table 21: Transgovernmentalism and Depth of Cooperation in CEAs

Form of Agreement

\begin{tabular}{|l|c|c|c|c|}
\hline $\begin{array}{l}\text { Enforcement } \\
\text { Cooperation }\end{array}$ & Transgovernmental & "Intergovernmental" & Total & $\begin{array}{c}\text { Probability of } \\
\text { high cooperation }\end{array}$ \\
\hline $\begin{array}{l}\text { Low } \\
\text { Cooperation }\end{array}$ & 29 & 6 & 35 & .17 \\
\hline $\begin{array}{l}\text { High } \\
\text { Cooperation }\end{array}$ & 2 & 14 & 16 & .88 \\
\hline $\begin{array}{l}\text { Total No. of } \\
\text { agreements }\end{array}$ & 31 & 20 & 51 & \\
\hline
\end{tabular}

How confident can we be of this relationship? The adjusted $95 \%$ confidence interval for the true difference is $(.57, .85)$. In other words, we can be $95 \%$ confident that the true difference of proportions is between .59 and .83 .

Again using the Bayesian approach from 14.1, and letting $\mathrm{P}(\mathrm{hi})=$ the conditional probability that a CEA is "intergovernmental" when enforcement cooperation is high, and $\mathrm{Q}(\mathrm{hi})=$ the conditional probability that a CEA is transgovernmental when enforcement cooperation is high, there is a probability of .978 that $\mathrm{P}(\mathrm{hi})$ is $300 \%$ larger than Q(hi).

That is, we can be nearly $98 \%$ confident that the conditional probability of a CEA being "intergovernmental" when enforcement cooperation is high is three times greater than the conditional probability of a CEA being transgovernmental when enforcement cooperation is high.

The odds ratio is 33.8 i.e. the estimated odds of a CEA being "intergovernmental" when enforcement cooperation is high, is 33.8 times higher than the odds of it being transgovernmental.

These results suggest that the depth of enforcement cooperation is a very good predictor of whether an agreement is transgovernmental or "intergovernmental."

\footnotetext{
${ }^{364}$ High cooperation is defined as level 5 or above on the EJI index.
} 
The results also suggest that there is value in disaggregation below a "soft/hard" instrument dichotomy. Because of the absence of binding dispute settlement mechanisms, and because many of the agreements explicitly state they are not binding, these 51 agreements are all arguably soft law instruments. Yet by disaggregating them by depth of jurisdictional integration, it is possible to discern two very clear patterns of state practice. Agreements that impinge less on states' enforcement jurisdiction are left to inter-agency agreements, while deeper agreements are very likely to attract the attention and the imprimatur of the government. This in turn supports the validity of the concept of jurisdictional integration, and the value of the enforcement cooperation index for measurement and research.

\subsection{Multivariate ANALYSIS}

Thus far the analysis has been confined to bivariate analysis, which does not allow for the possible confounding effect of unobserved variables on the two-way correlations. In this section, some initial multivariate analysis is undertaken to further test the strength of some of the relationships found in the previous sections. This analysis is conceived as exploratory analysis, and does not begin to attempt to rigorously control for the effect of confounding variables.

To begin with, a four-way contingency table is constructed that illustrates the relationships between the depth of enforcement cooperation and three variables. Variable 1 records whether the signatories to an agreement are both/all OECD members. A zero indicates there is at least one signatory that is a non-OECD member, and a 1 indicates that all signatories are members of the OECD. Variable 2 is the level of economic symmetry between signatories ( $0=$ low symmetry, $1=$ high symmetry). Variable 3 is whether the agreement is transgovernmental or "intergovernmental" $(0=$ transgovernmental). Table 22 presents the results. 
Table 22: Enforcement Cooperation, OECD Membership, Economic Symmetry, and Form of Agreement

Enforcement Cooperation

\begin{tabular}{|c|c|c|c|c|}
\hline & Low & High & Total & $\begin{array}{c}\text { Probability of high } \\
\text { cooperation }\end{array}$ \\
\hline $0,0,0$ & 8 & 2 & 10 & .20 \\
\hline $0,0,1$ & 17 & 12 & 29 & .41 \\
\hline $0,1,0$ & 4 & 2 & 6 & .33 \\
\hline $0,1,1$ & 3 & 5 & 8 & .63 \\
\hline $1,0,0$ & 2 & 4 & 6 & .67 \\
\hline $1,0,1$ & 2 & 16 & 18 & .89 \\
\hline $1,1,0$ & 1 & 6 & 7 & .86 \\
\hline $1,1,1$ & 0 & 5 & 5 & 1.0 \\
\hline Total & 37 & 52 & 89 & \\
\hline
\end{tabular}

The row $0,0,0$ refers to those agreements where a zero is recorded for each of the three variables. That is to say, of the agreements where at least one of the signatories was not an OECD member, and where economic symmetry was low, and which was a transgovernmental agreement, the row shows that 8 contained low enforcement cooperation, and 2 contained high cooperation (4+ on the EJI index).

From this four-way table, three-way tables can be constructed to analyse the effect of confounding variables one at a time on the relationship between OECD membership and the depth of enforcement cooperation.

For instance, the relationship between enforcement cooperation, OECD membership, and economic symmetry can be read from Table 22, and is presented in Table 23 below.

When the agreements are between countries with similar-sized economies (high economic symmetry), enforcement cooperation was high 42 percentage points more for OECD agreements compared to non-OECD agreements ( $92 \%$ - 50\%).

When the agreements are between countries with very different-sized economies, enforcement cooperation was high $47 \%$ more for OECD agreements compared to nonOECD agreements $(83 \%-36 \%)$. 
Table 23: Enforcement Cooperation, Economic Symmetry and OECD Membership

\begin{tabular}{|l|l|c|c|c|c|}
\hline & $\begin{array}{l}\text { OECD } \\
\text { membership }\end{array}$ & $\begin{array}{c}\text { Low } \\
\text { Cooperation }\end{array}$ & $\begin{array}{c}\text { High } \\
\text { Cooperation }\end{array}$ & Total & $\begin{array}{c}\text { Probability } \\
\text { of High } \\
\text { Cooperation }\end{array}$ \\
\hline Low symmetry & Non-OECD & 25 & 14 & 39 & .36 \\
& OECD & 4 & 20 & 24 & .83 \\
\hline High symmetry & Non-OECD & 7 & 7 & 14 & .50 \\
& OECD & 1 & 11 & 12 & .92 \\
\hline Total & Non-OECD & 32 & 21 & 53 & .40 \\
\hline & OECD & 5 & 31 & 36 & .86 \\
\hline & Total & 37 & 52 & 89 & \\
\hline
\end{tabular}

The difference of proportions is very similar in both cases. Thus, the strong relationship between OECD membership and the depth of enforcement cooperation, evident from the marginal association in Table 7, remains strong after allowing for the confounding effect of the level of economic asymmetry between the signatories. The level of economic asymmetry still appears to have little influence on the depth of enforcement cooperation.

Turning to the relationship between depth of cooperation, OECD membership, and the form of agreement, Table 24 presents the data.

When the agreements are transgovernmental, enforcement cooperation was high 52 percentage points more for OECD agreements compared to non-OECD agreements $(.77-.25)$ 
Table 24: Enforcement Cooperation, Form of Agreement, and OECD Membership

\begin{tabular}{|l|l|c|c|c|c|}
\hline Form of agreement & $\begin{array}{l}\text { OECD } \\
\text { membership }\end{array}$ & $\begin{array}{c}\text { Low } \\
\text { Cooperation }\end{array}$ & $\begin{array}{c}\text { High } \\
\text { Cooperation }\end{array}$ & $\begin{array}{c}\text { Total } \\
\text { Probability } \\
\text { of High } \\
\text { Cooperation }\end{array}$ \\
\hline Transgovernmental & Non-OECD & 12 & 4 & 16 & .25 \\
& OECD & 3 & 10 & 13 & .77 \\
\hline "Intergovernmental"" & Non-OECD & 20 & 17 & 37 & .46 \\
& OECD & 2 & 21 & 23 & .91 \\
\hline Total & Non-OECD & 32 & 21 & 53 & .40 \\
\hline & OECD & 5 & 31 & 36 & .86 \\
\hline
\end{tabular}

When the agreements are "intergovernmental," enforcement cooperation was high 45 percentage points more for OECD agreements compared to non-OECD agreements (.91-.46).

Again, the difference of proportions is very similar in both cases. Thus, the strong relationship between "intergovernmental" agreements and the depth of enforcement cooperation, evident in Table 20, remains strong after allowing for the confounding effect of OECD membership.

These results reflect the fact that OECD agreements are deeper, and deeper agreements are more likely to be "intergovernmental" i.e. the likely direction of influence (or causal mechanism) runs from depth of agreement to form of agreement, not the other way around.

Finally, the combination of OECD-only agreements and "inter-governmental" agreements appears to be a very good predictor of the depth of enforcement cooperation. When both of these variables are present, enforcement cooperation is high in $91 \%$ of cases $(21 / 23$ agreements). 


\subsection{VALIDITY OF RESULTS}

A test of inter-rater reliability is required in order to provide some assurance of the validity of the ordinal scale and the reliability of the rankings. That is, it is necessary to provide some assurance that other researchers and competition policy experts rate the agreements in broadly the same way; and that the methodology is reliable and can be replicated by other researchers.

To test this, a stratified random sample of 10 of the agreements was selected for independent ranking. The sample was taken from the population of 87 agreements in the dataset at the time ( 5 agreements were subsequently added). The sample was stratified, so that the distribution of agreements across levels 2-7 on the index is the same in the sample as in the dataset.

The selected agreements were:

1 CIS-Korea-Latvia-Romania 2003.

2 EFTA-Singapore 2003.

3 Japan-Thailand 2007.

4 Chile-Mexico 1999.

5 Australia-New Zealand 2006.

6 Brunei-Chile-New Zealand-Singapore 2005.

7 EC-South Africa 2000.

8 EFTA-Mexico 2001.

9 US-Canada 2004.

10 ANDEAN Group Decision 285 of 1991.

These 10 agreements were then independently rated by Dr. Philip Marsden on the basis of information sent to him drawn from Chapter 13.1 (with all references to specific agreements removed). Dr. Marsden is an expert on international competition policy cooperation. He is Director of the Competition Law Forum at the British Institute of International and Comparative Law, Editor of the European Competition Journal, and a Non-Executive Director of the UK Office of Fair Trading. 
Dr. Marsden's immediate ratings resulted in agreement in 8 out of the 10 cases. Subsequent discussion resulted in agreement on one further rating. Therefore, the final adjusted rate of agreement is $90 \%$.

Dr. Marsden's rating of, and subsequent discussion of the tenth agreement, prompted a small redefinition of the index, through a change to the treatment of references to mutual legal assistance. This affected the rating of only four agreements.

The results of the inter-rater reliability check provide a high degree of confidence in the validity and replicability of the results in this thesis.

\subsection{CONCLUSIONS}

The results in this chapter can be summarised as:

1. There is a very strong positive relationship between the depth of enforcement cooperation and whether all the signatories are OECD members, but only a moderate relationship between the depth of enforcement cooperation and country level of development.

2. We can be very confident that enforcement cooperation is low when signatories' substantive competition laws are dissimilar. Legal similarity is a necessary but not a sufficient condition for deep enforcement cooperation.

3. The depth of enforcement cooperation is a very good predictor of whether an agreement is a transgovernmental agreement or an "intergovernmental" agreement, especially when the effect of OECD membership is also incorporated.

4. There is only a moderate positive relationship between the depth of trade integration between countries and their depth of enforcement cooperation.

5. Economic asymmetry appears to have little impact on the depth of enforcement cooperation.

6. Geographic proximity appears to be an important factor influencing the depth of competition enforcement cooperation in RTAs, but appears to play little if any role in influencing the depth of cooperation in CEAs.

7. Enforcement cooperation in Customs Unions is in general deeper than in FTAs, but the data do not support the hypothesis that this gap is narrowing over time. The reason appears to be that the deepening of enforcement 
cooperation in some FTAs has been accompanied by an increasing number of shallower FTAs involving countries newly active in international competition policy enforcement cooperation.

8. Within RTAs, Customs Unions as a category are becoming less and less relevant. Nearly all new trade agreements are now FTAs, and it is variation in the depth of enforcement cooperation in FTAs that should be the object of more attention.

The result suggesting that the level of economic asymmetry has only weak effects on the depth of enforcement cooperation is, at first glance, perhaps surprising. There are theoretical reasons to expect that larger economies will not want to constrain their ability to act unilaterally in enforcing their competition laws. The fact that this variable appears to have little influence over the depth of enforcement cooperation may be due to the fact that the two largest economies, the US and the EC, are widely acknowledged to have been engaged in regulatory competition, in an attempt to have their model of competition law and enforcement adopted by countries in their region and more widely. ${ }^{365}$ This both provides advantages to their domestic firms operating in foreign jurisdictions, and increases their leverage in multilateral negotiations on international competition policy cooperation. Regulatory export could explain why large economies have signed relatively deep cooperation agreements with much smaller economies. In the case of the EC, foreign policy considerations are also an important factor that could explain the masking of the functionalist, economic causal mechanisms.

In addition, the relationship between economic asymmetry and depth of enforcement cooperation may be masked by the methodology used here. Transforming continuous data on GDP into ordinal categories (high and low symmetry), in order to undertake contingency table analysis, means that some of the information in the continuous data is lost. The same is true for data on trade integration. Additional statistical analysis, using logit or probit regression techniques would be an interesting follow-on from this study.

With respect to an "OECD-effect", on this evidence OECD membership appears to be a much better predictor of the depth of enforcement cooperation than country level of development. There are plausible reasons for this. The OECD has been very active in

\footnotetext{
${ }^{365}$ See for instance the discussion in Raustiala 2002.
} 
promoting deeper enforcement cooperation, both through its successive

Recommendations on Restrictive Business Practices since 1967, and through the activities of its Competition Law and Policy Committee, which promotes networking and fosters the relationships between Competition Authorities that are necessary to support the development of trust and closer cooperation.

On the other hand, a small number of observations drive this result. Mexico, a nonadvanced economy, is a party to a number of deep cooperation agreements, and this could be in part a "NAFTA effect" rather than an "OECD effect." NAFTA came into force the same year that Mexico joined the OECD, and increased the attractiveness of Mexico for international business and as a partner in economic cooperation agreements.

Countering this is the fact that Singapore is an advanced economy that has, as noted, signed seven RTAs with competition enforcement provisions, five of which are only level 2 or level 3 agreements. It seems plausible to speculate that Singapore's late adoption, for an advanced economy, of a competition law is related to the fact that it is not an OECD member. Section 12-1 of the 2004 Singapore-US FTA stipulated that Singapore shall enact general competition legislation by January 2005.

The case of Chile, a non-advanced country that is not a member of the OECD, could point either to an "OECD effect" or to a "NAFTA effect," although the latter is perhaps more plausible. Chile has signed six deep enforcement cooperation agreements (level 4 or 5) since 1997. It has been participating in OECD activities for a number of years, and in 2007 was invited to open discussions towards becoming an OECD member. This may reflect a wider "OECD effect." 366 On the other hand, Chile has actively been seeking to join NAFTA since the mid-1990s, and its Competition Policy Chapters in FTAs with Canada and Mexico in 1997 and 1999 respectively were closely modelled on the Competition Chapter in NAFTA. ${ }^{367}$

\footnotetext{
${ }^{366}$ In addition, the Israeli Competition Authority, which has a positive comity agreement with the US, has been an observer within the OECD since 2001 (although the Israel-US agreement was concluded in 1999). Dabbah, 2007, p.67. The OECD's influence in competition policy extends considerably beyond its member and prospective member countries. Yacheivstova notes its influence in the CIS countries since the mid-1990s. Yacheivstova 2000, p. 14.

${ }^{367}$ See Marsden 2005, p.5. Marsden notes that Chile was invited by the three NAFTA signatories in December 1994 to begin accessions talks.
} 
OECD membership may reflect, in turn, at least two causal mechanisms. The first is the hypothesized influence of quality of governance on the depth of enforcement cooperation - although this should also show through when using country level of development as a proxy for quality of governance, and, as noted, this is less apparent.

A second causal mechanism is elite norm diffusion, which does not operate with the same force amongst all advanced economies. "Advanced economy" is an administrative classification, not the basis of an international network or organisation. Participation in the OECD Competition Law and Policy Committee is viewed as a powerful transmission belt for the diffusion of norms, and a mechanism for the socialisation of officials in common ways of thinking. ${ }^{368}$ Furthermore, one would have expected that elite norm diffusion would operate more through CEAs than through RTAs, because of the much closer involvement of Competition Authority officials, who participate in OECD meetings, in negotiating CEAs. The statistical results that show a much stronger relationship between depth of enforcement cooperation and OECD membership in CEAs than in RTAs provide support for this.

Overall, the evidence is that common membership of the OECD is a very strong predictor of the depth of enforcement cooperation. Given the very active role played by the OECD over the last few decades in promoting international competition policy cooperation, and the consensus that its activities have an impact, the results suggest that membership of the OECD is likely to be a causal factor. Further empirical analysis is required to test this conclusion, however, both case study research, and additional multivariate analysis that attempts to control for the effects of confounding variables e.g. democracy.

Finally, when the data are disaggregated into CEAs and RTAs some differences are apparent in the relationship between the depth of enforcement cooperation and independent variables. There are theoretical reasons to expect some differences between CEAs and RTAs in this respect. First, RTAs are multi-sector instruments, which allow bargaining and trade-offs across issue areas. This can expand the set of feasible outcomes in the direction of deeper enforcement cooperation. Secondly, CEAs are negotiated directly by competition officials, and this facilitates the development of the

${ }^{368}$ Waller, 1999, p. 1125, cited in Slaughter 2004, p. 253. 
trust necessary to support deeper agency to agency cooperation. These factors are reflected in the fact that the deepest cooperation (level 7) is found only amongst countries that are signatory to an RTA; and the deepest competition policy-specific agreements (level 6) are CEAs. They may also be a factor in two of the further findings in this Chapter - when economic symmetry and geographic proximity are high, RTAs are somewhat more likely to feature high enforcement cooperation than are CEAs. However, it is difficult to discern a theoretical explanation for the difference in the relationship between CEAs and RTAs, on the one hand, and the level of trade integration, or advanced economy status on the other. When disaggregated, the number of agreements is relatively small, and there may be idiosyncratic features relating to a small number of agreements that is affecting the relationships. Further statistical analysis and case study research may help to throw additional light on this. 
Table 25: Summary Table: International Cooperation in Enforcing Competition Laws

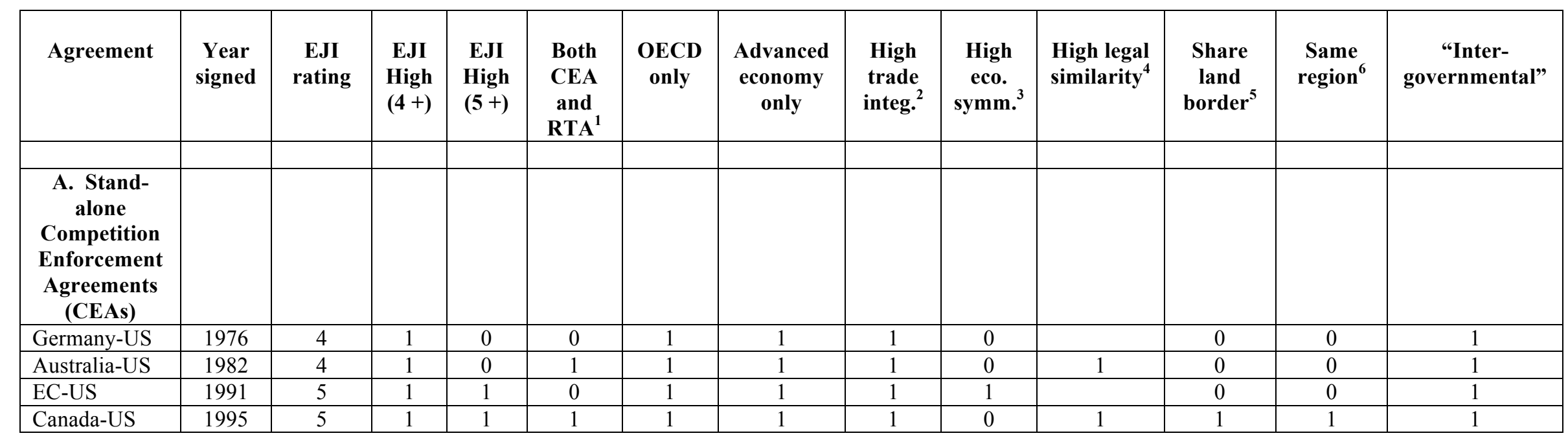

${ }^{1}$ This column records the existence of both a stand-alone competition enforcement agreement between the parties, and an RTA containing competition enforcement provisions.

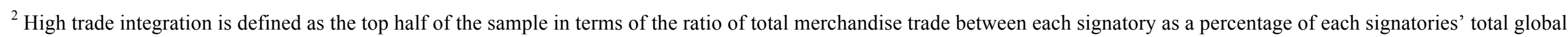
merchandise trade.

${ }^{3}$ High economic symmetry is defined (following Smith 2000), for a bilateral agreement, as where neither country's GDP exceeds 70\% of joint GDP; and for a pluritalateral agreement, where the largest country's GDP share is not more than twice as large as the second largest country's share.

${ }^{4}$ High legal similarity is defined as a score of $45+$ on the Bollard index (see Table 14).

${ }^{5}$ Where an agreement has more than two signatories, it is ranked as involving countries with a common land border if half or more of the signatories have a common border.

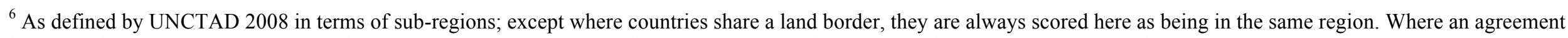
has more than two signatories, it is ranked as involving countries from the same region if half or more of the signatories are from the same region. 


\begin{tabular}{|c|c|c|c|c|c|c|c|c|c|c|c|c|c|}
\hline Agreement & $\begin{array}{l}\text { Year } \\
\text { of sig. }\end{array}$ & $\begin{array}{c}\text { EJI } \\
\text { rating }\end{array}$ & $\begin{array}{c}\text { EJI } \\
\text { High } \\
(4+)\end{array}$ & $\begin{array}{c}\text { EJI } \\
\text { High } \\
(5+)\end{array}$ & $\begin{array}{l}\text { Both } \\
\text { CEA } \\
\text { and } \\
\text { RTA }\end{array}$ & $\begin{array}{c}\text { OECD } \\
\text { only }\end{array}$ & DC only & $\begin{array}{l}\text { High } \\
\text { trade } \\
\text { integ. }\end{array}$ & $\begin{array}{c}\text { High } \\
\text { eco. } \\
\text { symm. }\end{array}$ & $\begin{array}{l}\text { High legal } \\
\text { similarity }\end{array}$ & $\begin{array}{c}\text { Share } \\
\text { land } \\
\text { border }\end{array}$ & $\begin{array}{l}\text { Same } \\
\text { region }\end{array}$ & $\begin{array}{c}\text { "Inter- } \\
\text { governmental" }\end{array}$ \\
\hline $\begin{array}{l}\text { Australia- } \\
\text { Taipei }\end{array}$ & 1996 & 4 & 1 & 0 & 0 & 0 & 1 & 0 & 1 & 0 & 0 & 0 & 0 \\
\hline China-Russia & 1996 & 2 & 0 & 0 & 0 & 0 & 0 & 0 & 0 & & 1 & 1 & 1 \\
\hline $\begin{array}{l}\text { Lithuania- } \\
\text { Ukraine }\end{array}$ & 1996 & 3 & 0 & 0 & 0 & 0 & 0 & 0 & 0 & & 0 & 1 & 0 \\
\hline $\begin{array}{l}\text { Hungary- } \\
\text { Russian Fed. }\end{array}$ & 1997 & 2 & 0 & 0 & 0 & 0 & 0 & 1 & 0 & & 0 & 1 & 0 \\
\hline EC-US & 1998 & 6 & 1 & 1 & 0 & 1 & 1 & 1 & 1 & & 0 & 0 & 1 \\
\hline Australia-US & 1999 & 6 & 1 & 1 & 1 & 1 & 1 & 1 & 0 & 1 & 0 & 0 & 1 \\
\hline Brazil-US & 1999 & 5 & 1 & 1 & 0 & 0 & 0 & 1 & 0 & & 0 & 0 & 1 \\
\hline Israel-US & 1999 & 5 & 1 & 1 & 0 & 0 & 1 & 1 & 0 & & 0 & 0 & 1 \\
\hline Japan-US & 1999 & 5 & 1 & 1 & 0 & 1 & 1 & 1 & 0 & 1 & 0 & 0 & 1 \\
\hline Canada-EC & 1999 & 5 & 1 & 1 & 0 & 1 & 1 & 0 & 0 & & 0 & 0 & 1 \\
\hline $\begin{array}{l}\text { Australia- } \\
\text { Papua New } \\
\text { Guinea }\end{array}$ & 1999 & 4 & 1 & 0 & 0 & 0 & 0 & 1 & 0 & & 0 & 1 & 0 \\
\hline $\begin{array}{l}\text { China- } \\
\text { Kazakhstan }\end{array}$ & 1999 & 2 & 0 & 0 & 0 & 0 & 0 & 0 & 0 & & 1 & 1 & 1 \\
\hline Korea-Russia & 1999 & 2 & 0 & 0 & 0 & 0 & 0 & 0 & 1 & & 0 & 0 & 0 \\
\hline CIS Regs. & 1999 & 4 & 1 & 0 & 1 & 0 & 0 & 1 & 0 & & 1 & 1 & 1 \\
\hline Mexico-US & 2000 & 5 & 1 & 1 & 1 & 1 & 0 & 1 & 0 & 1 & 1 & 1 & 1 \\
\hline $\begin{array}{l}\text { Australia- } \\
\text { Canada- NZ }\end{array}$ & 2000 & 4 & 1 & 0 & 0 & 1 & 1 & 1 & 1 & $\begin{array}{c}\text { A-C } 1 \\
\text { C-NZ } 1\end{array}$ & 0 & 0 & 0 \\
\hline $\begin{array}{l}\text { Canada- } \\
\text { Mexico }\end{array}$ & 2001 & 5 & 1 & 1 & 1 & 1 & 0 & 0 & 1 & 1 & 0 & 0 & 1 \\
\hline $\begin{array}{l}\text { Denmark- } \\
\text { Iceland- } \\
\text { Norway }\end{array}$ & 2001 & 6 & 1 & 1 & 1 & 1 & 1 & 1 & 1 & & 0 & 1 & 0 \\
\hline Canada-Chile & 2001 & 4 & 1 & 0 & 1 & 0 & 0 & 0 & 0 & & 0 & 0 & 0 \\
\hline
\end{tabular}




\begin{tabular}{|c|c|c|c|c|c|c|c|c|c|c|c|c|c|}
\hline Agreement & $\begin{array}{l}\text { Year } \\
\text { signed }\end{array}$ & $\begin{array}{c}\text { EJI } \\
\text { rating }\end{array}$ & $\begin{array}{c}\text { EJI } \\
\text { High } \\
(4+)\end{array}$ & $\begin{array}{c}\text { EJI } \\
\text { High } \\
(5+)\end{array}$ & $\begin{array}{l}\text { Both } \\
\text { CEA } \\
\text { and } \\
\text { RTA }\end{array}$ & $\begin{array}{c}\text { OECD } \\
\text { only }\end{array}$ & DC only & $\begin{array}{l}\text { High } \\
\text { trade } \\
\text { integ. }\end{array}$ & $\begin{array}{c}\text { High } \\
\text { eco. } \\
\text { symm. }\end{array}$ & $\begin{array}{l}\text { High legal } \\
\text { similarity }\end{array}$ & $\begin{array}{c}\text { Share } \\
\text { land } \\
\text { border }\end{array}$ & $\begin{array}{l}\text { Same } \\
\text { region }\end{array}$ & $\begin{array}{c}\text { "Inter- } \\
\text { governmental" }\end{array}$ \\
\hline Brazil-Russia & 2001 & 2 & 0 & 0 & 0 & 0 & 0 & 0 & 1 & & 0 & 0 & 1 \\
\hline $\begin{array}{l}\text { Australia- } \\
\text { Korea }\end{array}$ & 2002 & 4 & 1 & 0 & 0 & 1 & 1 & 0 & 1 & 0 & 0 & 0 & 0 \\
\hline $\begin{array}{l}\text { Australia- NZ- } \\
\text { Taiwan }\end{array}$ & 2002 & 4 & 1 & 0 & 0 & 0 & 1 & 1 & 1 & $\begin{array}{c}\text { A-T } 0 \\
\text { NZ-T } 1\end{array}$ & 0 & 0 & 0 \\
\hline Australia-Fiji & 2002 & 2 & 0 & 0 & 0 & 0 & 0 & 1 & 0 & & 0 & 1 & 0 \\
\hline ECA Mergers & 2002 & 4 & 1 & 0 & 1 & 1 & 1 & & 0 & & 1 & 1 & 0 \\
\hline $\begin{array}{l}\text { Australia-NZ- } \\
\text { UK }\end{array}$ & 2003 & 4 & 1 & 0 & 0 & 1 & 1 & 1 & 0 & & 0 & 0 & 0 \\
\hline Canada-UK & 2003 & 4 & 1 & 0 & 0 & 1 & 1 & 0 & 1 & & 0 & 0 & 0 \\
\hline $\begin{array}{l}\text { CIS- Korea } \\
\text { Latvia- } \\
\text { Romania }\end{array}$ & 2003 & 2 & 0 & 0 & 0 & 0 & 0 & & 1 & & 0 & 0 & 0 \\
\hline EC-Japan & 2003 & 5 & 1 & 1 & 0 & 1 & 1 & 1 & 0 & & 0 & 0 & 0 \\
\hline $\begin{array}{l}\text { ECN (Reg. } \\
1 / 2003)\end{array}$ & 2003 & 7 & 1 & 1 & 1 & 0 & 0 & 1 & 1 & & 1 & 1 & 1 \\
\hline $\begin{array}{l}\text { Mexico- } \\
\text { Russian Fed. }\end{array}$ & 2003 & 2 & 0 & 0 & 0 & 0 & 0 & 0 & 1 & & 0 & 0 & 0 \\
\hline $\begin{array}{l}\text { Bolivia- } \\
\text { Russian Fed. }\end{array}$ & 2003 & 2 & 0 & 0 & 0 & 0 & 0 & 0 & 0 & & 0 & 0 & 0 \\
\hline Canada-US & 2004 & 6 & 1 & 1 & 1 & 1 & 1 & 1 & 0 & 1 & 1 & 1 & 1 \\
\hline France-Taiwan & 2004 & 3 & 0 & 0 & 0 & 0 & 1 & 0 & 0 & & 0 & 0 & 0 \\
\hline $\begin{array}{l}\text { Korea - } \\
\text { Mexico }\end{array}$ & 2004 & 5 & 1 & 1 & 0 & 1 & 0 & 0 & 1 & 0 & 0 & 0 & 0 \\
\hline EC-Korea & 2004 & 3 & 0 & 0 & 0 & 1 & 1 & 1 & 0 & & 0 & 0 & 0 \\
\hline $\begin{array}{l}\text { Russian Fed.- } \\
\text { Sweden }\end{array}$ & 2004 & 2 & 0 & 0 & 0 & 0 & 0 & 0 & 0 & & 0 & 1 & 0 \\
\hline China-EC & 2004 & 2 & 0 & 0 & 0 & 0 & 0 & 1 & 1 & & 0 & 0 & 0 \\
\hline Canada -Japan & 2005 & 5 & 1 & 1 & 0 & 1 & 1 & 0 & 0 & 1 & 0 & 0 & 1 \\
\hline
\end{tabular}




\begin{tabular}{|c|c|c|c|c|c|c|c|c|c|c|c|c|c|}
\hline Agreement & $\begin{array}{l}\text { Year } \\
\text { signed }\end{array}$ & $\begin{array}{c}\text { EJI } \\
\text { rating }\end{array}$ & $\begin{array}{c}\text { EJI } \\
\text { High } \\
(4+)\end{array}$ & $\begin{array}{c}\text { EJI } \\
\text { High } \\
(5+)\end{array}$ & $\begin{array}{l}\text { Both } \\
\text { CEA } \\
\text { and } \\
\text { RTA }\end{array}$ & $\begin{array}{c}\text { OECD } \\
\text { only }\end{array}$ & DC only & $\begin{array}{l}\text { High } \\
\text { trade } \\
\text { integ. }\end{array}$ & $\begin{array}{c}\text { High } \\
\text { eco. } \\
\text { symm. }\end{array}$ & $\begin{array}{l}\text { High legal } \\
\text { similarity }\end{array}$ & $\begin{array}{c}\text { Share } \\
\text { land } \\
\text { border }\end{array}$ & $\begin{array}{l}\text { Same } \\
\text { region }\end{array}$ & $\begin{array}{c}\text { "Inter- } \\
\text { governmental" }\end{array}$ \\
\hline Korea-Turkey & 2005 & 3 & 0 & 0 & 0 & 1 & 0 & 0 & 1 & & 0 & 0 & 0 \\
\hline $\begin{array}{l}\text { Romania- } \\
\text { Turkey }\end{array}$ & 2005 & 2 & 0 & 0 & 0 & 0 & 0 & 0 & 0 & & 0 & & 0 \\
\hline Australia-NZ & 2006 & 4 & 1 & 0 & 0 & 1 & 1 & 1 & 0 & 1 & & 1 & 0 \\
\hline Canada-Korea & 2006 & 4 & 1 & 0 & 0 & 1 & 1 & 0 & 1 & 0 & 0 & 0 & 0 \\
\hline $\begin{array}{l}\text { Albania- } \\
\text { Greece }\end{array}$ & 2006 & 2 & 0 & 0 & 0 & 0 & 0 & 1 & 0 & & 1 & 1 & 0 \\
\hline $\begin{array}{l}\text { Armenia- } \\
\text { Moldova }\end{array}$ & 2007 & 4 & 1 & 0 & 1 & 0 & 0 & 0 & 1 & & 0 & 0 & 0 \\
\hline Australia-NZ & 2007 & 4 & 1 & 0 & 0 & 1 & 1 & 1 & 0 & 1 & 0 & 1 & 0 \\
\hline $\begin{array}{l}\text { Mongolia- } \\
\text { Taiwan }\end{array}$ & 2007 & 2 & 0 & 0 & 0 & 0 & 0 & 0 & & & 0 & 0 & 0 \\
\hline $\begin{array}{l}\text { Portugal- } \\
\text { Turkey }\end{array}$ & 2008 & 3 & 0 & 0 & 1 & 1 & 0 & 0 & 0 & & 0 & 0 & 0 \\
\hline $\begin{array}{r}\text { Total CEAs } \\
\text { (percentage) }\end{array}$ & 51 & & $\begin{array}{c}32 \\
63 \%\end{array}$ & $\begin{array}{c}16 \\
31 \%\end{array}$ & 13 & $\begin{array}{c}26 \\
51 \%\end{array}$ & $\begin{array}{c}25 \\
49 \%\end{array}$ & $\begin{array}{c}26 \\
51 \%\end{array}$ & $\begin{array}{c}19 \\
37 \%\end{array}$ & & $\begin{array}{c}9 \\
18 \%\end{array}$ & $\begin{array}{c}17 \\
33 \%\end{array}$ & $\begin{array}{c}19 \\
37 \%\end{array}$ \\
\hline $\begin{array}{l}\text { B. RTAs with } \\
\text { enforcement } \\
\text { cooperation }\end{array}$ & & & & & & & & & & & & & \\
\hline $\mathrm{EC}$ & 1958 & 7 & 1 & 1 & & 1 & 1 & 1 & 1 & & 1 & 1 & 1 \\
\hline EFTA & 1960 & 7 & 1 & 1 & & 1 & 1 & 1 & 0 & & 0 & 1 & 1 \\
\hline $\begin{array}{l}\text { ANDEAN } \\
\text { Group } \\
\text { (Decision 285) }\end{array}$ & 1991 & 7 & 1 & 1 & & 0 & 0 & 0 & 1 & & 1 & 1 & 1 \\
\hline EEA & 1994 & 7 & 1 & 1 & & 1 & 1 & 1 & 0 & & 0 & 1 & 1 \\
\hline NAFTA & 1994 & 3 & 0 & 0 & & 1 & 0 & 1 & 0 & All 1 & 1 & 1 & 1 \\
\hline WAEMU & 1994 & 7 & 1 & 1 & & 0 & 0 & 1 & 0 & & 1 & 1 & 1 \\
\hline EC-Turkey & 1996 & 5 & 1 & 1 & & 1 & 0 & 1 & 0 & & 1 & 1 & 1 \\
\hline
\end{tabular}




\begin{tabular}{|c|c|c|c|c|c|c|c|c|c|c|c|c|c|}
\hline Agreement & $\begin{array}{l}\text { Year } \\
\text { signed }\end{array}$ & $\begin{array}{c}\text { EJI } \\
\text { rating }\end{array}$ & $\begin{array}{c}\text { EJI } \\
\text { High } \\
(4+)\end{array}$ & $\begin{array}{c}\text { EJI } \\
\text { High } \\
(5+)\end{array}$ & $\begin{array}{c}\text { Both } \\
\text { CEA } \\
\text { and } \\
\text { RTA }\end{array}$ & $\begin{array}{c}\text { OECD } \\
\text { only }\end{array}$ & DC only & $\begin{array}{l}\text { High } \\
\text { trade } \\
\text { integ. }\end{array}$ & $\begin{array}{c}\text { High } \\
\text { eco. } \\
\text { symm. }\end{array}$ & $\begin{array}{l}\text { High legal } \\
\text { similarity }\end{array}$ & $\begin{array}{c}\text { Share } \\
\text { land } \\
\text { border }\end{array}$ & $\begin{array}{l}\text { Same } \\
\text { region }\end{array}$ & $\begin{array}{c}\text { "Inter- } \\
\text { governmental" }\end{array}$ \\
\hline Canada-Israel & 1997 & 3 & 0 & 0 & & 0 & 1 & 0 & 0 & & 0 & 0 & 1 \\
\hline Canada-Chile & 1997 & 3 & 0 & 0 & & 0 & 0 & 0 & 0 & & 0 & 0 & 1 \\
\hline Chile-Mexico & 1999 & 2 & 0 & 0 & & 0 & 0 & 0 & 0 & & 0 & 0 & 1 \\
\hline CEMAC 1/99 & 1999 & 7 & 1 & 1 & & 0 & 0 & 0 & 0 & & 1 & 1 & 1 \\
\hline $\begin{array}{l}\text { CARICOM } \\
\text { Protocol VIII }\end{array}$ & 2000 & 7 & 1 & 1 & & 0 & 0 & 1 & 1 & & 0 & 1 & 1 \\
\hline EC-Mexico & 2000 & 4 & 1 & 0 & & 1 & 0 & 0 & 0 & & 0 & 0 & 1 \\
\hline Israel-Mexico & 2000 & 3 & 0 & 0 & & 0 & 0 & 0 & 0 & & 0 & 0 & 1 \\
\hline $\begin{array}{l}\text { EC-South } \\
\text { Africa }\end{array}$ & 2000 & 5 & 1 & 1 & & 0 & 0 & 1 & 0 & & 0 & 0 & 1 \\
\hline EFTA-Mexico & 2001 & 5 & 1 & 1 & & 1 & 0 & 0 & 0 & & 0 & 0 & 1 \\
\hline NZ-Singapore & 2001 & 2 & 0 & 0 & & 0 & 1 & 0 & 1 & & 0 & 0 & 1 \\
\hline $\begin{array}{l}\text { Japan- } \\
\text { Singapore }\end{array}$ & 2002 & 4 & 1 & 0 & & 0 & 1 & 1 & 0 & & 0 & 0 & 1 \\
\hline $\begin{array}{l}\text { Canada-Costa } \\
\text { Rica }\end{array}$ & 2002 & 4 & 1 & 0 & & 0 & 0 & 0 & 0 & & 0 & 0 & 1 \\
\hline SACU & 2002 & 2 & 0 & 0 & & 0 & 0 & & & & 1 & 1 & 1 \\
\hline Algeria-EC & 2002 & 4 & 1 & 0 & & 0 & 0 & 1 & 0 & & 0 & 0 & 1 \\
\hline Chile-EC & 2003 & 4 & 1 & 0 & & 0 & 0 & 1 & 0 & & 0 & 0 & 1 \\
\hline $\begin{array}{l}\text { EFTA- } \\
\text { Singapore }\end{array}$ & 2003 & 2 & 0 & 0 & & 0 & 1 & 0 & 0 & & 0 & 0 & 1 \\
\hline $\begin{array}{l}\text { Australia- } \\
\text { Singapore }\end{array}$ & 2003 & 2 & 0 & 0 & & 0 & 1 & 0 & 0 & & 0 & 0 & 1 \\
\hline Chile-EFTA & 2004 & 5 & 1 & 1 & & 0 & 0 & 0 & 1 & & 0 & 0 & 1 \\
\hline Chile-Korea & 2004 & 4 & 1 & 0 & & 0 & 0 & 0 & 0 & & 0 & 0 & 1 \\
\hline Chile-US & 2004 & 3 & 0 & 0 & & 0 & 0 & 1 & 0 & & 0 & 0 & 1 \\
\hline Singapore-US & 2004 & 2 & 0 & 0 & & 0 & 1 & 1 & 0 & & 0 & 0 & 1 \\
\hline $\begin{array}{l}\text { COMESA } \\
\text { Regs }\end{array}$ & 2004 & 7 & 1 & 1 & & 0 & 0 & 1 & 0 & & 1 & 1 & 1 \\
\hline Australia-US & 2005 & 5 & 1 & 1 & & 1 & 1 & 1 & 0 & 1 & 0 & 0 & 1 \\
\hline
\end{tabular}




\begin{tabular}{|c|c|c|c|c|c|c|c|c|c|c|c|c|c|}
\hline Agreement & $\begin{array}{c}\text { Year } \\
\text { entry } \\
\text { in } \\
\text { force }\end{array}$ & $\begin{array}{c}\text { EJI } \\
\text { rating }\end{array}$ & $\begin{array}{c}\text { EJI } \\
\text { High } \\
(4+)\end{array}$ & $\begin{array}{c}\text { EJI } \\
\text { High } \\
(5+)\end{array}$ & $\begin{array}{l}\text { Both } \\
\text { CEA } \\
\text { and } \\
\text { RTA }\end{array}$ & $\begin{array}{l}\text { OECD } \\
\text { only }\end{array}$ & DC only & $\begin{array}{l}\text { High } \\
\text { trade } \\
\text { integ. }\end{array}$ & $\begin{array}{c}\text { High } \\
\text { eco. } \\
\text { symm. }\end{array}$ & $\begin{array}{c}\text { High legal } \\
\text { similarity }\end{array}$ & $\begin{array}{c}\text { Share } \\
\text { land } \\
\text { border }\end{array}$ & $\begin{array}{l}\text { Same } \\
\text { region }\end{array}$ & $\begin{array}{c}\text { "Inter- } \\
\text { governmental" }\end{array}$ \\
\hline Japan-Mexico & 2005 & 5 & 1 & 1 & & 1 & 0 & 0 & 0 & 0 & 0 & 0 & 1 \\
\hline $\begin{array}{l}\text { Australia- } \\
\text { Thailand }\end{array}$ & 2005 & 3 & 0 & 0 & & 0 & 0 & 0 & 1 & 0 & 0 & 0 & 1 \\
\hline NZ-Thailand & 2005 & 3 & 0 & 0 & & 0 & 0 & 0 & 0 & 0 & 0 & 0 & 1 \\
\hline $\begin{array}{l}\text { Brunei-Chile- } \\
\text { NZ- Singapore }\end{array}$ & 2006 & 4 & 1 & 0 & & 0 & 0 & 0 & 1 & & 0 & 0 & 1 \\
\hline $\begin{array}{l}\text { Korea- } \\
\text { Singapore }\end{array}$ & 2006 & 2 & 0 & 0 & & 0 & 1 & 0 & 0 & & 0 & 0 & 1 \\
\hline $\begin{array}{l}\text { Panama- } \\
\text { Singapore }\end{array}$ & 2006 & 2 & 0 & 0 & & 0 & 0 & 1 & 0 & & 0 & 0 & 1 \\
\hline EFTA-Korea & 2006 & 3 & 0 & 0 & & 1 & 1 & 0 & 0 & & 0 & 0 & 1 \\
\hline $\begin{array}{l}\text { Japan- } \\
\text { Philippines }\end{array}$ & 2006 & 2 & 0 & 0 & & 0 & 0 & 1 & 0 & & 0 & 1 & 1 \\
\hline $\begin{array}{l}\text { EFTA- } \\
\text { Lebanon }\end{array}$ & 2007 & 2 & 0 & 0 & & 0 & 0 & 0 & 0 & & 0 & 0 & 1 \\
\hline $\begin{array}{l}\text { Japan- } \\
\text { Thailand }\end{array}$ & 2007 & 3 & 0 & 0 & & 0 & 0 & 1 & 0 & 0 & 0 & 0 & 1 \\
\hline Chile-Japan & 2007 & 2 & 0 & 0 & & 0 & 0 & 0 & 0 & & 0 & 0 & 1 \\
\hline & & & & & & & & & & & & & \\
\hline $\begin{array}{l}\text { Total RTAs } \\
\text { (percentage) }\end{array}$ & 41 & & $\begin{array}{c}21 \\
51 \%\end{array}$ & $\begin{array}{c}14 \\
34 \%\end{array}$ & 13 & $\begin{array}{c}10 \\
24 \%\end{array}$ & $\begin{array}{c}12 \\
29 \%\end{array}$ & $\begin{array}{c}18 \\
44 \%\end{array}$ & $\begin{array}{c}7 \\
17 \%\end{array}$ & & $\begin{array}{c}8 \\
20 \%\end{array}$ & $\begin{array}{c}12 \\
29 \%\end{array}$ & $\begin{array}{c}41 \\
100 \%\end{array}$ \\
\hline $\begin{array}{c}\text { Total CEAs } \\
\text { (percentage) }\end{array}$ & 51 & & $\begin{array}{c}32 \\
63 \% \\
\end{array}$ & $\begin{array}{c}16 \\
31 \% \\
\end{array}$ & & $\begin{array}{c}26 \\
51 \% \\
\end{array}$ & $\begin{array}{c}25 \\
49 \% \\
\end{array}$ & $\begin{array}{c}26 \\
51 \% \\
\end{array}$ & $\begin{array}{c}19 \\
37 \% \\
\end{array}$ & & $\begin{array}{c}9 \\
18 \% \\
\end{array}$ & $\begin{array}{c}17 \\
33 \% \\
\end{array}$ & $\begin{array}{c}19 \\
37 \% \\
\end{array}$ \\
\hline $\begin{array}{c}\text { Total CEAs } \\
\text { and RTAs }\end{array}$ & 92 & & $\begin{array}{c}53 \\
58 \%\end{array}$ & $\begin{array}{c}30 \\
33 \%\end{array}$ & 13 & $\begin{array}{c}36 \\
39 \%\end{array}$ & $\begin{array}{c}37 \\
40 \%\end{array}$ & $\begin{array}{c}44 \\
48 \%\end{array}$ & $\begin{array}{c}26 \\
28 \%\end{array}$ & & $\begin{array}{c}17 \\
18 \%\end{array}$ & $\begin{array}{c}29 \\
32 \%\end{array}$ & $\begin{array}{c}60 \\
65 \%\end{array}$ \\
\hline
\end{tabular}


PART 4

Conclusion 


\section{Chapter 15}

\section{THESIS CONCLUSIONS}

\subsection{CONTRIBUTION TO KNOWLEDGE}

The burgeoning literature on globalization has focused on international economic integration, but has paid relatively little attention to international policy integration as a distinct phenomenon. The result is that there is no recognized direct measure of the depth of international policy cooperation, in terms of measuring the extent to which states voluntarily agree to limit their authority to make and/or to implement policies.

Existing indicators use proxies that are less and less accurate as measurements of the depth of policy cooperation - such as the number of treaties a country has signed or whether an RTA is an FTA or a Customs Union. International economic cooperation increasingly takes place directly between government agencies and their counterparts in other states, rather than in formal government-to-government agreements such as FTAs. And, with respect to FTAs, merely counting their increasing number fails to account for the very wide variation across and within different FTAs, in the extent to which their provisions impinge on signatories' authority to make or to enforce rules free from external interference or involvement.

There appear to have been few previous attempts to directly measure the depth of international policy cooperation. There have also been few attempts to assess policy cooperation in a specific policy domain across the different international instruments in which such cooperation is embodied. A number of studies, for instance, analyze international policy cooperation in a particular policy domain by looking only at the provisions in RTAs, or only at the provisions in stand-alone Competition Enforcement Agreements. 
This thesis has attempted to address this "international policy cooperation deficit" in a comprehensive and systematic way. It has done so by:

1. Developing a new conceptual framework based on the concept of state jurisdiction rather than state sovereignty.

2. Defining a new variable to measure the depth of international economic policy cooperation - jurisdictional integration - and designing instruments to measure distinct dimensions of jurisdictional integration in the field of competition policy.

3. Compiling a comprehensive dataset of international competition policy cooperation agreements, and ranking the agreements against the ordinal indices.

4. Generating summary descriptive statistics, and testing descriptive propositions in the literature.

5. Conducting exploratory statistical analysis of hypothesized relationships between the depth of policy cooperation and a range of predictor variables.

The "international policy cooperation deficit" is first and foremost due to the fact that there is no conceptually coherent basis for measuring the depth of international policy cooperation. A key finding of the literature reviews was that insufficient attention has been paid to the phenomena of voluntarily agreed limitations on a state's recognised authority to make and to enforce policies. For instance, international law has focused on the problem of excessive extra-territorial assertions of state jurisdiction, and of overlapping and conflicting jurisdiction, rather than on the degree of intrusion on jurisdiction voluntarily agreed to between states. International relations theorists, on the other hand - with the exception of a neglected literature on regional integration from the 1960s, and the recent legalization literature - have focused on the conditions under which cooperation occurs, and the functions cooperation performs, rather than how cooperation varies in its impact on de jure state authority.

These conceptual shortcomings are inevitably reflected in an inability to satisfactorily measure the depth of international policy cooperation. Existing datasets were primarily compiled to measure phenomena such as the legal form of an agreement, the simple presence or absence of specific agreement features, or the extent to which provisions are compatible with the multilateral trading system, not to measure the depth of cooperation. 
To address these conceptual shortcomings, the fundamental but contested concept of state sovereignty must be revisited. Responding to calls for "research on the transformation of fundamental structures in international relations" (Ruggie, 1993), and an "... almost urgent need for much better analytical and disaggregated explorations of ...international economic law concepts" (Jackson, 2006), the thesis has argued that the concept of state jurisdiction is more conceptually coherent than the concept of state sovereignty.

In particular, the thesis introduces the concept of jurisdictional integration to better characterise the contemporary practice of state sovereignty. Drawing on established categories of international law, jurisdictional integration is defined as a process by which a state chooses, through entering formal agreements with other states, to restrict its recognized authority to autonomously make and/or to enforce decisions in a specific policy domain.

Jurisdictional integration constitutes a new variable to measure the depth of international economic policy cooperation. It is conceptually similar to, but more precise than Krasner's concept of “compromises of Westphalian sovereignty by invitation."

The conceptual framework thus builds on and is fully consistent with core concepts in international law, relating to state jurisdiction. It is also consistent with international relations scholarship on the nature of state sovereignty.

The distinct dimensions of jurisdictional integration identified in the thesis facilitate the identification and coherent categorization of the diverse range of international economic cooperation provisions. The new taxonomy introduced - simple cooperation, coordination, horizontal integration, vertical integration - also facilitates a richer discussion and a more precise exploration of policy alternatives than the prevailing "binary" approaches, such as shallow or deep cooperation, soft or hard law, or intergovernmental or supranational agreements. 
The thesis then attempted to demonstrate that jurisdictional integration is not only more conceptually coherent as a characterization of international economic policy cooperation, it is also more tractable.

To that end, two approaches were taken to operationalize the conceptual framework erected in Part 2 of the thesis. First, the concept of jurisdictional integration was applied to an existing WTO dataset of non-tariff provisions in RTAs. This yielded a measure of the changing depth of policy cooperation in RTAs. This new approach to the data reveals that the aggregate level of policy cooperation in RTAs signed between 19901998 was over six times higher than in pre-1990 RTAs; and that the average incidence of the deep policy cooperation provisions per RTA increased by $118 \%$ between the two periods.

For the period to 1998, these results constitute evidence refuting the hypothesis that multilateral trade liberalization leads to less politically integrated RTAs. The results also provide limited support for the hypothesis put forward in this thesis, that international economic policy cooperation is a complement to the increase in the number of countries - building on Alesina and Spolaore, 2003, whose research explored the relationship between trade liberalization and the size and number of countries.

The WTO dataset on non-tariff provisions does not allow for measurement of the depth of policy cooperation by country. Nor is there, to the author's knowledge, an existing dataset of the provisions of a substantial number of international economic agreements that would allow the ranking of countries by the depth of policy cooperation.

Therefore, to provide further evidence of the utility of the concept of jurisdictional integration, a new dataset was constructed of international agreements containing provisions on competition policy cooperation. This dataset is significantly larger than existing datasets in this field, and spans both RTAs and stand-alone Competition Enforcement Agreements, rather than being confined to one instrument. The dataset is available for use by other researchers.

Competition policy is a good candidate to pilot this research approach, for a number of reasons. First, increasingly mobile economic actors create the need for increased "regulatory reach" and potential jurisdictional conflict. Secondly, the rapid expansion in 
the number of countries that have national competition laws has increased the potential for jurisdictional conflicts. Thirdly, there is a growing number of international agreements of various types that are publicly available. Finally, for some time there has been a high level of international policy and research interest in international cooperation in competition policy, in part reflecting heightened concern over the welfare costs of international anti-competitive activities. For instance, it has been estimated that the monopoly rent extracted by international cartels is in the range of US\$20-25 billion per annum, approaching half the volume of total international development assistance. ${ }^{369}$

Measuring the depth of international competition policy cooperation required the construction of new measurement instruments. To that end, ordinal indices of jurisdictional integration, across the different domains of state jurisdiction, were designed. These are based on the framework of jurisdictional integration constructed in Part 2 of the thesis.

The indices were then used to rank the depth of enforcement cooperation in 92 international agreements. As a result of the influence of successive OECD Recommendations, and of key Competition Enforcement Agreements, there is a high degree of clarity around the concepts and terminology in this area, and a high degree of uniformity of substantive provisions across different international agreements containing provisions on enforcement cooperation. This facilitated the identification of discrete levels of jurisdictional integration, and the reliable coding of agreements against the indices. These rankings by depth of enforcement cooperation are similarly available to other researchers.

Compared to the binary distinction that is typical of many pre-existing approaches, the ordinal indices provide a more detailed ordering of distinct levels of depth of cooperation. It is difficult to use existing methods to directly compare the depth of policy cooperation across regions, across instrument types, or across different chapters in an RTA, because they mainly rely on proxies for depth of policy cooperation rather than direct measures. The method developed here facilitates comparisons between different regional agreements, including incorporation of the EC in such comparisons, and it is capable of comparing integration arrangements of varying types. This

${ }^{369}$ Jenny, 2003, pp. 615-616. 
functionality has been identified in the literature on comparative regional integration as a gap.

The indices of depth of jurisdictional integration build on the work of an earlier wave of scholars of regional integration, lead by Lindberg and Nye, who were interested in measuring levels of regional integration, and whose contribution has been somewhat neglected. The indices also build on the recent literature on the legalization of international relations, by adding to that literature's focus on adjudication, the important dimensions of prescriptive and non-judicial enforcement cooperation. The thesis also builds on the research by Smith (2000), whose index of legalism in dispute settlement mechanisms in RTAs is conceptually similar, and was drawn on in developing the index of integration of inter-state adjudication jurisdiction in this thesis. Smith's use of the index of legalism to test hypotheses about the causes of legalism in RTAs shows the potential for this general approach to add value. This thesis generalises Smith's approach to all types of international economic cooperation, and all types of agreements and instruments.

The 92 enforcement cooperation agreements were then used to compile summary statistics describing the nature of international cooperation in this field. These were used to test a number of descriptive propositions in the literature about the nature of international competition policy cooperation. Some of the propositions were found to be less than accurate, others to be no longer accurate, or to apply to one but not both types of agreement. For instance:

1. While the proportion of all enforcement cooperation agreements that are between OECD members is declining, as asserted in the literature, a different picture emerges from an analysis by instrument type. The proportion of standalone Competition Enforcement Agreements involving only OECD countries actually increased in the period 2000-2008, while there was a more than offsetting fall in the number of RTAs with provisions on competition enforcement cooperation that involved only OECD members.

2. It is no longer correct that the US is a partner in the majority of stand-alone Competition Enforcement Agreements. While the US was a party to just over half $(55 \%)$ of all such agreements in the period prior to 1999 , in the most recent period (1999-2008) it is a party to only six (15\%) of the forty one agreements. 
3. It is not correct that RTAs signed by developed economies other than the EC mostly pursue enforcement cooperation, rather than convergence of substantive competition policies. Approximately half of such agreements contain policy convergence provisions - albeit entailing low-level policy cooperation - but no enforcement cooperation, and half contain enforcement cooperation provisions in addition to policy cooperation.

4. It is no longer correct that less developed countries find it virtually impossible to sign a Competition Enforcement Agreement with a developed country. In the period 1999-2002, there were seven new agreements of this type, and between 2003 and 2008 there were nine such new agreements, representing over a third of all new agreements in each period.

5. There are hard cooperation agreements involving less developed countries - if hard cooperation is defined to include vertical integration of enforcement authority. There are five vertically integrated RTAs between less developed countries. If hard cooperation is defined to include positive comity, there are 9 agreements involving less developed countries that contain this provision.

6. Overall, positive comity is indeed rarely found in RTAs. However, in the most recent period (2000-2007) one in six new RTAs that contain competition enforcement provisions contains a positive comity clause.

7. While international competition policy enforcement cooperation in the form of CEAs is primarily transgovernmental, once competition chapters in RTAs are incorporated in the analysis, international cooperation in this domain is predominantly an "intergovernmental" phenomenon - when “intergovernmental" is defined as government-to-government agreements rather than agency-to-agency agreements.

The data also show that the depth of enforcement cooperation in the aggregate has increased over time. There were 63 agreements in the period 2000-2008, but only 29 in the entire period prior to 2000. There is a clear tendency for earlier agreements to be supplemented or replaced by deeper agreements between the same signatories. At the same time, this deepening has been accompanied by broadening: an increasing number of shallower FTAs have been signed by countries newly active in international competition policy cooperation, so that the median and modal depth of agreements fell in 2000-2008 compared to the previous period. 
Limited measurements are also reported of the depth of prescriptive jurisdictional integration in RTAs and Competition Enforcement Agreements, and the depth of cooperation in multilateral instruments, in order to illustrate how the concept of jurisdictional integration enables the identification of new "families" of agreements.

To this end, a vector approach was suggested as a means to succinctly summarise the depth of key dimensions of policy cooperation in an agreement or set of agreements. A vector summary provides a more precise method of describing the key differences between RTAs across regions, allowing more ready comparisons between the same types of international policy cooperation irrespective of the instrument in which they are contained.

The final step in the thesis was to use the ranked agreements to test hypotheses of the relationship between international economic policy cooperation, as the dependent variable, and a range of predictor variables. The main findings from this analysis are:

1. We can be very confident that enforcement cooperation is low when signatories' substantive competition laws are dissimilar. Similarity of substantive competition laws appears to be a necessary, but not a sufficient condition for deep international cooperation between Competition Authorities. This result casts doubt on a rival hypothesis, that enforcement cooperation is a substitute for convergence of competition laws.

2. Common OECD membership is a very good predictor of the depth of enforcement cooperation between signatories, while common advanced economy status is only a moderately good predictor. Disaggregating by instrument type reveals that all the difference is due to RTAs, for which advanced economy status is a poor predictor of depth of cooperation.

3. Enforcement cooperation is deeper in Customs Unions than in FTAs, but the data do not support the hypothesis that this gap is narrowing over time.

4. Within RTAs, Customs Unions as a category are becoming less and less relevant. Nearly all recent RTAs are FTAs. It is variation in the depth of enforcement cooperation in FTAs that should be the object of more attention.

5. The level of trade integration between countries appears to be a moderately good predictor of their depth of competition enforcement cooperation. 
6. The level of economic asymmetry between signatories is a weak predictor of the depth of their enforcement cooperation.

7. Geographic proximity appears to play little role in influencing the depth of enforcement cooperation in stand-alone competition enforcement agreements, but it is a good predictor of the depth of competition enforcement cooperation in RTAs.

8. When using jurisdictional integration as a predictor variable rather than the dependent variable, the depth of enforcement cooperation is a very good predictor of the legal form of the agreement i.e. whether an agreement is transgovernmental, or a more formal "intergovernmental" agreement.

9. Finally, the combination of agreements that involve only OECD members, and that are "inter-governmental," appears to be a very good predictor of the depth of enforcement cooperation. When both of these variables are present, enforcement cooperation is high in $93 \%$ of cases (21/23 agreements).

This thesis contributes to the small empirical literature on the causes of international policy cooperation, which at present is largely confined to studies looking at a binary choice of cooperation versus no cooperation. Examples include Mansfield, Milner and Rosendorff 2002, and Baier and Bergstrand 2002, who investigate why countries sign or do not sign RTAs; and Simmons 2000, who investigates the determinants of country acceptance of IMF obligations to maintain current account convertibility. An alternative approach is that taken by $\mathrm{Wu} 2004$, who uses the stage of economic integration as a combined measure of economic and policy integration, rather than directly measuring the depth of policy cooperation.

In the field of competition policy, the results of this thesis build on the finding by Cernat with respect to the inclusion of consultation and notification provisions in NorthSouth and North-North RTAs (as discussed in Chapter 11.2). Cernat found that a slightly higher percentage of North-South RTAs contain notification provisions of any kind compared to North-North RTAs. When CEAs are incorporated in the analysis, and the depth of cooperation is measured in addition to the presence of a notification clause, North-North agreements are found to be much deeper on average than North-South agreements. 
This empirical literature also includes the study by Smith of the determinants of the depth of legalism in dispute settlement mechanisms in RTAs (Smith 2000). Smith directly measures the depth of cooperation in a particular field, given the prior decision to cooperate. He developed a new index of legalism, which is analogous to the depth of policy cooperation, and found that legalism in RTAs was low where economic asymmetry between partners was high. His explanation for this was that large economies gain relatively less from trade, and are unwilling to constrain their ability to resort to diplomatic power to settle disputes with smaller economies e.g. by issue linkage, or the threat of retaliatory sanctions. This finding supports a realist perspective on international relations, where the wishes of more powerful states tend to prevail.

At first glance, the finding in this thesis, that the depth of competition enforcement cooperation is almost invariant to the level of economic asymmetry, is in contrast to Smith's finding, and to a realist perspective. However, two points should be borne in mind. First, with the exception of the deepest level of enforcement cooperation vertical integration - none of the international competition enforcement agreements have binding force. This is in contrast to the deeper levels of Smith's legalism index, which are binding. Therefore, the logic suggesting that larger economies will be unwilling to constrain their policy flexibility, has much less force in the case of competition policy.

Secondly, part of the motivation of the US and the EC in signing deeper cooperation agreements with smaller (developed) economies is likely to reflect their desire to export their approach to competition law and its enforcement. Regulatory competition is very much in line with a realist perspective of international relations. The literature on international competition policy supports regulatory export being an important motivation for the US and the EC e.g. Raustiala 2002, Slaughter 2004, pp. 174-176.

The findings in this thesis suggest that OECD membership is likely to be an important factor influencing the depth of international agreements to cooperate in enforcing competition policies. This provides some support for elite norm diffusion as a causal mechanism of international economic policy cooperation. The qualitative literature on international economic policy cooperation strongly suggests the possibility that the OECD has been influential in this policy domain. 
Both elite norm diffusion via the OECD, and regulatory competition, are possible explanations for the relatively weak relationship found between depth of enforcement cooperation and geographic proximity. They may also result in some masking of the functionalist, economic causal mechanisms, such as level of trade between signatories, and the level of economic asymmetry.

Finally, this thesis builds on the emerging literature on transgovernmentalism in international law and international relations, by:

1. Suggesting a new approach to operationalizing the dependent variable.

2. Assembling a large cross-country dataset rather than using a case study method.

3. Finding that international cooperation in enforcing competition policies is primarily "intergovernmental" rather than transgovernmetal, in contrast to previous studies.

4. Finding that the depth of international cooperation in enforcing competition policies is a very good predictor of whether an agreement is "intergovernmental." This finding supports a hypothesis that states are less likely to delegate authority to their competition agencies to sign international agreements that impinge on the state's enforcement jurisdiction.

\subsection{LIMITATIONS AND FURTHER RESEARCH}

\subsubsection{Potential Limitations of this Research}

The first potential limitation of the thesis is the validity of the concept of jurisdictional integration. The fact that the concept is based on analytical distinctions in authoritative texts in international law (such as The Third Restatement) and international relations (such as Krasner's work on sovereignty) provides a measure of confidence that the conceptual framework is sound, although no doubt in this initial formulation it can benefit from further improvement and refinement. Applying the framework of jurisdictional integration to additional policy domains will provide a good opportunity to do so. The full application of the index of integration of enforcement jurisdiction to the 92 agreements entailed an iterative refinement of that index. There is a need to similarly further develop and refine the indices in Chapter 10 of integration of prescriptive, judicial enforcement, and inter-state adjudication in competition policy; and to operationalize the concept of executive implementation jurisdiction in Chapter 5.2. 
A second question is how significant are the different levels on the index of enforcement cooperation? With most of the agreements being non-binding, and in many cases only limited actual use being made of the cooperation provisions in them, it could be argued that too much significance is being placed on differences in the wording of the agreements. Guzman, for instance, states that bilateral agreements i.e. Competition Enforcement Agreements as defined here, are extremely limited tools because they fail to bind states to coordinate laws or commit them to share information or otherwise cooperate. ${ }^{370}$ It is clear, however, that the benchmark against which Guzman was judging bilateral agreements is a legally binding international commitment that imposes substantive or procedural rules of some kind, and perhaps even a supranational competition authority.

The fact that most current international competition cooperation agreements fall well short of a legally binding obligation does not, however, render them homogenous, in terms of their impact on states' authority to enforce their competition laws without the need to engage in any form of discussion, justification, or cooperative action with other states. The glass of international competition cooperation may not be half full, but neither is it empty. States go to considerable lengths to negotiate the wording of international agreements and international standards (as argued, for instance, by Chayes and Chayes, 1995, pp. 3-4). This is true also in competition policy cooperation. State behaviour suggests that the inclusion or exclusion of different provisions is regarded as salient. Leading international lawyers, such as Slaughter, consider the concept of positive comity, developed largely in the anti-trust community, to be a significant development and have advocated its expansion to other policy domains. ${ }^{371}$ Some commentators, such as Zanettin, consider some bilateral CEAs to be binding under international law. ${ }^{372}$ The very strong relationship found in this thesis, between the existence of provisions such as positive comity, and the legal form of the agreement, lends support to the view that such provisions do indeed reflect a deeper level of international cooperation - or at least, they reflect a deeper level of intended or permitted cooperation, as there may still be obstacles to actual cooperation, such as constraints on sharing confidential information.

\footnotetext{
${ }^{370}$ Guzman 2007, pp. 426-427.

${ }^{371}$ Slaughter, 2004, pp. 250-253. Quotation is from p. 250.
} 
Furthermore, in all cases the statistical tests in this thesis use a binary approach, in which the 7 levels on the enforcement cooperation index are collapsed into two (high/low cooperation). This greatly reduces the scope for statistical results to be driven by spurious or immaterial distinctions between broadly similar levels of cooperation. In addition, in a number of instances level 5, positive comity, is used as the threshold between low and high cooperation to test the sensitivity of results to the specification of high cooperation. Positive comity, as noted, is widely regarded as a significant and deeper level of cooperation. In addition, in some cases the sensitivity of the results to the inclusion of agreements at level 7 on the index - the binding agreements involving vertical integration - is tested on the basis that these agreements are arguably of a different character, rather than just constituting a higher level on the same index.

A related potential limitation is the validity of the indices of jurisdictional integration with respect to competition policy, particularly the index of enforcement cooperation on which most of the statistical analysis is based. The well-established and carefully defined concepts of international enforcement cooperation (such as notification, positive comity, and third party enforcement) appear to provide coherent gradations of increasing depth of cooperation. These are confirmed in the extensive literature on the subject. In addition, the progressive evolution of the OECD Recommendations through the addition of deeper levels of cooperation, and the manner in which bilateral and regional agreements have evolved in practice, in some cases foreshadowing future deepening, provide further confidence that the enforcement cooperation index does measure what it purports to measure: increasing degrees of intrusion on the recognized authority of signatory states to enforce their competition laws free from external interference or involvement. This confidence is increased by the fact that there is a consistent progression of cooperation provisions in most of the agreements rated. For instance, in nearly all cases, agreements coded level 5 or 6 contain cooperation provisions from all the lower cooperation levels as well.

The next potential limitation is the reliability of the coding of agreements against the index. Even if the enforcement cooperation index is coherent and well designed, if the 92 agreements have not been accurately coded this would call into question the validity of the statistical results. Relevant here is the fact that the influence of the OECD

${ }^{372}$ Zanettin, 2002, p. 77. 
Recommendations, and of key bilateral agreements, has resulted in a high degree of uniformity in structure and language across these agreements. In many cases, identical language is used in key clauses, such as notification and positive comity, based on the OECD Recommendations. This greatly facilitates the reliable coding of agreements.

However, in view of the importance of this issue, an inter-rater reliability test was conducted. A random sample of 10 agreements was rated against the index by Dr. Philip Marsden, an expert in international competition policy cooperation. This resulted in an adjusted $90 \%$ rate of agreement, which provides a high degree of confidence in the reliability of the ratings.

One inevitable limitation in this sort of research is that the dataset of international competition enforcement cooperation agreements may not be representative of the total population of such agreements. While the 92 agreements could well represent at least $60 \%$ of all agreements, the fact that there are a number of known agreements missing from the dataset because they are not available in English, could represent a source of systematic bias in the descriptive or inferential results. It would be possible to analyse the missing agreements to check whether any of the results are dependent on the existing sample. Similarly, the small number of Mutual Legal Assistance Treaties that are applicable to competition policy enforcement cooperation could be incorporated in the analysis.

The analysis of the changing depth of policy cooperation in RTAs in Chapter 8 is also limited by the availability of data. It would be possible to apply the approach used here to analyse the depth of policy cooperation in post-1998 RTAs, to check whether there has been any further change in the most recent period.

With respect to the statistical analysis, the objective has been to begin to explore relationships between the depth of international cooperation and some of the more salient predictor variables, rather than attempt to identify all the predictor variables and rigorously control for confounding effects. Additional multivariate analysis of relationships between predictor variables and the depth of enforcement cooperation would provide more complete and robust tests of possible confounding effects. 


\subsubsection{Possible Extensions of this Research}

The influence of additional predictor variables on the depth of international enforcement policy cooperation could be tested e.g. domestic political regime, country size, number of signatories, allies, former colonies. With respect to country size, it might be hypothesized that international economic policy cooperation will be deeper for smaller countries, because they are typically more open to and dependent on international trade. On the other hand, in the realm of competition policy, in small economies there will be more markets where the dominant firm has yet to attain a minimum scale for productive efficiency. Small countries may therefore have less of an incentive to curtail anticompetitive conduct. This makes the relationship between country size and depth of international policy cooperation in competition policy theoretically ambiguous.

International competition policy agreements could be ranked against the index of prescriptive jurisdictional integration, and the indices of adjudication jurisdictional integration, to further test the practicality of the approach taken in this thesis. This would also enable additional hypothesis testing, for example, of the relationship between economic asymmetry and the depth of prescriptive jurisdictional integration. However, measuring the depth of integration of prescriptive jurisdiction in competition policy may well be more difficult than measuring the depth of enforcement cooperation (and more difficult than measuring the depth of legalism, as carried out in Smith 2000). There may be less clear-cut categories and more grey areas, which could make reliable coding more difficult.

An attempt could be made to combine measures of enforcement cooperation and prescriptive jurisdictional integration to produce a single quantitative rating of the depth of international competition policy cooperation by country. This could prove useful for research purposes, with the elements weighted according to the purpose at hand.

There are inherent limitations to cross-country, cross-section analysis, that might be reduced by supplementing the approach taken in this thesis with a carefully designed case study e.g. to test the presence of an "OECD-effect" or a "NAFTA effect" in the diffusion of international cooperation; or to measure the relationship between de jure authority to cooperate and actual levels of cooperation (see below). 
The thesis is confined to measuring the effects of depth of cooperation, given an existing cooperation agreement. This could be supplemented by a two-step approach, which also tests factors associated with decisions by countries over whether or not to sign cooperation agreements in the first place - similar to the approach of Mansfield, Milner and Rosendorff 2002 with respect to participation and non-participation in PTAs.

It would also be interesting to analyse the relationship, in international competition policy enforcement cooperation, between de jure cooperation and de facto cooperation. This would require data on actual cooperation activities pursuant to international agreements, which may be difficult to obtain at a broad cross-country level, but which may be available through a case study approach e.g. the case study of competition cooperation by Marsden and Whelan (2005).

The measures of depth of enforcement cooperation could be used as a predictor variable, rather than the dependent variable, in an attempt to discern what impact de jure cooperation has on variables of policy interest, such as levels of foreign investment or trade - similar to the research by Anderson and Evenett 2006.

Analysis could also be attempted of the relationship between the different categories of jurisdiction. How do prescriptive, enforcement, and adjudicative jurisdictional integration co-vary in practice? What would be hypothesized? For instance, the American Law Institute has observed, with respect to prescriptive and enforcement jurisdiction, and the jurisdiction to adjudicate, that: "These categories of jurisdiction are often interdependent, and their scope and limitations are shaped by similar considerations. Jurisdiction to prescribe may be more acceptable where jurisdiction to adjudicate or to enforce is plainly available; jurisdiction to adjudicate may be more acceptable where the state of the forum also has jurisdiction to prescribe by virtue of its links to the persons, interests, relations or activities involved. However, the purposes and consequences of the different categories of jurisdiction are not necessarily congruent, and balancing the competing interests in the different contexts can lead to different results. ${ }^{373}$ Testing these propositions would be worthwhile.

\footnotetext{
${ }^{373}$ American Law Institute 1987, p. 233.
} 
Taking a further step, the framework could be used to help explore normative questions such as what the policy options are for balancing the prescriptive and adjudicative powers. For instance, Trachtman has commented: "One of the core problems of the WTO is the imbalance between its dispute resolution authority, on the one hand, and its extremely limited legislative capacity." ${ }^{, 374}$ Trachtman goes on to suggest a normative rule for the allocation of regulatory authority between states and international organisations such as the WTO: "The basic goal is to allocate authority to those to whom it is most valuable - those most greatly affected - at the lowest transaction cost." The framework of jurisdictional integration and its different dimensions may help to identify the full range of horizontal and vertical policy options for allocating regulatory authority at the international level.

\subsubsection{Possible Applications to Other Policy Domains}

In principle, it should be possible to apply the analytical framework and measurement techniques developed in this thesis to other types of international economic cooperation. For example, the approach could be applied to:

- $\quad$ Other Chapters in RTAs, such as Chapters on Investment, on Technical Barriers to Trade, on Sanitary and Phytosanitary Measures, or to the provisions on Services.

- Measuring the depth of cooperation in other policy domains across the different types of international agreements in which cooperation is embodied - for example, measuring the depth of cooperation in the regulation of international financial markets, and in international investment agreements, such as RTAs, Bilateral Investment Treaties, and the WTO 1994.

- $\quad$ The comparative analysis of Regional Integration Agreements in different parts of the world, whether they are FTAs, Customs Unions, Common Markets or some other type of arrangement.

- The comparative analysis of the depth of cooperation within the EU across different policy domains, for example by developing ordinal indices of the depth of cooperation.

- $\quad$ Measuring the depth of international regulatory coordination in different domains, including steps such as mutual recognition of various types, convergence, harmonization, and third party enforcement.

${ }^{374}$ Trachtman 2007, p. 649. 
- Measuring the depth of international cooperation in the realm of fiscal policy. While fiscal authority is in general closely held by states (even in the EC), there is arguably a progression of steps at lower levels of cooperation.

- $\quad$ Exploring why, in some policy domains, domain-specific cooperation between two or more countries is deeper than the general jurisdiction-tojurisdiction cooperation, while in other domains it is determined by the latter.

However, it is not clear the extent to which there is sufficient data available to researchers in other policy domains to replicate the approach used in this thesis. It may also be the case that there is less uniformity of provisions and language in areas outside competition policy. The influence of the OECD Recommendations, and of key bilateral agreements, in creating a uniformity of approach and of specific clauses and language, may not be as apparent in some other policy domains, making the development of coherent indices, and the consistent coding of the depth of cooperation more difficult.

It should be possible to replicate the approach in this thesis to measuring transgovernmentalism and intergovernmentalism in other policy domains.

More broadly, it would be possible to attempt to devise a better, practical measure of a country's overall depth of international policy cooperation, to replace the current measures of international "political engagement."

In the medium term, an attempt could be made to devise and operationalize a framework for measuring the horizontal scope of international (economic) policy cooperation - as conceived by Nye and Lindberg in the 1960s. This would make it possible to combine measures of vertical depth and horizontal scope to produce measures of the overall volume (or footprint) of international cooperation, by policy domain or domains, or even by country.

Finally, it is recognized that the concept of jurisdictional integration has potential for broader application than to international economic agreements alone. In principle, it would appear capable of providing a framework for the conceptualisation and analysis 
of the full range of international agreements. ${ }^{375}$ The choice of foreign economic policy as the domain of interest, reflects the fact that most international integration of policies and institutions (whether bilateral, regional or multilateral) has taken place in the form of trade and economic cooperation agreements - even though other policy objectives, such as defence and security, may at times have been the underlying driver. It also reflects the theoretical perspective from international relations theories (neo-realism, neo-liberal institutionalism) that international cooperation is more likely in the "low politics" areas of economic policy than the "high politics" areas of defence and security, where power relationships are expected to predominate. Confining the scope of this thesis to international economic cooperation, it is hoped, has successfully revealed the range of phenomena involved, while offering gains in tractability. Nevertheless, exploring the application of the concept of jurisdictional integration to international cooperation in non-economic policy domains, such as the environment, security, and human rights, could be a fruitful avenue for further research.

\footnotetext{
${ }^{375}$ It might also be applied to the measurement and analysis of the allocation of functions between national and sub-national governments.
} 


\section{Appendix 1: Table of Selected Empirical Studies of International Policy Cooperation ${ }^{376}$}

\begin{tabular}{|c|c|c|c|c|c|c|}
\hline Author & $\begin{array}{l}\text { Objective/thesis } \\
\text { investigated }\end{array}$ & $\begin{array}{l}\text { Dependent } \\
\text { variable }\end{array}$ & $\begin{array}{l}\text { Explanatory } \\
\text { variables }\end{array}$ & Data sources & Methods & Findings \\
\hline Smith, 2000 & $\begin{array}{l}\text { Legalism reflects trade- } \\
\text { off between treaty } \\
\text { compliance and policy } \\
\text { discretion. Legalism } \\
\text { most likely where } \\
\text { economic asymmetry is } \\
\text { low and proposed level } \\
\text { of integration is high }\end{array}$ & $\begin{array}{l}\text { Levels of } \\
\text { legalism in } \\
\text { dispute } \\
\text { settlement } \\
\text { mechanisms in } \\
\text { sixty-two } \\
\text { RTAs signed } \\
1957-1995 \\
\text { (both } \\
\text { successful and } \\
\text { failed } \\
\text { agreements) }\end{array}$ & $\begin{array}{l}\text { Index of economic } \\
\text { asymmetry, } \\
\text { proposed level of } \\
\text { integration (shallow } \\
\text { (FTA, CU), deep } \\
\text { (CM, EU)), and a } \\
\text { term capturing } \\
\text { interaction between } \\
\text { these two }\end{array}$ & $\begin{array}{l}\text { Various (e.g. } \\
\text { web sites, } \\
\text { International } \\
\text { Legal } \\
\text { Materials, UN } \\
\text { Treaty Series) }\end{array}$ & $\begin{array}{l}\text { Developed new index of } \\
\text { legalism; Chi-squared tests } \\
\text { of statistical significance } \\
\text { between level of legalism, } \\
\text { economic asymmetry, } \\
\text { proposed depth of } \\
\text { integration, and their } \\
\text { interaction } \\
\text { Ordered probit regression. } \\
\text { Null hypothesis of } \\
\text { independence rejected with } \\
\text { very high levels of } \\
\text { confidence (less than .01) } \\
\text { suggesting significant } \\
\text { relationship to legalism }\end{array}$ & $\begin{array}{l}\text { Economic asymmetry, interacting } \\
\text { with the proposed depth of } \\
\text { integration, is a robust predictor } \\
\text { of dispute settlement design. } \\
\text { Legalism low where asymmetry } \\
\text { high (even where proposed level } \\
\text { of integration is deep). Where } \\
\text { asymmetry low, legalism is high } \\
\text { when proposed level of } \\
\text { integration is deep }\end{array}$ \\
\hline Schiff, 2000 & $\begin{array}{l}\text { Uses two theories - that } \\
\text { multilateral trade } \\
\text { liberalization (MTL) } \\
\text { leads to more Regional } \\
\text { Integration Agreements } \\
\text { (RIAs) (Ethier) and that } \\
\text { MTL leads to political } \\
\text { disintegration (Alesina } \\
\text { et al, below) to } \\
\text { hypothesize that MTL } \\
\text { will result in more, but } \\
\text { less politically } \\
\text { integrated RIAs }\end{array}$ & $\begin{array}{l}\text { The ratio of } \\
\text { FTAs to } \\
\text { Customs } \\
\text { Unions, taken } \\
\text { as a measure } \\
\text { of policy and } \\
\text { institutional } \\
\text { integration }\end{array}$ & $\begin{array}{l}\text { Index of global } \\
\text { openness (world } \\
\text { exports to GDP) }\end{array}$ & $\begin{array}{l}\text { WTO for } \\
\text { information on } \\
\text { RTAs }\end{array}$ & Simple ratio analysis & $\begin{array}{l}\text { Ratio of FTAs to Customs } \\
\text { Unions 3-7 times higher in the } \\
\text { 1990s (following increased MTL } \\
\text { in earlier decades) } \\
\text { Ratio higher for north-south } \\
\text { RIAs than for south-south RIAs } \\
\text { (hypothesis: less heterogeneity in } \\
\text { south-south) }\end{array}$ \\
\hline
\end{tabular}

${ }^{376}$ These studies use levels of international policy cooperation as either the dependent variable or as a predictor variable. 


\begin{tabular}{|c|c|c|c|c|c|c|}
\hline Author & $\begin{array}{l}\text { Objective/thesis } \\
\text { investigated }\end{array}$ & $\begin{array}{l}\text { Dependent } \\
\text { variable }\end{array}$ & $\begin{array}{l}\text { Explanatory } \\
\text { variables }\end{array}$ & Data sources & Methods & Findings \\
\hline $\begin{array}{l}\text { Mansfield, } \\
\text { Milner and } \\
\text { Rosendorff, } \\
2002\end{array}$ & $\begin{array}{l}\text { To test whether more } \\
\text { democratic states are } \\
\text { more likely to form } \\
\text { PTAs because they } \\
\text { represent more credible } \\
\text { commitments than } \\
\text { unilateral trade barrier } \\
\text { reduction }\end{array}$ & $\begin{array}{l}\text { Binary } \\
\text { dependent } \\
\text { variable is log } \\
\text { of the odds } \\
\text { that a pair of } \\
\text { countries } \\
\text { enters a PTA } \\
\text { in a given year } \\
1951-1992\end{array}$ & $\begin{array}{l}\text { Index of } \\
\text { democracy, GDP, } \\
\text { change in GDP, } \\
\text { exports, former } \\
\text { colony, ally, } \\
\text { military disputes, } \\
\text { distance, GATT } \\
\text { membership, trade } \\
\text { hegemony }\end{array}$ & $\begin{array}{l}\text { For PTAs, } \\
\text { primarily } \\
\text { WTO } \\
\text { Jaggers and } \\
\text { Gurr index of } \\
\text { regime type; } \\
\text { Summers- } \\
\text { Heston; IMF; } \\
\text { various other }\end{array}$ & $\begin{array}{l}\text { Mathematical model of the } \\
\text { economy and polity, and } \\
\text { the impact of trade } \\
\text { agreements on voter and } \\
\text { government behaviour } \\
\text { Pool data across time and } \\
\text { country pairs, then logistic } \\
\text { regression } \\
\text { Derived probability of pair } \\
\text { of states entering a trade } \\
\text { agreement }\end{array}$ & $\begin{array}{l}\text { Democracies twice as likely, and } \\
\text { pairs of democracies four times } \\
\text { as likely to form PTA compared } \\
\text { to autocratic pairs. } \\
\text { Probability of PTA membership } \\
\text { declining with GDP. Countries } \\
\text { more likely to form PTA where } \\
\text { home market small, prior } \\
\text { colonial relationship, alliance } \\
\text { partners, parties to GATT, close } \\
\text { geographic proximity, and during } \\
\text { periods of waning hegemony. }\end{array}$ \\
\hline $\begin{array}{l}\text { Baier and } \\
\text { Bergstrand } \\
2002\end{array}$ & $\begin{array}{l}\text { To test the cross- } \\
\text { sectional variation in } \\
\text { FTAs for a given year, } \\
\text { to determine the } \\
\text { economic factors } \\
\text { influencing likelihood } \\
\text { of pairs of countries } \\
\text { forming FTAs. Hope to } \\
\text { provide an empirical } \\
\text { benchmark for } \\
\text { determinants of FTAs } \\
\text { upon which strategic } \\
\text { and political factors can } \\
\text { subsequently be } \\
\text { embedded }\end{array}$ & $\begin{array}{l}\text { Presence of } \\
\text { full FTA } \\
\text { between } 54 \\
\text { country pairs, } \\
1996\end{array}$ & $\begin{array}{l}\text { Capital/labour } \\
\text { ratios, distance, } \\
\text { remoteness, } \\
\text { population, real and } \\
\text { per capita GDP, } \\
\text { capital per worker. } \\
1996 \text { data except } \\
\text { used } 1960 \text { data for } \\
\text { incomes, capital } \\
\text { stocks, and } \\
\text { populations to } \\
\text { account for } \\
\text { endogenous } \\
\text { influence of (prior) } \\
\text { FTA on } 1996 \text { levels } \\
\text { of these variables. }\end{array}$ & $\begin{array}{l}\text { WTO (full } \\
\text { FTAs and } \\
\text { Customs } \\
\text { Unions } \\
\text { notified) }\end{array}$ & $\begin{array}{l}\text { Four methods: general } \\
\text { equilibrium model of world } \\
\text { trade,; qualitative discrete } \\
\text { choice model (FTA, no } \\
\text { FTA) } \\
\text { Probit regressions, percent } \\
\text { correctly predicted. } \\
\text { Sensitivity analysis to test } \\
\text { for non-independence of } \\
\text { bilateral observations } \\
\text { (country clusters of FTAs), } \\
\text { to exclude European } \\
\text { countries, and to test for } \\
\text { exogeneity of } 1996 \text { values } \\
\text { of income and capital stock. }\end{array}$ & $\begin{array}{l}\text { Probability of FTA higher the } \\
\text { closer the economies } \\
\text { geographically, the more remote } \\
\text { a pair of natural trading partners } \\
\text { is from the rest of the world, the } \\
\text { larger and more similar in } \\
\text { economic size, the larger the } \\
\text { difference in capital/labour ratios. } \\
\text { These effects are economically } \\
\text { and statistically significant. } \\
\text { These pure economic } \\
\text { characteristics can accurately } \\
\text { predict } 83 \% \text { of the } 289 \text { FTAs } \\
\text { existing among } 1,431 \text { country } \\
\text { pairs in } 1996 \text {, and } 97 \% \text { of the } \\
\text { remaining } 1,142 \text { pairs of } \\
\text { countries with no FTAs. }\end{array}$ \\
\hline
\end{tabular}




\begin{tabular}{|c|c|c|c|c|c|c|}
\hline Author & $\begin{array}{l}\text { Objective/thesis } \\
\text { investigated }\end{array}$ & $\begin{array}{l}\text { Dependent } \\
\text { variable }\end{array}$ & $\begin{array}{l}\text { Explanatory } \\
\text { variables }\end{array}$ & Data sources & Methods & Findings \\
\hline $\begin{array}{l}\text { Dorrucci, } \\
\text { Firpo, } \\
\text { Fratzscher } \\
\text { and } \\
\text { Mongelli, } \\
2002\end{array}$ & $\begin{array}{l}\text { To test the hypothesis } \\
\text { that institutional } \\
\text { integration interacts } \\
\text { with economic } \\
\text { integration at the } \\
\text { regional level. } \\
\text { (Institutional integration } \\
\text { defined as outcome of } \\
\text { joint policy decisions } \\
\text { designed to affect } \\
\text { breadth and depth of } \\
\text { regional integration). }\end{array}$ & $\begin{array}{l}\text { Original index } \\
\text { of institutional } \\
\text { integration } \\
\text { (based on } \\
\text { Balassa } \\
\text { stages) for } \\
\text { EU-15 from } \\
1957-2001 \\
\text { and for } \\
\text { Mercosur } \\
\text { members } \\
1991-201\end{array}$ & $\begin{array}{l}\text { Synchronization of } \\
\text { business cycles; } \\
\text { convergence of } \\
\text { inflation and } \\
\text { interest rates; } \\
\text { exchange rate } \\
\text { variability; trade } \\
\text { openness; financial } \\
\text { market integration; } \\
\text { income } \\
\text { convergence. }\end{array}$ & $\begin{array}{l}\text { Detailed } \\
\text { expert } \\
\text { knowledge of } \\
\text { EU history of } \\
\text { policy } \\
\text { decisions. }\end{array}$ & $\begin{array}{l}\text { Assign scores from } 0-25 \text { for } \\
\text { each of the four stages for } \\
\text { each point in time, on the } \\
\text { basis of expert judgment of } \\
\text { when implementation of } \\
\text { relevant regional policy } \\
\text { decisions started since EU- } \\
6 \text { created. } \\
\text { Non-linear approach (last } \\
\text { integration step scores } \\
\text { higher than intermediate } \\
\text { steps). } \\
\text { Simple comparison of } \\
\text { economic integration and } \\
\text { institutional integration } \\
\text { across periods. } \\
\text { Cluster analysis to identify } \\
\text { groupings of similar } \\
\text { countries over six sub- } \\
\text { periods. }\end{array}$ & $\begin{array}{l}\text { Strong correlation between } \\
\text { economic integration and } \\
\text { institutional integration for EU } \\
\text { (following each institutional } \\
\text { phase, economic integration } \\
\text { deepened; further institutional } \\
\text { integration feasible only if } \\
\text { economic integration supports it). } \\
\text { Between 1950s-1970s economic } \\
\text { integration in EU occurred } \\
\text { among geographically close } \\
\text { countries. Since early 1980s, } \\
\text { clusters correspond more closely } \\
\text { to institutional arrangements (e.g. } \\
\text { participation or not in EMU) than } \\
\text { to neighbours. }\end{array}$ \\
\hline $\begin{array}{l}\text { Alesina, } \\
\text { Spolaore, } \\
\text { and } \\
\text { Wacziarg, } \\
1997, \\
\text { Alesina and } \\
\text { Spolaore } \\
2003\end{array}$ & $\begin{array}{l}\text { Economic integration } \\
\text { has lead to, and will } \\
\text { continue to lead to } \\
\text { political disintegration }\end{array}$ & $\begin{array}{l}\text { Number of } \\
\text { countries in } \\
\text { world; country } \\
\text { size (log of } \\
\text { population, } \\
\text { log of total } \\
\text { GDP) }\end{array}$ & $\begin{array}{l}\text { Trade openness } \\
\text { (average ratio of } \\
\text { imports + exports to } \\
\text { GDP) by country }\end{array}$ & $\begin{array}{l}\text { Encyclopaedia } \\
\text { Britannica for } \\
\text { date of } \\
\text { country } \\
\text { independence; } \\
\text { Summers- } \\
\text { Heston for } \\
\text { trade: GDP } \\
\text { ratio }\end{array}$ & $\begin{array}{l}\text { Formal model derives } \\
\text { equilibrium number and } \\
\text { size of nations as function } \\
\text { of trade regime } \\
\text { Regression analysis } \\
\text { Qualitative discussion of } \\
\text { history of country } \\
\text { formation and dissolution }\end{array}$ & $\begin{array}{l}\text { Support for two critical } \\
\text { implications of model: } 1 \text { ) the } \\
\text { effect of country size on } \\
\text { economic growth falls as trade } \\
\text { openness increases; } 2 \text { ) the history } \\
\text { of nation creation and secession } \\
\text { influenced by trade regime. }\end{array}$ \\
\hline
\end{tabular}




\begin{tabular}{|c|c|c|c|c|c|c|}
\hline Author & $\begin{array}{l}\text { Objective/thesis } \\
\text { investigated }\end{array}$ & $\begin{array}{l}\text { Dependent } \\
\text { variable }\end{array}$ & $\begin{array}{l}\text { Explanatory } \\
\text { variables }\end{array}$ & Data sources & Methods & Findings \\
\hline $\begin{array}{l}\text { Dorrucci, } \\
\text { Firpo, } \\
\text { Fratzscher } \\
\text { and } \\
\text { Mongelli, } \\
2004\end{array}$ & $\begin{array}{l}\text { Building on Dorrucci et } \\
\text { al } 2002 \text {, assess whether } \\
\text { institutional integration } \\
\text { leads to more economic } \\
\text { integration or vice } \\
\text { versa; is a certain } \\
\text { degree of economic } \\
\text { integration a pre- } \\
\text { requisite for deepening } \\
\text { institutional integration? }\end{array}$ & $\begin{array}{l}\text { Original index } \\
\text { of institutional } \\
\text { integration for } \\
\text { EU-6 from } \\
1960-2000 \\
\text { and for } \\
\text { Mercosur } \\
\text { members } \\
1991-2001\end{array}$ & $\begin{array}{l}\text { As for Dorrucci et } \\
\text { al } 2002\end{array}$ & $\begin{array}{l}\text { As for } \\
\text { Dorrucci et al } \\
2002\end{array}$ & $\begin{array}{l}\text { Non-structural VAR model } \\
\text { to test for direction of } \\
\text { causality between real } \\
\text { exchange rate variability } \\
\text { and index of institutional } \\
\text { integration. Impulse } \\
\text { response functions show } \\
\text { how each endogenous } \\
\text { variable reacts over time to } \\
\text { an exogenous positive } \\
\text { shock in each variable in } \\
\text { the VAR system. Granger } \\
\text { causality test }\end{array}$ & $\begin{array}{l}\text { Exogenous changes in } \\
\text { institutional integration lead to } \\
\text { deeper economic integration. } \\
\text { European countries experienced } \\
\text { sharp acceleration of economic } \\
\text { integration in the } 1960 \text { s and } \\
\text { 1990s. } \\
\text { A virtuous circle may be } \\
\text { identified between institutional } \\
\text { integration and economic } \\
\text { integration at the regional level. }\end{array}$ \\
\hline $\begin{array}{l}\text { Vlachos } \\
2004\end{array}$ & $\begin{array}{l}\text { To investigate } \\
\text { systematically whether } \\
\text { harmonization of } \\
\text { securities regulations } \\
\text { actually promotes } \\
\text { financial market } \\
\text { integration }\end{array}$ & $\begin{array}{l}\text { The log of } \\
\text { portfolio asset } \\
\text { holdings in } \\
\text { country } j \text { by } \\
\text { residents of } \\
\text { country } i \text {, for } \\
38 \text { countries }\end{array}$ & $\begin{array}{l}\text { Main variable is } \\
\text { index of differences } \\
\text { in securities } \\
\text { regulation. } \\
\text { Plus per capita } \\
\text { GDP, volume of } \\
\text { bilateral trade, } \\
\text { common land } \\
\text { border and } \\
\text { language, religious } \\
\text { beliefs, judicial } \\
\text { efficiency, } \\
\text { membership in } \\
\text { RTAs, index of } \\
\text { govt. effectiveness }\end{array}$ & $\begin{array}{l}\text { Indices of } \\
\text { securities } \\
\text { regulation } \\
\text { from La Porta } \\
2003 \text {. } \\
\text { IMF trade } \\
\text { data, WB on } \\
\text { pop. and GDP. } \\
\text { Rose } 2002 \text { for } \\
\text { common } \\
\text { language, land } \\
\text { border, } \\
\text { Alesina et al } \\
\text { 2003 for } \\
\text { religion }\end{array}$ & $\begin{array}{l}\text { Empirical gravity model } \\
\text { (ala trade theory). Country- } \\
\text { pair specific detailed } \\
\text { indices of regulatory } \\
\text { differences constructed. } \\
\text { OLS and 2SLS regression } \\
\text { analysis. } \\
\text { Home and host country } \\
\text { fixed effects, standard } \\
\text { controls for bilateral trade } \\
\text { relations. } \\
\text { Used instrumental variables } \\
\text { (pop. size, GDP, rule of } \\
\text { law) to investigate direction } \\
\text { of causality between } \\
\text { harmonization and asset } \\
\text { holdings, using differences } \\
\text { in regulation as dependent } \\
\text { variable }\end{array}$ & $\begin{array}{l}\text { Harmonization of securities } \\
\text { regulation can have very large } \\
\text { effects on integration of } \\
\text { securities markets. } \\
\text { Differences in institutional } \\
\text { quality and religious beliefs } \\
\text { decrease asset holdings. } \\
\text { When investigating reverse } \\
\text { causality, larger differences in } \\
\text { regulation associated with } \\
\text { differences in legal origin, larger } \\
\text { geographic distance, common } \\
\text { border, reverse for trade volumes, } \\
\text { common language. With } \\
\text { instrumentation, found } \\
\text { "surprisingly" that instrumented } \\
\text { asset holdings associated with } \\
\text { larger regulatory differences }\end{array}$ \\
\hline
\end{tabular}




\begin{tabular}{|c|c|c|c|c|c|c|}
\hline Author & $\begin{array}{l}\text { Objective/thesis } \\
\text { investigated }\end{array}$ & $\begin{array}{l}\text { Dependent } \\
\text { variable }\end{array}$ & $\begin{array}{l}\text { Explanatory } \\
\text { variables }\end{array}$ & Data sources & Methods & Findings \\
\hline $\mathrm{Wu}, 2004$ & $\begin{array}{l}\text { To isolate common } \\
\text { traits of RTAs and } \\
\text { define contributing } \\
\text { characteristics; to test } \\
\text { whether economic or } \\
\text { political uncertainty is a } \\
\text { positive contributor to } \\
\text { the chosen level of } \\
\text { integration. }\end{array}$ & $\begin{array}{l}\text { Level of } \\
\text { regional } \\
\text { integration of } \\
150 \text { countries } \\
1960-1998 \\
\text { and } 1987- \\
1998\end{array}$ & $\begin{array}{l}\text { Trade uncertainty } \\
\text { (X+M: GDP), } \\
\text { political uncertainty } \\
\text { (indices of eco. } \\
\text { freedom and } \\
\text { corruption), } \\
\text { business cycle } \\
\text { uncertainty (change } \\
\text { in GDP), price } \\
\text { uncertainty } \\
\text { (inflation), } \\
\text { democracy, } \\
\text { geographic } \\
\text { indicators, } \\
\text { membership of } \\
\text { IMF, OECD }\end{array}$ & $\begin{array}{l}\text { Penn World } \\
\text { Tables; World } \\
\text { Bank; } \\
\text { Economic } \\
\text { Freedom of } \\
\text { the World; } \\
\text { Transparency } \\
\text { International; } \\
\text { Polity }\end{array}$ & $\begin{array}{l}\text { Database of regional trade } \\
\text { integration developed } \\
\text { which ranks levels of } \\
\text { integration across countries } \\
\text { according to the Balassa } \\
\text { stages of economic } \\
\text { integration. Each country } \\
\text { coded with its highest level } \\
\text { RTA } \\
\text { Ordered probit maximum } \\
\text { likelihood estimation in a } \\
\text { discrete choice framework } \\
\text { of probability a country } \\
\text { chooses a given level of } \\
\text { regional integration given } \\
\text { country characteristics. }\end{array}$ & $\begin{array}{l}\text { Higher regional integration } \\
\text { associated with democracy, } \\
\text { geographic characteristics, IMF } \\
\text { membership, per capita income, } \\
\text { economic freedom and trade } \\
\text { openness } \\
\text { For the sub-period 1987-1998, } \\
\text { only democracy and per capita } \\
\text { income contributed significantly } \\
\text { (inferred that end of cold war } \\
\text { changed country motivations) }\end{array}$ \\
\hline $\begin{array}{l}\text { Obydenkova } \\
2006\end{array}$ & $\begin{array}{l}\text { What factors contribute } \\
\text { to transnational } \\
\text { cooperation between } \\
\text { the EU and the } 89 \\
\text { regions of Russia, given } \\
\text { that such cooperation } \\
\text { varies widely across } \\
\text { regions despite } \\
\text { common history and } \\
\text { institutional framework }\end{array}$ & $\begin{array}{l}\text { The level of } \\
\text { Regional } \\
\text { Cooperation } \\
\text { with EU } \\
\text { comprising: } \\
\text { Trade coop., } \\
\text { project coop., } \\
\text { investment } \\
\text { risk, and } \\
\text { investment } \\
\text { performance }\end{array}$ & $\begin{array}{l}\text { Geographical } \\
\text { proximity, common } \\
\text { border, size, level } \\
\text { of economic } \\
\text { development, } \\
\text { ethnicity, } 3 \text { level } \\
\text { index of autonomy } \\
\text { from Moscow }\end{array}$ & $\begin{array}{l}\text { EBRD, } \\
\text { Russian legal } \\
\text { sources }\end{array}$ & $\begin{array}{l}\text { Logistic and linear } \\
\text { regression on each of the } 4 \\
\text { components of the level of } \\
\text { Regional Cooperation in } \\
\text { turn }\end{array}$ & $\begin{array}{l}\text { Levels of economic development, } \\
\text { ethnicity, constitutional } \\
\text { autonomy, geographic proximity } \\
\text { not important for trade or project } \\
\text { cooperation } \\
\text { Cross-regional integration seems } \\
\text { to be an alternative to } \\
\text { nationalism and secession. } \\
\text { Common border important for } \\
\text { project cooperation. Autonomy } \\
\text { important both for trade and } \\
\text { project cooperation. } \\
\text { Level of investment risk reduced } \\
\text { by geographic proximity and } \\
\text { level of economic development }\end{array}$ \\
\hline
\end{tabular}




\section{Appendix 2: Table of RTAs Containing Provisions on Competition Policy Cooperation Other Than Enforcement Cooperation}

\begin{tabular}{|c|c|c|}
\hline $\begin{array}{l}\text { C. RTAs with Competition-related } \\
\text { provisions other than enforcement } \\
\text { cooperation }\end{array}$ & $\begin{array}{c}\text { In OECD } \\
2006\end{array}$ & $\begin{array}{c}\text { In Cernat } \\
2005\end{array}$ \\
\hline Albania-Bosnia & $\sqrt{ }$ & \\
\hline Albania-Bulgaria*377 & $\sqrt{ }$ & \\
\hline Albania-Croatia & $\sqrt{ }$ & $\sqrt{ }$ \\
\hline Albania-Macedonia & $\sqrt{ }$ & \\
\hline Albania-Romania* & $\sqrt{ }$ & \\
\hline Albania-Serbia & $\sqrt{ }$ & \\
\hline Algeria-EC & $\sqrt{ }$ & $\sqrt{ }$ \\
\hline Australia-NZ (ANZCERTA) & $\sqrt{ }$ & \\
\hline Armenia-Georgia & $\sqrt{ }$ & \\
\hline Armenia-Kazakhstan & $\sqrt{ }$ & \\
\hline Armenia-Kyrgyzstan & $\sqrt{ }$ & $\sqrt{ }$ \\
\hline Armenia-Moldova & $\sqrt{ }$ & \\
\hline Armenia-Russian Federation & $\sqrt{ }$ & \\
\hline Armenia-Turkmenistan & $\sqrt{ }$ & \\
\hline Armenia-Ukraine & $\sqrt{ }$ & \\
\hline Azerbaijan-Georgia & $\sqrt{ }$ & $\sqrt{ }$ \\
\hline BAFTA Industrial goods & & $\sqrt{1}$ \\
\hline Bosnia-H-Croatia & $\sqrt{ }$ & $\sqrt{ }$ \\
\hline Bosnia-H-Macedonia & $\sqrt{ }$ & \\
\hline Bosnia-H-Slovenia* & & $\sqrt{ }$ \\
\hline Bosnia-H-Turkey & $\sqrt{ }$ & $\sqrt{ }$ \\
\hline Bulgaria-Estonia* & & $\sqrt{ }$ \\
\hline Bulgaria-Israel* & $\sqrt{ }$ & $\sqrt{ }$ \\
\hline Bulgaria-Latvia* & & $\sqrt{ }$ \\
\hline Bulgaria-Lithuania* & & $\sqrt{ }$ \\
\hline Bulgaria-Macedonia* & & $\sqrt{ }$ \\
\hline Bulgaria-Moldova* & $\sqrt{ }$ & \\
\hline Bulgaria-Serbia* & $\sqrt{ }$ & \\
\hline Bulgaria-Turkey* & & $\sqrt{ }$ \\
\hline CARICOM-Costa Rica & & $\sqrt{ }$ \\
\hline CEFTA* & $\sqrt{ }$ & $\sqrt{ }$ \\
\hline CEMAC & $\sqrt{ }$ & \\
\hline Central America-Chile & $\sqrt{ }$ & $\sqrt{ }$ \\
\hline \multicolumn{3}{|l|}{ Central America-Dominican Republic } \\
\hline CIS & $\sqrt{ }$ & \\
\hline COMESA & $\sqrt{ }$ & $\sqrt{ }$ \\
\hline Croatia-EFTA & $\sqrt{ }$ & \\
\hline Croatia-Lithuania* & & $\sqrt{ }$ \\
\hline Croatia-Macedonia & $\sqrt{ }$ & $\sqrt{ }$ \\
\hline Croatia-Moldova & $\sqrt{ }$ & \\
\hline Croatia-Slovenia* & & $\sqrt{ }$ \\
\hline Croatia-Turkey & $\sqrt{ }$ & $\sqrt{ }$ \\
\hline Czech Rep.-Estonia* & & $\sqrt{ }$ \\
\hline
\end{tabular}

377 * Signifies agreements involving at least one country that subsequently joined the EU. 


\begin{tabular}{|c|c|c|}
\hline Agreement & $\begin{array}{c}\text { In OECD } \\
2006\end{array}$ & $\begin{array}{c}\text { In Cernat } \\
2005\end{array}$ \\
\hline Czech Rep.-Latvia* & & $\sqrt{ }$ \\
\hline Czech Rep.- Lithuania* & & $\sqrt{ }$ \\
\hline Czech Rep.- Slovakia*378 & & $\sqrt{ }$ \\
\hline Czech Rep.-Turkey* & & $\sqrt{ }$ \\
\hline \multicolumn{3}{|l|}{ EC-Albania } \\
\hline \multicolumn{3}{|l|}{ EC-Armenia } \\
\hline \multicolumn{3}{|l|}{ EC-Azerbaijan } \\
\hline \multicolumn{3}{|l|}{ EC-Bosnia-H } \\
\hline EC-Bulgaria* & & $\sqrt{ }$ \\
\hline EC-Croatia & & $\sqrt{ }$ \\
\hline EC-Czech Rep. ${ }^{*}$ & & $\sqrt{ }$ \\
\hline EC-Egypt (updated) & $\sqrt{ }$ & $\sqrt{ }$ \\
\hline EC-Estonia* & & $\sqrt{ }$ \\
\hline \multicolumn{3}{|l|}{ EC-Georgia } \\
\hline EC-Hungary* & & $\sqrt{ }$ \\
\hline EC-Iceland & & $\sqrt{ }$ \\
\hline EC-Israel & & $\sqrt{ }$ \\
\hline EC-Jordan & $\sqrt{ }$ & $\sqrt{ }$ \\
\hline EC-Latvia* & & $\sqrt{ }$ \\
\hline EC-Lithuania* & & $\sqrt{ }$ \\
\hline EC-Lebanon (updated) & $\sqrt{ }$ & $\sqrt{ }$ \\
\hline EC-FYRMacedonia & & $\sqrt{ }$ \\
\hline \multicolumn{3}{|l|}{ EC-Moldova } \\
\hline \multicolumn{3}{|l|}{ EC-Montenegro } \\
\hline EC-Morocco & $\sqrt{ }$ & $\sqrt{ }$ \\
\hline EC-Norway & & $\sqrt{ }$ \\
\hline EC-Poland* & & $\sqrt{ }$ \\
\hline EC-Romania* & & $\sqrt{ }$ \\
\hline \multicolumn{3}{|l|}{ EC-Russian Federation } \\
\hline EC-Slovakia* & & $\sqrt{ }$ \\
\hline EC-Slovenia* & & $\sqrt{ }$ \\
\hline EC-Switz./Licht. & & $\sqrt{ }$ \\
\hline EC-Tunisia & & $\sqrt{ }$ \\
\hline \multicolumn{3}{|l|}{ EC-Ukraine } \\
\hline EFTA-Bulgaria* & & $\sqrt{ }$ \\
\hline EFTA-Czech Rep. * & & $\sqrt{ }$ \\
\hline EFTA-Estonia* & & $\sqrt{ }$ \\
\hline EFTA-Hungary* & & $\sqrt{ }$ \\
\hline EFTA-Israel & & $\sqrt{ }$ \\
\hline EFTA-Jordan & $\sqrt{ }$ & $\sqrt{ }$ \\
\hline EFTA-Latvia* & & $\sqrt{ }$ \\
\hline EFTA-Lithuania* & & $\sqrt{ }$ \\
\hline EFTA-Macedonia & $\sqrt{ }$ & $\sqrt{ }$ \\
\hline EFTA-Morocco & & $\sqrt{ }$ \\
\hline EFTA-Poland* & & $\sqrt{ }$ \\
\hline EFTA-Romania* & & $\sqrt{ }$ \\
\hline EFTA-Slovakia* & & $\sqrt{ }$ \\
\hline
\end{tabular}

$378 *$ Signifies agreements involving at least one country that subsequently joined the EU. 


\begin{tabular}{|c|c|c|}
\hline Agreement & $\begin{array}{c}\text { In OECD } \\
2006\end{array}$ & $\begin{array}{c}\text { In Cernat } \\
2005\end{array}$ \\
\hline EFTA-Slovenia* & & $\sqrt{ }$ \\
\hline EFTA-Turkey & & $\sqrt{ }$ \\
\hline Estonia-Hungary* & & $\sqrt{ }$ \\
\hline Estonia-Slovakia* & & $\sqrt{ }$ \\
\hline Estonia-Slovenia*379 & & $\sqrt{ }$ \\
\hline Estonia-Turkey* & & $\sqrt{ }$ \\
\hline Estonia-Ukraine* & & $\sqrt{ }$ \\
\hline Georgia-Kazakhstan & $\sqrt{ }$ & $\sqrt{ }$ \\
\hline Georgia- Russian Federation & $\sqrt{ }$ & $\sqrt{ }$ \\
\hline Georgia-Turkmenistan & $\sqrt{ }$ & $\sqrt{ }$ \\
\hline Georgia-Ukraine & $\sqrt{ }$ & $\sqrt{ }$ \\
\hline Hungary-Israel* ${ }^{*}$ & & $\sqrt{ }$ \\
\hline Hungary-Latvia* & & $\sqrt{ }$ \\
\hline Hungary-Lithuania* & & $\sqrt{ }$ \\
\hline Hungary-Turkey* & & $\sqrt{ }$ \\
\hline Israel-Poland* & & $\sqrt{ }$ \\
\hline Israel-Slovakia* & & $\sqrt{ }$ \\
\hline Israel-Slovenia* & & $\sqrt{ }$ \\
\hline Israel-Turkey & & $\sqrt{ }$ \\
\hline Kazakhstan-Kyrgyzstan & & $\sqrt{ }$ \\
\hline Kyrgyzstan-Moldova & & $\sqrt{ }$ \\
\hline Kyrgyzstan- Russian Federation & & $\sqrt{ }$ \\
\hline Kyrgyzstan-Ukraine & & $\sqrt{ }$ \\
\hline Kyrgyzstan-Uzbekistan & & $\sqrt{ }$ \\
\hline Latvia-Poland* & & $\sqrt{ }$ \\
\hline Latvia-Slovakia* & & $\sqrt{ }$ \\
\hline Latvia-Slovenia* & & $\sqrt{ }$ \\
\hline Latvia-Turkey* & & $\sqrt{ }$ \\
\hline Lithuania-Poland* & & $\sqrt{ }$ \\
\hline Lithuania-Slovakia* & & $\sqrt{ }$ \\
\hline Lithuania-Slovenia* & & $\sqrt{ }$ \\
\hline Lithuania-Turkey* & & $\sqrt{ }$ \\
\hline FYR Macedonia-Slovenia* & & $\sqrt{ }$ \\
\hline FYR Macedonia-Turkey & $\sqrt{ }$ & $\sqrt{ }$ \\
\hline MERCOSUR & $\sqrt{ }$ & \\
\hline Moldova-Romania* & & $\sqrt{ }$ \\
\hline Morocco-Turkey & & \\
\hline Poland-Turkey* & & $\sqrt{ }$ \\
\hline Romania-Turkey* & & $\sqrt{ }$ \\
\hline SADC & & \\
\hline Slovakia-Turkey* & & $\sqrt{ }$ \\
\hline Slovenia-Turkey* & & $\sqrt{ }$ \\
\hline $\begin{array}{l}\text { TOTAL of RTAs with Competition } \\
\text { Cooperation Provisions Other Than } \\
\text { Enforcement Cooperation }\end{array}$ & 133 & \\
\hline
\end{tabular}

\footnotetext{
$379 *$ Signifies agreements involving at least one country that subsequently joined the EU.
} 


\section{GLOSSARY}

Comity: the passive and voluntary deference accorded by one state to the acts of another state unless the state judges such deference to be not in its own interests (Slaughter 2004, p. 250).

Competition policy: used in this thesis in the narrow sense of competition law, or in US-parlance, anti-trust law. While the term is also used to refer to a broader set of policies that promote competitive markets - including trade policies and market deregulation - the focus here is solely on generic, economy-wide laws that directly regulate the structure of markets and the behaviour of firms in the market.

De facto: in practice, in fact (in contrast to what the law says).

De jure: what the law says, by law (as opposed to in practice).

Enforcement jurisdiction: the authority to induce or compel compliance or to punish non-compliance, whether through the courts or by use of executive, administrative, police, or other non-judicial action.

Hard core cartels: an anticompetitive agreement, concerted practice, or arrangement by competitors to fix prices, make rigged bids, establish output restrictions or quotas, or share or divide markets (OECD, Recommendation of the Council Concerning Effective Action Against Hard Core Cartels, 1999).

International economic integration: can be defined broadly as increasing levels of trade and foreign investment, the trans-national integration of production chains within firms, and the progressive creation of single markets for factors of production.

International policy cooperation: refers to the wide variety of agreements or arrangements between states to cooperate in the development or implementation of government policies. International policy cooperation is embodied in international agreements, official international organisations, or less formal cross-border interactions between official institutions.

Jurisdiction: the recognized authority to apply legal rules or processes to persons or property.

Jurisdictional integration: a process by which a state chooses, through entering formal agreements with another state or states, to restrict its recognized authority to autonomously make, and/or to enforce, and/or to adjudicate decisions in a specific domain or domains.

Negative comity: "a country's consideration of how it may prevent its law enforcement actions from harming another country's important interests" (OECD, 1999). 
Positive comity: “.... country's consideration of another country's request that it open or expand a law enforcement proceeding in order to remedy conduct that is substantially and adversely affecting another country's interests." (OECD,1999).

Prescriptive jurisdiction: the recognized authority to make rules applicable to particular persons or circumstances.

State Sovereignty: used variously to refer to the possession of international legal personality, or to the possession of particular legal competences or powers. It may refer to de jure state authority or to de facto state capacity. It may be used to refer to the full set of a state's legal powers or capacities, to the minimum autonomy a state must possess to be a state, or to just one or other of those powers and capacities. It is often not clear which aspect or meaning is being applied in a particular case.

Stages of economic integration: refers to progressively deeper levels of international economic integration and international policy cooperation, typically described as being embodied in the stages of Free Trade Agreement, Customs Union, Common Market, Economic Union, and total economic integration.

State jurisdiction: the recognized authority of a state under international law to govern persons and property by its municipal law i.e. domestic or national law. In European terminology, jurisdiction as recognized authority is also referred to as competence. 


\section{REFERENCES}

Abbott, Kenneth, Robert Keohane, Andrew Moravscik, Anne-Marie Slaughter, and Duncan Snidal. 2000. The Concept of Legalization. International Organization 54(3): 401-419.

Abbott, Kenneth and Duncan Snidal. 2000. Hard and Soft Law in International Governance. International Organization 54 (3): 421-456.

Acharya, Amitav. 2002. Regionalism and the Emerging World Order. In New Regionalisms in the Global Political Economy. Shaun Breslin, Christopher Hughes, Nicola Phillips, and Ben Rosamond (Eds). 20-32. Warwick Studies in Globalisation. Centre for the Study of Globalisation and Regionalisation. London: Routledge.

Agresti, Alan. 2007. An Introduction to Categorical Data Analysis. $2^{\text {nd }}$ Edition. New Jersey: Wiley and Sons.

Alesina, A, E. Spolaore, and R. Wacziarg. 1997. Economic Integration and Political Disintegration. NBER Working Paper 6163. September 1997.

Alesina, A, and E. Spolaore. 2003. The Size of Nations. Cambridge: MIT Press.

Alvarez, Jose. 2005. International Organizations as Law Makers. Oxford: Oxford University Press.

American Law Institute. 1987. Restatement of the Law, Third, Foreign Relations Law of the United States. St. Paul, Minnesota: American Law Institute Publishers.

Anderson, R, and S. Evenett. 2006. Incorporating Competition Elements Into Regional Trade Agreements: Charaterization and Empirical Analysis. Washington DC: Inter-American Development Bank and World Trade Organisation.

Arend, A. 1999. Legal Rules and International Society. Oxford: Oxford University Press.

A.T. Kearney/Foreign Policy. 2005. Measuring Globalization. In Foreign Policy May/June 2005: 52-60.

Babones, Salvastore., 2007. Studying Globalization: Methodological Issues. In The Blackwell Companion to Globalization. G. Ritzer Ed. Chapter 7: 144-161.

Banting, K, G. Hoberg and R. Simeon (Eds). 1997. Degrees of Freedom: Canada and the United States in a Changing World. Kingston and Montreal: McGill-Queens University Press. 
Bhagwati, Jagdish and R. Hudec, Eds. 1996. Fair Trade and Harmonization: Prerequisites for Free Trade? Volume 1, Economic Analysis. Cambridge, MA: MIT Press.

Baier, S, and Bergstand, J. 2002. On the Economic Determinants of Free Trade Agreements. National Bureau of Economic Research Working Paper \#290. January 2002.

Balassa, Bela. 1961. The Theory of Economic Integration. Homewood: Richard D Irwin, Inc.

Bloom, M. 2005. What is the Future for International Antitrust? ABA Section of Antitrust Law Fall Forum, November 15-16, 2005.

Bollard, A, and K. Vautier. 1998. The Convergence of Competition Law within APEC and the CER Agreement. In Business Markets and Government in Asia Pacific: Competition, policy convergence and pluralism. Rong-I Wu and Y-P Chu (Eds). Chapter 6: 120-156.

Braithwaite, J, and P. Drahos. 2000. Global Business Regulation. Cambridge: Cambridge University Press.

Breslin, Shaun, Richard Higgott, and Ben Rosamond. 2002. Regions in Comparative Perspective. In New Regionalisms in the Global Political Economy. S. Breslin, C. Hughes, N. Phillips, and B. Rosamond Eds. 1-19.

Breslin, Shaun, Christopher Hughes, Nicola Phillips, and Ben Rosamond, Eds. 2002. New Regionalisms in the Global Political Economy. Warwick Studies in Globalisation. Centre for the Study of Globalisation and Regionalisation. London: Routledge.

Brinsmead, S. Undated. Rulemaking in ICAO, the ILO and the IMF: The Rise of Standards, available at http;//ssrn.com/abstract $=1002758$.

Brownlie, Ian. 1998. Principles of Public International Law. Fifth Edition. Oxford: Oxford University Press.

Bryman, Alan, and Duncan Cramer. 1994. Quantitative Data Analysis for Social Sciences. Revised Edition. Routledge: London and New York.

Caporaso, J. 1971. Theory and Method in the Study of International Integration. International Organization Vol. 25, No. 2 (Spring 1971): 228-253.

Cernat, L. 2005. Eager to ink, but ready to act? RTA proliferation and international cooperation on competition policy. In Competition Provisions in Regional Trade Agreements: How to Assure Development Gains. Philippe Brusick, Ana Maria Alvarez, and Lucian Cernat Eds. UNCTAD 2005: 1-36.

Charlesworth, Hilary, M. Chiam, D. Hovell, and G. Williams. 2005. International Law and National Law: Fluid States. In The Fluid State: International Law and 
National Legal Systems. H. Charlesworth, M. Chiam, D. Hovell, and G. Williams. Sydney: The Federation Press.

Chayes, Abram and Antonia Chayes. 1995. The New Sovereignty: Compliance with International Regulatory Agreements. Cambridge: Harvard University Press.

Cohen, E. 2001. Globalization and the Boundaries of the State: A Framework for Analyzing the Changing Practice of Sovereignty. Governance 14(1), January 2001: 75-97.

Cooper, Richard. 1987. International Economic Co-operation: Overview and a Glimpse of the Future. In Interdependence and Co-operation in Tomorrow's World, Organisation for Economic Cooperation and Development. 180-194. Paris: OECD.

Crawford, James. 2006. The Creation of States in International Law. Oxford: Clarendon Press.

Crawford, J-A, and R. Fiorentino. 2005. The Changing Landscape of Regional Trade Agreements. World Trade Organization. Discussion Paper No. 8, 2005.

Creswell, J. 2003. Research Design: Qualitative, Quantitative, and Mixed Method Approaches. $2^{\text {nd }}$ edition. Thousand Oaks, California: SAGE Publications.

Czempiel, E-O, and J. Rosenau (Eds.). 1989. Global Changes and Theoretical Challenges: Approaches to World Politics for the 1990s. Lexington, Massachusetts/Toronto: Lexington Books.

Dabbar, M. 2007. The Internationalisation of Antitrust Policy. Cambridge: Cambridge University Press.

Damro, Chad. 2005. Sole of discretion: competition relations in the trans-atlantic marketplace. In Creating a transatlantic marketplace. Egan, Michelle P. Ed. Manchester: Manchester University Press. Chapter 4

Deutsch, Karl. 1957. Political Community and the North Atlantic Area: International Organization in the Light of Historical Experience. Princeton: Princeton University Press.

Dingwerth, K, and P. Pattberg. 2006. Global Governance as a Perspective on World Politics. Global Governance. A Review of Multilateralism and International Organizations 12 (2): 185-203.

Dorrucci, E, S. Firpo, M. Fratzscher, and F. Mongelli. 2002. European Integration: What Lessons For Other Regions? The Case of Latin America. European Central Bank Working Paper Series.Working Paper No. 185, October 2002.

Dorrucci, E, S. Firpo, M. Fratzscher, and F. Mongelli. 2004. The Link Between Institutional and Economic Integration: Insights for Latin America from the European Experience. Open Economies Review 15: 239-260. 
Economics and Strategy Group. 2002. Analysing and Managing Global Integration, Report Commissioned by the New Zealand Department of Labour. Wellington: May 2002.

Egan, Michelle P. Ed. 2005. Creating a transatlantic marketplace. Manchester: Manchester University Press.

Egeberg, M. 2006. Towards an Organisational Theory of International Integration. Centre for European Studies, Working Paper No. 13, October 2006.

Elhauge, E and D. Geradin. 2007. Global Competition Law and Economics. Oxford and Portland, Oregon: Hart Publishing.

Ethier, W. 1998. The New Regionalism. The Economic Journal 108 (July): 11491161.

Ewing, K. 2006. Competition Rules for the $21^{\text {st }}$ Century: Principles from America's Experience. $2^{\text {nd }}$ Edition. The Hague: Kluwer Law International.

Fernandez, R and J. Portes. 1998. Returns to Regionalism: An Analysis of International Gains from Regional Trade Arrangements. The World Bank Economic Review 12 (May): 197-220.

Finnemore, Martha and Stephen J. Toope. 2001. Alternatives to "Legalization": Richer Views of Law and Politics. International Organization 55 (2): 743-758.

Goddard, D. 2002. Business Laws and Regulatory Institutions: Mechanisms for CER Co-ordination. In States of Mind: Australia and New Zealand. Wevers, L, A. Grimes, and G. Sullivan, Eds. Wellington: Institute of Policy Studies.

Goldstein, J, Miles Kahler, Robert Keohane, and Anne-Marie Slaughter. 2000. Introduction: Legalization and World Politics. International Organization 54(3):385399.

Goldstein, J, Miles Kahler, Robert Keohane, and Anne-Marie Slaughter. 2001. Response to Finnemore and Toope. International Organization 55(2):759-760.

Guzman, A. 2007. International Competition Law. In Research Handbook in International Economic Law. Guzman, A and A. Sykes Eds. Cheltenham, UK and Northampton, MA, USA: Edward Elgar. Chapter 10: 418-443.

Haas, Ernst. 1958. The Uniting of Europe: Political, Social and Economic Forces. Stanford: Stanford University Press.

Haas, Ernst. 1976. The Obsolescence of Regional Integration Theory. Research Monograph No. 25. Berkeley: Institute of International Studies, University of California.

Hart, H. L. A. 1961. The Concept of Law. New York: Oxford University Press. 
Hoberg, George. 2001. Globalization and Policy Convergence: Symposium Overview. Journal of Comparative Policy Analysis: Research and Practice 3: 127132.

Hoekman, B. 1998. Competition Policy and Preferential Trade Agreements. Washington D.C.: The World Bank.

Holmes, P, H. Muller, A. Papadopoulos, and A. Sydorak. Undated draft. The Legal Framework of Bilateral Relations in the Field of Competition Law and Policy: A Taxonomic Approach. Centre for Economic Policy Research, Chapter 13, Second Draft.

Holmes, P, A. Papadopoulos, B. Kayali, and A. Sydorak. 2005. Trade and Competition in RTAs: A missed opportunity? In Competition Provisions in Regional Trade Agreements: How to Assure Development Gains. Brusick, P, A. Alvarez, and L. Cernat (Eds). 66-121. New York and Geneva: UNCTAD.

Howse, Robert. 2008. Sovereignty, Lost and Found. In Redefining Sovereignty in International Economic Law. Shan, W, P. Simons and D. Singh Eds. Chapter 3: $61-75$.

International Competition Network. 2006. Cooperation Between Competition Agencies in Cartel Investigations. ICN Cartels Working Group, Sub-Group 1 general framework. Report to the ICN Annual Conference, Cape Town. May 2006.

International Monetary Fund. Direction of Trade Statistics Yearbooks. Various. Washington DC.

Jackson, John. 2003. Sovereignty Modern: A New Approach to an Outdated Concept. American Journal of International Law 97(782):1-25.

Jackson, John. 2005. The Changing Fundamentals of International Law and Ten Years of the WTO. Journal of International Economic Law 8(1), 3-15.

Jackson, John. 2006. Sovereignty, the WTO, and Changing Fundamentals of International Law. Cambridge: Cambridge University Press.

Jackson, John. 2008. Sovereignty: Outdated Concept or New Approaches. In Redefining Sovereignty in International Economic Law. Shan, W, P. Simons and D. Singh Eds. Chapter 1: 3-25.

Jenny, F. 2003. Competition Law and Policy: Global Governance Issues. World Competition 26(4): 609-624.

Jenny, F. and P. Horna. 2005. Modernization of the European System of Competition Law Enforcement: Lessons for other regional groupings. In Competition Provisions in Regional Trade Agreements: How to Assure Development Gains. Brusick, P, A. Alvarez, and L. Cernat, Eds. Chapter 9: 282-327. New York and Geneva: UNCTAD. 
Joelson, M. 2006. An International Antitrust Primer: A Guide to the Operation of United States, European Union, and Other Key Competition Laws in the Global Economy. The Hague: Kluwer Law International.

Kahler, Miles. 1995. International Institutions and the Political Economy of Integration. Washington DC: The Brookings Institute.

Kahler, Miles. 2000. Legalization as Strategy: The Asia-Pacific Case. International Organization 54(3).

Kahler, M, and Lake, D, Eds. 2003. Governance in a Global Economy: Political Authority in Transition. Princeton New Jersey: Princeton University Press.

Keohane, Robert. 2002. Ironies of Sovereignty: The European Union and the United States. Journal of Common Market Studies Vol. 40(4), 743-765.

Keohane, R and Nye, J. 1989. Power and interdependence. Glenview, Illinois.

Kobrin, S. 1997. The Architecture of Globalization: State Sovereignty in a Networked Global Economy. Government, Globalization, and International Business. New York: Oxford University Press.

Krahmann, Elke. 2003. National, Regional, and Global Governance: One Phenomenon or Many? Global Governance 9, 323-346.

Krasner, Stephen. 1983. Structural causes and regime consequences: regimes as intervening variables. In International Regimes. Stephen Krasner (Ed). 1-21. Ithaca: Cornell University Press.

Krasner, Stephen. 1999. Sovereignty: Organized Hypocrisy. Princeton: Princeton University Press.

Laursen, F, Ed. 2003. Comparative Regional Integration: Theoretical Perspectives. Hampshire: Ashgate Publishing.

Lawrence, Robert. 1996. Regionalism, Multilateralism, and Deeper Integration. Washington DC: Brookings Institution.

Lawrence R.Z. (Ed). 1998. Brookings Trade Forum: 1998. Washington DC: Brookings Institution Press.

La Porta, Rafael, Florencio Lopez-de-Silanes, Andre Shleifer. 2003. What Works in Securities Laws? Mimeo, Harvard University.

Leebron, David. 1996. Lying Down with Procrustes: An Analysis of Harmonization Claims. In Fair Trade and Harmonizatio. Jagdish Bhagwati and Robert Hudec Eds. Cambridge, MA: The MIT Press. Volume 1: 41-117.

Lindberg, Leon. 1970. Political Integration as a Multidimensional Phenomenon Requiring Multivariate Measurement. International Organization 24(4):649-731. 
Louis-Beck, M, A. Bryman, T. Liao. 2004. SAGE Encyclopedia of Social Science Research Methods. Thousand Oaks, California: SAGE Publications.

Lowe, Vaughan. 2008. Sovereignty and International Economic Law. In Redefining Sovereignty in International Economic Law. Shan, W, P. Simons and D. Singh (Eds). Chapter 4: 78-84. Studies in International Trade Law. Oxford and Portland, Oregon: Hart Publishing.

Lowenfeld, Andreas. 2002. International Economic Law. Oxford: Oxford University Press.

Majone, Giandomenico. 1996. Temporal Consistency and Policy Credibility: Why Democracies Need Non-Majoritarian Institutions. European University Institute. Working Paper RSC No. 96/57.

Mann, F.A. 1990. The Doctrine of International Jurisdiction Revisited After 20 Years. In Further Studies in International Law. F.A. Mann. Oxford: Clarendon Press.

Mansfield, E, H. Milner, and B. Rosendorff. 2002. Why Democracies Cooperate More: Electoral Control and International Trade Agreements. International Organization 56:3, 477-513.

Marsden, P. and P. Whelan. 2005. The Contribution of Bilateral Trade or Competition Agreements To Competition Law Enforcement Cooperation Between Canada and Chile. London: British Institute of International and Comparative Law. CPFTR Paper XIV.

Mathis, J. 2005. North-South Cooperation Instruments: The Effectiveness and Impediments for Bi-lateral Approaches to Cross-border Anti-trust Enforcement. Centre for Economic Policy Research. Paper 19.

Mattli, W. 1999. The Logic of Regional Integration: Europe and Beyond. Cambridge: Cambridge University Press.

Mehta, P, M. Agarwal, V. Singh. 2007. Politics Trumps Economics - Lessons and experiences on competition and regulatory regimes from developing countries. Jaipur, India: CUTS Institute for Regulation and Competition. CIRC and CUTS C-CIER.

Melamed, D. 1999. International Cooperation in Competition Law and Policy: What can be achieved at the bilateral, regional, and multilateral levels. Journal of International Economic Law September 1999, Vol. 2, Issue 3, 423.

Molle, F. 1997. The Economics of European Economic Integration: theory, practice, policy. 3rd Edition. Aldershot, England.

Moravscik, A. 1993. Preferences and Power in the European Community: A Liberal Intergovernmentalist Approach. Journal of Common Market Studies 31 (4): 473-524. 
Moravscik, Andrew. 1998. The Choice for Europe: Social Purpose and State Power from Messina to Maastricht. Ithaca: Cornell University Press.

Nye, Joseph. 1968. Comparative Regional Integration: Concept and Measurement. International Organization 22(4): 855-880.

Nye, Joseph. 1990. Bound to Lead: The Changing Nature of American Power. New York: Basic Books.

Obydenkova, A. 2006. Democratization, Europeanization, and Regionalization Beyond the EU: Search for Empirical Evidence. European Integration online Papers (EIOP) Vol 10 (2006) No. 1. http://eiop.or.at/eiop/texte/2006-001a.htm

Olson, Mancur. 1982. The Rise and Decline of Nations. New Haven: Yale University Press.

Organization for Economic Cooperation and Development. 1994. Regulatory Cooperation for an Interdependent World. Public Management Studies. Paris: OECD.

Organization for Economic Cooperation and Development. 1999. CLP Report on Positive Comity. OECD Paper, DAFFE/CLP(99)19, 10 June 1999. Paris: OECD.

Organization for Economic Cooperation and Development, 2003. Service Providers on the Move: Mutual Recognition Arrangements. Working Party of the Trade Committee, TD/TC/WP(2002)48/FINAL. Paris: OECD.

Organization for Economic Cooperation and Development. 2004. Global Forum on Competition. Fourth Meeting 2-13 February 2004. Paris: OECD.

Organization for Economic Cooperation and Development. 2005. Handbook on Economic Globalisation Indicators. Paris: OECD.

Organization for Economic Cooperation and Development. 2006. Competition Provisions in Regional Trade Agreements. Trade Policy Working Paper No. 31, 21 March 2006, by Oliver Solano and Andreas Sennekamp. Paris: OECD.

Osiander, Andreas. 2001. Sovereignty, International Relations, and the Westphalian Myth. International Organization 55(2):251-287.

Petersmann, Ernst-Ulrich. 1996-97. Constitutionalism and International Organisations. Northwestern Journal of International Law and Business 17:398: 398469.

Picciotto, Sol. 1996. The Regulatory Criss-Cross: Interaction between Jurisdictions and The Construction of Global Regulatory Networks. In International Regulatory Competition and Coordination. J. McCahery, W. Bratton, S. Picciotto, C. Scott, Eds. Chapter 3, 89-123. Oxford: Clarendon Press.

Putnam, R. 1988. Diplomacy and Domestic Politics: The Logic of Two-level Games. 42 International Organisation 427. 
Raustiala, Kal. 2002. The Architecture of International Cooperation:

Transgovernmental Networks and the Future of International Law. Virginia Journal of International Law 43(1), Fall 2002.

Raustiala, Kal. 2003. Rethinking The Sovereignty Debate in International Economic Law. Journal of International Economic Law 6 (4): 841- 864.

Ritzer, George, Ed. 2007. The Blackwell Companion to Globalization. Massachusetts: Blackwell Publishing.

Rose, A. 2002. Do We Really Know that the WTO Increases Trade? National Bureau of Economic Research Working Paper \# 9273.

Rosenau, J. 1989. Subtle Sources of Global Interdependence. In Interdependence and Conflicts in World Politics. James Rosenau and H. Tromp Eds. Aldershot: Avebury.

Rosendorff, P, and H. Milner. 2001. The Optimal Design of International Trade Institutions: Uncertainty and Escape. International Organization Vol. 55, Issue 04, November 2001, 829-857.

Ruggie, John. 1993. Territoriality and beyond: problematizing modernity in international relations. International Organization 47(1):139-174.

Ruta, M. 2005. Economic Theories of Political (Dis)Integration. Journal of Economic Surveys Vol. 19, No. 1, 1-21.

Sandholtz, Wayne, and Alec Stone Sweet. 1998. Integration, Supranational Governance, and the Institutionalization of the European Polity. In European Integration and Supranational Governance. Sandholtz, Wayne, and Alec Stone Sweet (Eds.). Chapter 1, 1-26. Oxford: Oxford University Press.

Schaub, A. 1998. International co-operation in antitrust matters: making the point in the wake of the Boeing/MDD proceedings.

http://ec.europa.eu/comm/competition/speeches/text/sp1998 004 en.html

Schelling, T. 1958. International Economics. Boston: Allyn and Bacon.

Schiff, M. 2000. Multilateral Trade Liberalization, Political Disintegration, and the Choice of Free Trade Agreements versus Customs Unions. World Bank Policy Research Working Paper No. WPS 2350, 31 May 2000.

Schiff, M, and A. Winters. 2003. Regional Integration and Development. Washington DC.: World Bank.

Scholte, Jan Aaart. 2000. Globalization: a critical introduction. New York: St. Martins Press. 
Shan, W, P. Simons and D. Singh (Eds). 2008. Redefining Sovereignty in International Economic Law. Studies in International Trade Law. Oxford and Portland, Oregon: Hart Publishing.

Simmons, B. 2000. The Legalization of International Monetary Affairs. International Organization 54, 3, Summer 2000, 573-602.

Skelcher, C. 2005. Jurisdictional Integrity, Polycentrism, and the Design of Democratic Governance. Governance Vol. 18, No. 1, January 2005, 89-110.

Slaughter, Anne-Marie. 2000. Judicial Globalization. Virginia Journal of International Law Vol. 40: 1103.

Slaughter, Anne-Marie. 2004. A New World Order. Oxford: Oxford University Press.

Slaughter, Anne-Marie, Andrew Tulumello, and Stepan Wood. 1998. International Law and International Relations Theory: A New Generation of Interdisciplinary Scholarship. The American Journal of International Law 92(3): 367-398.

Smith, James. 2000. The Politics of Dispute Settlement Design: Explaining Legalism in Regional Trade Pacts. International Organization 54(1): 137-180.

Sokol, D. 2007a. Why is this Chapter Different From all the Others?: An Examination of Why Countries Enter Into Non-enforceable Competition Policy Chapters in Free Trade Agreements. Columbia Legal Studies Research Paper Series. Research Paper Number 2007-13.

Sokol, D. 2007b. Monopolists Without Borders: The Institutional Challenge of International Antitrust in a Global Gilded Age. Berkely Business Law Journal Vol. 4.1, 2007, 41-123.

Steffenson, Rebecca. 2005. Competing trade and regulatory strategies for the mutual recognition of conformity assessment in the transatlantic marketplace. In Creating $a$ transatlantic marketplace. Egan, Michelle P. (Ed.) 156-174. Manchester: Manchester University Press.

Stein, Eric. 2001. International Integration and Democracy: No Love at First Sight. The American Journal of International Law 95(3): 489-534.

Stephenson, Sherry. 1999. Approaches to Services Liberalization by Developing Countries. OAS Trade Unit Studies Analyses on trade and integration in the Americas. Organization of American States Trade Unit. February 1999.

Summers, Lawrence. 1999. Reflections on Managing Global Integration. Journal of Economic Perspectives Spring 1999, Vol. 13, Iss. 2, 3-19.

Taylor, Martyn. 2006. International Competition Law: A New Dimension for the WTO? Cambridge: Cambridge University Press. 
Teh, R, M. Prusa, and M. Budetta. 2007. Trade Remedy Provisions in Regional Trade Agreements. WTO Staff Working Paper ERSD-2_-7-03, September 2007.

Trachtman, Joel P. 1996. The International Economic Law Revolution. 17 University of Pennsylvania Journal of International Economic Law 33:1-22.

Trachtman, Joel. 2007. Regulatory Jurisdiction and the WTO. Journal of International Economic Law 10(3), 631-651, 30 July 2007.

UNCTAD. 2003. Experiences Gained So Far On International Cooperation on Competition Policy Issues and the Mechanisms Used. TD/B/Com.2/CLP/21/REV.2, 25 April 2003.

UNCTAD. 2004. Model Law on Competition. UNCTAD Series on Issues in Competition Law and Policy. New York and Geneva: United Nations.

UNCTAD. 2005. Competition Provisions in Regional Trade Agreements: How to Assure Development Gains. Brusick, P, A. Alvarez, and L. Cernat (Eds). New York and Geneva: United Nations.

UNCTAD. 2008. Handbook of Statistics. New York and Geneva.

Vautier, Kerrin and Peter Lloyd. 1997. International Trade and Competition Policy: $C E R, A P E C$ and the WTO. Wellington: Institute of Policy Studies, Victoria University of Wellington.

Vlachos, Jonas. 2004. Does Regulatory Harmonization Increase Bilateral Asset Holdings? IUI Working Paper No. 612. The Research Institute of Industrial Economics, Stockholm.

Waller, Spencer Weber. 1999. Harmonization in the Enforcement of Competition Law. Cardozo Law Review 18 (1999), 1111.

Weiler, J.H.H., and Trachtman, Joel P. 1996/97. European Constitutionalism and its Discontents. Northwestern Journal of International Law and Business, 17:470, 354398.

Whalley, J. 1998. Why Do Countries Seek Regional Trade Agreements? In The Regionalisation of the World Economy. Frankel J. A. (Ed.). Chicago: University of Chicago Press.

White, David. 1997. Trans-Tasman Company Tax Horizons. PhD Dissertation. Sydney: University of Sydney Faculty of Law.

Whytock, Christopher. 2005. A Rational Design Theory of Transgovernmentalism: The Case of EU-US Merger Review Cooperation. Boston University International Law Journal Volume 23.

Wildasin, D. 2008. Fiscal Federalism. The New Palgrave Dictionary of Economics Second Edition. S. Durlauf and L. Blume (Eds.). Palgrave Macmillan. 
Wolf, Martin. 2004. Why Globalisation Works. New Haven: Yale University Press.

World Bank. 2007. World Development Indicators. Washington DC.

World Trade Organization. 1998. Inventory of non-tarriff provisions in regional trade agreements. Background Note by the Secretariat. WT/REG/W/26, 5 May 1998.

World Trade Organization. 2002. Modalities for Voluntary Cooperation. Working Group on the Interaction Between Trade and Competition Policy, Background Note by the Secretariat. WT/WGTCP/W/192, 28 June 2002.

World Trade Organization. 2005. World Trade Report 2005, Trade, Standards, and the WTO. Chapter II, 29-169.

World Trade Organization. 2005a. Addressing Institutional Challenges in the New Millennium. Report by the Consultative Board to the Director General of the WTO. (January 2005).

Wu, J. 2004. Measuring and Explaining Levels of Regional Economic Integration. Center for European Integration Studies. Working Paper No.12.

Wu, Rong-I and Yun-Peng Chu (Eds.). 1998. Business Markets and Government in Asia Pacific: Competition, policy convergence and pluralism. London and New York: Routledge.

Yacheivstova, Nataliya. 2000a. What May the Commonwealth of Independent States Expect From Multilateral Competition Rules? Law and Economics Review Vol. 23, No. 1, March 2000.

Yacheivstova, Nataliya. 2000b. Competition Policy In Countries In Transition - Legal Basis and Practical Experience. New York and Geneva: UNCTAD.

Yarbourough, B, and R. Yarbourough. 1990. International institutions and the new economics of organization. International Organization 44, 2, Spring 1990: 235-259.

Zanettin, B. 2002. Cooperation Between Antitrust Agencies at the International Level. Oxford and Portland Oregon: Hart Publishing.

\section{Web Sites}

APEC Competition Policy and Law Database: www.epeccp.org.tw/about.html

European Commission Competition Directorate: http://ec.europa/comm/competition/

Free Trade Agreement of the Americas Inventory of Competition Agreements in the Americas: www.ftaa-alca.org/ngroups/NGCP/Publications/Treaty_e.asp 
International Competition Network: www.internationalcompetitionnetwork.org

OECD Competition Law and Policy Committee:

http://www.oecd.org/topic/0,3373,en_2649_37463_1_1_1_1_37463,00.html

Tuck Trade Agreements Database: www.dartmouth.edu/ tradedb/

UNCTAD: www.unctad.org/Templates/StartPage.asp?intItemID=2239\&lang=1

World Trade Organization, Regional Trade Agreements web page:

http://www.wto.org/english/tratop_e/region_e/region_e.htm 